\title{
Site Safety Plan \\ for \\ Lawrence Livermore National Laboratory \\ CERCLA Investigations
}

July 1993

R. Bainer

J. Duarte

Lawrence Livermore National Laboratory

University of California Livermore, California 94551 


\section{DISCLAIMER}

Work performed under the auspices of the U.S. Department of Energy by Lawrence Livermore National Laboratory under contract number W-7405-ENG48.

This document was prepared as an account of work sponsored by an agency of the United States Government. Neither the United States Government aor the University of California nor any of their employees, makes any wirranty, express of implied, or assumes any legal liability or responsibility for the accuracy, completeness, or usefulness of any information, apparatus, product, or process disclosed, or represents that its use would not infringe privately owned rights. Reference herein to any specific commercial products, process, or service by trade name, trademark, manufacturer, or otherwise, does not necessarily constitute or imply its endorsement, recommendation, or favoring by the United States Government or the University of California. The views and opinions of authors expressed herein do not necessarily state or reflect those of the United States Government or the University of California, and shall not be used for advertising or product endorsement purposes. 


\section{Site Safety Plan}

for

\section{Lawrence Livermore National Laboratory \\ CERCLA Investigations}

\section{Review and Concurrence:}

witiain. UVCarade

William A. McConachie

Environmental Restoration Division Leader
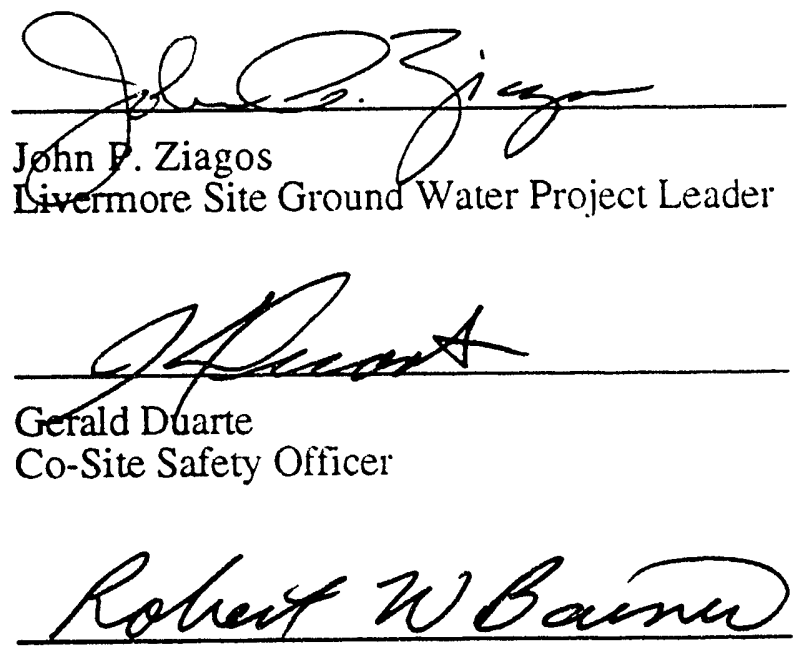

Robert W. Bainer

Co-Site Safety Officer
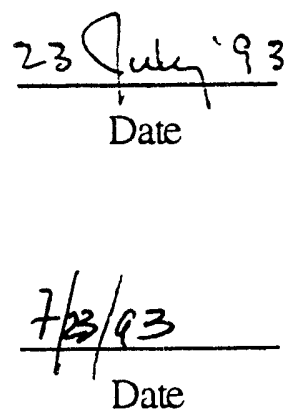

\section{$2-23-23$ \\ Date}

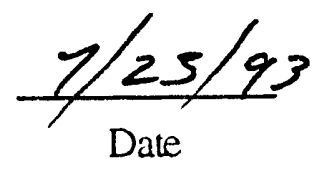

Reviewed by Lois Halunen Hazards Control Salety Team 7 


\section{Table of Contents}

1. Emergency Contacts and Telephone Numbers ….............................................................. 1

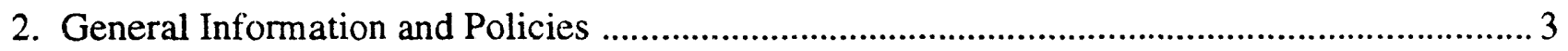

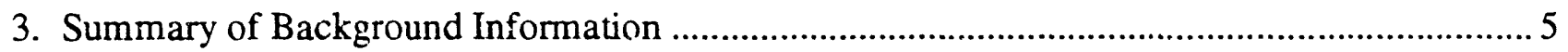

4. Organization, Responsibilities, and Authority ................................................................... 7

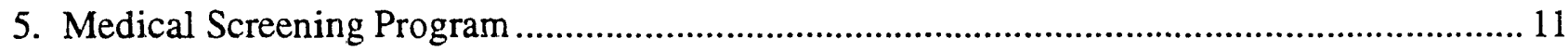

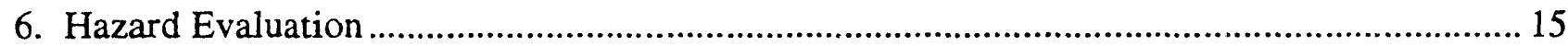

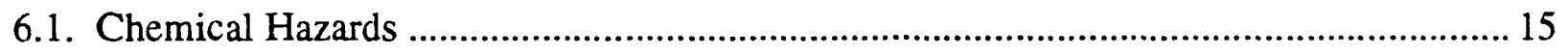

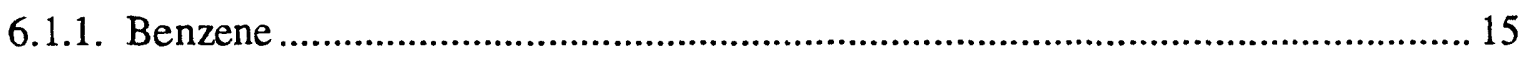

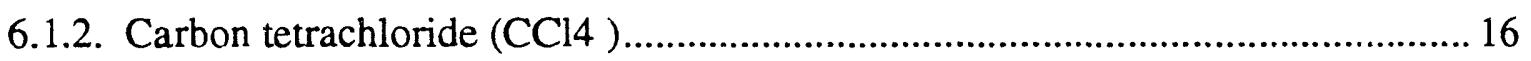

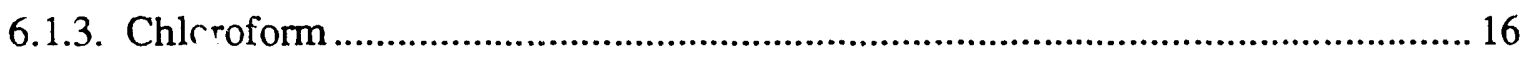

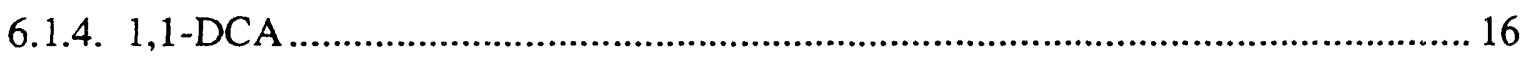

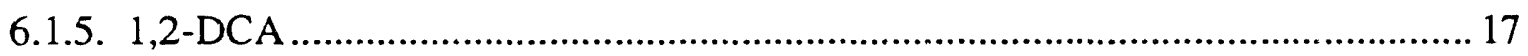

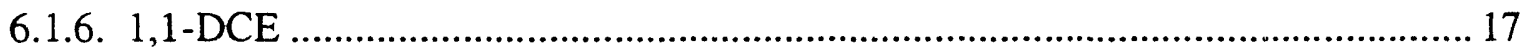

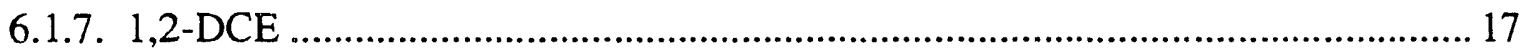

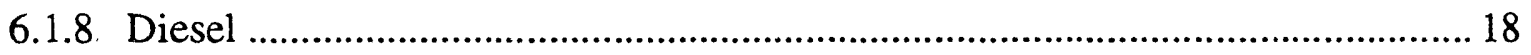

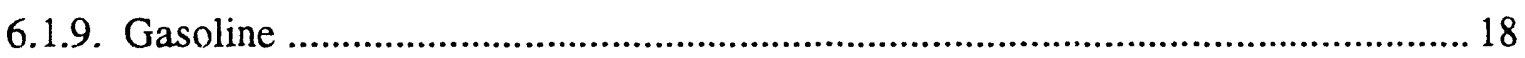

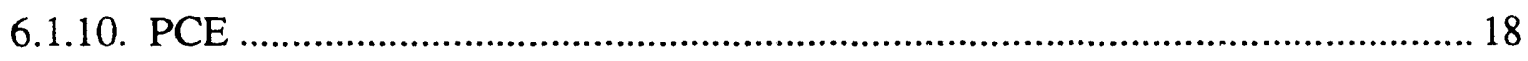

6.1.11. TCE …

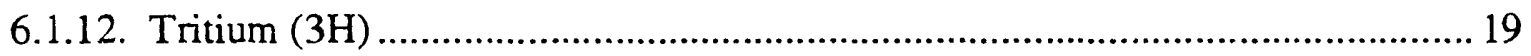

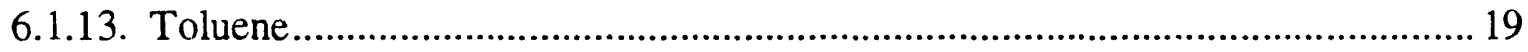

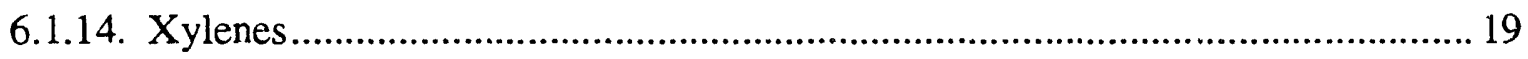

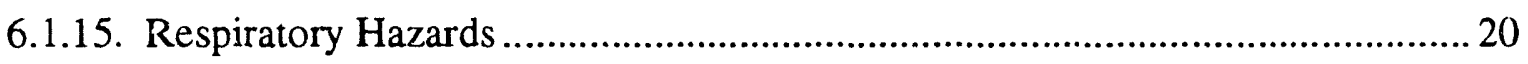

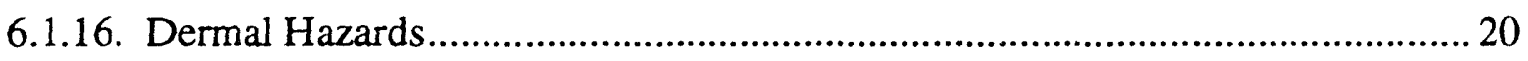

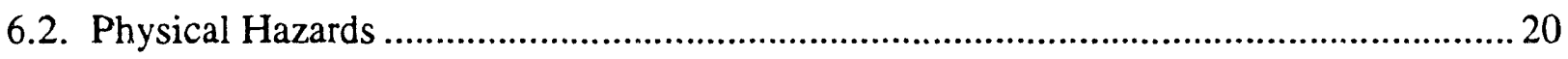

6.2.1. Heavy Equipment ........................................................................................... 20

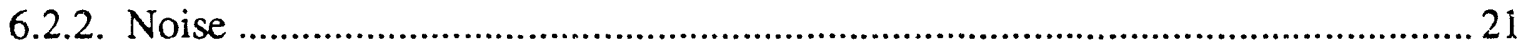

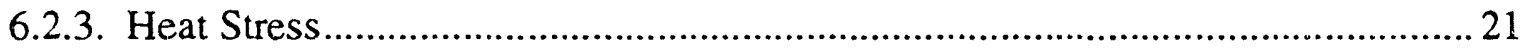

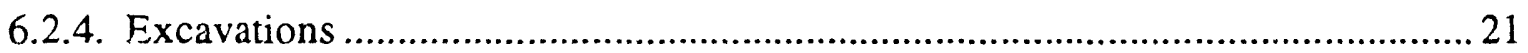

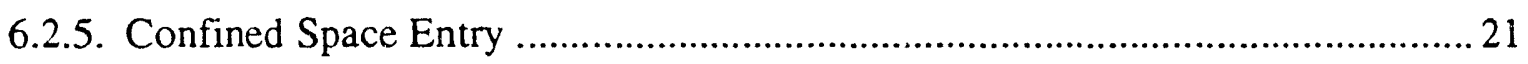

6.2.6. Overhead Power Lines .................................................................................... 22 


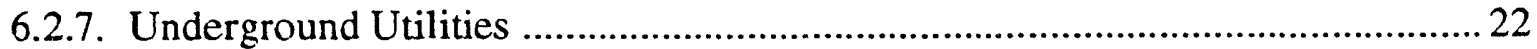

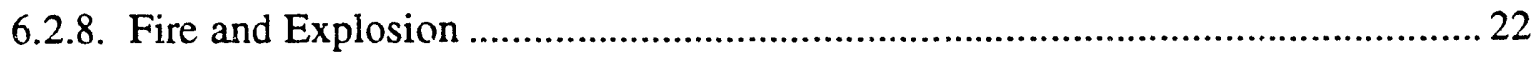

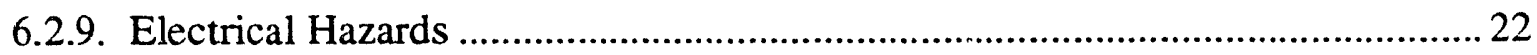

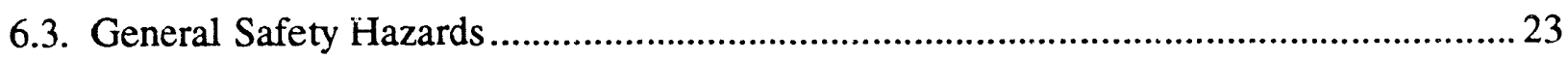

6.4. Hazards to Nonproject Personnel .................................................................................. 23

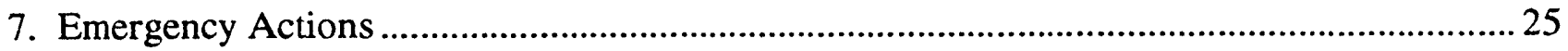

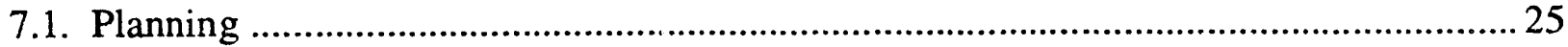

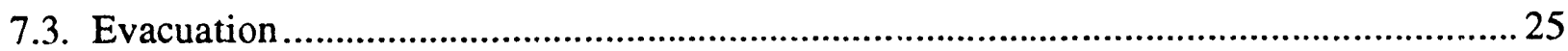

7.4. Emergency Evacuation From Contaminated Areas ………………............................. 25

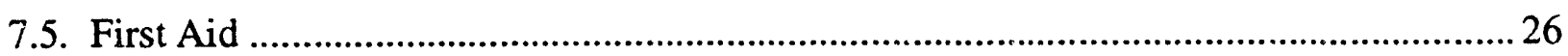

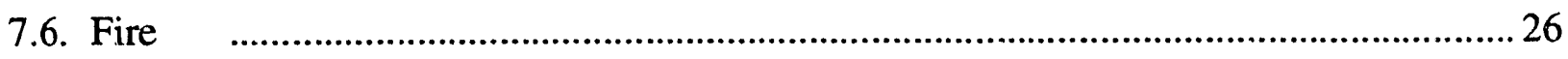

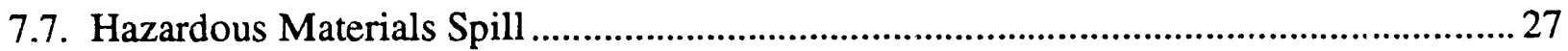

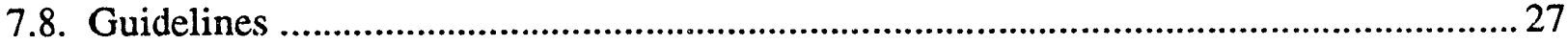

8. Personal Protective Apparel and Equipment ……….........................................................2 29

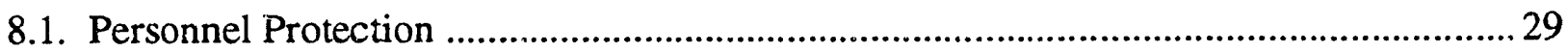

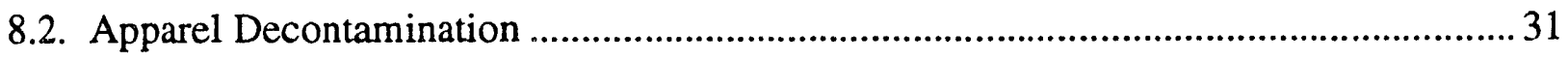

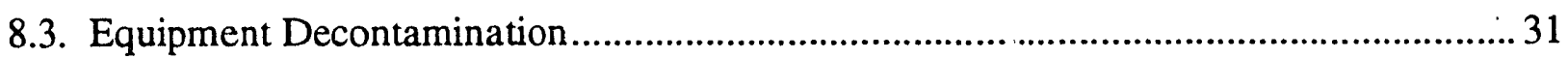

8.4. Personnel Decontamination and Personal Hygiene ………........................................... 32

8.5. Monitoring Equipment ................................................................................................. 32

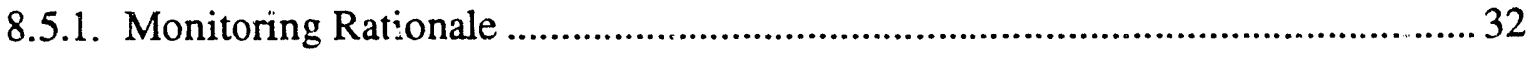

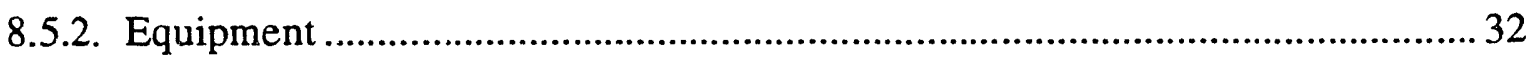

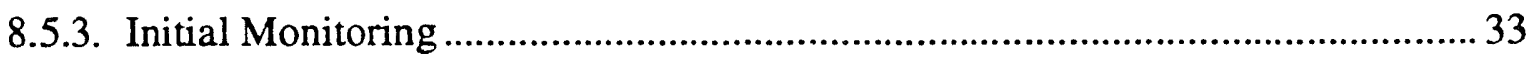

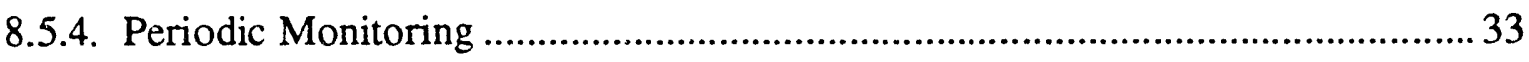

8.5.5. High Risk Employees ..................................................................................... 34

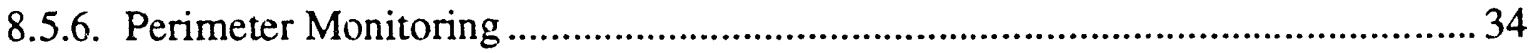

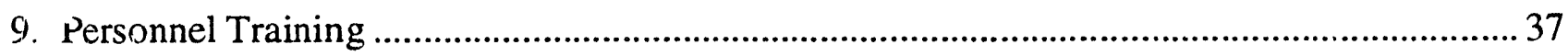

9.1. Hazardous Waste Operations and General Safety Requirements ................................. 37

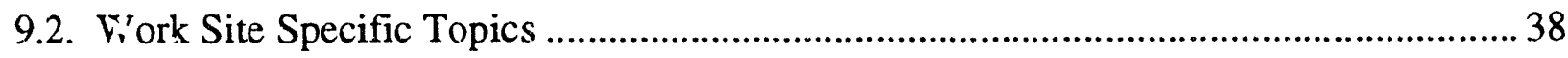

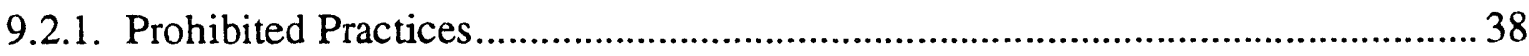

9.2.2. Emergency Pror edures and Services ................................................................. 39

9.2.3. General Safety Requirements............................................................................... 39

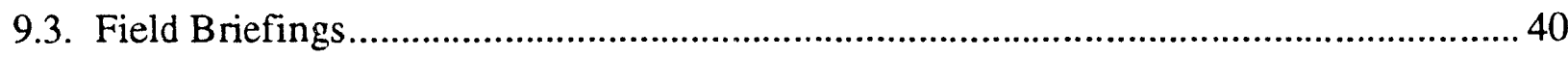




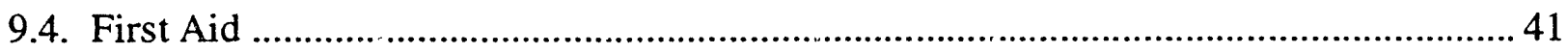

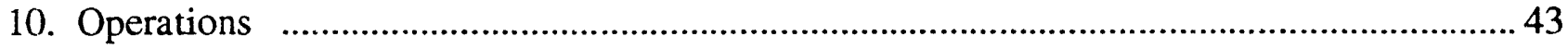

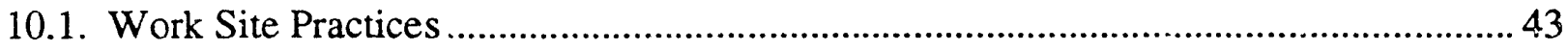

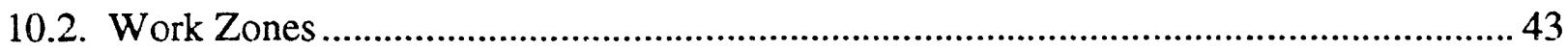

10.2.1. Exclusion Zone ....................................................................................... 43

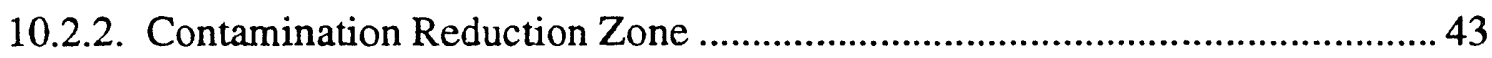

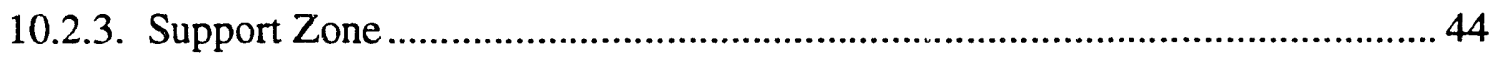

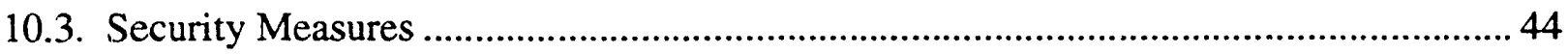

10.4. Hazard Control Measures......................................................................................... 44

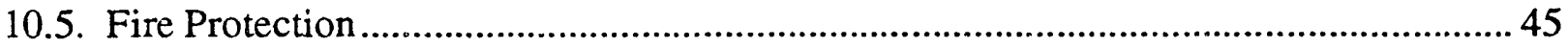

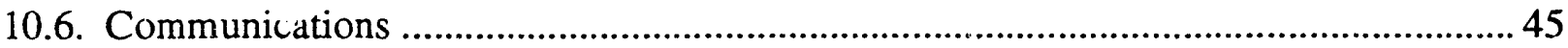

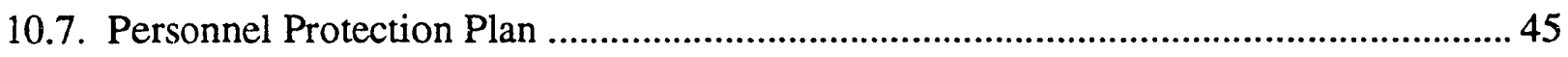

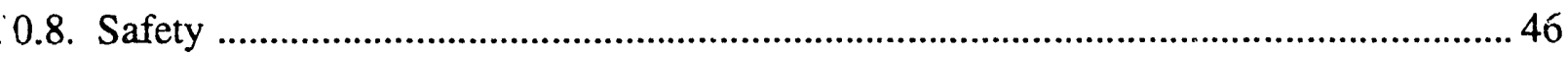

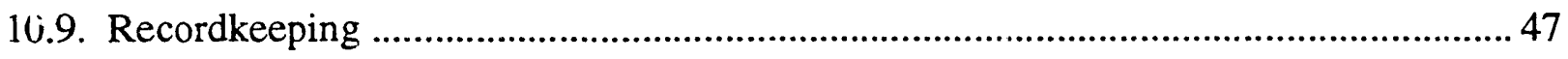

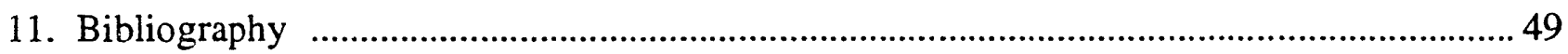

Appendix A: Site-Specific Operational Satety Procedure

Appendix B: Acronyms

Appendix C: Material Safety Data Sheets

Appendix D: Trench and Excavation

Appendix E: Electrical Safety

Appendix F: OSP Example

Appendix G: Levels of Personal Protection 


\section{Foreward}

This Site Safety Plan for the Environmental Restoration Division's environmental investigations has been prepared specifically for the Lawrence Livermore Nationai Laboratory (LLNL) Site in Livermore, California, on the basis of available data. This Health and Safety Plan was written to comply with applicable requirements of Occupational Safety and Health Administration regulations, including 29 CFR 1910.120, Hazardous Waste Operations and Emergency Response. This document is intended as a gen rral health and safety plan for LLNL and will be supplemented by Operational Safety Procedures for activities which are not sufficiently covered by this plan. As additional facts, monitoring data, or analytical data on hazards become available, this Plan will be modified. It is the responsibility of the co-Site Safety Officers (SSOs) to evaluate data that may impact health and safety during these act:vities and to modify the Plan as appropriate. Either of the co-SSO shall have the authority to institute any change that provides greater health and safety protection for workers at the LLNL Site. 


\section{Emergency Contacts and Telephone Numbers}

This list needs to be updated as necessary to reflect current personnel, telephone numbers, positions and any other outdated information.

\section{Local Contacts for All Emergencies}

From Lawrence Livermore National Laboratory (LLNL) phones

Offsite Emergency Response

911

\section{Hazardous Materials Information}

Toxline

(301) 496-1131

CHEMTREC (24-hour, emergency only)

(800) 424-9300

ORNL, Toxicology Information Response Center

(615) 576-1743

\section{LLNL Contacts}

John P. Ziagos, Project Leader

(510) $422-5479$

Gerald Duarte, Co-Site Safety Officer

(510) 423-2638

Beeper

(510) 423-7705-3180

Robert W. Bainer, Co-Site Safety Officer

(510) 422-4635

$$
\text { Beeper }
$$

(510) 423-7705-5554

\section{Contractor Contacts}

Michael Dresen, Senior Project Hydrogeologist, Weiss Assoc. (510) 547-5420 


\section{Standard Procedures for R.eporting Emergencies}

When calling 911 for assis:ance in an emergency situation, the following information should be provided:

1. Name of person making ...all.

2. Telephone number and location of person making call.

3. Name of person(s) exposed or injured and location.

4. Nature of emergency and type of exposure, when appropriate.

5. Actions already taken.

Never hang up first when calling for emergency assistance. Wait for the dispatch operator to finish all questions. 


\section{General Information and Policies}

The safety policy of LLNL is to take every reasonable precaution in the performance of work to protect the environment and the health and safety of employees and the public, and to prevent property damage. With respect to hazardous agents, this protection is provided by limiting human exposures, releases to the environment, and contamination of property to levels that are as low as reasonably achievable (ALARA). It is the intent of this Plan to supply the broad outline for completing environmental investigations within ALARA guidelines. It may not be possible to determine actual working conditions in advance of the work; therefore, planning must allow the opportunity to provide a range of protection based upon actual working conditions. Requirements will be the least restrictive possible for a given set of circumstances, such that work can be completed in an efficient and timely fashion.

Due to the relatively large size of the LLNL Sitc, and the different types of activities underway, site-specific Operational Safety Procedures (OSPs) will be prepared to supplement activities not covered by this Plan. Although the LLNL Site is one operable unit for Comprehensive Environmental Response, Compensation, and Liability Act (CERCLA) compliance, Occupational Safety and Health Administration (OSHA) compliance would be more readily implemented by developing OSPs for each activity not covered by this Plan. These site-specific OSPs provide the detailed information for each specific activity and act as an addendum to this Plan, which provides the general plan for LLNL Main Site operation.

Employees working at LLNL must follow the policies set forth in this Plan, as well as LLNL and the U.S. Department of Energy (DOE) policies, procedures, and instructions. Of special value are the LLNL Health and Safety Manual (Hazards Control Department, 1989) and support provided by the LLNL Hazards Control Safety Team. Subcontractors musi develop their own health and safety procedures, which may be modeled on those provided by LLNL. These procedures must be reviewed and approved by the Site Safety Officer (SSO), or a designee, prior to the initiation of work.

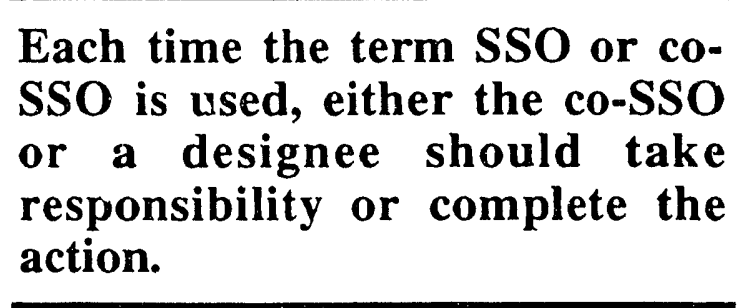

Employees are encouraged to bring to the attention of their supervisor any unsafe or hazardous condition that they observe as they carry out their responsibilities. The supervisor 
shall then inform the SSO promptly so that the situation can be corrected and personnel can be advised of an improved procedure. It is clearly impossible to anticipate all specific safety and health hazards beforehand; therefore, all personnel must exercise common sense and good judgment in their approach to a given situation.

The Health and Safety Training described in Section 9 of this document will assist in preparing indiv :duals to recognize hazards. This document incorporates appropriate rules, guidelines, and recommended work practices contained in previously published material. All personnel potentially exposed to physical or chemical hazards as described in this Plan shall follow the safety and health procedures set forth herein.

Any modifications to this Plan will be issued as attachments to this document. 


\section{Summary of Background Information}

LLNL is located about 40 miles east of San Francisco, California, in the Livermore Valley of eastern Alameda County approximately 3 miles east of Livermore. LLNL is operated by the University of California for the DOE. The Laboratory was established in 1952 to conduct nuclear weapon and other research. LLNL also carries out a variety of project work for other Federal and State agencies. In the 1940s, the Livermore Air Station was operated on the LLNL Site by the U.S. Navy.

The DOE is required to maintain an environmental protection program and has implemented the Comprehensive Environmental Response, Compensation, and Liability Act (CERCLA) through DOE Order 5480.14. Under Environmental Protection Agency (EPA) oversight, the responsibility for conducting the remedial investigation and feasibility study of the LLNL Site is vested in the LLNL Ground Water Project, which is part of LLNL's Environmental Protection Department, Environmental Restoration Division (ERD).

During installation assessment of the LLNL Site, five areas were identified as CERCLA hazardous waste disposal sites as defined in DOE Order No. 5480.14. The five areas are: (1) the southwest quadrant of the Laboratory and offsite area to the west, (2) the gasoline spill area near the former Building 403, (3) the southeast section, (4) the east-central section, and (5) the remainder of site area, which includes all areas not in areas 1 through 4 . These areas are now combined in a single operable unit for CERCLA compliance.

In 1983, LLNL began a ground water study beneath the LLNL Site and vicinity. Initial findings from that study indicated that volatile organic compounds (VOCs) were present in ground water. Ongoing investigations have indicated the presence of a variety of substances in ground water and soil. On the basis of analytical results, the substances present in concentrations greater than California Department of Toxic Substances Control (DTSC) or EPA Action Levels include:

- Trichloroethylene (TCE).

- Tetrachloroethylene (PCE).

- Carbon tetrachloride $\left(\mathrm{CCl}_{4}\right)$.

- 1,1-Dichloroethane (1,1-DCA).

- 1,2-Dichloroethane (1,2-DCA).
- 1,2-Dichloroethylene (1,2-DCE).

- Chloroform.

- 1,1-Dichloroethylene (1,1-DCE).

- Tritium.

Sampling results have shown several locations with VOCs in ground water in the partper-billion (ppb) range and several areas where concentrations greater than 1 part per million (ppm) were detected. In one area, one well contains tritium above the drinking water standard of $20,000 \mathrm{pCi} / \mathrm{L}$.

Results of Ground Water Project chemical analyses for the Gasoline Spill Area also identified the presence of:

- Benzene.

- Xylene isomers.

- 1,2-Dichloroethane (1,2-DCA).

- Total fuel hydrocarbons (TFH). 
- Toluene.

- Ethlyene dibromide (EDB).

Other work activities may pose potential exposures or problems due to:

- Heat stress.

- Noise.

- Nuisance dust.
- Heavy equipment.

- Confined space entry.

- Electrical hazards.

This plan addresses health and safety issues related to the various tasks and phases for the environmental work planned and ongoing at LLNL. Technical issues and specifications for the scope of work are presented in the specific LLNL quality assurance, work, and closure plans and in the Standard Operating Procedures manual. Copies of the specific LLNL Quality Assurance Plan, and closure plans, as well as The Standard Operating Procedures manual referred to in the LLNL Health and Safety Manual are available for ready reference in the ERD office. The SSO should review these documents in order to correctly carry out assigned responsibilities and to assist in presenting pertinent health and safety concerns to site workers. 


\section{Organization, Responsibilities, and Authority}

Key personnel are listed below by name, title, address, and telephone number.

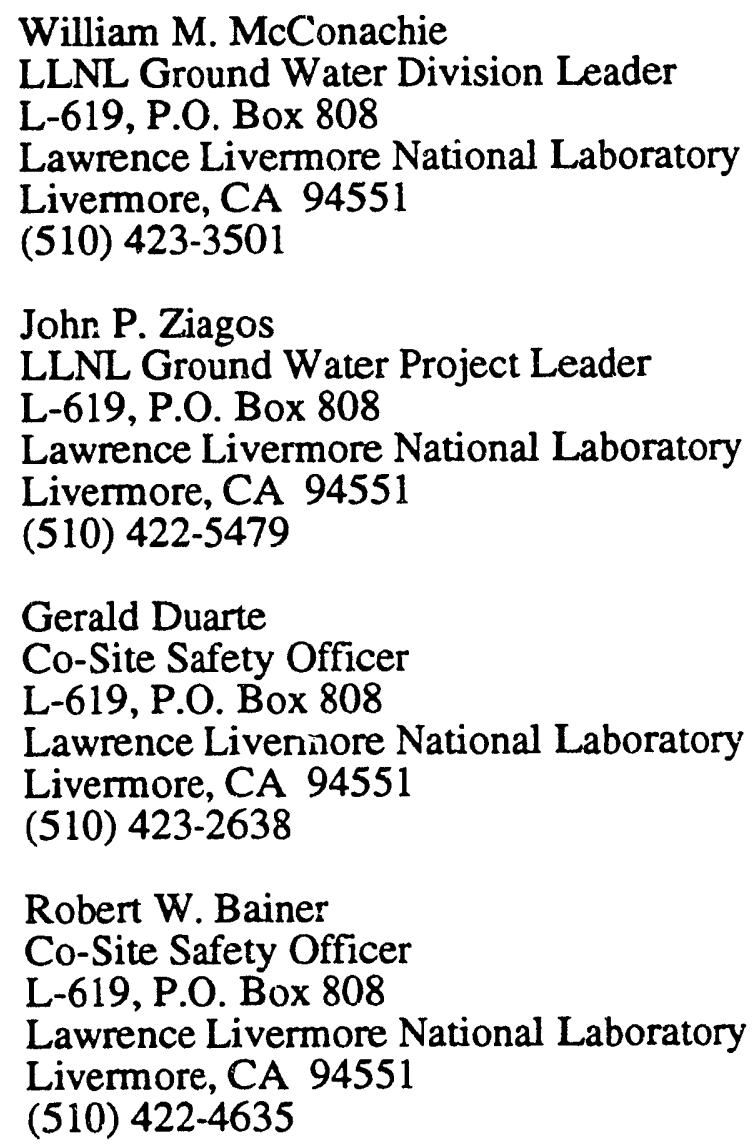

The ERD Leader has ultimate authority over the overall operations of the site. He approves changes in the scope of the operations, contractors bids, schedules, etc.

The LLNL Ground Water Project Leader has ultimate authority over the overall operation of the site in the absence of the ERD Leader. He also has the responsibility to ensure that all operations are conducted by the SSO's in accordance with this Site Safety Plan.

Health and safety activities are important during all phases of any project. The degree of implementation of the activities or services is related to the perceived risk. The SSO shall have the responsibility to determine health and safety needs for this project and the authority to ensure that appropriate measures are taken. All site personnel shall comply with the requirements of this plan and cooperate with project management in its implementation. It is the responsibility of all site personnel to immediately report any of the following to the SSO:
A. All accidents or injuries.
B. Unsafe or malfunctioning equipment.
C. Any symptoms or signs of chemical exposure. 
7. Unexpected or uncontrolled releases of chemicals.

E. Unauthorized personnel entry onto the site.

F. Any changes in the site conditions which might adversely affect the health and safety of personnel.

The SSO shall immediately inform the Project Leader, John P. Ziagos (510) 422-5497, of any health and safety conditions that may adversely affect the project.

The SSO, or a designee, has the authority to:

- Obtain information and assistance from Hazards Control Safety Team Four or other appropriate support as warranted.

- Require specific health and safety precautions prior to work site entry by LLNL and contracioi personnel, and ensure that personnel adhere to requirements of this Plan.

- Require any LLNL or contractor employee to obtain immediate medical attention in case of an injury or illness.

- Deny LLNL and/or contractor personnel access to any LLNL work site.

- Establish an area in the support zone upwind of the work zone where personnel are to gather if there is an evacuation from the work zone.

- Order the innmediate evacuation of LLNL and/or subcontractor employees from any work site when hazardous conditions arise in the course of work.

- Permit visitors (i.e., anyone other than an LLNL or contractor employee) at work sites only at the direction of, and with the permission of, responsible LLNL personnel. Visitors shall abide by the requirements specified in this Plan and, when possible, shall be restricted from areas of potential exposure to hazardous substances.

- Monitor LLNL and contractor operations for the existence of hazardous conditions, and monitor personnel for signs of exposure, heat stress, fatigue, etc.

- Evaluate results of the monitoring program and determine its impact on future operations.

- Ensure that environmental and personnel monitoring operations are ongoing and carried out in accordance with technical specifications, procedures, and project instructions.

- Monitor site conditions during operations to determine whether any changes in work zones or personnel protection are required.

- Ensure that proper personal protective equipment (PPE) is are available and worn by onsite personnel, and ensure that PPE and other equipment are maintained and properly stored.

- Ensure that work areas are kept clean and orderly to control potential general safety hazards.

- Know the emergency procedures and contacts. 
The SSO will review and update the Plan every 3 years or as necessary to ensure that the listed organizational structure reflects the current status of the site operations. The review will reflect changes in technology, operation, contamination, etc. The SSO will also conduct work site safety briefings to cover the contents of this Plan, safe work practices, PPE use, and emergency procedures.

All LLNL and subcontractor personnel assigned to this project are responsible for following this Plan, using safe work practices, and wearing the PPE specified by the SSO. The SSO shall inform all subcontractors of emergency response procedures and known hazards of the operations prior to site entry. Project personnel shall report hazards and unsafe conditions and practices to the SSO. Project personnel must comply with all Federal, State, and local health and safety regulations.

This Plan and supporting health and safety documents must be available for review and use by the SSO, cognizant regulatory agencies, and all project personnel.

The Team Leader of Environmental Safety and Health (ES\&H) Team 4 (Hazards Control Department) provides an interface between the members of Team 4 and ERD. The health and safety professionals and technicians assigned to Team 4 provide support and technical services to the SSO or a designate as requested and required by LLNL policy. 


\section{Medical Screening Program}

The purpose of the medical screening program is to assess the health status of personnel prior to work, monitor personnel for evidence of postproject adverse health effects, and determine the suitability of individuals for future work assignments of this type. All personnel who will be working on this project must undergo a medical evaluation before participating in these operations. If the SSO determines that significant exposure to hazardous materials is encountered in these operations, a follow-up medical exam shall be conducted on the exposed individuals.

Baseline and periodic health assessments for project personnel shall be consistent with LLNL requirements and OSHA regulations prescribed in 29 CFR 1910, especially those in 1910.120, Hazardous Waste Operations and Emergency Response.

At a minimum, the examination should include:

- Medical and organizational histories.

- Physicai examination.

- Vision test.

- Urinalysis.

- Blood chemistry panel and complete blood count.

- Pulmonary function tests and respirator use clearance.

Optional tests include:

- X-rays.

- Electrocardiograms.

- Bioassays for specific compounds, if recommended by the examining physician due to previous or expected exposures.

Due to the low risk of acute exposure, additional medical monitoring specific to this project is not anticipated.

If an individual has completed an occupational medical exam within the past 12 months, the examining physician may determine that another complete exam is unnecessary.

In addition to the medical screening program, a medical surveillance program will be provided by the LLNL ERD for its employees when one or more of the following items are applicable:

A. All employees who are or may be exposed to airborne levels of hazardous substances above OSHA Permissible Exposure Limits (PEL) or, in the absence of PEL, other published exposure limits, without regard to the use of respirators, for 30 days or more per year.

B. All those who use a respirator for 30 or more days per year or are required to do so under 29 CFR 1910.134 Respiratory Protection. 
C. All employees who are injured due to overexposure from an emergency incident involving hazardous substances or health hazards.

Employees covered by the medical surveillance program will be given medical examinations and consultations at the following frequency:

A. Prior to assignment.

B. Annually unless attending physician extends the interval up to 2 years or decreases the interval as medically necessary.

C. At termination of employment or reassignment to another area where employee will not be under medical surveillance if the employee has not had an examination within the last 6 months.

D. As soon as possible after development of signs or symptoms indicating overexposure to hazardous substances above PEL or other published exposure levels in an emergency situation.

Medical examinations will include a medical and work history (or updated history if one is in the employee's file) with special emphasis on: symptoms related to the handling of hazardous substances, health hazards of these substances, and fitness for duty, including the ability to wear any required PPE under the conditions (i.e., temperature extremes) that may be expected at the work site. All medical examinations and procedures shall be performed by or under the supervision of a licensed physician.

The attending physician will be provided with the following information by the site safety officer or supervisor in conjunction with Hazards Control:

A. A description of the employee's duties as they relate to employee's exposures.

B. Th. employee's exposure levels or anticipated exposure levels.

C. A description of any personal protective equipment used or to be used. If respirators are to be worn, then information will be provided concerning the type, anticipated periods of use, workloads, etc., as required by 29 CFR 1910.134 .

D. Where feasible, information from previous medical examinations of the employee which is not readily available to the examining physician.

E. A copy of this standard and its appendices.

LLNL Health Services will provide each covered employee with a written opinion from the attending physician containing the following:

A. A summary of the results of the examination.

B. An opinion as to whether the employee has any detected medical conditions which would place the employee at increased risk of impairment of the employee's health from work in hazardous waste site operations or from the use of respirators. The written opinion shall not reveal specific findings or diagnoses unrelated to occupational exposure.

C. Any recommended limitations upon the employee's assigned work.

D. Any medical conditions which require further medical examination or treatment. 
An accurate record of the medical surveillance required by this standard shall be retained in accordance with 29 CFR 1910.20. The record shall include at least the rollowing items:

A. Employee's name and social security number.

B. Physician's written opinion, recommended limitations, and results of examinations and tests.

C. Any employee medical complaints related to exposure to hazardous substances.

D. A copy of the information provided to the examining physician by the employer with the exception of the standard and its appendices.

Employees who may be exposed to chemical hazards while performing project work must receive medical screening. LLNL will screen at-risk LLNL employees, and contract firms will screen their at-risk employees, as specified in their contracts with LLNL and DOE. 


\section{Hazard Evaluation}

The potential hazards associated with the environmental investigations and clean up of the LLNL Site include:

Chemical hazards

- Trichloroethylene (TCE).

- Tetrachloroethylene (PCE).

- Carbon tetrachloride $\left(\mathrm{CCl}_{4}\right)$.

- 1,1-Dichlorethane (1,1-DCA).

- 1,2-Dichloroethane (1,2-DCA).

- 1,2-Dichloroethylene (1,2-DCE).

- Chloroform.

- 1,1-Dichloroethylene (1,1-DCE).

- Tritium.

- Benzene.

- Toluene.

- Xylenes.

- Gasoline and diesel fuel.
Physical hazards

- Heavy equipment (drill rig, backhoe, crane).

- Noise.

- Heat stress.

- Excavations.

- Underground utilities.

- Fire and explosion.

- Electrical.

- Confined space.

General Safety Hazards

Hazards to Nonproject Personnel

These particular hazards have been identified from existing knowledge of site conditions and prior site activities, and represent likely or potential hazards to site personnel during the environmental investigations. It is possible, however, that unforeseen hazards could be encountered during site work. In the event that any such encounter occurs, work should cease and the SSO should be informed as soon as possible so that the situation can be evaluated and appropriate steps can be taken by the SSO to address the safe resumption of work.

\subsection{Chemical Hazards}

Because analytical and operational monitoring data demonstrate negligible or very low concentrations for many VOCs, this evaluation has been restricted to a consideration of benzene, carbon tetrachloride, chloroform, 1,1-DCA, 1,2-DCA, 1,1-DCE, 1,2-DCE, diesel, gasoline, PCE, TCE, tritium, toluene, and xylenes. These chemicals may enter the body through inhalation, ingestion, or skin absorption. They may enter by more than one route, may cause damage at the point of entry, or may cause organ damage after being metabolized. During project activities, ingestion is unlikely. Pertinent data are summarized below.

\subsubsection{Benzene}

Odor

Odor threshold

Fire potential
Aromatic odor.

Approximately 4.7 ppm.

Dangerous; when exposed to heat or flame, can react vigorously with oxidizing materials. 
Flammable limits

Explosive limits

Exposure

OSHA PEL

ACGIH TLV

$\mathrm{NIOSH}$

IDLH
Lower Flammable Limit (LFL) 1.3\%, Upper Flammable Limit (UFL) $7.9 \%$.

Lower Explosive (LEL) 1.3\%, Upper Explosive Limit (UEL) $7.1 \%$.

Irritating to eyes, nose, and throat at high concentrations.

Prolonged exposure may affect the blood-forming system.

Symptoms: nervous excitation and giddiness followed by depression, drowsiness, or fatigue, and a tightness in the chest.

Time-Weighted Average (TWA) 1 ppm; Short-term Exposure Limit (STEL) 5 ppm.

TWA 10 ppm; a suspected human carcinogen.

TWA 0.1 ppm; Ceiling Exposure Limit (CEIL) 1 ppm; a human carcinogen (leukemia).

2,000 ppm.

\subsubsection{Carbon tetrachloride $\left(\mathrm{CCl}_{4}\right)$}

Odor

Odor threshold

Fire potencial

Exposure

OSHA PEL

ACGIH TLV

NIOSH

IDLH

\subsubsection{Chloroform}

Odor

Odor threshold

Fire potential

Exposure

OSHA PEL

ACGIH TLV

$\mathrm{NIOSH}$

IDLH

\subsubsection{1,1-DCA}

Odor

Odor threshold

Fire potential

Flammable limits
Heavy, ether-like odor.

50 ppm.

Not combustible.

Primarily a narcotic, but prolonged exposure can cause liver and kidney damage. Symptoms: drowsiness, dizziness, and incoordination.

TWA 10 ppm; CEIL 25 ppm; maximum peak (PEAK) 200 ppm, 5 minutes in any 4 hours (transitional limits). TWA 2 ppm (final limit).

TWA 5 ppm; skin; a suspected human carcinogen.

CEIL 2 ppm; a human carcinogen (liver).

$300 \mathrm{ppm}$.

Pleasant; ether-like; nonirritating.

50 to 200 ppm.

Nonflammable, but will burn on prolonged exposure to flame or high temperature.

Irritating to eyes, nose, and throat. Symptoms: headache, dizziness, drunkenness, and narcosis.

STEL 50 ppm (transitional limit); TWA 2 ppm (final limit)

TWA 10 ppm; a suspected human carcinogen.

CEIL 2 ppm; a suspected human carcinogen.

$1,000 \mathrm{ppm}$.

Aromatic, ether-like odor.

88-200 ppm.

Very volatile flammable liquid.

LFL 5.9\%, UFL $15.9 \%$. 
Explosive limits

Exposure

OSHA

ACGIH TLV

IDLH

\subsubsection{1,2-DCA}

Odor

Odor Threshold

Fire Potential

Flammable limits

Explosive limits

Exposure

OSHA PEL

ACGIH TLV

NIOSH

IDLH

\subsubsection{1,1-DCE}

Odor

Odor threshold

Fire potential

Flammable limits

Explosive limits

Exposure

OSHA

ACGIH TLV

\subsubsection{1,2-DCE}

Odor

Odor threshold

Fire potential

Flammable limits

Exposure

OSHA PEL

ACGIH TLV

IDLH
LEL 5.6\%, UEL, $11.4 \%$.

A narcotic and can also cause damage to liver, kidneys, and lungs. Symptoms: drowsiness.

TWA 100 ppm.

TWA 200 ppm; STEL 250 ppm.

$4000 \mathrm{ppm}$.

Mild, sweet odor resembling that of chloroform.

$50 \mathrm{ppm}$.

Very volatile flammable liquid.

LFL $6.2 \%$, UFL $15.9 \%$.

LEL $6.2 \%$, UEL $16 \%$.

Irritating to eyes, nose, and throat. Symptoms: nausea, dizziness, and vomiting.

TWA 50 ppm; CEIL 100 ppm; PEAK 200 ppm, 5 minutes in any 3 hours.

TWA $10 \mathrm{ppm}$.

TWA 1 ppm; CEIL 2 ppm; a suspected human carcinogen. $1,000 \mathrm{ppm}$.

Mild, sweet odor resembling that of chloroform.

500 to $1,000 \mathrm{ppm}$.

Very volatile flammable liquid.

LFL 7.3\%, UFL $16 \%$.

LEL $5.6 \%$, UEL $11.4 \%$.

Irritating to eyes, nose, and throat. Symptoms: nausea, dizziness, and drunkenness.

TWA 1 ppm (final limit).

TWA 5 ppm; STEL 20 ppm.

Ether-like, slightly acrid odor.

$0.1 \mathrm{ppm}$.

Very volatile flammable liquid.

LFL 9.7\%, UFL $12.8 \%$.

Irritating to eyes, nose, and throat, and a narcotic. Symptoms:

dizziness and drowsiness.

TWA $200 \mathrm{ppm}$.

TWA $200 \mathrm{ppm}$.

$4,000 \mathrm{ppm}$. 


\subsubsection{Diesel}

Odor

Fire potential

Exposure

ACGIH TLV

\subsubsection{Gasoline}

Odor

Fire potential

Flammable limits

Exposure

ACGIH TLV:

\subsubsection{PCE}

Odor

Odor threshold

Fire potential

Exposure

OSHA PEL

ACGIH TLV

IDLH

\subsubsection{TCE}

Odor

Odor threshold

Fire potential

Flammable limits

Explosive limits

Exposure

OSHA PEL

ACGIH TLV
Characteristic of petroleum distillate.

Flash point $85^{\circ} \mathrm{C}$; fire hazard greater if liquid temperature exceeds $85^{\circ} \mathrm{F}$; may explode if pressure is used to empty drums.

Irritating to eyes, nose, and throat; central nervous system depressant if inhaled; possible carcinogen. Symptoms: headache, dizziness, loss of appetite, weakness, and loss of coordination. Incomplete combustion produces carbon monoxide; toxic fumes may accumulate.

Not established. Reduce exposure to lowest feasible level.

Characteristic of gasoline; threshold, $0.25 \mathrm{ppm}$.

Flammable; flashback along vapor trail may occur. Vapor may explode if ignited in an enclosed area.

LFL $1.4 \%$, UFL $7.4 \%$.

Irritating to eyes, nose, and throat. Symptoms: irritation of mucous membranes, dizziness, headache, incoordination, anesthesia, and coma.

TWA, 300 ppm; STEL, 500 ppm.

Chloroform-like odor.

5 ppm.

Nonflammable.

Irritating to eyes, nose, and throat. Symptoms: affects central nervous system, causes anesthesia.

TWA 100 ppm; CEIL 200 ppm; PEAK 300 ppm, 5 minutes in any 3 hours.

TWA 50 ppm; STEL 200 ppm.

$500 \mathrm{ppm}$.

Chloroform-like odor.

$50 \mathrm{ppm}$.

Low fire hazard.

LFL $8 \%$, UFL $10.5 \%$.

LEL $12.5 \%$, UEL $90 \%$.

Irritating to eyes, nose, and throat. Symptoms: nausea, blurred vision, and disturbance of central nervous system.

TWA 100 ppm; CEIL 200 ppm; PEAK 300 ppm, 5 minutes in any 2 hours (transitional limits). TWA 50 ppm; STEL 200 ppm (final limits).

TWA 50 ppm; STEL 200 ppm. 
NIOSH

IDLH
TWA 25 ppm; a suspected human carcinogen.

$1,000 \mathrm{ppm}$.

\subsubsection{Tritium $\left({ }^{3} \mathrm{H}\right)$}
Half-life:
Physical: $\quad 12.3$ years.
Biological: $\quad \sim 10$ days (range: 4-18) total body for HTO.

Special Chemical and Biological Characteristics:

Not selectively concentrated in any organ. Metabolized as $\mathrm{H}_{2} \mathrm{O}$. Tritium is assumed to be readily and completely absorbed by the body and to be distributed evenly throughout the body.

Principal Human Metabolic and Dosimetric Parameters

$f_{1}=1.0$.

ALI $(\mu \mathrm{Ci})=8.1 ¥ 10^{4}(\mathrm{HTO})$.

$\operatorname{DAC}\left(\mu \mathrm{Ci} / \mathrm{cm}^{3}\right)=2.2 ¥ 10^{7}(\mathrm{HTO})$.

\subsubsection{Toluene}

Udor

Odor threshold

Fire potential

Flammable limits

Explosive limits

Exposure

OSHA PEL

ACGIH TLV

NIOSH

IDLH

\subsubsection{Xylenes}

Odor

Odor threshold

Fire potential

Flammable limits

Exposure

OSHA PEL

ACGIH TLV
Sweet, pungent, benzene-like odor.

0.17 to $2.1 \mathrm{ppm}$.

Flammable liquid ignitable under almost all normal temperature conditions.

LFL $1.2 \%$, UFL $7.1 \%$.

LEL $1.2 \%$, UEL $7.1 \%$.

Irritating to eyes, nose, and throat. Symptoms: dizziness, headache, and anesthesia.

TWA 200 ppm; CEIL 300 ppm; PEAK 500 ppm, 10 minutes (transitional limits). TWA 100 ppm; STEL 150 ppm (final limits).

TWA 100 ppm; STEL $150 \mathrm{ppm}$

TWA 100 ppm; CEIL 200 ppm.

$2,000 \mathrm{ppm}$.

Like benzene.

$0.05 \mathrm{ppm}$.

Material is flammable and can form explosive mixtures with air.

XLM: LFL $1.1 \%$, UFL $6.4 \%$.

XLO: LFL $1.1 \%$, UFL $7.0 \%$.

XLP: LFL $1.1 \%$, UFL $6.6 \%$.

Irritating to eyes, nose, and throat. Symptoms: headache, dizziness, coughing, and pulmonary edema.

TWA $100 \mathrm{ppm}$ (transitional and final limit).

STEL $150 \mathrm{ppm}$ (final limit).

TWA 100 ppm; STEL 150 ppm. 
NIOSH

IDLH
TWA 100 ppm; CEIL 200 ppm.

$1,000 \mathrm{ppm}$.

Exposure limits, detectable limits, and other references to airborne chemical concentrations given are for vapors in air. Concentrations encountered in soil and ground water are several orders of magnitude lower than the specified limits. Therefore, even direct contact with soil and ground water in the field and exposure to associated vapors would not constitute acute exposures at high concentrations. Some operations may involve the use of hazardous substances which are not hazardous wastes, but are used in the operations or stored onsite. For example, hydrogen peroxide (50\%), which is a strong oxidizer, is used on some sites to treat ground water contamination. The SSO and/or site supervisor will ensure that all site employee's are trained in accordance with 29 CFR 1910.1200, Hazard Communication, and the LLNL Health and Safety Manual Supplement 7.02 (formerly 1.02). The acronyms that describe exposure limits are defined in Appendix A. Material Safety Data Sheets (MSDS) for the compounds listed above are included in Appendix B.

\subsubsection{Respiratory Hazards}

The respiratory hazards associated with work activities are exposure to vapors, gases, or dusts during drilling, well installation, water sampling, tank excavation, de:,ontamination, and other operations. It is not anticipated that exposure levels in excess of recommended PELs or TLVs will be encountered. Air monitoring will be conducted, as discussed in Section 8. The open-air environment at the site should provide adequate ventilation to reduce potential respiratory hazards to very low or negligible levels.

\subsubsection{Dermal Hazards}

Dermal hazards result from direct contact of solids, liquids, or vapors with the skin. Since the potential for vapor contact is low, dermal hazards from vapors are expected to be negligible. Direct contact with contaminated soil and ground water in the field would not generaliy result in dermal effects. However, good hygienic practices, and the fact that these chemicals may be absorbed through the skin, warrant protecting the skin.

Based upon previous experience at this and other sites, it is anticipated that direct skin contact is unlikely to occur if protective clothing and/or protective equipment is used.

\subsection{Physical Hazards}

Working conditions at the site involve potential exposure to the physical hazards discussed below.

\subsubsection{Heavy Equipment}

The hazards associated with heavy equipment, especially drilling rigs, primarily involve moving parts and exposure to possible pinch points. Safety protection, including equipment guards, will be provided to mitigate this problem. In addition, no loose hair will be allowed around the heavy equipment, and only qualified personnel will operate machinery. Hard hats and steel-toed boots will be worn by all personnel operating or working in proximity to heavy

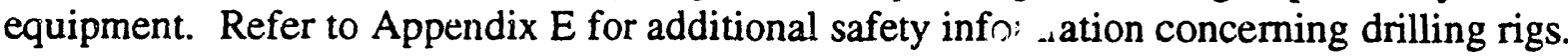




\subsubsection{Noise}

The site operations are monitored for detection of excessive noise levels. When a survey indicates that hearing protection is necessary, appropriate hearing protection devices will be provided to field personnel. The use of hearing protection is required in those high noise areas when excessive sound levels are present.

Noise exposure is primarily associated with heavy equipment, steam cleaning, and air compressors. Based upon previous experience, it is not anticipated that the noise levels will be of concern. Ear protection is provided for all field personnel, and its use is encouraged when appropriate for personnel comfort.

\subsubsection{Heat Stress}

Heat stress is associated with exposure to high temperatures, wearing protective clothing, and physical exertion. Temperatures at the site can exceed $100^{\circ} \mathrm{F}$ on occasion. Drinking water is available onsite, and appropriate breaks shall be taken if temperature and levels of personal protection so dictate. Based upon previous experience and work performed at this site, it is not anticipated that heat stress will be a major concern.

Personnel will inform the SSO of any symptoms of heat stress, such as:

- Weakness and fatigue.

- Dizziness.
- Nausea.

- Headache.

The SSO will be alert to signs of heat stress in site personnel and increase the frequency of breaks and fluid consumption as necessary.

\subsubsection{Excavations}

Open excavations are dangerous because personnel may fall into the excavation or the side walls may collapse while personnel are inside the excavation. To minimize these hazards, each excavation shall be barricaded as described in Section 10.2. Also, the excavation walls shall be properly sloped or shored before allowing anyone to enter the excavation. Personnel not directly involved in excavation activities or who do not need to be in the area will remain at least 10 feet away from the edge of the excavation. Work in or around excavations shall be carefully planned in consultation with the SSO regarding protective measures and equipment use. Additional information regarding necessary precautions and Cal/OSHA requirements is presented in Appendix C.

\subsubsection{Confined S'?ace Entry}

Although no colifined space entries are currently anticipated, employees will be trained in what types of areas inight be confined spaces. When entry into a confined space is necessary, Hazards Control will be contacted to obtain a confined space entry permit. The procedures required by the LLNL Health and Safety Manual Supplement 26.14, "Working in Confined Spaces," and the 29 CFR 1910.146 Permit Required Confined Spaces will be followed. 


\subsubsection{Overhead Power Lines}

No equipment shall be operated closer than 15 feet in any direction to overhead power lines. Operation closer than 15 feet may be permitted only when overhead power lines have been deenergized, locked, and tagged out.

\subsubsection{Underground Utilities}

Prior to any drilling or excavation all underground utilities will be located by licensed utility locators and/or LLNL Plant Operations personnel.

\subsubsection{Fire and Explosion}

It is not anticipated that ground water and soil contaminants exist at concentrations sufficient to create fire and explosion hazards during routine drilling and sampling activities. Removal of underground tanks could create a potential for fire and explosion hazards. [Refer to the LLNL Site Safety Plan for Tank Excavation and Removal of Underground Storage Tanks at Buildings 401, 402, and 411 (October 29, 1988) or information on the safety considerations associated with underground tank removal.]

Several chemicals that may be encountered at the site during tank excavation are highly flammable liquids, and they are explosion hazards if vapors are present at levels above the lower explosive limit (LEL).

Chemical Name
Benzene
Gasoline
Xylenes

LEL (\% by volume in air)
1.3
1.4
1.0

To minimize explosion hazards, all tanks and piping will be emptied and flushed prior to excavation. All piping will be disconnected from tanks, the tanks emptied, and dry ice applied to the tank interior to displace oxygen prior to tank removal. The atrnosphere inside the tank will be monitored with a combustible gas indicator prior to removal. At least one 20-pound dry chemical fire extinguisher will be available. No hot work or open flames will be allowed in the work area without the express authorization of the SSO and the Fire Department, and ensuring appropriate safety controls being implemented. It is anticipated that concentrations of these substances in fill or soil materials will be sufficiently low to present no fire hazard. However, the detection of $\mathrm{fl}$ ! products in fill and soil materials shall be cause to initiate the evaluation for vapors with respect to fire, explosion, and personnel exposure.

\subsubsection{Electrical Hazards}

Ignorance of basic electrical principles and misuse of electrical equipment contribute to many accidents. The electrical resistance of the human body can be drastically reduced by working with wet tools, in wet or damp locations, inside tanks and boilers, or around metal piping or other grounding materials. Other factors that affect the severity of electrical 
injuries include the path of the current through the body, the vital organs in that path, and the duration of the current through the body.

There are many ways an employee can come into contact with energized circuits. The most common way is contact with exposed live parts and overhead or buried power lines. When working in the vicinity of live electrical parts, such as exposed wires, switches, or contacts, the parts must be guarded from contact by effective insulation or other means. If that is not possible, the circuit must be de-energized and visibly grounded. Pertinent information on electrical safety can be found in Appendix D.

\subsection{General Safety Hazards}

Other possible safety hazards include the potential for slipping, falling, head trauma, lifting heavy objects, insect bites, etc. All personnel working on the project will wear appropriate PPE, including eye protection, head protection (hard hat), and steel-toed boots as required by the SSO. At a minimum, EPA Level D protection is required. First aid will be available onsite to take care of any minor injuries. Contact Emergency Response Dispatch (911) in emergency situations more serious than cuts or scrapes (offsite, dial 911).

\section{Contact Emergency Response Dispatch (911) in emergency situations more serious than cuts or scrapes.}

\subsection{Hazards to Nonproject Personnel}

Potential risks to project personnel have been outlined above. Potential risks to other persons on the site, who are not working on this project, are exposure to vapors, gases,and chemicals in soil or ground water and the physical hazards associated with heavy equipment.

Air monitoring will be conducted to minimize the possibility of public and personnel exposure to vapors and gases. These procedures are described in Section 8. Due to the openair environment at the site and the fact that the work zone will be barricaded, the risk to the public and LLNL personnel is expected to be negligible. 


\section{Emergency Actions}

\subsection{Planning}

The SSO shall plan escape routes and discuss them with project personnel before they enter a site to begin work. Initial planning includes establishing the best means for evacuation from the site in case of a catastrophe (e.g., explosion, tank rupture, fire, etc.).

\subsection{Emergency Services}

A tested system must be in place for rapid and clear distress communications, preferably voice, from all personnel to the emergency response unit of the LLNL Fire Department and the SSO. The SSO shall ensure that all personnel working at the site know how to communicate with the LLNL Emergency Response Dispatch at 911 (Offsite, dial 911). The SSO shall notify appropriate local emergency response units, and provide adequate and clear directions to reach LLNL work sites from the location of those units before beginning any onsite investigations or operations. All personnel shall have adequate and clear directions and access to personnel transportation (e.g., keys in ignition) to local emergency services.

\subsection{Evacuation}

If evacuation is necessary, all personnel will proceed to a predetermined location in the support zone upwind of the work zone.

The predetermined evacuation route and assembly location will be specified at each site. ERD employees and subcontractors will evacuate the worksite and not directly assist in handling the emergency.

\section{The signal for evacuation will be three short blasts in succession on an air or car horn.}

\subsection{Emergency Evacuation From Contaminated Areas}

Any person requiring medical attention shall be evacuated promptly from any contaminated area. However, personnel shall not enter an area to attempt a rescue if their own lives would also be threatened because of inadequate personal protection (e.g., oxygendeficient atmosphere and no self-contained breathing apparatus). Contact the LLNL Emergency Response Dispatch at 911 to evacuate any person from any area of the site if necessary and to provide special decontamination treatment or procedures for any injured person. The SSO shall order evacuation of any person whose PPE fails. 


\section{Contact Emergency Response Dispatch at}

911 for evacuation or decontamination treatment or procedures (from offsite, dial 911).

\subsection{First Aid}

Qualified personnel shall give first aid and stabilize any employee needing assistance. Life support techniques such as CPR and treatment of life-threatening problems, such as bleeding, airway maintenance, and shock, shall be given top priority. Professional medical assistance shall be obtained at the earliest possible opportunity. If assistance beyond first aid is required, phone the LLNL Emergency Response Dispatch at 911.

Maintain a first aid kit and portable eyewash in the support zone. When drilling, these items should be kept in a clean location near or on the drill rig.

Emergency first aid procedures for organic compounds.

\begin{tabular}{|c|c|}
\hline Exposure & Procedures \\
\hline Eyes & $\begin{array}{l}\text { Flush eyes immediately with fresh water for at least } 15 \text { minutes while holding } \\
\text { the eyelids open. Call LLNL Emergency Response Dispatch at } 911 \\
\text { immediately. }\end{array}$ \\
\hline Skin & $\begin{array}{l}\text { Wash skin thoroughly with soap and water. See a doctor if any unusual signs } \\
\text { or symptoms or if any skin irritation occurs. Launder contaminated clothing. }\end{array}$ \\
\hline Inhalation & $\begin{array}{l}\text { Move exposed person to fresh air. If breathing has stopped, apply artificial } \\
\text { respiration. Call LLNL Emergency Response Dispatch at } 911 \text { immediately. }\end{array}$ \\
\hline Ingestion & $\begin{array}{l}\text { If swallowed, DO NOT make person vomit. Call LLNL Emergency Response } \\
\text { Dispatch at } 911 \text { immediately. }\end{array}$ \\
\hline
\end{tabular}

\subsection{Fire}

Call the LLNL Fire Department at 911 in the event of any fire. 


\subsection{Hazardous Materials Spill}

For spills greater in volume than one gallon, call LLNL Emergency Response Dispatch at 911. Refer to the appropriate MSDS (see Appendix B) for special instructions regarding cleanup or spills.

\subsection{Guidelines}

If any emergency involving actual or suspected personal injury occurs, the SSO, work supervisor, and surviving personnel shall follow these steps:

- Remove the exposed or injured person(s) from immediate danger.

- Render first aid if necessary. Decontaminate affected personnel at the LLNL Medical Facility, Building 663.

- Obtain paramedic service or ambulance transport to local hospital by calling the LLNL Emergency Response Dispatch at 911. This procedure shall be followed even if there is no visible injury.

- Other personnel onsite shall be evacuated to a safe distance until the Fire Department determines that it is safe for work to resume.

- At the earliest time practicable, the SSO shall contact the Project Leader or a designee and Hazards Control, giving details of the incident and the steps taken to prevent its recurrence.

- A written report of the incident must be forwarded to the Project Leader or a designee within 24 hours following the incident.

Subsequent reporting shall be completed according to the requirements of the $L L N L$ Health and Safety Manual, Section 4: Incident Analysis and Reporting. 


\section{Personal Protective Apparel and Equipment}

Suggested item specifications and descriptions in this section are for information only. Equivalent items may be purchased.

\subsection{Personnel Protection}

The nature of this work is such that several potentially hazardous conditions could be encountered. It is not possible to determine in advance of actual conditions all protective requirements. Items specified below are intended to allow the SSO the latitude to provide a range of protection based upon actual working conditions. Where feasible, engineering controls in accordance with 29 CFR 1910, Subpart G and work practices are used to prevent exposure of employees to hazardous substances above their PEL or other published exposure limit if no PEL exists. However, when such is not feasible or not required, a reasonable combination of engineering controls, work practices, and PPE will be used. PPE selection is made to protect the employees from hazards or potential hazards at the site in accordance with 29 CFR 1910, Subpart I, Personal Protective Equipment.

The proper use and selection of PPE include consideration of at least the following items:

A. Proper usage procedure (i.e., donning and doffing).

B. Equipment limitations (i.e., reduced dexterity, vapor versus liquid contact, hazardous substance and concentration, and temperature).

C. Anticipated duration of use.

D. Maintenance and storage requirements.

E. Decontamination and disposal.

F. Inspection procedures.

G. Heat and cold stress, activity levels, and other medical consideration.s.

H. Employee training and fitting of equipment.

The use of employee rotation in order to achieve compliance of employee exposures to hazardous substances with PEL's is not anticipated and would only be used when no other feasible means is available (i.e., a reasonable combination of engineering controls, work practices, PPE, etc.).

At a minimum, EPA Level D protection shall be worn during investigations at the Livermore Site. It is not expected that higher levels of protection would be required often.

Depending upon the circumstances and the hazards present at a given site, the level of PPE will be determined by Hazards Control Team 4. Some of the items recommended for a given level may be modified as appropriate (see Appendix G). The level of protection is selected based primarily upon:

A. Characteristics of hazardous substances (i.e., toxicity, concentration, entry routes, warning properties, etc.). 
B. The potential for exposure in air, from splashes or from immersion in liquids, or other direct contact with hazardous substances.

Level $D$ consists of a work uniform which provides minimal protection and essentially no protection against chemical hazards. It is used when no inhalation hazard is present nor anticipated to occur during the operations and skin contact with hazardous substances by immersion or splashes is not anticipated.

Many of the following items are only necessary for upgrading to Modified Level C protection. However, the SSO or a designee shall ensure that all workers have all the following items available for their use:

- Gloves

Inner, surgical type (vinyl disposable)

Outer, chemical protective (neoprene or nitrile)

- Protective clothing

Cotton, regular, washable coveralls

AND Tyvek, regular, disposable, zippered coveralls

- Footwear

Chemical protective boots (low-temperature vinyl), steel-toed

OR safety shoes worn with protective rubber overshoes

- Eye protection

Safety glasses with optional side-shields

OR goggles

OR single unit plastic "specs" with side-shields

- Hard hat with attachable face shield (optional)

- Hearing protection

Muffs and/or earplugs

- Respirators

National Institue for Occupational Safety and Health (NIOSH) approved full face mask air-purifying respirator equipped with a high-efficiency particulate filter (HEPA) with protection for organic vapors, acid gases, dusts, fumes, and mists, asbestos, and radionuclides. The protection for dusts, fumes, and mists shall be furnished for a TWA less than $0.05 \mathrm{mg} / \mathrm{m}^{3}$.

OR NIOSH-approved half-mask air-purifying respirator equipped with a HEPA filter with protection for organic vapors, acid gases, dusts, fumes, and mists, asbestos, and radionuclides. The protection for dusts, fumes, and mists shall be for a TWA less than $0.05 \mathrm{mg} / \mathrm{m}^{3}$.

Conventional eyeglass frames cannot be used with full-face mask respirators because of interference with the face seal. Special eyeglasses can be mounted inside the face mask; however, there is a delay to obtain prescription lenses.

The SSO shall specify which employees are required to wear the items listed above. The SSO shall instruct site personnel to don appropriate respiratory protection when air monitoring results show breathing zone concentrations of benzene greater than 1 ppm, or 
when total hydrocarbon monitoring results for nonbenzene in the breathing zone are greater than $5 \mathrm{ppm}$. The SSO shall determine which level of personal protective items (gloves, goggles, etc.) is needed, based on professional judgment regarding site conditions and the likelihood of exposure. Respiratory protection should be used if personnel exposure above TLVs is probable, or if personnel desire protection for odor or nuisance mitigation.

Personnel who wear respirators will be trained in their proper usage, have a current medical examination, and have been fit tested within the past 12 months. Facial hair which interferes with the respirator seal must be removed prior to respirator usage (29 CFR 1910.134 and LLNL Respiratory Protection Program).

It should be recognized that the nature of the potential hazards is such that it is not possible to provide maximum protection for all suspected contaminants. If unanticipated conditions are encountered that require additional personnel protection, the SSO shall ensure that appropriate additional personal protective apparel and equipment are in use prior to continuing activities under those conditions.

\subsection{Apparel Decontamination}

The SSO may establish at least one safety apparel decontamination station at the work site in the contamination reduction zone. At a minimum, soap/detergent, rinse water, towels, wash pans, and brushes for scrubbing boots shall be available. Decontamination is defined as removing any potentially contaminated soil from boots by washing with soap and water or removing boot covers in the contamination reduction zone upon exiting the work zone. Wash water will be available in a basin suitable for standing in while washing boots. If there is reason to believe that this wash water requires containment and disposal, it will be contained, sampled, and properly disposed of based upon the analytical results.

The location of the decontamination process will be selected to minimize the exposure of uncontaminated employees and equipment to the contaminated employees and equipment. The SSO will monitor decontamination procedures to determine their effectiveness.

In the event that permeable clothing should become wetted with hazardous substances, the employee will immediately remove that clothing and proceed to shower.

When protective clothing or equipment is sent to commercial cleaning establishments for decontamination, those establishments will be informed of the potentially harmful effects of exposures to the hazardous substances present.

If additional PPE is used, such as Polytyvek suits and chemical-resistant gloves, remove them in the contamination reduction zone after leaving the work zone. If this equipment is used, it must be decontaminated or disposed of properly.

\subsection{Equipment Decontamination}

Soils remaining on tools, sampling equipment, or heavy equipment will be removed by steam cleaning. If there is reason to believe that the water used for this decontamination procedure requires containment and disposal, it will be contained and properly disposed of based upon analytical results. 


\subsection{Personnel Decontamination and Personal Hygiene}

Personnel may be subject to skin or eye irritation from contaminants. Before eating, drinking, or smoking, site workers should thoroughly wash their hands and other exposed skin surfaces after leaving a contaminated area Workers should shower and change clothes at the end of the work shift to ensure that contaminants from the site are not transferred into personal vehicles or taken home on soiled clothing.

Where regular showers and change rooms are needed for decontamination outside of contaminated areas, they will meet the requirements of 29 CFR 1910.141, "SANITATION." Protective equipment and/or clothing will not be removed from change-rooms by unauthorized personnel.

\subsection{Monitoring Equipment}

The SSO shall ensure that all necessary monitoring equipment is available in sufficient quantities prior to work initiation. Other equipment deemed necessary by the SSO, based on the potential for contamination, shall be obtained at his direction prior to work initiation. The SSO shall also ensure that these instruments are used only by persons who have had prior experience with their care, calibration, and operation and who know their limitations. No work shall be done unless this instrumentation is available and in proper working order.

\subsubsection{Monitoring Rationale}

Monitoring shall be sufficient to deternine:

- Airborne concentrations of hazardous chemical substances.

- Combustible gas and oxygen levels.

- Surface contamination of work areas.

- Contamination of personal protective apparel and equipment.

- Personnel contamination.

- Suitability of release of equipment and material to unrestricted areas.

\subsubsection{Equipment}

The SSO, or his designee, may use any or all of the following monitoring equipment to assist in evaluating potential hazards:

- Combustible gas/oxygen meter.

- Passive chemical dosimeters (i.e., 3M Organic Vapor Monitor, Draeger DirectReading Diffusion Tubes).

- Other real-time monitoring instruments (i.e., hydrogen sulfide, carbon monoxide, etc.).

- Photoionization detector (PID).

- Flame ionization dectector (FID). 
- Hand pump (e.g., Draeger) with colorimetric detector tubes for specific compounds, particularly benzene.

- Constant flow personnel air sampling pumps, which can be calibrated to appropriate volumetric air flow rates to collect airborne samples consistent with NIOSH requirements. The other items required for air sampling include: tubing, filter cassette holders, charcoal tubes, filters, and calibration equipment.

- Radiation detection equipment/monitors.

\subsubsection{Initial Monitoring}

A preliminary survey of existing air quality is performed by a qualified person to determine the presence of any of the following conditions prior to commencement of operations:

- Immediately dangerous to life and health (IDLH).

- Potential exposure to hazardous substance in excess of PEL or other published exposure limit when applicable.

- Exposure to radioactive substances in excess of established dose limits.

- Exposure to other dangerous conditions (i.e., flammable atmospheres or oxygen deficiency).

The site is initially inspected for visual signs of dangerous conditions and surveyed with a OVM or OVA and a combustible gas/oxygen meter prior to initiation of any work activities to establish background levels for use in proper selection of engineering controls, safe work practices, and PPE. Where radiation is anticipated, the site is also surveyed with radiation detection equipment.

If the presence of other hazardous substances not detectable with the above equipment is anticipated (hydrogen sulfide, carbon monoxide, etc.), the appropriate monitoring equipment will be used to survey the site (i.e., Drager detector tubes, substance-specific monitors, etc.).

This survey will focus on the following areas:

- The contamination reduction zone downwind from drilling activities, excavation, and other work activities.

- Locations where workers may assemble or congregate.

- Confined spaces or areas where gases may be trapped.

\subsubsection{Periodic Monitoring}

When the potential for exposure is unknown, periodic monitoring of onsite ambient concentrations of VOCs in the immediate vicinity of work activities will be performed using a OVM or OVA. The SSO will compare monitoring results with OSHA standards and other exposure guidelines to ensure that proper protection is provided.

Where work activities may generate dust contaminated with beryllium or lead, it may be necessary to use a calibrated sampling pump to collect an airborne sample of particulate on a 
filter. When this is done, samples should be analyzed by an American Industrial Hygiene Association (AIHA) accredited laboratory according to NIOSH procedures.

Caution is necessary during any fuel tank excavation and removal. OVM or OVA results are not compound specific; the instrument reading is for total organic vapors. When benzene is a potential exposure problem, a direct readout of benzene vapor concentrations should be obtained using an instrument similar to a Draeger pump with a colorimetric detector tube specific for benzene. Personnel protection, respirator selection, monitoring, and operational protocols and procedures must be developed for work atmospheres where benzene concentrations are greater than the PEL of $1 \mathrm{ppm}$.

Periodic monitoring shall be performed whenever there is a possibility that an IDLH condition or explosive atmosphere has developed or when an indication that exposure may be in excess of the PEL or other published exposure limits. When any of following situations exist, additional precautions shall be considered:

- Initiation of work in a different portion of the site.

- If new contaminants : $:$ known to be, or suspected of being present.

- When employees are handling leaking containers or working in areas with obvious contamination.

- Upon initiation of a different type of opeartion.

\subsubsection{High Risk Employees}

The employees who are most likely to be exposed to hazardous substances above the PEL or other applicable published exposure limits will be monitored first. If they are being exposed to levels above the PEL, then monitoring will be performed to establish which other employees, if any, may also be exposed above PEL.

\subsubsection{Perimeter Monitoring}

Under certain circumstances, it may be necessary to conduct perimeter monitoring to evaluate emissions resulting from work covered by this Plan. If such monitoring is conducted and results are higher than baseline levels of any contaminant, immediate steps will be taken to determine the cause, make changes to site operations, evacuate unprotected personnel and the public, if necessary, and notify agency contact personnel. Specific protocols to be implemented shall be determined by the SSO and the Project Leader for each incident.

\subsection{First Aid and Safety Equipment}

To provide first response assistance to field personnel in the event of an injury or illness, the SSO shall have the following items immediately available at the site investigation command post, $\mathrm{O}^{-}$at work areas, as appropriate:

- First aid kit.

- First aid handbook. 
- Portable emergency eyewash station or bottles.

- Supply of clean water.

- Hand soap, or waterless hand cleaner, and clean hand towels.

- Portable cooler with drinking water (or replenishment drink such as Gatorade) and ice. 


\section{Personnel Training}

Individuals assigned to this project who may be exposed to physical and chemical hazards shall undergo training to:

- Ensure that the health and safety of LLNL employees, contractor employees, employees or representatives of other agencies, and the public is maintained.

- Safeguard the health and safety of all employees and the public by complying with all laws, rules, and regulations.

- Increase the ability of employees to react responsibly to emergencies and to handle emergency situations in a safe manner.

- Increase the ability of employees to complete their work in an efficient and timely manner.

\subsection{Hazardous Waste Operations and General Safety Requirements}

All personnel working on hazardous waste cleanup sites at LLNL who may be exposed to physical and chemical hazards shall attend 40 hours of health and safety training, 24 hours of on-the-job field training under supervision, or other combinations deemed equivalent by the SSO, as specified in OSHA 29 CFR 1910.120. Personnel will be trained prior their participation in field activities and written certificates are to be issued upon successful completion of that training. The Project Leader, SSO, and contractor supervisors are required to complete an additional 8 hours of "Hazardous Waste Management" training. All site personnel are required to complete 8 hours of "Refresher" training annually.

Instructors shall have completed a training program for the subjects that they are expected to teach or have academic credentials and instructional experience for teaching the subjects.

The above requirements address minimal training needs and additional training will be provided as deemed appropriate.

At a minimum, worker training should address the following topics:

- Names of personnel and alternates responsible for site health and safety.

- Onsite Medical Surveillance and Signs of Overexposure.

- Elements of the Site Safety Plan and any applicable OSP.

- Program Discussion/Regulatory Overview.

- Training Rationale.

- Chemical and Physical Hazards.

- Toxicology.

- Medical Surveillance Program.

- Environmental Planning 
Hazards Analysis

Work Plan

Site Safety Plan.

- Characterization and Site Activities.

- Site Control.

- Personal Protective Equipment

Clothing

Respirators and Fit Testing.

- Air Monitoring.

- Decontamination.

- Emergencies.

- Site Operations.

- Hazardous Substance Identification.

- Hazard Communication Program.

\subsection{Work Site Specific Topics}

All site personnel (LLNL employees and contractors) shall attend a site-specific training session which addresses: nature and degree of exposure anticipated at the site; prohibited practices; emergency procedures; site-specific safety requirements; and general safety requirements.

\subsubsection{Prohibited Practices}

The following practices must be strictly observed at all times during the project work. The prohibitions shall remain in effect from the time of entry into the work site until after leaving that portion of the site. They include:

- Eating, chewing, drinking, or smoking items will not be allowed past the Contamination Control Line (i.e., "Hotline"). Avoid all hand-to-mouth contact when your clothing or body may be contaminated (i.e., be careful until after showering). Any open wounds must be covered with an air-tight bandage; ideally, someone with an open wound should not enter a work site. Persons with lesions or sores in the mouth, eyes, or nose shall not enter the work site.

- Never climb over or under any refuse or obstacles.

- Facial hair that may interfere with the satisfactory fit of respiratory protective equipment will not be allowed. Workers with beards will not be allowed to do work requiring respiratory protection.

- Personnel may not wear loose, ragged, or poorly fitted clothing, dangling jewelry, or rings when working around equipment or tools. Long hair must be restrained so that it does not get caught in moving parts. Any of these items can become snagged in moving equipment and result ja serious injury. 
- Alcohol and/or drugs are not permitted at the site. Any person reporting to work under the influence of alcohol and/or illegal drugs will be permanently prohibited from working at the site.

The following prohibitions and practices shall be in effect when deemed necessary by the SSO due to the existence of hazardous conditions at the work area:

- Do not wear contact lenses. Eye contamination while wearing contact lenses can result in serious injury to the eye before the lens can be removed and the eye properly washed.

- Practice contamination avoidance: never sit down or kneel, never place equipment on contaminated surfaces, avoid obvious sources of contamination such as puddles, avoid unnecessary contact with on-site objects.

- Do not start or maintain an open flame of any type unless authorized.

- No employee may enter a work site alone or work alone without prior approval. Special work tasks, such as water level measurements or water sampling, may require that an individual work alone. In such cases, procedures shall be developed delineating emergency response and communication activities and responsibilities.

In addition to the prohibitions and practices listed above, the SSO may impose any other prohibitions which he/she believes may be required for safe operations.

\subsubsection{Emergency Procedures and Services}

The training session should include:

- LLNL Emergency Response Dispatch (911).

- Signals, alarms, and hazard signs.

- Evacuation routes and procedures.

- Assembly points.

- Buddy system.

- Communications.

- Fire protection.

- Barricades and scaffolds.

- Emergency equipment.

- First aid and contaminated wounds.

- Spills.

Refer to page 1 of this document for emergency telephone numbers and Section 7 of this document for emergency procedures.

\subsubsection{General Safety Requirements}

All project work shall be performed in a manner consistent with providing a safe work environment. General safety guidelines are to: 
- Wear appropriate protective clothing for the job, including, but not limited to, hard hat, work clothing, safety shoes, and eye protection.

- Decontaminate known sources of contamination (such as gloves and boots) at the appropriate location as specified by the SSO. Remove equipment only after decontamination or containerization onsite.

- Keep track of weather conditions and wind direction when working outside.

- Plan activities thoroughly ahead of time: enter work sites by a designated route only to get to a designated point for a specific purpose.

- Always use the buddy system: never enter or exit alone, and never work alone in an isolated area.

- Always maintain contact with the SSO and the Ground Water Project Trailer (T4383), where site access and operations are controlled. Trailer 4383 should be continuously occupied while team members are onsite.

- Shower thoroughly as soon as possible after removing protective equipment.

- Wash hands thoroughly upon leaving any area of suspected contamination.

- All personal safety equipment is to be inspected prior to work site entrance. The condition of the equipment must be acceptable to the SSO.

- All personnel who will enter a work site should wear secure identification (e.g., badge with photo and name; name on clothing). A name on the hard hat is not secure identification. Identification must be visible even when all PPE or gear is worn.

- Never assume that a situation is as safe as it appears to be.

- Be alert to any unusual behavior on the part of other workers that might indicate distress, disorientation, or other ill effects. Be alert to any unusual changes in your own condition; never ignore warning signs or hesitate to report them at once. Inform each other of symptoms of nausea, dizziness, headache, or respiratory or eye irritation.

- Maintain a clean and organized work area.

- Delineate work zones with barricades and markers.

- Label raw materials, debris, scrap, waste, intermediates, and contaminated clothing with appropriate and understandable precautionary labels.

- Post warnings in areas with high noise levels and require PPE.

- Inspect fire extinguishers monthly for adequate pressure.

- Inspect emergency eyewash/showers daily for proper operation, before work begins.

- Only trained and experienced operators are to operate heavy equipment onsite.

\subsection{Field Briefings}

The SSO, or a designee, shall conduct daily health and safety field briefings that include 
- Work activities that day.

- Health and safety requirements for that day.

- Work zones.

- Evacuation routes.

- Assembly point upwind of work area, in case of emergency or evacuation.

- Emergency signals.

- Location of first aid and emergency safety equipment.

\subsection{First Aid}

The SSO, or a designee, shall identify those individuals who have previously completed training programs in First Aid and CPR. These individuals should be appointed as alternates for the SSO if he/she is incapacitated or needs assistance. Specific responsibilities will be assigned to these individuals by the SSO, who will take into consideration their familiarity with the following topics:

- Principles of first aid.

- Restoration of breathing/CPR.

- Control of bleeding.

- Recognition and treatment of physical shock.

- Open and closed wounds and burns.

- Fractures and dislocations. 


\section{Operations}

Operations shall be conducted in a safe manner consistent with the policies and procedures outlined in this Plan. The number of personnel shall be restricted to the minimum necessary to complete the required work as an administrative control to limit the exposure of personnel to chemical hazards onsite.

\subsection{Work Site Practices}

The prohibited practices and general safety requirements listed in Section 9 are applicable to this site work. In addition, no worker may engage in any activity for which the health and safety consequences of his/her actions are unclear (e.g., previously unplanned work) without the approval of the SSO. If such activities become necessary to complete any phase of the work, a project instruction or procedure shall be developed and followed.

Smoking will not be permitted in any restricted work location or other locations posted "No Smoking" by LLNL.

\subsection{Work Zones}

Site access shall be controlled to reduce the possibility of entry by unauthorized or unprotected individuals and prevent the transfer of contaminants by personnel or equipment from the site. Three zones, the exclusion zone, the contamination reduction zone, and the support zone, will be delineated by barricades and flagging as appropriate. Zones will be established by the SSO based on local conditions. In most situations, such as during drilling operations in small, individual areas, only a barrier delineating the exclusion zone and the support zone will be needed.

The SSO or designee will be alert to persons entering active zones and will prohibit unauthorized or unprotected persons from entering these zones. Zones may be modified or expanded by the SSO depending upon changing wind and site conditions.

\subsubsection{Exclusion Zone}

The exclusion zone shall include, at a minimum, the immediate vicinity of the work area (such as the drill rig and the boring location at the rear of the rig) plus an additional 15-foot corridor. Persons entering this zone are required to wear PPE as prescribed by the SSO for that particular zone.

\subsubsection{Contamination Reduction Zone}

The contamination reduction zone shall be located upwind of the exclusion zone. The purpose of this zone is to prevent the transfer of contaminants by personnel or equipment exiting the exclusion zone. All decontamination activities shall occur in this area.

In the case of drilling rig activities, a separate contamination reduction zone may not be necessary. It will usually suffice to establish a decontamination point at the entrance/exit to 
the barricade around the drilling site. Personnel may discard any contaminated articles before stepping outside of the barrier into the support zone (the remainder of the site).

\subsubsection{Support Zone}

The support zone is the outermost zone and is considered a noncontaminated (or clean) area. Any supplies, equipment, or personnel required to support site activities should be kept in this zone. The support zone shall be upwind of the contamination reduction and exclusion zones.

\subsection{Security Measures}

All areas and containers where potentially contaminated soil or water are to be stored unattended and any excavations that are to be left open and unattended are to be surrounded by a barricade to prevent accidental access by unauthorized personnel. Potentially contaminated soil shall be properly packaged and labeled.

\subsection{Hazard Control Measures}

Specific considerations shall be given to the following topics to ensure that adequate hazard control measures are implemented for site operations:

- Minimization of dust generation (e.g., applying water when excavating or drilling).

- Prevention of surface contamination by subsurface material or vice versa.

- Decontamination of sampling equipment.

- Decontamination of excavation/construction/maintenance equipment.

- Decontamination and disposal of personnel protective apparel and equipment.

- Use of decontamination solutions-acids, alkalis, or solvents.

- Disposal of decontamination solutions and other materials used on equipment, surfaces, or systems.

- Disposal of drilling spoils and other wastes associated with environmental characterization.

- Disposal of contaminated materials by placing them in 55-gallon drums, which may be sealed, labeled, and disposed of as necessary.

- Monitoring for flammable/explosive vapors.

- Minimization of personnel exposures through appropriate use of administrative work practices consistent with ALARA.

- Handling and disposal of contaminated water, filtrates, etc.

- Use and operation of electrical equipment (see Appendix D).

- Use and maintenance of personnel protective apparcl and equipment.

- Heavy equipment operations and safety protocols (see Appendix E). 
- Personnel air monitoring protocols for evaluation of full-shift and short-term chemical exposures.

- Direct reading instrumentation protocols and techniques for estimating real-time chemical exposures onsite.

- Respiratory protection as per 29 CFR 1910.134 and ANSI Z88.2.

The Hazards Control Department, Safety Team Four. can be contacted for guidance and evaluation.

\subsection{Fire Protection}

To ensure that fire and explosion hazards are minimized, plans and procedures must be coordinated with the LLNL Fire Department (911). If suitable water supplies are unavailable or where water use may be inappropriate, 20- or 30-lb ABC fire extinguishers may be necessary for each drill rig or field crew. No smoking is allowed in the work area nor near any flammable materials. Any use of open flame requires prior authorization by the SSO.

Employees are informed of the fire hazards of the materials and processes to which they are exposed. Upon initial assignment, each employee will be trained in the portions of the fire prevention plan that will protect the employee in the event of an emergency.

The hazardous work sites at LLNL have the fire hazards typical of construction sites and chemical treatment facilities such as: combustible and flammable materials, potential for explosive atmospheres, occasional welding and open flames, oxidizers, and motor fuels.

The LLNL Fire Department and the SSO are responsible for the maintenance of any fire prevention and suppression systems or equipment used on the hazardous work sites.

The accumulation of flammable and combustible waste materials will be minimized as a means of fire prevention.

\subsection{Communications}

The SSO shall maintain contact with workers on a continuing basis. Individuals shall meet and register at the checkpoint established by the SSO prior to work site entry. Each worker shall ensure that he maintains contact with other workers or his "buddy." No individual may either enter or leave the work site alone. Exiting workers shall inform the SSO, or a designee, that they are departing.

\subsection{Personnel Protection Plan}

Environmental operations pose unusual health and safety problems. A very careful review of OSHA and EPA regulations, standards, and guidelines by the SSO is important. At a minimum, these requirements may include:

- Medical surveillance.

- Personnel exposure monitoring program.

- Respiratory protection. 
- PPE and clothing.

- Prohibited activities.

- Compliance program.

- Hygiene facilities and practices.

- Employee information and training.

- Recordkeeping.

\subsection{Safety}

The industrial health and fire safety aspects of this program will focus on evaluation of hazards associated with:

- Transportation equipment.

- Material handling equipment.

- Machinery and parts.

- Hand tools and pressurized equipment.

- Hazardous supplies and materials.

- Fire protection.

- Electrical equipment (i.e., motors, relays, and starters).

Prior to the initiation of work and weekly thereafter, safety inspections will be conducted by the SSO or a designee. This inspection will include those activities necessary to ensure the safe operating condition of all equipment consistent with 29 CFR 1910 and 1926 and the LLNL Safety Manual. Additionally, it will be the responsibility of LLNL's subcontractors to provide a routine maintenance program for this equipment.

The areas accessible by employees will be provided with adequate illumination while work is in progress in accordance with Table H120.1.

Table H120.1. Minimum illumination intensities in foot-candles

\begin{tabular}{ll}
\hline Foot-candles & Area or operations \\
\hline 5 & $\begin{array}{l}\text { General site areas. } \\
\text { Excavation and waste areas, accessways, active storage areas, loading } \\
\text { platforms, and field maintenance areas. } \\
\text { Indoors: warehouse, corridors, hallways, and exitways. }\end{array}$ \\
\hline 5 & $\begin{array}{l}\text { Tunnels, shafts, and general underground work areas. Exception: } \\
\text { minimum of } 10 \text { foot-candles is required at tunnel and shaft heading } \\
\text { during drilling, mucking, and scaling. Mine Safety and Health } \\
\text { Administration approved cap lights shall be acceptable for use in the } \\
\text { tunnel heading. } \\
\text { General shops (e.g., mechanical and electrical equipment rooms, } \\
\text { active storerooms, barracks or living quarters, locker or dressing } \\
\text { rooms, dining areas, and indoor toilets and workrooms). }\end{array}$
\end{tabular}


First aid stations, infirmaries, and offices.

Although drums and containers of hazardous waste are not routinely handled during site operations, the provisions of Paragraph J, "Handling Drums and Containers," shall be implemented when appropriate.

\subsection{Recordkeeping}

Health and safety records shall be maintained in accordance with applicable regulatory requirements. Records are maintained for LLNL personnel at the LLNL Environmental Protection Department offices: these records document safety training, medical surveillance, respiratory protection training and testing, injuries, and illnesses. All subcontractors working on the project are required to maintain similar records at their respective offices. 


\section{Bibliography}

OSHA Safety and Health Standards, U.S. Department of Labor, Safety and Health Administration, 29 CFR 1910.120, "Hazardous Waste Operations and Emergency Response."

Casarett and Doull's Toxicology: The Basic Science of Poisons (1980), 2nd ed., J. Doull, C.D. Klassen, and M.O. Amdur (Eds.), Macmillan Publishing Co., Inc.

Chemical Hazards Response Information System (CHRIS), Manual Two (October 1978), U.S. Coast Guard.

Chemical Manufacturers Association, Inc., A Hazardous Waste Site Management Plan (1982).

Contractor Industrial Hygiene Program, U.S. Department of Energy (DOE 5480.10).

Dangerous Properties of Industrial Materials (1984), N. I. Sax et al. (Eds.), Van Nostrand Reinhold Co.

"Supplement 4.08-Incident Analysis Manual," LLNL Health and Safety Manual, DiGrazia, H. X., and R. M. Latimer, revised April 1, 1987.

Dynamics, Exposure and Hazard Assessment of Toxic Chemicals (1980), R. Hague (Ed.), Ann Arbor Science.

Environmental Protection, Safety, and Health Protection Appraisal Program, U.S. Department of Energy (DOE 5482.1A).

Environmental Protection, Safety, and Health Protection Program for DOE Operations, U.S. Department of Energy (DOE 5480.1A).

Environmental P'rotection Safety, and Health Protection Reporting Requirements, U.S. Department of Energy (DOE 5484.1).

Guidance on Feasibility Studies Under CERCLA (June 1985), U.S. Environmental Protection Agency.

Guidance on Remedial Investigations Under CERCLA (June 1985), U.S. Environmental Protection Agency.

Handbook of Toxic and Hazardous Chemicals and Carcinogens, Sittig, M. (1985), Noyes Publicatis,ns.

Hazardous Waste Site Investigation Training Manual (May 1981), U.S. Environmental Protection Agency.

LLNL Health and Safety Manual, Lawrence Livermore National Laboratory, Livermore, Calif., Current edition, M-010.

Occupational Health Guidelines for Chemical Hazards (January 1981), National Institute for Occupational Safety and Health/Occupational Safety and Health Administration. 
Occupational Safety and Health Program for Federal Employees, U.S. Department of Energy (DOE 3790.1).

Occupational Health and Safety Manual, Chapter 9 (August 1980), U.S. Environmental Protection Agency.

OSHA Safety and Health Regulations for Construction, U.S. Department of Labor, Occupational Safety and Health Administration (29 CFR 1926).

OSHA Safety and Health Standards, U.S. Department of Labor, Occupational Safety and Health Administration (29 CFR 1910).

Practices for Respiratory Protection (1980), American National Standards Institute (ANSI Z88.2-1980).

Priority Toxic Pollutants -Health Impacts and Allowable Limits, Sittig, M. (1980), Noyes Publications.

Protection of Environment, U.S. Environmental Protection Agency (40 CFR 53, 58, and 61). Respiratory Protection, U.S. Environmental Protection Agency (EPA Order 1440.3).

Safety Manual for Hazardous Waste Site Investigations (September 1979), U.S. Environmental Protection Agency.

Site Safety Plan for Tank Excavation and Removal of Underground Storage Tanks at Buildings 401, 402, and 411, Lawrence Livermore National Laboratory, Livermore, Calif., October 29, 1988.

Standard Operating Safety Guides (November 1984), U.S. Environmental Protection Agency.

Technical Methods for Investigating Sites Containing Hazardous Substances (June 1981), Technical Monograph Series 1-29, U.S. Environmental Protection Agency.

TLVs Threshold Limit Values for Chemical Substances and Physical Agents in the Work Environment and Biological Exposure Indices with Intended Changes for 1984-85, American Conference of Governmental Industrial Hygienists. 


\section{Appendix A Site-Specific Operational Safety Procedures}




\section{Appendix A}

\section{Site-Specific Operational Safety Procedures}

The Site-Specific Operational Safety Procedures (OSPs) supplements the LLNL General Site Safety Plan and provides detailed information for a specific operation not fully addressed in the Plan. A copy of the OSP shall be kept at the work site at all times. The OSPs typically includes the following items as applicable and any additional items deemed necessary:
A. Hazard Assessment For Each Task in Work Plan.
B. Personal Protective Equipment For Each Task.
C. Type and Frequency of Air Monitoring.
D. Site Control Measures.
E. Decontamination Procedures.
F. Spill Containment Program.
G. Employee Training Assignments.
H. Confined Space Entry Procedures.
I. Emergency Response Procedures.
J. Site Inspections.
K. Medical Surveillance.
L. Pre-Entry Briefing. 
Appendix B Acronyms 


\section{Appendix B}

\section{Acronyms}

ACGIH American Conference of Governmental Industrial Hygienists

AIHA American Industrial Hygiene Association

ALARA As low as reasonably achievable

ALI

Allowable Limit on Intake $(\mu \mathrm{Ci})$. The $\mathrm{ALI}$ is the annual intake that would lead to an effective committed dose equivalent not exceeding 5 rem and an annual dose equivalent to any single organ or tissue not exceeding 50 rem

CERCLA Comprehensive Environmental Response, Compensation, and Liability Act

CPR

Cardiopulmonary resuscitation

DAC

Derived Air Concentration $\left(\mu \mathrm{Ci} / \mathrm{cm}^{3}\right)$. The DAC is the average atmospheric concentration that would lead to the ALI in a reference person exposed to the DAC for a 2,000-hour work year

DHS Department of Health Services

DOE Department of Energy

DTSC California Department of Tox Substances Control

EPA Environmental Protection Agency

ERD Environmental Restoration Division

$f_{1}$

Retention factor in organs of the body by specific radioactive isotopes

FID Flame Ionization Detector

HEPA High Efficiency Particulate Arrestor

HTO Tritiated water

IDLH Immediately Dangerous to Life or Health concentration that represents the maximum level from which one could escape within 30 minutes without any escape-impairing symptoms or any other irreversible health effects

LELUEL Lower and Upper Explosive Limits; percent by volume of potentially explosive substance in air

LFLUFL Lower and Upper Flammable Limits; percent by volume of potentially flammable substance in air

LLNL Lawrence Livermore National Laboratory

MSDS Material Safety Data Sheets

NIOSH National Institute for Occupational Safety and Health

OSHA Occupational Safety and Health Administration

OSPs Operational Safety Procedures 
PEL Permissible Exposure Limit set by OSHA; values usually are expressed in ppm or $\mathrm{mg} / \mathrm{m}^{3}$. PELs are expressed as:

- 8-hour TWA exposure limit.

- Ceiling exposure limit (CEIL); at no time shall an employee's exposure exceed this limit.

- Short-term exposure limit (STEL); the maximum exposure in any 15minute period.

- Maximum peak (PEAK); acceptable above the specified ceiling limit for the stated concentration and duration.

PID Photoionization Detector

PPE Personal Protective Equipment

SSO Site Safety Officer

TLV Threshold limit value as issued by ACGIH; values usually are expressed in $\mathrm{ppm}$ or $\mathrm{mg} / \mathrm{m}^{3}$. TLVs are expressed as:

- TLV-TWA: the TWA concentration for a normal 8-hour workday and a 40-hour workweek, to which nearly all workers may be repeatedly exposed, day after day, without adverse effect.

- TLV-STEL: the 15-min TWA to which a worker can be exposed for a period of up to 15 minutes continuously without suffering from irritation, chronic or irreversible tissue damage, or narcosis of sufficient degree to increase the likelihood of accidental injury, impair self-rescue, or materially reduce worker efficiency, and provided that the daily TLV-TWA is not exceeded.

TWA Time-weighted average; this is generally expressed as an 8-hour TWA

VOCs Volatile organic compounds

XLM, XLO, The $\mathrm{m}, \mathrm{o}$, and $\mathrm{p}$ isomers of xylene and XLP 


\section{Appendix C \\ Material Safety Data Sheets}




\section{Appendix C}

\section{Material Safety Data Sheets}

Benzene MSDS \#Genium/316

Carbon Tetrachloride (CHCl4) MSDS \#Genium/410

Chloroform MSDS \#Genium/315

1,1-Dichloroethane (1,1-DCA)

1,2-Dichloroethane (1,2-DCA) MSDS \#/359

1,1-Dichloroethylene (1,1-DCE)

1,2-Dichloroethylene (1,2-DCE)

Diesel

Gasoline, Automotive Lead Free MSDS \#Genium/467

Perchloroethylene (PCE) MSDS \#Genium/313

Trichloroethylene (TCE) MSDS \#Genium/312

Toluene MSDS \#Genium/317

Tritium

Xylene MSDS \#Genium/318 
Meteriel serety Dete $\sin \theta e t$

Geniun Publishing Corporation

1145 Catalyn street, Schenectady, NY (518) $377-8854$

Fron Geniun's collection, to be used as reference
Product: BENZENE

Msos No: Geniun / 316

Revision: D

Date: April, 1988

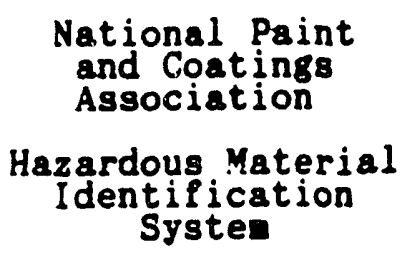

\begin{tabular}{l} 
HEALTH HAZARD \\
TLAMAABILITY HAZARD \\
REACTIVITY HAZARD 0 - Moderate \\
\hline PERSONAL PROTECTION
\end{tabular}

+-
+-
Trad
Descr
Other
CAs:
R 1
I 4
S 4
K

Trade/Material Nase: BENZENE

Description: Used in the nanufacture of nedicinal chenicals, dyes, linoleun, airplane dopes, varnishes, and lacquers; and as solvent for waxes, resins, and oils.

Other Designations: Benzol; Phene; Phenylhydride; CsHo; NIOSH BTECS No. CY1400000

CAs: $0071-43-2$

Manufacturer: Contact your supplier or distributor. Consult the latest edition of the Chenicalweek Buyers Guide (Geniua ref. 73) for a iist of suppliers.

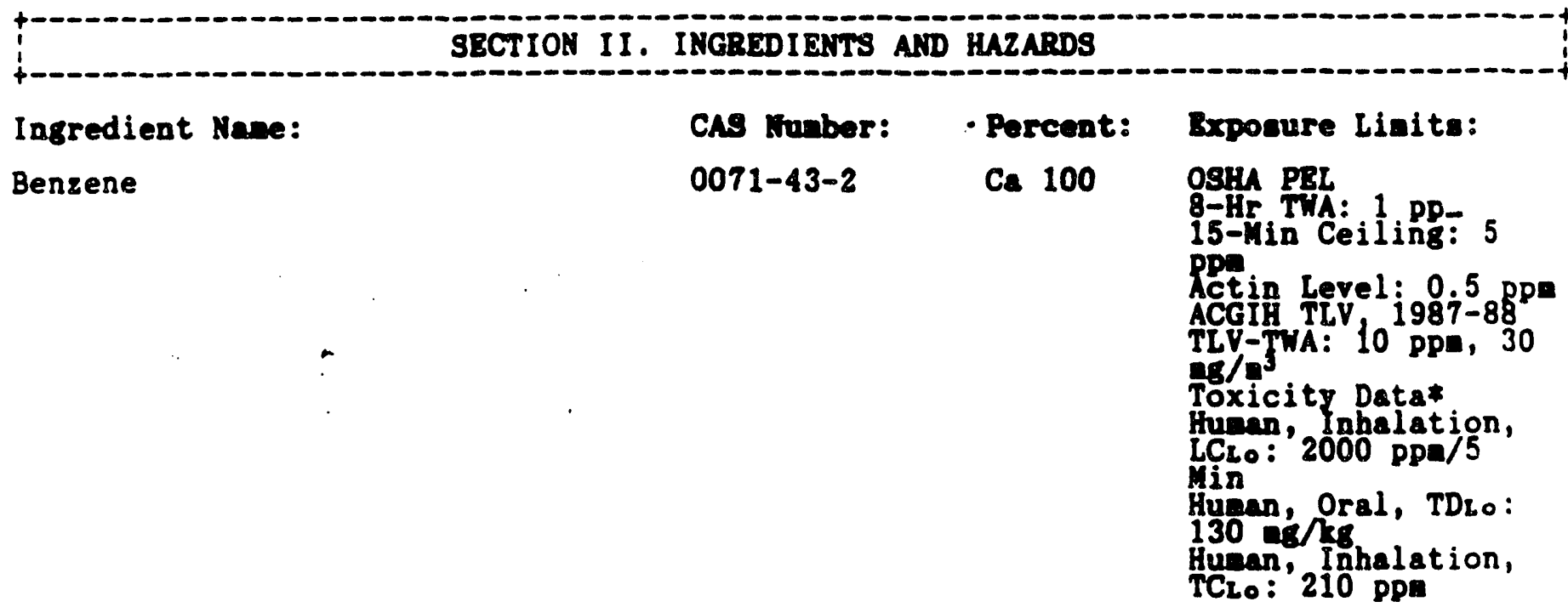

Pase 1 --

IMCPEDIBNTS AND BAZARDS continues on pase 2 
Geniun Publishing Corporation 1145 Catalyn street; Schenectady, NY

12303
Product: BENZENE

MSDS No: Geniun / 316

Bevision: D

Date: April, 1988

* See NIOSH, RTECS, for additional data with references to irritative, autagenic, tumorigenic, and reproduct ive effects.

$$
\text { i }
$$$$
\text { SECTION III. PHYSICAL DATA }
$$

Appearance ador: A colorless liquid; characteristic aronatic odor.

Boiling point: $1760 \mathrm{P}\left(80^{\circ} \mathrm{C}\right)$

Vapor preasure: 75 Torrs at $68^{\circ} \mathrm{P}\left(20^{\circ} \mathrm{C}\right)$ Nater solubility $(x)$ : Slight

vapor density (air=1): >1
Specific sravity $\left(\mathrm{H}_{2} \mathrm{O}=1\right): 0.87865 \mathrm{at}$

Mltins point: $42^{\circ} \mathrm{p}\left(5.5^{\circ} \mathrm{C}\right)$

$x$ rolatile by voluse: 100
SECTION IV. PIRE AND EXPLOSION DATA

Plesh Point (wethod): $12^{\circ} \mathrm{P}\left(-11.1^{\circ} \mathrm{C}\right)$ (CC)Liaita: LAL $\mathrm{x}: 1.3$ MPPA Pire Hasard Syabol Codes: Flemability: 3 Health: 2

Extinguishins Media: Use dry chenical, foan, or carbon dioxide to put out benzene 1 ires. Water an be ineffective as an ext inguighing agent becouse it can scatter and gpread the fire. Use water to cool fire-exposed containers, lush spills away frow exposures, disperse benzene vapor, and protect personnel attenpting to stop an unignited benzene leak.

Unusual lire or explosion hasarda: Benzene vapor is heavier than sir and can collect in low-lying areas such as suaps or wells. Elninate all sources of ignition there to prevent a dangerous liashack to the or iginal liquid bensene.

Danger: Explosive and Ulannhle benzene vapor-air aixtures can easily forn at roon tenperature; alm ne thle enterial in way that aininizes dispersion of its vapor into general wort aren.

Special fire-lletele procedurea:

$$
\sim \rightarrow
$$

Wear a self-contained breathine apparatus (SCBA)

with a lull lacepiece operated in the

pressure-denand or positive-pressure node.

Reactivity: 0 Special: 
Geniun Publishing Corporation

1145 Catalyn streot, Schenectady, NY (518) $377-8854$

Fron Geniun's collection, to be used as reference
Product: BENZENE

MSDS No: Geniun / 316

Revision: D

Date: April, 1988

\section{SECTION V. REACTIVITY DATA}

Material is stable in closed containers during routine operations. Hazardous polynerization does not occur

Chemical incoupatibilities: Hazardous chenical reactions involving benzene and the following naterials are reported in Geniun reference 84: bronine pentafluoride, chlorine, chlorine trifluoride, chronic anhydride, nitryl perchlorate, oxygen, ozone, perchlorates, perchloryl fluoride and aluninum chloride, permanganates and sulfuric acid, potassiun peroxide, silver perchlorate, and sodiun peroxide.

Conditions to avoid: Avoid all exposure to sources of ignition and to inconpatible chenicals.

Hazardous decomposition Products: Toxic gases like carbon monoxide $(C O)$ aay be produced during benzene fires.

SECTION VI. HEALTH HAZARD INPORYATION

This product is considered a suspected human carcinosen br ACGIH.

Sunary of risk: Prolonged skin contact with bensene or excessive inhalation of its vapor may cause headache, weakness, loss of appetite, and lassitude. Cont inued exposure can cause collapse, bronchitis, and preunonia. The post inportant health hazards are cancer (leukenia), bone marrow elfects, and injuries to the blood-forning tissue fron chronic low-level exposure.

Medical conditions which any be agrravated by contact: Ailnents of heart, lungs, liver, kidneys, blood, and central nervous systen (CNs) nay be worsened by exposure. Adninister preplaceent and periodic nedical exans eaphasizing these organs functions and reassign workers who test positive.

Target orgens: Blood, CNS, skin, bone asrow, eyea, and upper respiratory tract (URT). Prieary entry route(e): Skin contact, inhalation.

Acute effects: Diszinese, ental dullness, nausea, headsche, fatigue, and giddiness. Chronic effect(s): Posalble cancer (leukenia).

Pirst aid:

Bje contect: Indiatels 1 lush eyes, including under the eyelids cotls but thoroughly with plenty of muning water for at loent 15 ninutes.

Skin contact: Inediately wash the affected area with soap and water. 
Material Safety Data Sheet

Geniun Publishing Corporation

1145 Catalyn street Schenectady, NY (518) $377-8854$

Froe Geniun's collection, to be used as reference
Product: BEN2ENE

MSDS No: Geniue / 316

Revision: D

Date: April, 1988

HEALTH HAZARD INFORMATION continued fron page 3

Inhalation: Resove the exposed person to fresh air; restore and/or support his or her breathing as needed.

Ingestion: Never give anything by mouth to soneone who is unconscious or convulsing. Do not induce vositing because of the possibility of aspiration.

GET MEDICAL HELP (IN PLANT, PARANEDIC, COMUNITY) FOR ALL EXPOSURES. Seek pronpt aedical assistance for further treateent, observation, and support after first aid.

SECTION VII. SPILL, LEAK AND DISPOSAL PROCEDURES

Spill / Leak procedures: Notify safety personnel, provide ventilation, and eliainate all sources of ignition inediately. Cleanup personnel need protection against contact with and inhalation of vapor (see sect. 8). Contain large spills and collect waste or absorb it with an inert waterial such as gand, earth, or verniculite. Use nonsparking tools to place waste liquid or absorbent into closable containers for disposal. Reep waste out of sewers, watersheds, and waterways.

Waste management / Disposal: Contact your supplier or a licensed contractor for detailed reconendations. Follow Pederal, state, and local regulations.

OSHA Designations

Air Contasinant (29 CFR 1910.1000 Subpart Z)

EPA Designations (40 CFR 302.4)

RCRA Hazardous Haste, No. U019

CERCLA Hazardous Substance, Reportable Quantity: 1000 lba (454 kg)

\section{SECTION VIII. SPECIAL PBOTECTION INPORMATION}

Personal protective equipment:

Gocsles: Al wiven protoctive eyeglasseg or chenical safety gossles. Where optur ta poesible wear a full lace shield. Pollow the eje- and Peor-protection suidelines in $29 \mathrm{CrR} 1910.133$.

Reapirator: Wew a nIOst-approved respirator per the NIOSH Pocket Gujde to Cond I lnes for the maximum-use concentrations andor the exporare 101 s cited in section 2. Pollow the respirator guidelines in $29 \mathrm{CrB} 1910.134$. Por evergency or nonroutine use (e.s. cleaning reactor vessels or torage tanks), wear an SCBA with a full lacepiece operated in the pressure-denand or positive-pressure code.

Warning: Air-purifying respirators will not protect workers in oxygen-deficient at ospheres. 
Geniw Publishing Corporation

1145 Cataljo street Schenectady, NY 12303 (518) $377-8854$

Fron Geniun's collection, to be used as reference
Product: BENZENE

MSDS No: Geniun / 316

Revision: D

Date: April, 1988

SPECIAL PROTECTION INFORMATION continued Pron page 4

Other: Wear inpervious gloves, boots, aprons, gauntlets, etc, to prevent any possibility of skin contact with this suspected hunan carcinogen.

Workplace considerations:

Ventilation: Install and operate general and local ventilation systeas powerful enough to maintain airborne levels of benzene below the OSRA PEL standard cited in section 2 .

Safety stutions:

Make eyewash stations, washing facilities, and safety showers available in use and handling areas.

Conteninate $\perp$ equipent:

Contact lenses pose a special harard; soft lenses aag absorb irritants, and all lenses concentrate then. Do not wear contact lenses in any work area. Remove contaninated clothing and launder it before wearing it again; clean this aterial fron oboes and equipment.

Practice good personal hygiene; always wash thoroughly after using this aterial. Keep it off of your clothing and equipment. Avoid transferring it sou your hands to your wouth while eating, drinking, or seoking. Do not eat, drink, or snoke in any work area. Do not inhale bengene vapor!

Storage segregation: Store benzene in a cool, dry, well-ventilated area away fron sources of ignition and incoupatible chenicals.

Spacial handlins / storage: Protect containers froa physical damage. Electrically ground and bond all metal containers used in shipping or Eransferring operations. Pollow all parts of 29 C F 1910.1028.

Bngineerins controls: All engineering systens (production, transportation, etc.) nust b-of exinua explosion-prool desiga (nonsparking, electrically (rounded and bonded, etc.).

If ussible subetitute legs toxic solvents for benzene; use this aterial with extrene caution and il it is absolutely essential.

Transportetion Data (49 CF2 172.101-2)

DOT Shippin Nane: Benzene

DoT Label: Fl mable Liquid

IMo Label: Flanable Liquid

Ino Class: 3.2

Dor Clans: Flanable Liquid UN Reriater: UN1114

Date source code $(a): 1,2,12,73,84-94,100,103$. 
1145 Geniue Publishing Corporation

1145 Catalisn street, Schenectady, NY 12303 (518) 377-8854

Fron Geniun's collection, to be used as reference
Product: BENZENE

MoDs No: Geniue / 316

Bevieion: D

Date: April, 1988

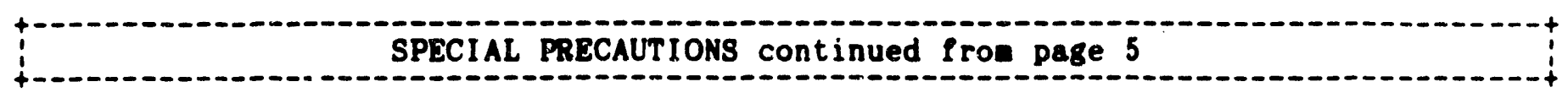

Prepared/revised is: Geniun Publishing Corporation

April, 1988

Judgenents as to the suitability of infornation herein for purchaser's purposes are necessarily purchaser's :esponsibility. Therefore, al thouth reasonable care has been taken in the preparation of such inforsation Genium Publishing corporation extends no warranties, akes no representations and assunes no responsibility as to the accuracy or suitability of such inforeation for application to purchaser's intended purposes or for the consequences of its use. 


\section{Materia1 Safety Data Sheat}

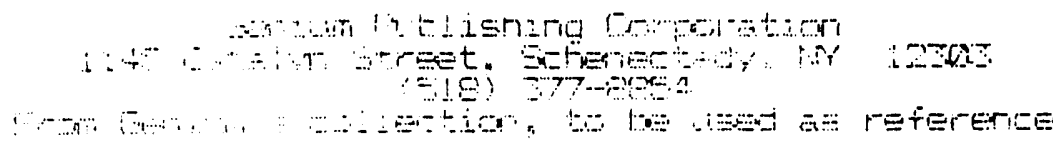

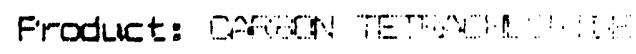

MSDS No: Grinin a dis

fievision: ini

Date:

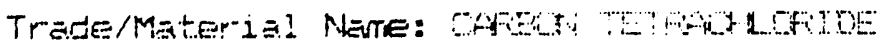

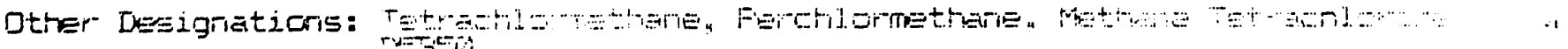
r...를

CAS: $2 \%, 0$

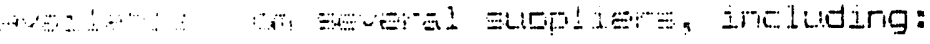

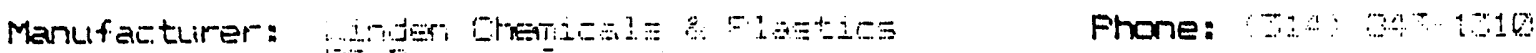

Propus i

O!n

EETT: I. ITHEDIEUTS AND HAZFIS

Ingredient Name:

Fercent: Exposure Limits:

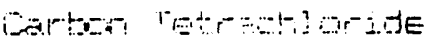

ca 100

e-ro Then sir

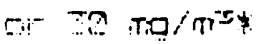

thitrasi a rir

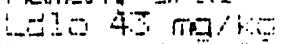

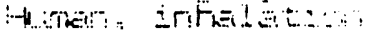

lom taxa aro

TCY $=20$ DETT : TH

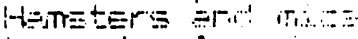

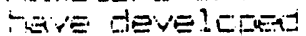

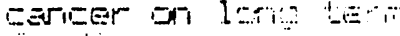

reeding.

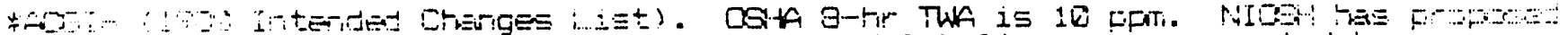
19 p. ר.

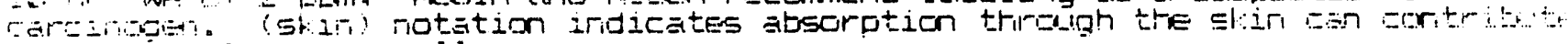
ER

XETION III. FHYICAR DATF

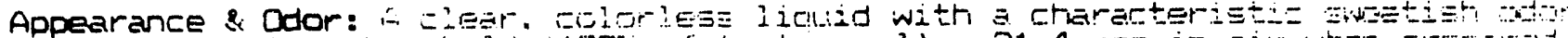

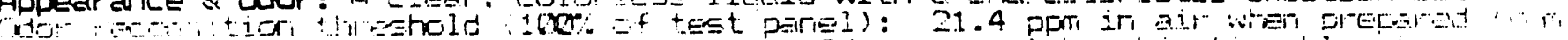

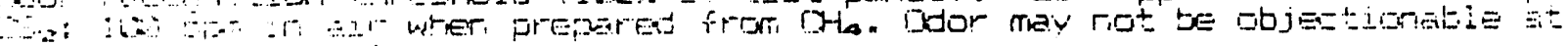

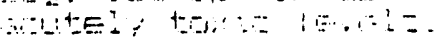




\section{Material Safety Data Sheet}

\author{
Earium Fublisting Coirooratior.

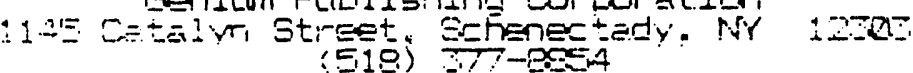

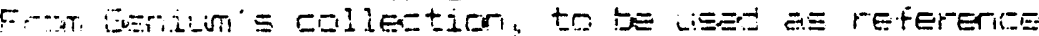

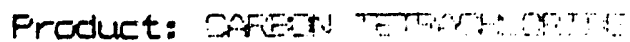

MSDS ND: EERILLT: i $\triangle \mathrm{j}$

Revision: $A$

Date:

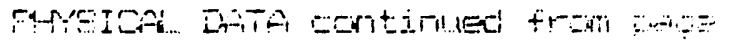

Boiling point: $!$ atit: T․ Tor.

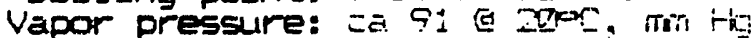

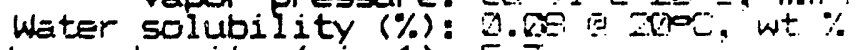
vaper density $(a i r=1): 5 .$.
Specific gravity (HoO=1):

Melting point: $\%$ volatile by volume: Mulecular weight:

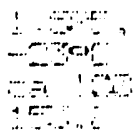

10

\section{BECTIDU I'v. FIFE ATD EXFLOEIC}

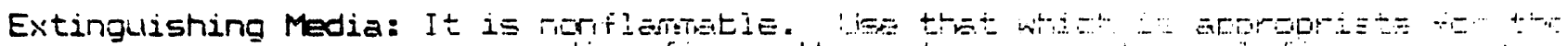

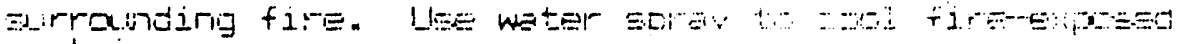
contairier

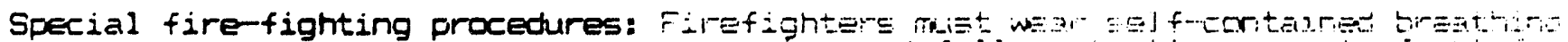

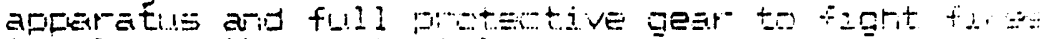
irivolving this materisi.

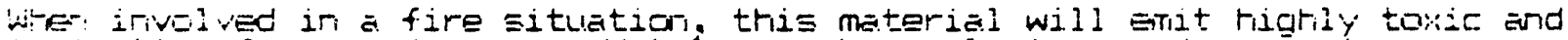
irritatirig fumes ard qases. Metals. such as aluminum ard miagiesiuvi. Ean react vigleritly with garecr, tetractiloride when fot or burtiirig.

\section{DECTION $U$. FEACTIVITY DATA}

MetEria! is stable under rormal conditions of randing ard lise. Hazardaus Delyimerizaticri carinict aceir

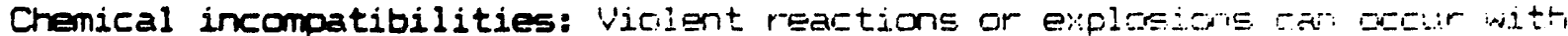

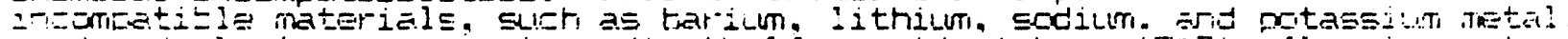

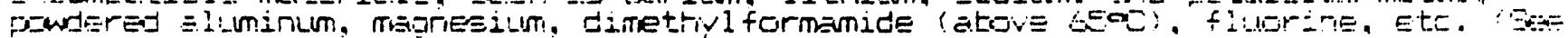

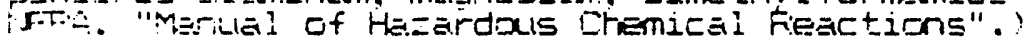

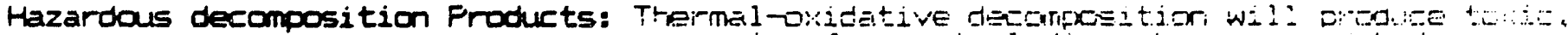

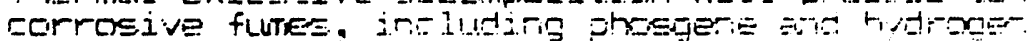
thlstide.

SECTIIN WT. HEGLTH HAZAFD INFDFMATIOX:

Sumany of risks: Carbor tetrachloride is highly towif ard irritatirig br iritulatiror.

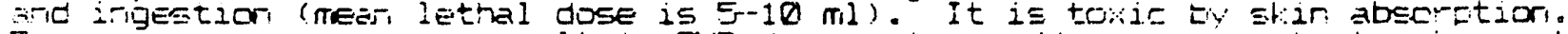

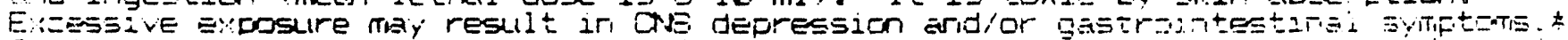

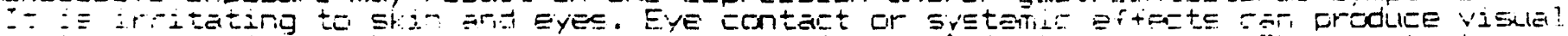

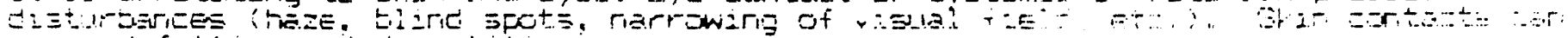
callse defatting arid dermatitis.

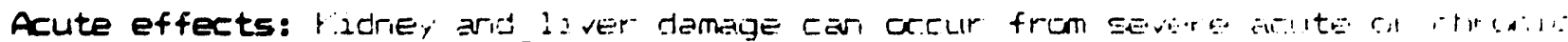
eyposuire. It 15 a susperted careinogeri iri thurisis. 


\section{Material Safety Data Sheet}

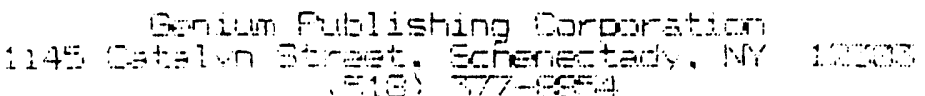

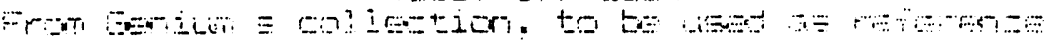

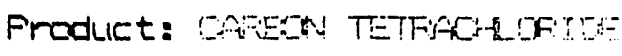

MSDS ND: Genidinn; 410

Revision: $A$

Date:

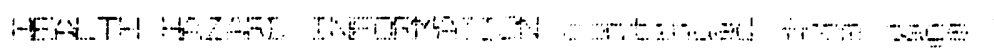

First aid:

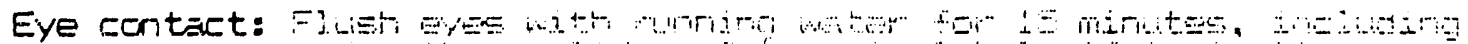

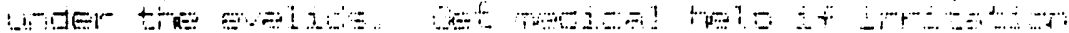
arr

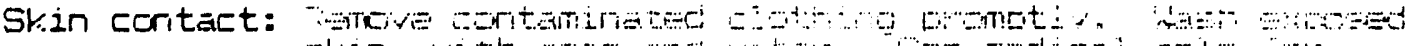

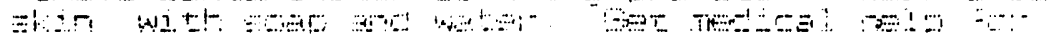
Erotad or oros

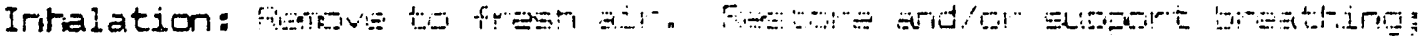

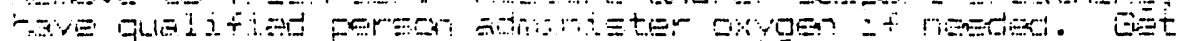
MEdiG: $P=1 F$.

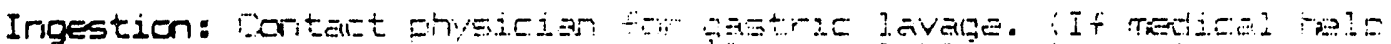

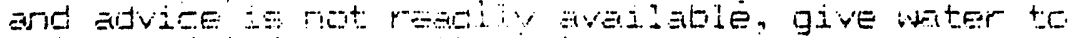

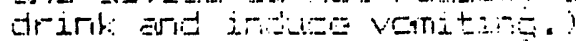

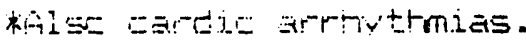

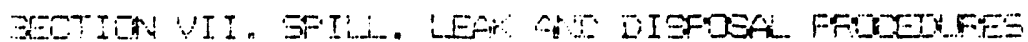

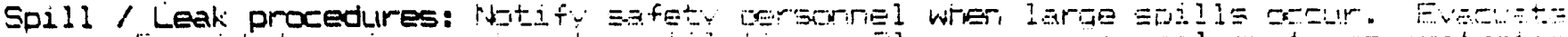

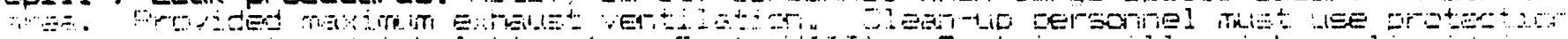

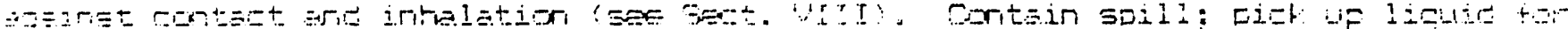
A

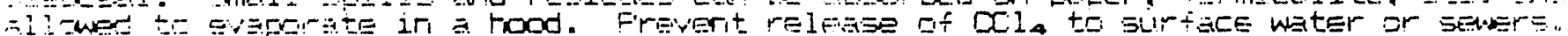

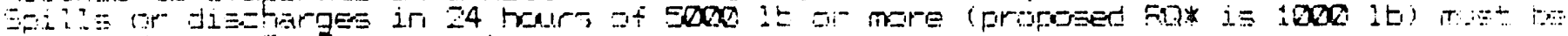

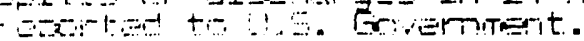

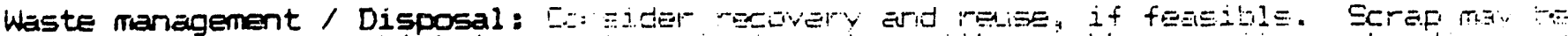

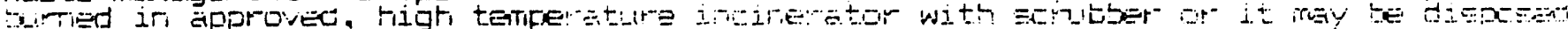

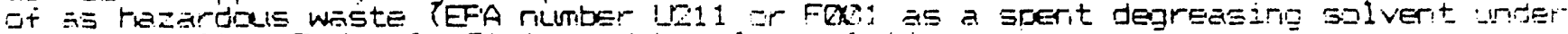

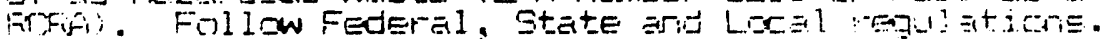

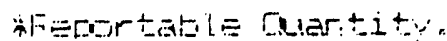

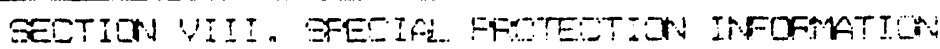

Fersonal protective equipment:

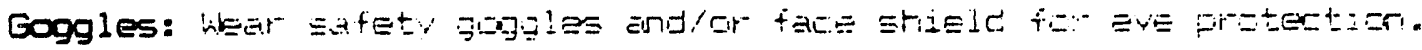

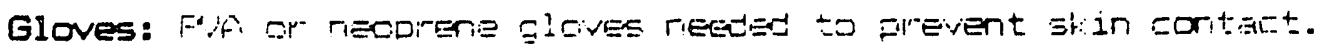




\section{Material Safety Data Sheet}

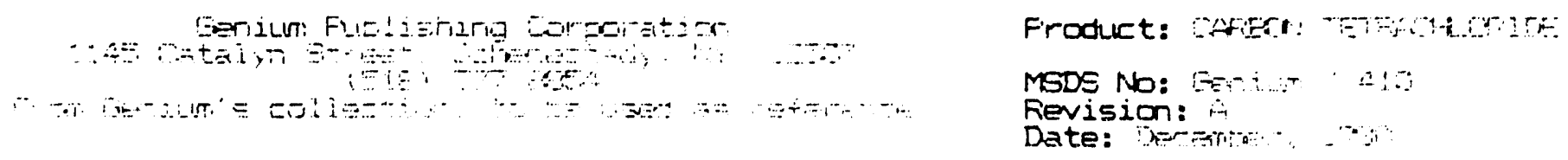

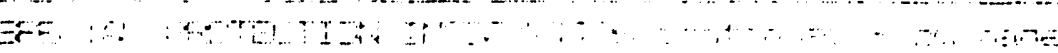

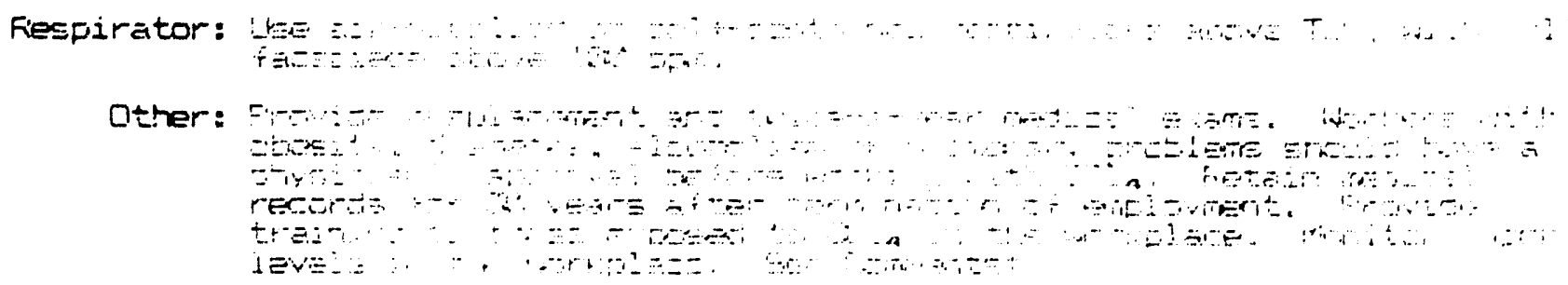

Whrt:place consideratioris:

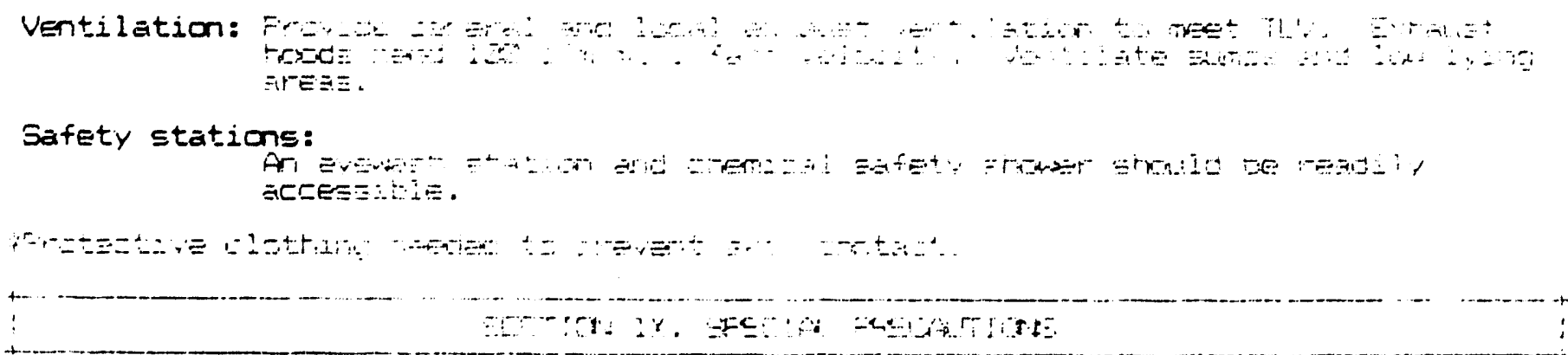

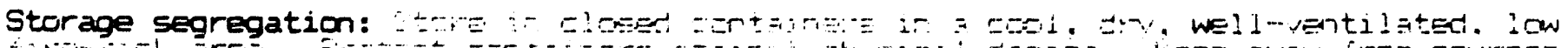

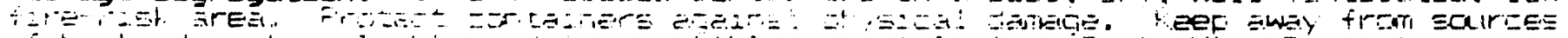

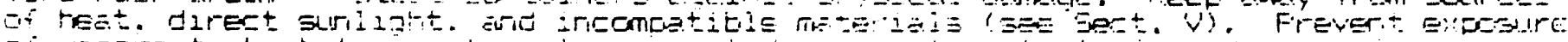

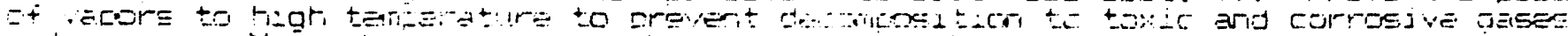

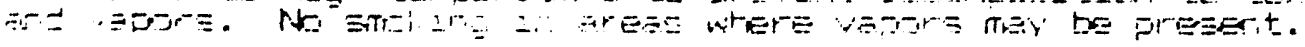

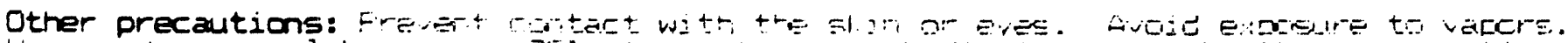

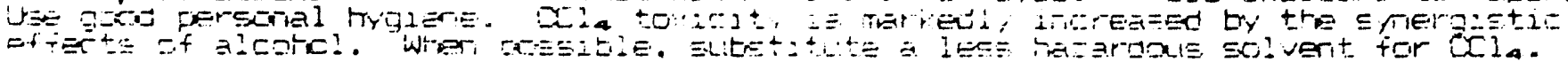

DQ : : -

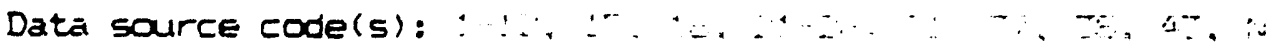

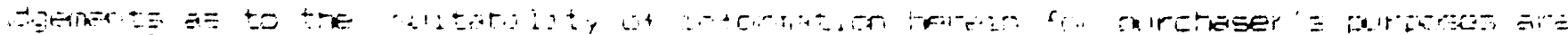

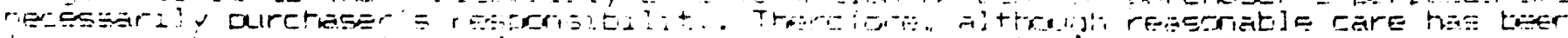

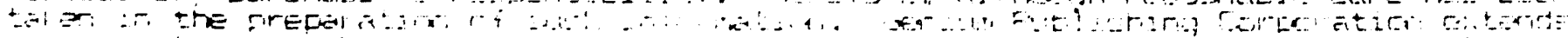

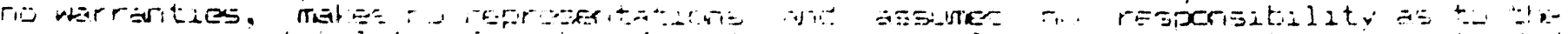

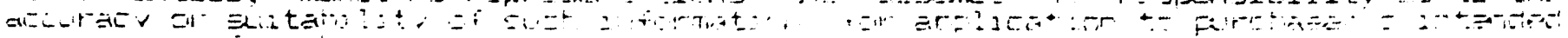

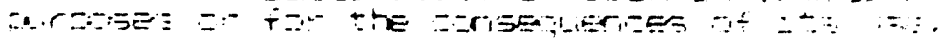




\section{Materiax Safety Data Sheet}

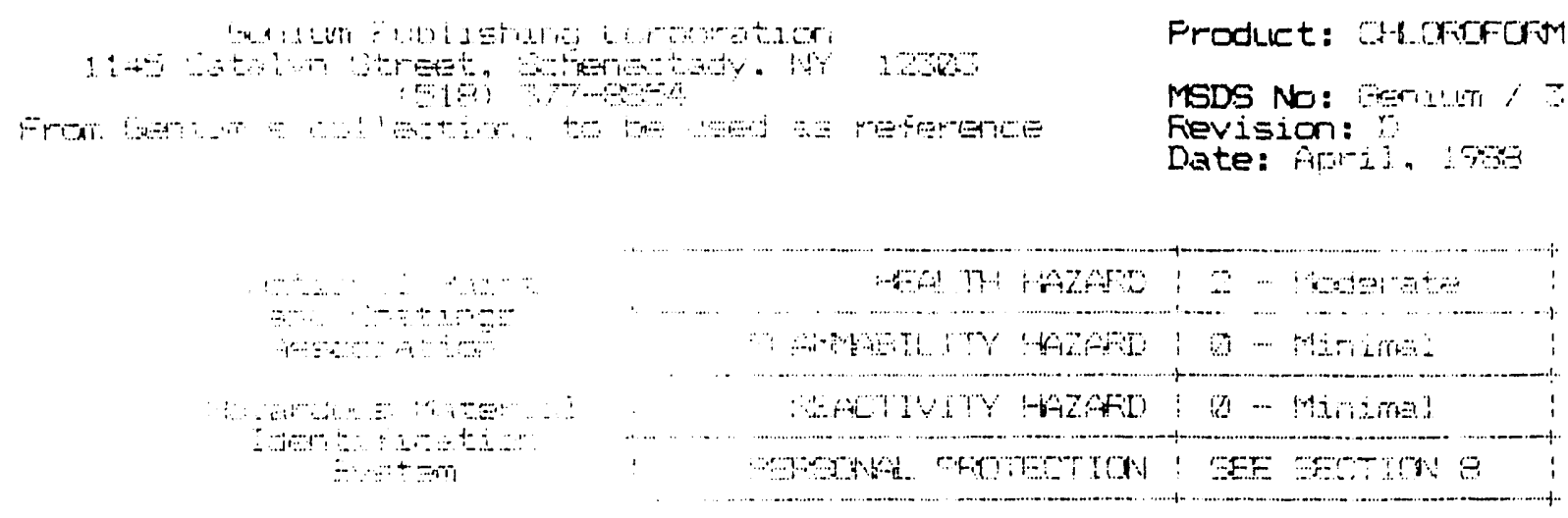

…

Trade,Material Name: -

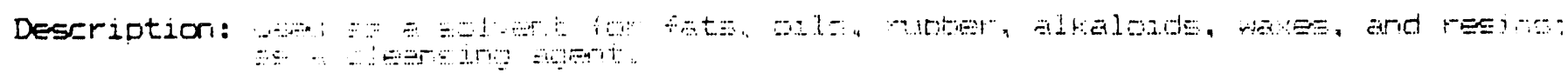

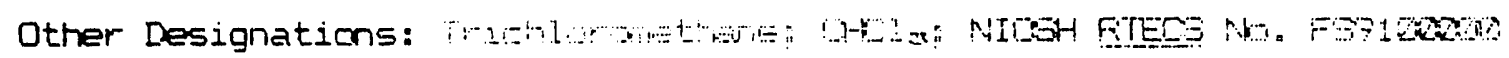

CAS: $\mathrm{WO}, \cdots, \cdots, \cdots$

J

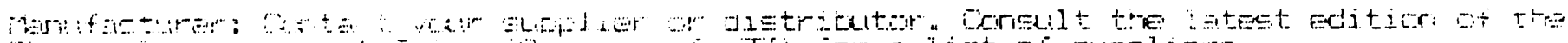

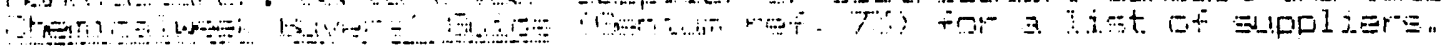

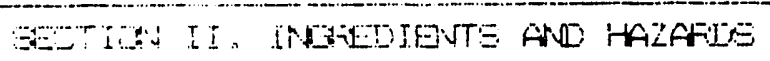

Ingredient Name:

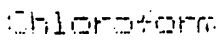

CAS Number:

anc-ay
Fercent:

Es 100

\section{Exposure Limits:}

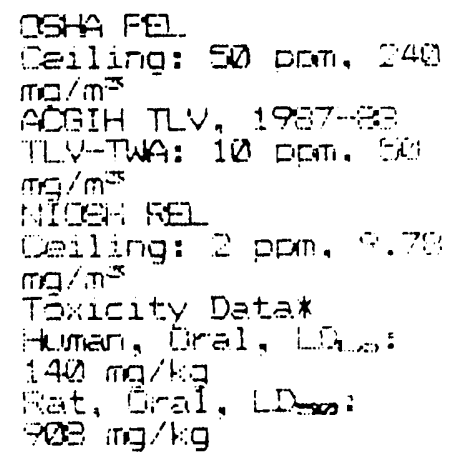

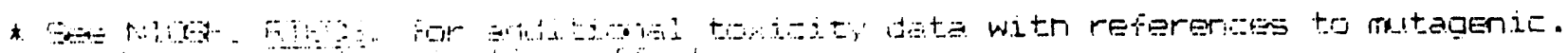

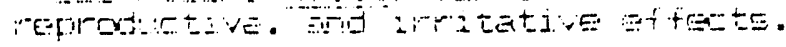


Material Safety Data Sheet

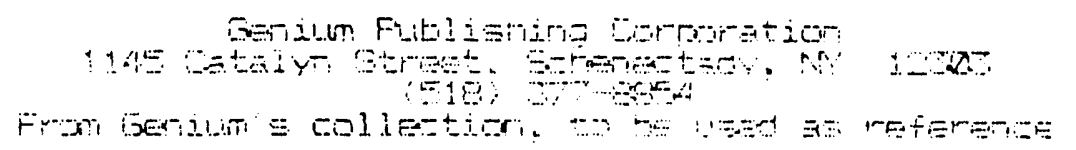

Froduct: ats antint

MSDS No: Eeril!nri ; 1 i Fievision: $\bar{n}$ Date: fipr-i. : 7 a

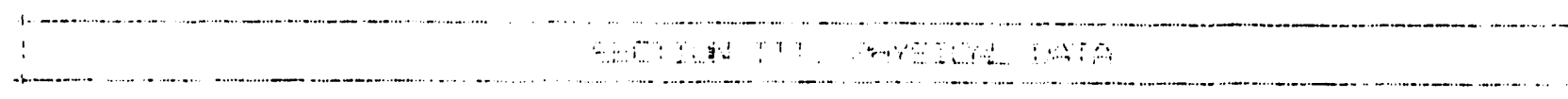
Appearance \&: Ddor:

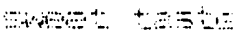

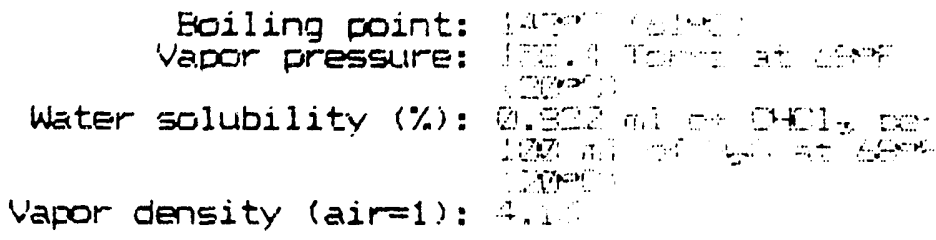

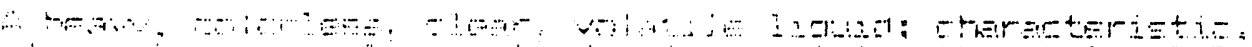
a d

Specific gravity $(H, O=1): \therefore$ :

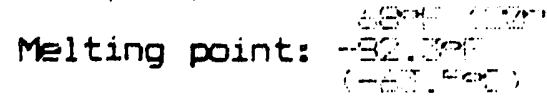

\% volatile by volume: 1. ber. Molecular weight: 1 is : ar :

Flash Foint (method): * Limits: Le \%: * LE \%: * NFPA Fire Hazard Symbol Codes: Flammaility: $\oslash$ Health: 2 Reactivity: $\emptyset$ Special:

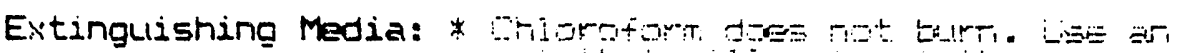

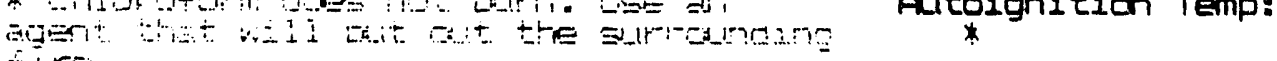

Lhusulal fire or explosion hazards: Hone recortes:

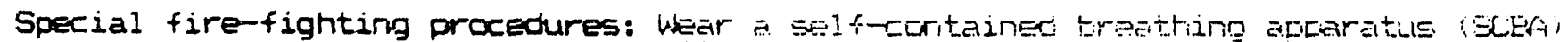
witr a fill facebiene coerated in the

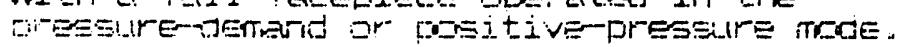

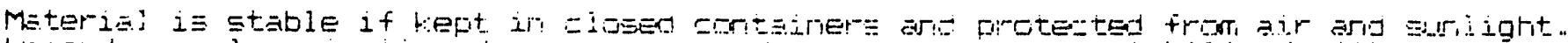

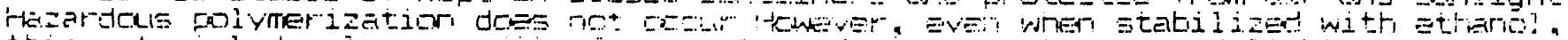

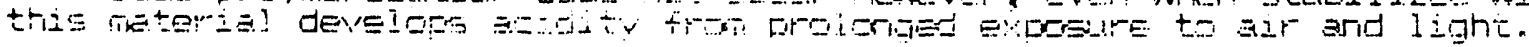

Chemical incompatibilities: This, rivterieal is incometible with strong altalies.

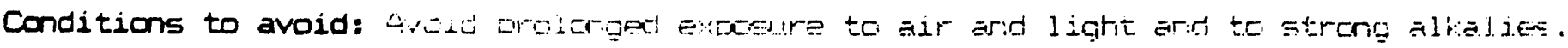

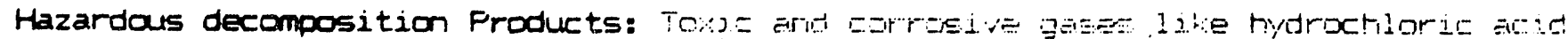

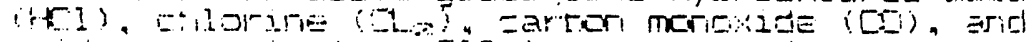

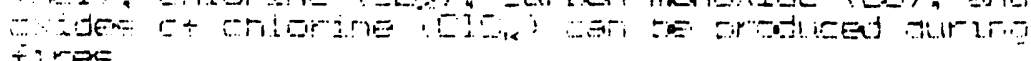




\section{Material Safety Data Sheet}

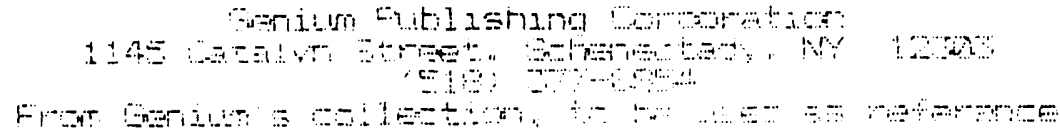

Froduet: At HFIFIFI

MBDE ND: Feritin? Fievision: Date: 190

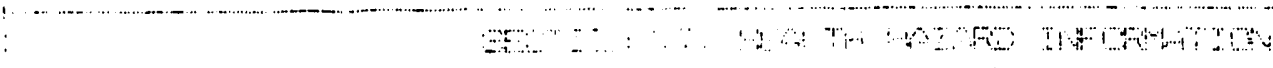

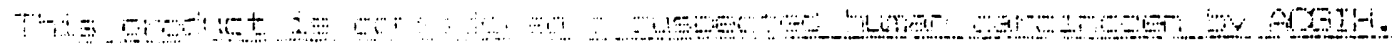

Sumary of ristis: Fegetre t...

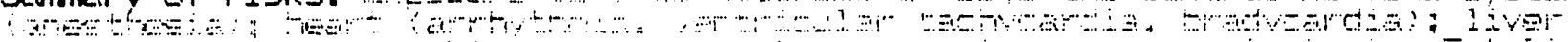
r.s.

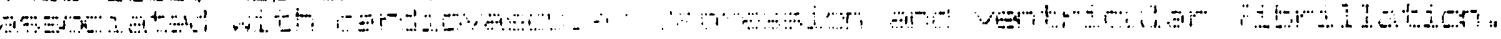

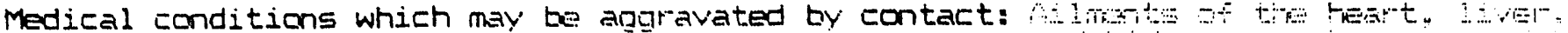

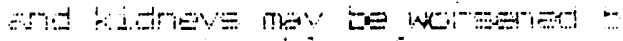

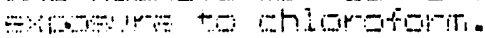

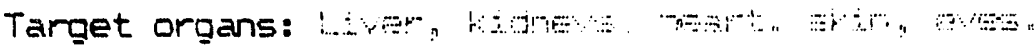

Frimary entry route(s): 9 im . . r.

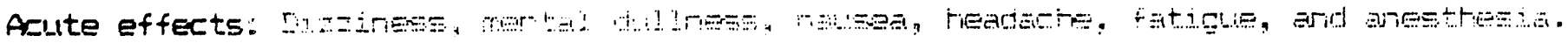

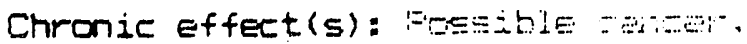

\section{First aid:}

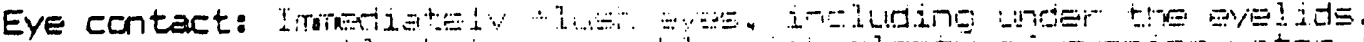

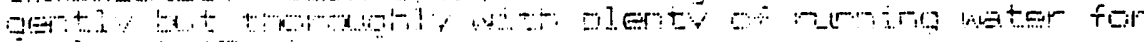
it 1 LEst

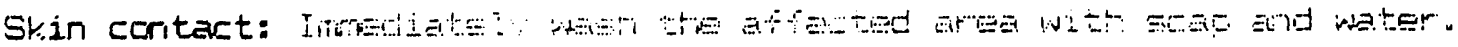

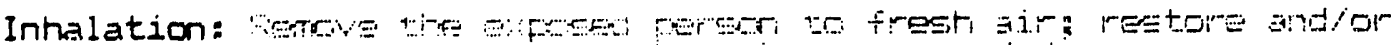

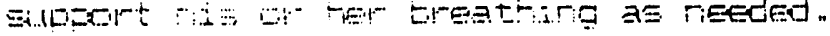

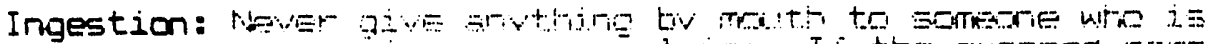

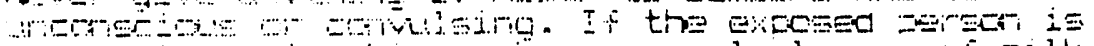

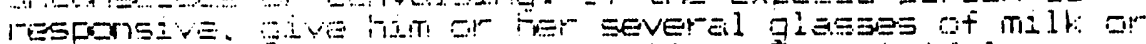

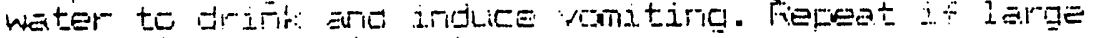
quantities has:- ingester.

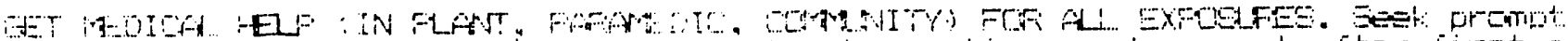

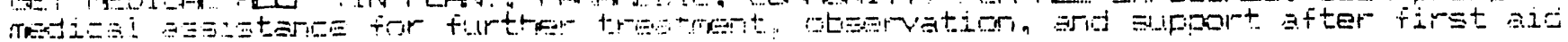

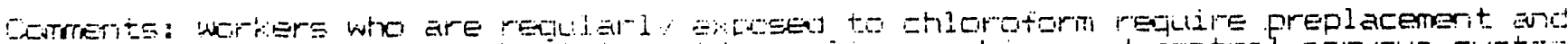

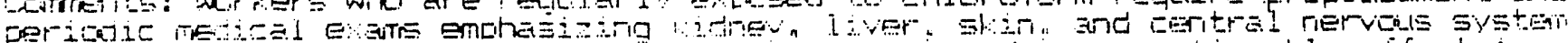

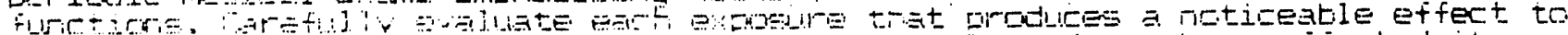

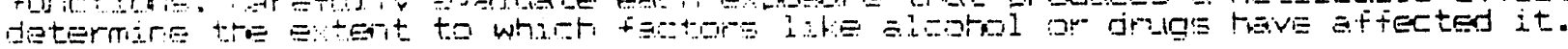




\section{Material Safety Data Sheet}

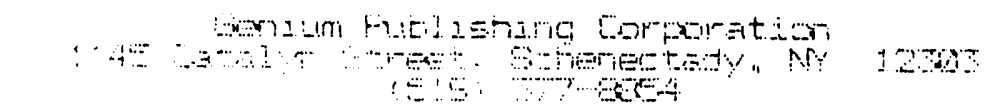

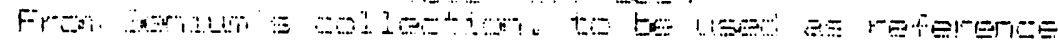

Froduct: DHeKrfartin

MSDS No: Gerium Revision: I

Date: :A-

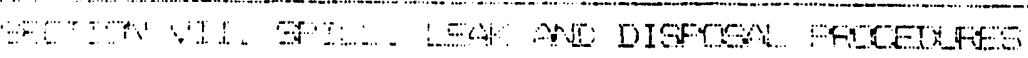

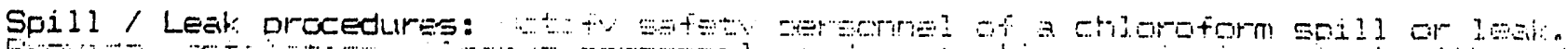

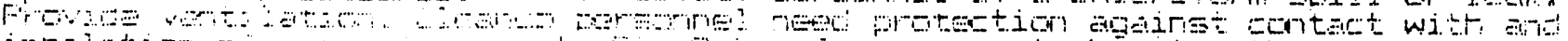

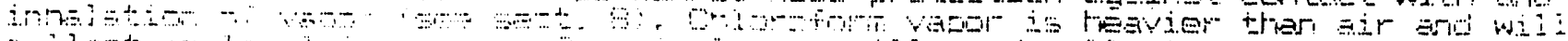

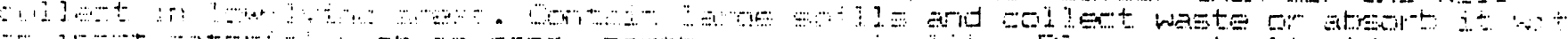

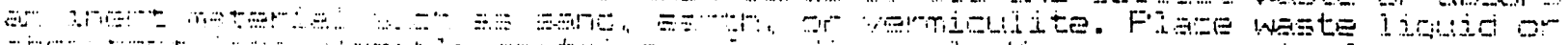

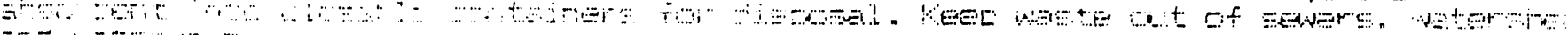
$\theta=-1, \cdots$

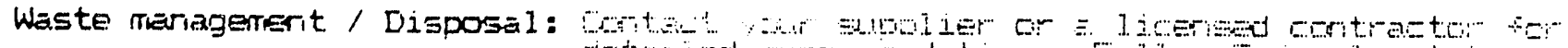

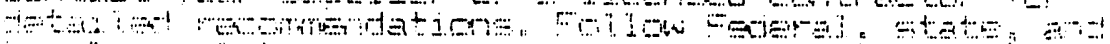
1.

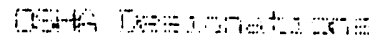

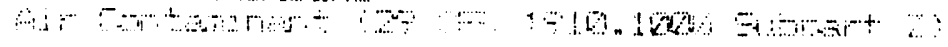

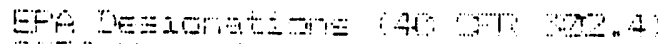

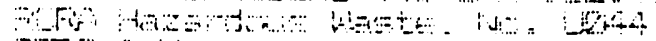

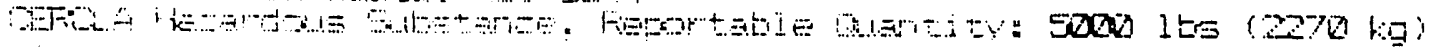

!

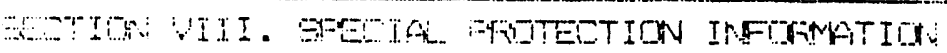

\section{Personal protective equipment:}

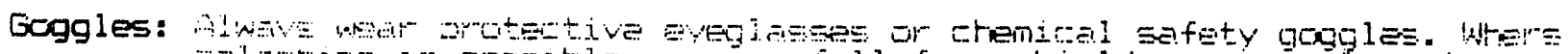

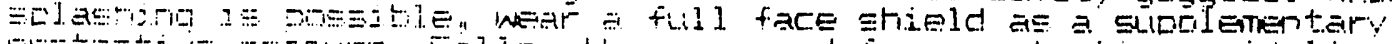

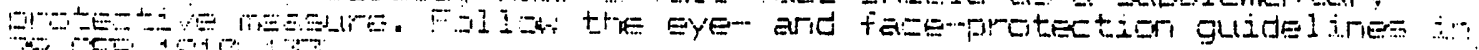
$20,10,0$

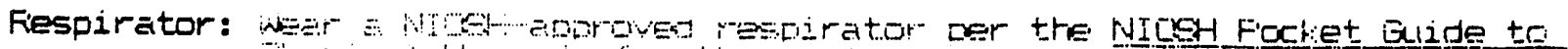

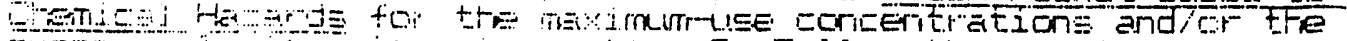

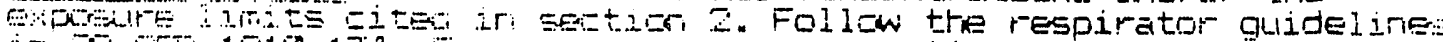

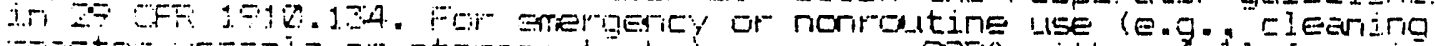

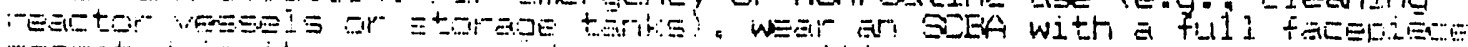

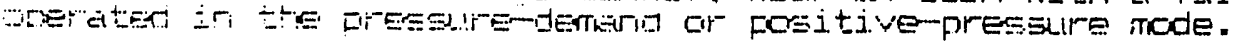

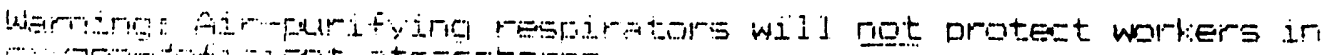

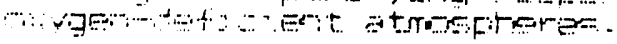

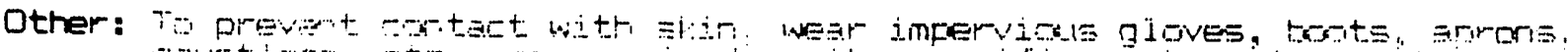

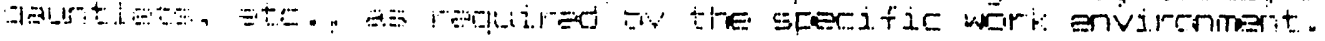

\section{Workplace considerations:}

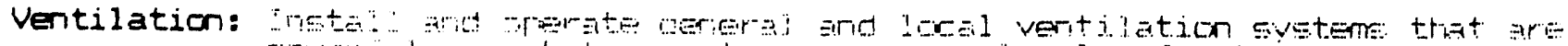

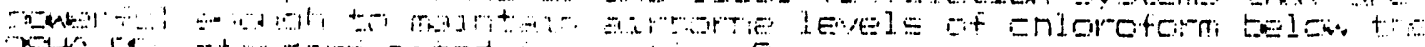

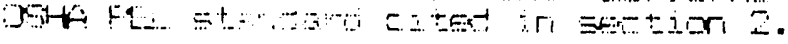




\title{
Material Safety Data Sheet
}

\author{
1.

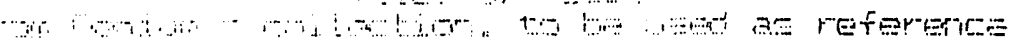 \\ Froduet: Find

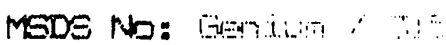 \\ Fevision: : \\ Date:
}

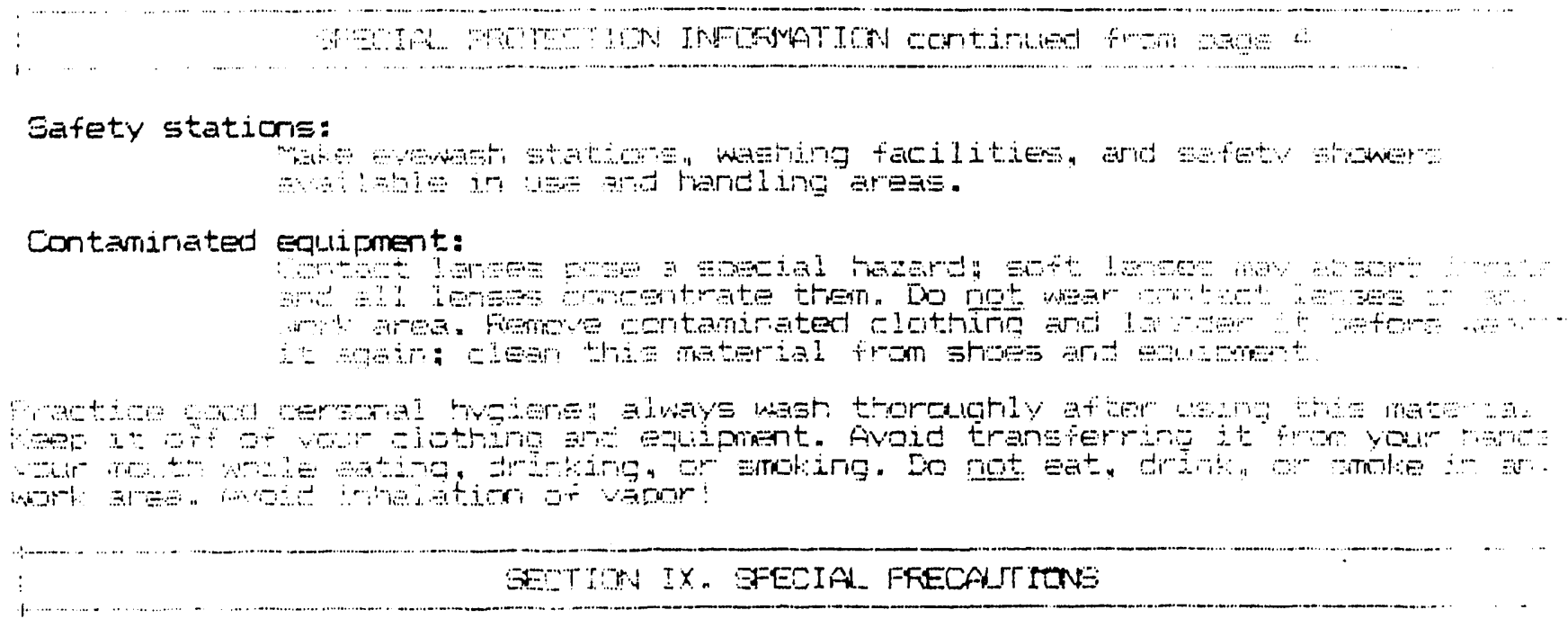

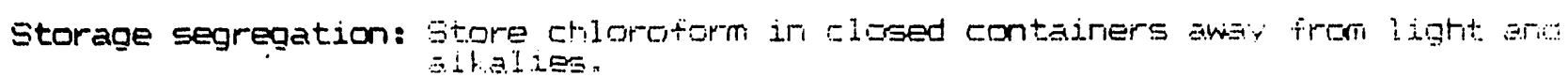

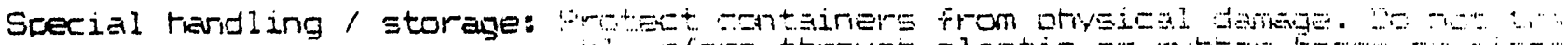

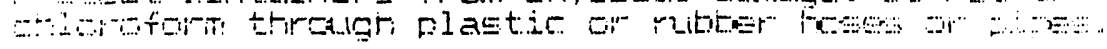

Pro

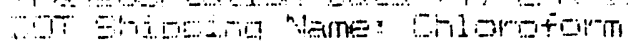

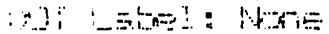

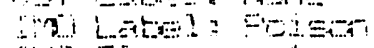

MT

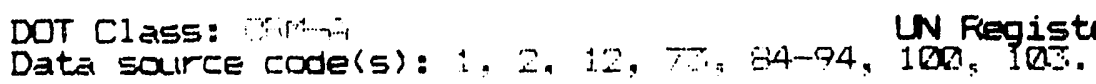

UN Register: N1608

Frepared/revised by: Gerillm Fitilistifig Dorforation

$\therefore-11,10$

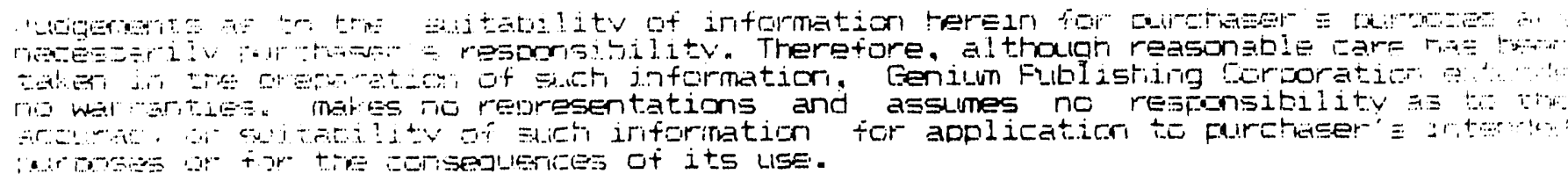




\begin{tabular}{|c|c|}
\hline Extion & 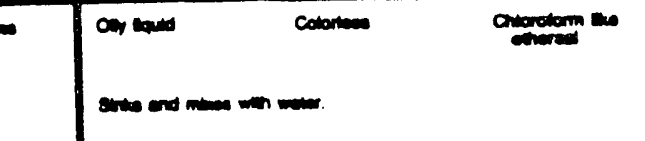 \\
\hline \multicolumn{2}{|c|}{ 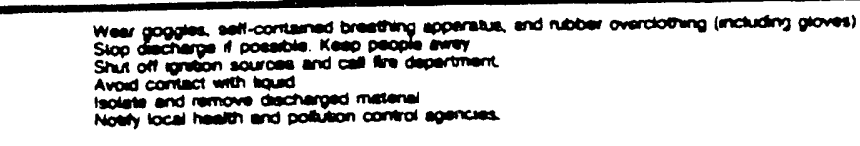 } \\
\hline Fire & 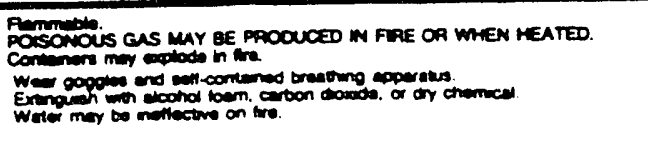 \\
\hline Exposure & 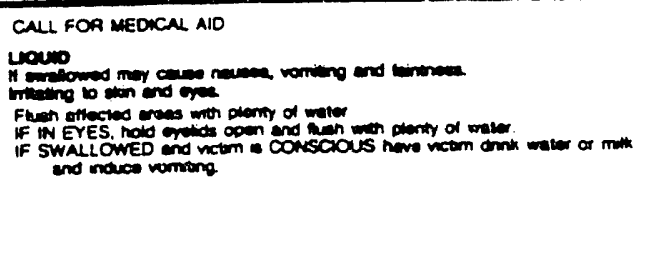 \\
\hline $\begin{array}{l}\text { Water } \\
\text { Pollution }\end{array}$ & 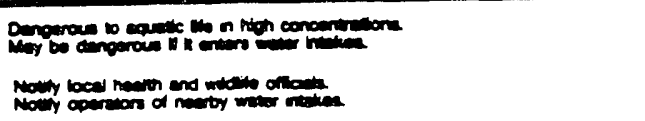 \\
\hline
\end{tabular}

1 cesponse to orsenuese

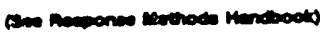

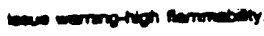

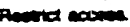

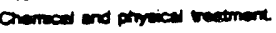
21 Comener None

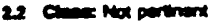

\section{1. chencel oessematrous}

21 co compons motrocition

22 Forminc Catha.

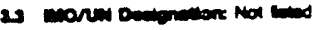

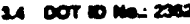

is cas nomiter Ma: 75343

\section{Insm warnos}

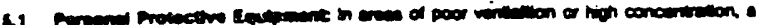

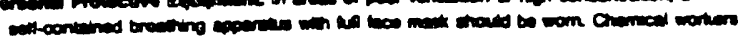

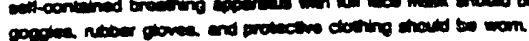

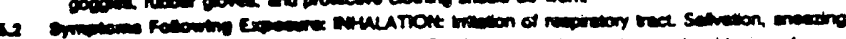

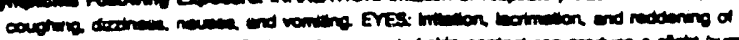

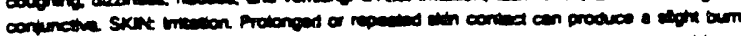

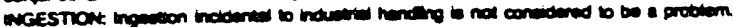
Sipto grovin ond cramion the

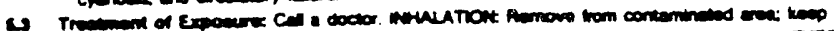

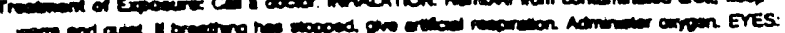

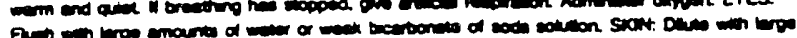

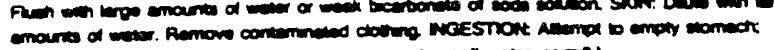

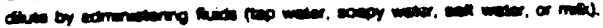

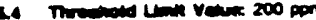

19. Tom

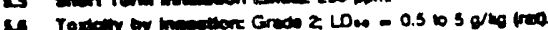

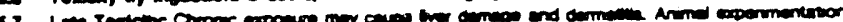

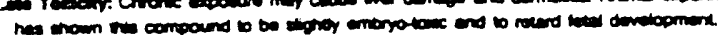

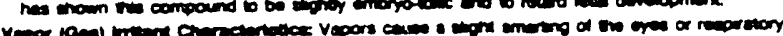

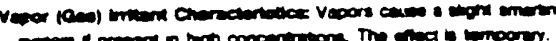

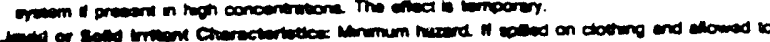

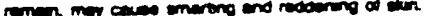

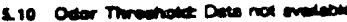

C.11 DUH Vere $4,000 \mathrm{pom}$

\section{c fluc movens

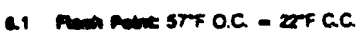

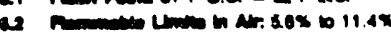

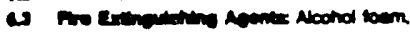

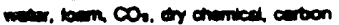

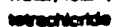

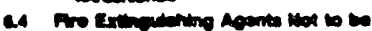

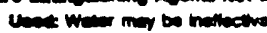

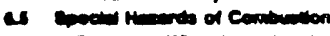

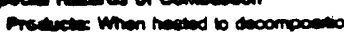

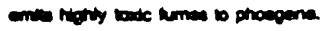

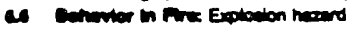

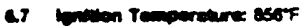

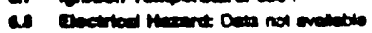

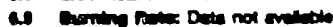 \\ are

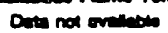

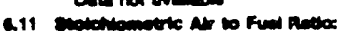

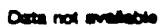

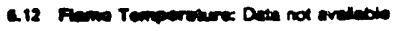

\section{CHEMICA REACTMTI}

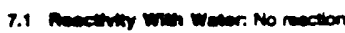

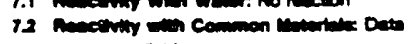

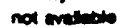

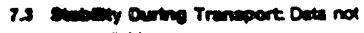
(1)

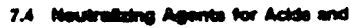

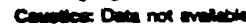

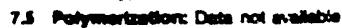

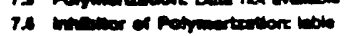

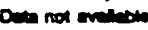

7.7 o

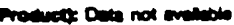

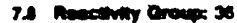

\section{2 warea poutrom}

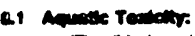

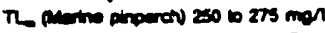

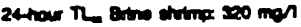
24hor Th Prosed $100 \mathrm{~mol}$

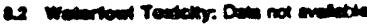

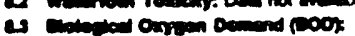

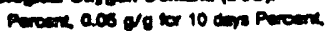
$0.0020 / 9$ tor 5 dos

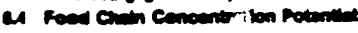
ond not and

\section{2 shaprinc inrominon}

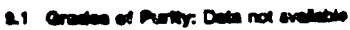

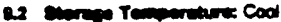

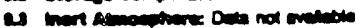

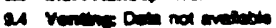

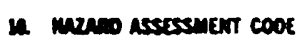

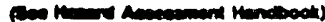
Anoth

11 nezes cussincanoms

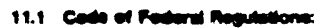

$$
\text { Not end }
$$

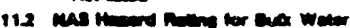

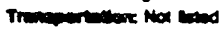

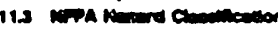

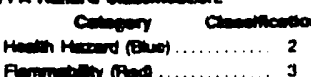

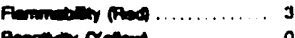

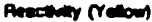

12 mrices ano cigarel moremes

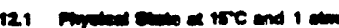
Uant

122 (2)

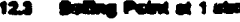

$196.147-57.50=300.57 x$

224 (1)

$-10505=-9.4^{\circ} \mathrm{C}=17575{ }^{\circ} \mathrm{K}$

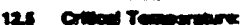

$\operatorname{sen} \pi$ - $2015 c-534.65^{\circ} \mathrm{K}$

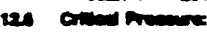

rese $-60 \mathrm{am}$ - $5.006 \mathrm{mw} / \mathrm{m}^{\circ}$

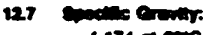

$1.174=200$

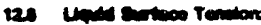

24.75 drem $=0.02475 \mathrm{~N} / \mathrm{m}$ a arc

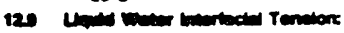
Dim not on

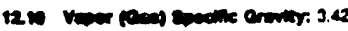

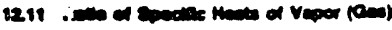
$1.1350 \mathrm{arc}$ (a)

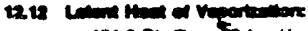

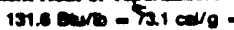
$\operatorname{sen} \times 10^{\circ}$ the

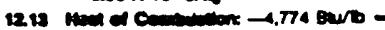
-2062 cong - $-111 \times 10^{0} \mathrm{~J} / \mathrm{k}$

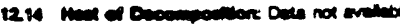

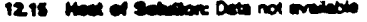

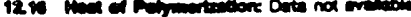

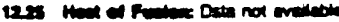

12 12.

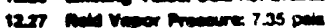


From Genium's Reference Collection

Genium Publishing Corporation 1145 Catalyn Street

Schenectady, NY 12303-1836 USA

(518) $377-8855$

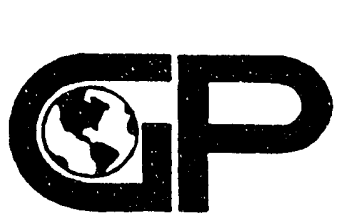

GESUM PUBUSHANG CORP.

CHEMICAL NAME: ETHYLENE DICHLORIDE (Changed to reflect common industrial practice)

DESCRIPTION (Origin/Uses): Made from acetylene and HCl. Used as a degreaser, a scavenger in leaded gasoline, as an intermediate in the manufacture of vinyl chloride, in paint removers, in wetting and penetration agents, in ore flotation processes, as a fumigant and as a solvent for fats, oils, waxes, and gums.

OTHER DESIGNATIONS: 1,2-Dichloroethane; sym-Dichloroethane; Dutch Liquid; Dutch Oil; EDC;

Ethane Dichloride; Ethylene Chloride; 1,2-Ethylene Dichloride; Glycol Dichloride; $\mathrm{C}_{2} \mathrm{H}_{4} \mathrm{Cl}_{2}$;

NIOSH RTECS KI0525000; CAS $\$ 0107-06-2$

MANUEACTURERS/SUPPLIERS: Available from several suppliers, including:

Dow Chemical USA, 2020 Dow Center, Midland, MI 48640; Telephone: (517) 636-1000

COMMENTS: Ethylene dichloride is a flammable, toxic liquid.

SECTION 2. INGREDIENTS AND HAZARDS

Euhylene Dichloride, CAS \#0107-06-2; NIOSH RTECS \#KJ0525000

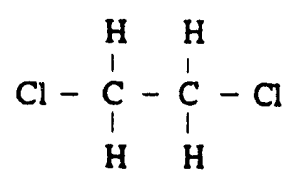

* The maximum allowable peak concentration (above the ceiling level value) of ethylene dichloride is $200 \mathrm{ppm}$ for 5 minutes in any 3 -hour period.

COMMENTS: Additional data concerning toxic doses and umorigenic,

reproductive, and mutagenic effects is lisied (with references) in the NiOSH

RTECS 1983-84 supplement, pages 865-66.

\section{SECTION 3. PHYSICAL DATA}

Boiling Point ... 182.3. $\mathrm{F}\left(83.5^{\circ} \mathrm{C}\right)$

Vapor Pressure ... 87 Torr at $77^{\circ} \mathrm{F}\left(25^{\circ} \mathrm{C}\right)$

Water Solubility ... Soluble in about 120 Parts Water

Vapor Density $(\mathrm{Air}=1) \ldots 3.4$

Appearance and odor. Colorless, clear liquid. Sweet chlorofolike Molecular Weight ... 98.96 Grams/Mole recognition threshold ( $100 \%$ of test panel) for ethylene dichbride is $40 \mathrm{ppm}$. Odor detection probably indicates an excessive exposure to vapor. High volatility and flammability, coupled with its toxicity and carcinogenic potential, make this material a major health hazard.

COMMENTS: Ethylene dichloride is miscible with alcohol, chloroform, and ether.

\begin{tabular}{|c|c|c|c|c|}
\hline SECTION 4. FIRE AND EXPLOSION DATA & LOWER & UPPER \\
\hline Flash Point and Method & Autoignition Temperature & Flammability Limits in Air & & \\
\hline See Below & $775^{\circ} \mathrm{F}\left(413^{\circ} \mathrm{C}\right)$ & $\%$ by Volume & 6.2 & 15.9 \\
\hline
\end{tabular}

EXTINGUISHING MEDIA: Use chemical, carbon dioxide, alcohol foam, water spray/fog, or dry sand to fight fires involving echylene dichloride. Direct water sprays may be ineffective extinguishing agents, but they may be successfully used to cool fire-exposed containers. Use a smothering effect to extinguish fires involving this material. UNUSUALERE/EXPLOSION HAZARDS: Ethylene dichloride is a dangerous fire and explosion hazard when exposed to sources of ignition such as heat open names, sparks, etc. Its vapors are heavier than air and can flow along surfaces to distant, low-lying sources of ignition and flash back. If it is safe to do so, remove this material from the fire area. Ethylene dichloride burns with a smoky flame. SPECIAL FIRE-FIGHTING PROCEDURES: Wear a self-contained breaching apparatus with a full facepiece operated in a pressure-demand or another positive-pressure mode.

COMMENTS: Flash Point and Method: $56^{\circ} \mathrm{F}\left(13^{\circ} \mathrm{C}\right) \mathrm{CC} ; 65^{\circ} \mathrm{F}\left(18^{\circ} \mathrm{C}\right) \mathrm{OC}$.

OSHA Flammabilitv Class (29 CFR 1910.106): IB. DOT Flammability Class (49 CFR 173.115): Flammable Liquid

SECTION 5. REACTIVITY DATA

Elhylene dichloride is stable. Hazardous polymerization cannot occur.

CHEMICAL INCOMPATIBILITIES include strong oxidizing agents. Explosions have occurred with mixtures of this material and liquid ammonia or dimethylaminopropylamine. Finely divided aluminum or magnesium metal may be hazardous in contact with ethylene dichloride.

CONDCIIONS TO AVOID: Eliminate sources of ignition such as excessive heat, open flames, or electrical sparks, particularly in low-lying areas, because the explosive, heavier-than-air vapors will concentrate there.

BRODUCTS OF HAZARDOUS DECOMPOSITION can include vinyl chloride, chloride fumes, and phosgene. Phosgene is an extrcmely poisonous gas. Products of thermal-oxidative degradation (i.e., fire conditions) must be treated with appropriate caution. 


\section{SECTION 6. HEALTH HAZARD INFORMATION}

Ethylene dichloride is listed as an anticipated human carcinogen by the NTP and as a probable human carcinogen (Group 2B), by ihe IARC. It was found to be an animal-positive carcinogen by the IARC. NCI reported positive resulis (mouse, rat) from its carcinogenesis bioassay. SUMMARY OF RISKS: Ethylene dichloride is considered to be one of the more toxic of the common chlorinated hydrocarbons. Deaths from accidental ingestion of this material have been reported. Inhalation of vapors reportedly caused three fatalities. Excessive inhalation of ethylene dichloride vapors can cause respiratory iritation, inloxication, narcotic and anesthetic effects, vomiting, dizziness, depression, and diarthea. The hepaloxic (injurious to liver) effects of this material are significant. The systemic effects from overexposure can appear in the liver, kidneys, digestive tract blood, lungs, adrenal glands, and the central nervous system. Tests on animals have revealed reproductuve failure and fetal resorption. There may be increased risk to nursing infants of exposed mothers. TARGET ORGANS: Central nervous system, eyes, kidneys, liver, hearh adrenal glands, and sicin. PRIMARY ENTRY: Inhalation, absorption through skin, oral, or eye contacL ACUTE EEFECIS: Skin contact causes irritation, defatting, and, if repeated or prolonged, burming. Eye contact causes irritation and serious injury (clouding of the comea) if it is not removed prompty. CHRONIC EFEECTS: Injuries to the liver (hepatoxicity) and kidneys, weight loss, low blood pressure, jaundice, oliguria (reduced excretion of Injune) or anemia MEDICAL CONDITIONS'AGGRAVATED BY LONG TERM EXPOSORE: Persons taking anticoagulants could experience an increase in tendency to bleed. Persons taking insulin face an increased risk of lowered blood sugar. ElRST experence an icce to restrain a hyperactive victim. EYE CONTACT: Flush eyes, including under the eyelids, gently but thoroughly with plenty of runing water for at least 15 minutes. Get medical help." SKRN CONTACT: Immediately flush the affected area with water. Wash thoroughly with soap and water. Remove and launder contaminated clothing before wearing it again; clean material from shoes and equipment. Get medical help.* INHALATION: Remove victim io fresh air; restore and/or support his breathing as needed. Get medical help.* INGESTION: Never give anything by mouth to someone who is unconscious or convulsing. Rinse victim's mouth with water. Oxygen and aruficial respiration may be needed. Get medical help.* * GET MEDICAL ASSISTANCE = IN PLANT, PARAMEDIC, COMMUNITY. Get prompt medical assistance for further treatment observation, and support after first aid.

\section{SECTION 7. SPILL, LEAK, AND DISPOSAL PROCEDURES}

SPILULEAK: Before using ethylene dichloride, it is essential that proper emergency procedures be established and made known to all personnel involved in handling it. Notify safety personnel of ethylene dichloride spills or leaks and implement containment procedures. Remove and eliminate all possible sources of ignition such as heat, sparks, and open flames from the area. Cleanup personnel should use protection against inhalation of vapors and contact with liquid. Contain spills by using an absorbent material such as dry sand or vermiculite. Use nonsparking tools to mix waste material thoroughly with absorbent and place it in an appropriate container for disposal. Flush trace residues with large amounts of water. Do not flush waste to sewers or open waterways. WASTE DISPOSAL: Consider reclamation, recycling, or destruction rather than disposal in a landfill. Waste may be burned in an approved incinerator equipped with an afterburner and a scrubber. Follow Federal, state, and local regulations.

Ethylene dichloride is designated as a hazardous substance by the EPA (40 CFR 116.4). Ethylene dichloride is reported in the 1983 EPA TSCA Inventory.

EPA Hazardous Waste Number (40 CFR 261.33): U077

EPA Reportable Quantity (40 CFR 117.3): $5000 \mathrm{lbs}(2270 \mathrm{kgs})$

Aquatic Toxicity Rating, TLm 96: $1000-100$ ppm

\section{SECTION 8. SPECIAL PROTECTION INFORMATION}

GOGGLES: Always wear protective eyeglasses or chemical safety goggles. Ethylene dichloride is particularly harmful to the eyes, and direct contact results in corneal opacity (permanent clouding of the eye). GLOVES: Wear impervious rubber gloves to prevent skin contact. BESPIRATOR: Use a NIOSH-approved respirator per the NIOSH Packet Guide to Chemical Hezards (Genium ref. 88) for the maximum-use concentrations and/or the exposure limits cited in section 2. Follow the respirator guidelines in 29 CFR 1910.134. Any detectable concentration of ethylene dichloride requires an SCBA, full facepiece, and pressure-demand/positive-pressure modes. Waning: Air-purifying respirators will not protect workers from oxygen-deficient atmospheres. OTHER: Wear rubber boots, aprons, and other prolective clothing suitable for use conditions to prevent stin contact Remove contaminated clothing and launder it before wearing it again. Discard contaminated shoes. VENTILATION: Provide maximum explosion-proof local fume exhaust ventilation systems to maintain the airborne concentrations of ethylene dichloride vapors below the exposure limits cited in section 2 . Install properly designed hoods that maintain a minimum face velocity of $100 \mathrm{fm}$ (linesr feet per minute). SAEETY STATOONS: Make eyewash stations, washing facilities, and safety showers available in wreas of use and handling. SPEClAL

CONSIDERATIONS: Vapors are heavier than air and will collect in low-lying areas. Eliminate sources of ignition in these areas and again provide sood ventilation there. COMMENTS: Practice good perscual hygiene. Keep malerials off of your clothes and equipment. Avoid transferring this material from hands to mouth while eating, drinking, or smoking. Immediately remove ethylene dichloride-saturated clothing to avoid flammability and health hazards. Contact lenses pose a special hazard; soft lenses may absorb irritants, and all lenses concentrate them.

\section{SECTION 9. SPECIAL PRECAUTIONS AND COMMENTS}

STORAGE SEGREGATION: Store ethylene dichloride in tightly closed containers in a cool, dry, well-ventilated area away from sources of ignition. Protect containers from physical damage and from exposure to excessive heat. Avoid direct physical contact with strong acids, bases, oxidizing agents, and reducing agents. SPECIAL_HANDLING/STORAGE: Use nonsparking tools. Outside or detached storage is preferred. Store and handle ethylene dichloride in accordance with the regulations concerning OSHA class IB flammable liquids. ENGINEERING CONTROLS: During transfer operations involving ethylene dichloride, the liquid and its vapors must not be exposed to nearby sources of ignition from engineering systems that are not explosion proof. Preplan emergency response procedures.

TRANSPORTATION DATA (per 49 CFR 172.101-2):

DOT Hazard Class: Flammable Liquid

DOT Label: Flammable Liquid

IMO Class: 3.2

DOT Shipping Name: Ethylene Dichloride

DOT ID No. UN 1184

IMO Label: Flammable Liquid, Poison

References: $1-9,12,19,21,26,43,47,73,87-102$. CK

Judgements as to the aritubility of information hereun for purchasers purposen are necessanly purchaser's responsibility. Therefore, although reasonable care $n=$ been lakea is the preparation of such information, Genium Publishing Corp. extesds do warmates, makes do representations and asrumes ao responsibility a to the acouracy of sultability of such information for applicition to purchaers inteoded purposes of for comequences of is use.

\begin{tabular}{|c|c|}
\hline Approvals 90 & \\
\hline Indust. Hygiene/Safeity $\quad \bar{v} / 20$ & $11-18-87$ \\
\hline Medical Review & $11-30-87$ \\
\hline
\end{tabular}




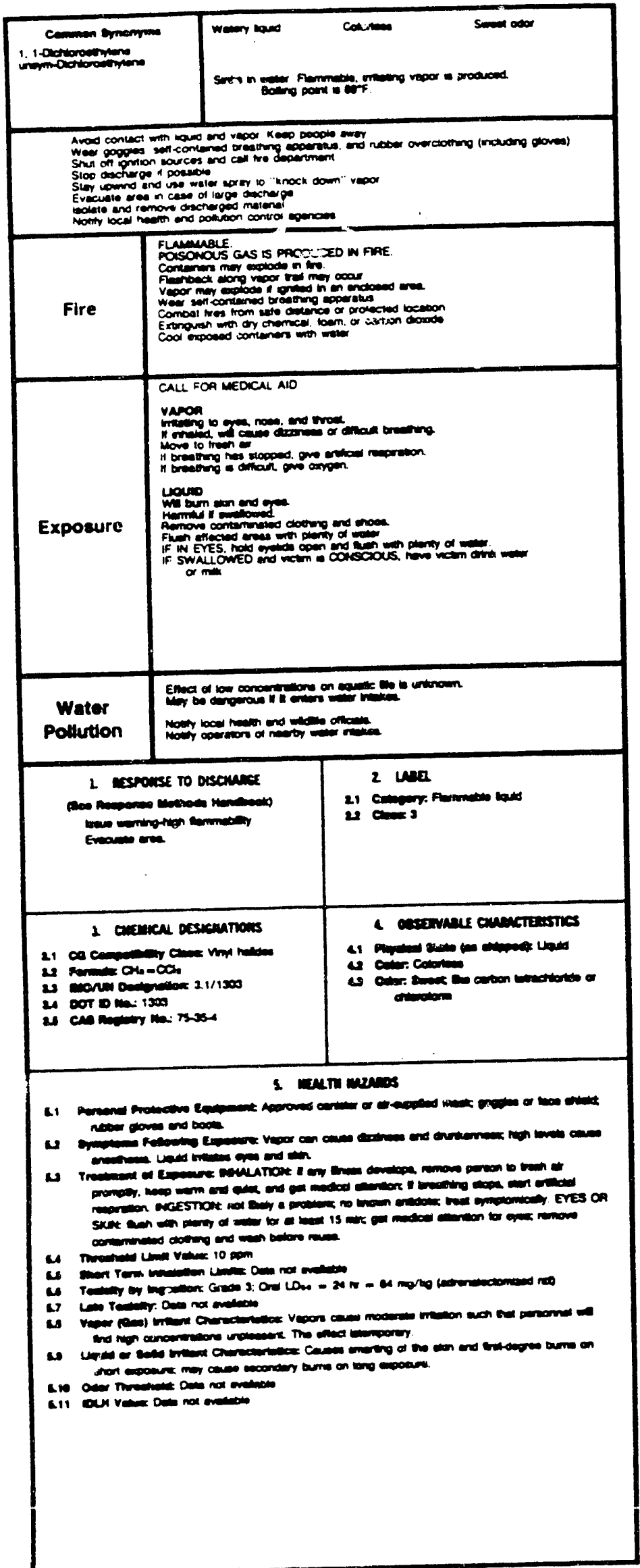

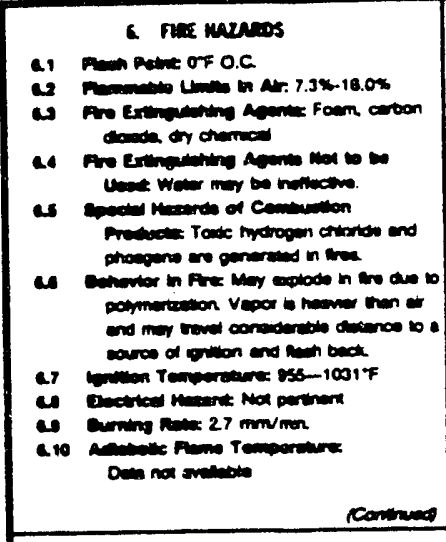

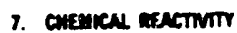

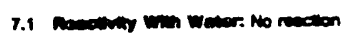

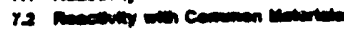

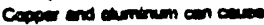
popmentedion

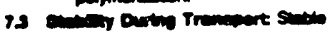

is

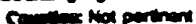

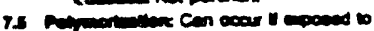

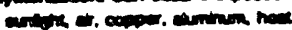

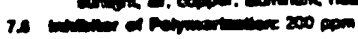

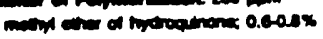
mas

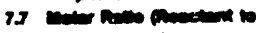

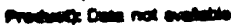

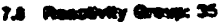

\section{2. wara routrom}

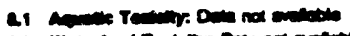

us

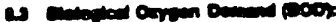

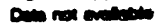

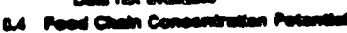
nom

2. smomis uresention

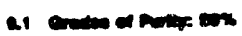

al

es

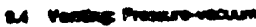

2a. munuro assessiment coor

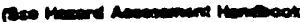
$A-x-y-2$

1L. meneo chessineanows

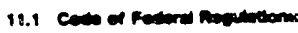

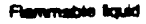

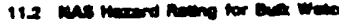

Trenomentert

Fon conser

Fin.m.

Veor max

Laver or Sold mimen ............. 2

Ponome.....

Werr Potreon

Hemen Toldity-....________ 0

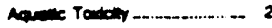

Anerence Enat

Reconary

Oner Oremsins

miner.

s.t Penction

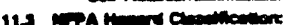

Carar Crmation

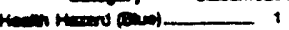

Pnem Ged

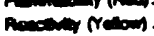
$-2$

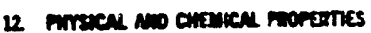

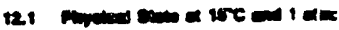

$$
\text { Lan }
$$

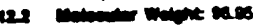

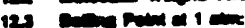

$$
2 \pi-\pi \tau=-3040 x
$$

(2)

$-19807-1220 C-1512 K$

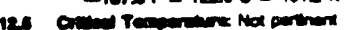

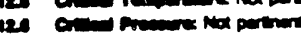

12)

121 a $\operatorname{arc}$ mante

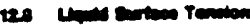

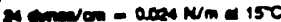

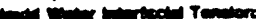

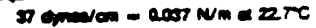

1210

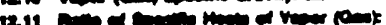
on

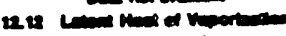

$190 \mathrm{cas}$ - $r \mathrm{cov} / \mathrm{O}$ $30 \times 100+12$

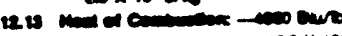

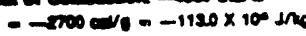

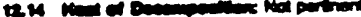

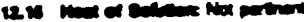

12. 15 ato

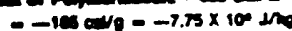

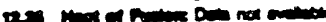

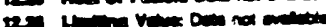

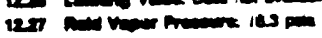

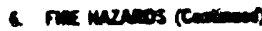

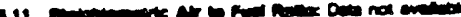

ald 


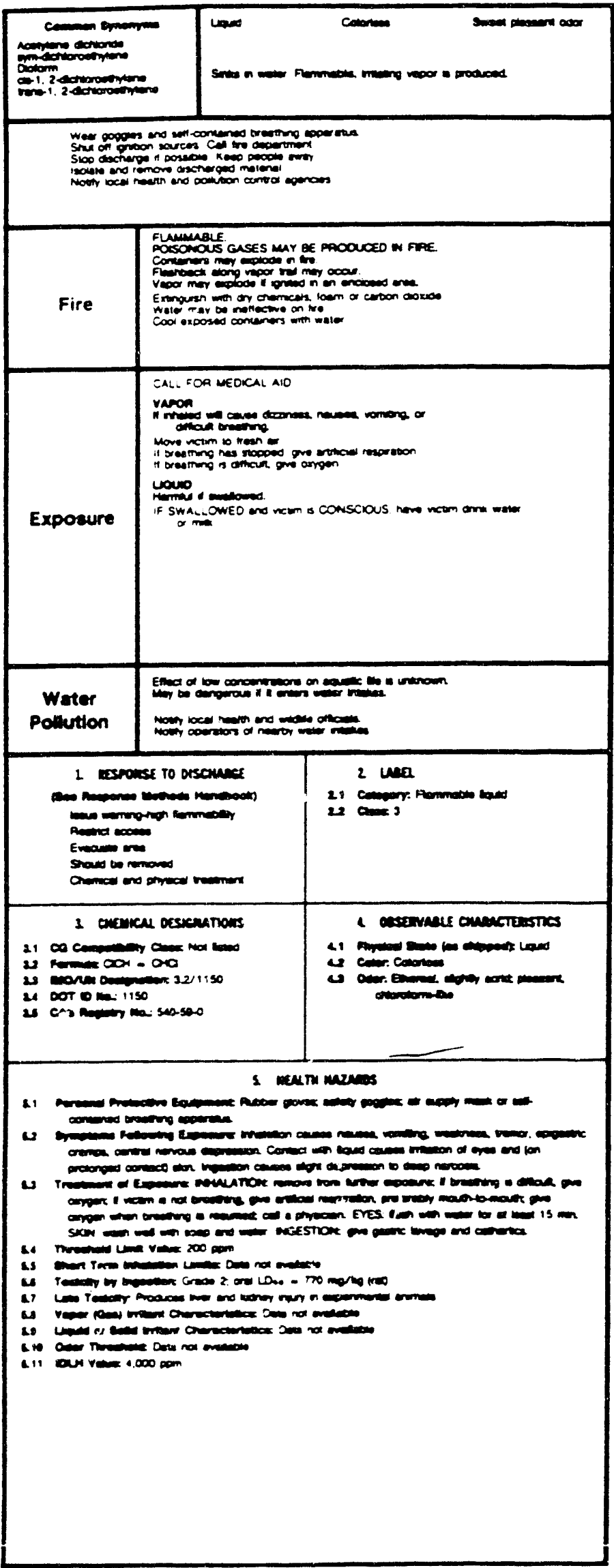

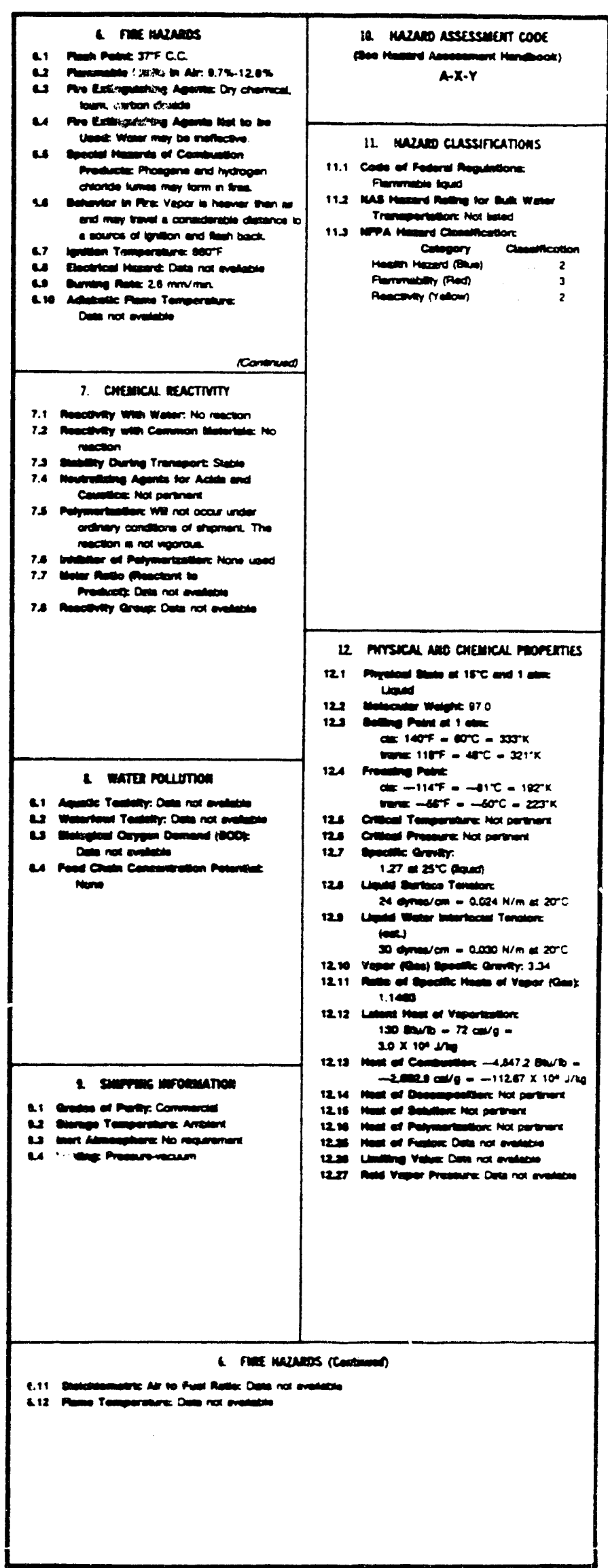




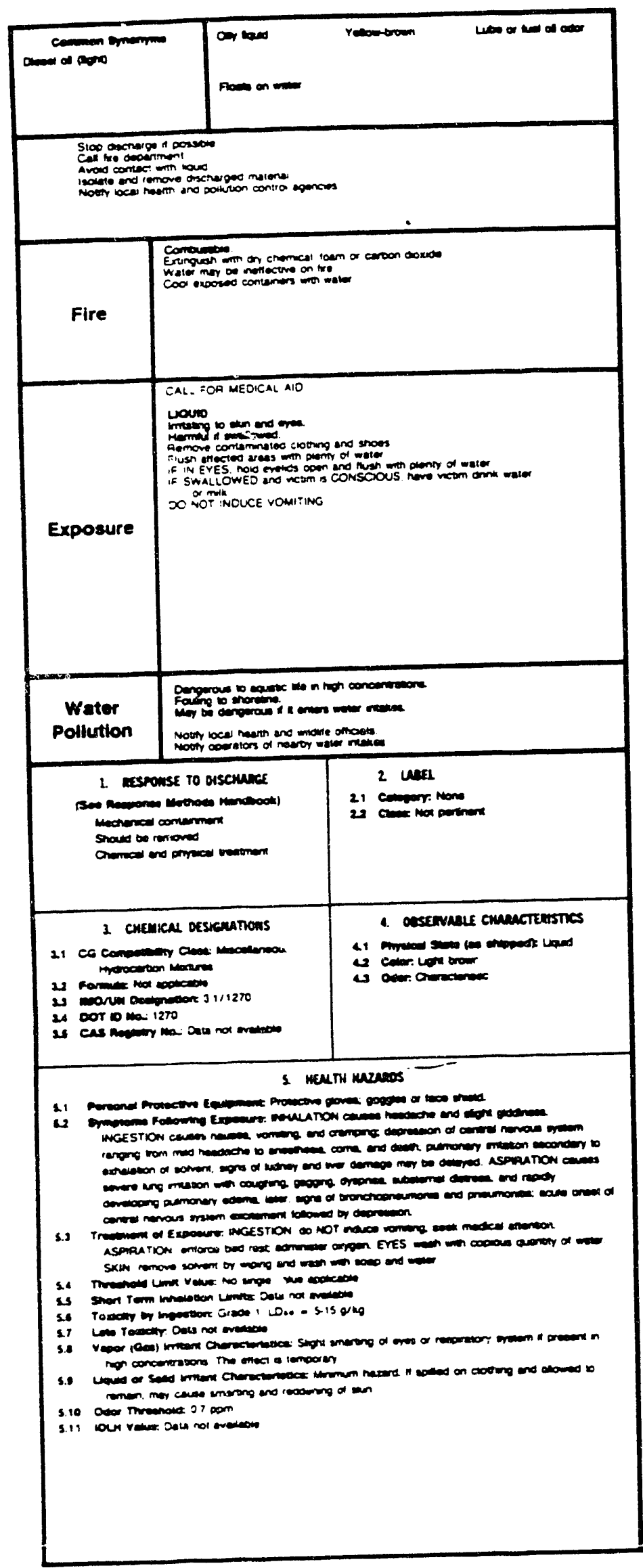

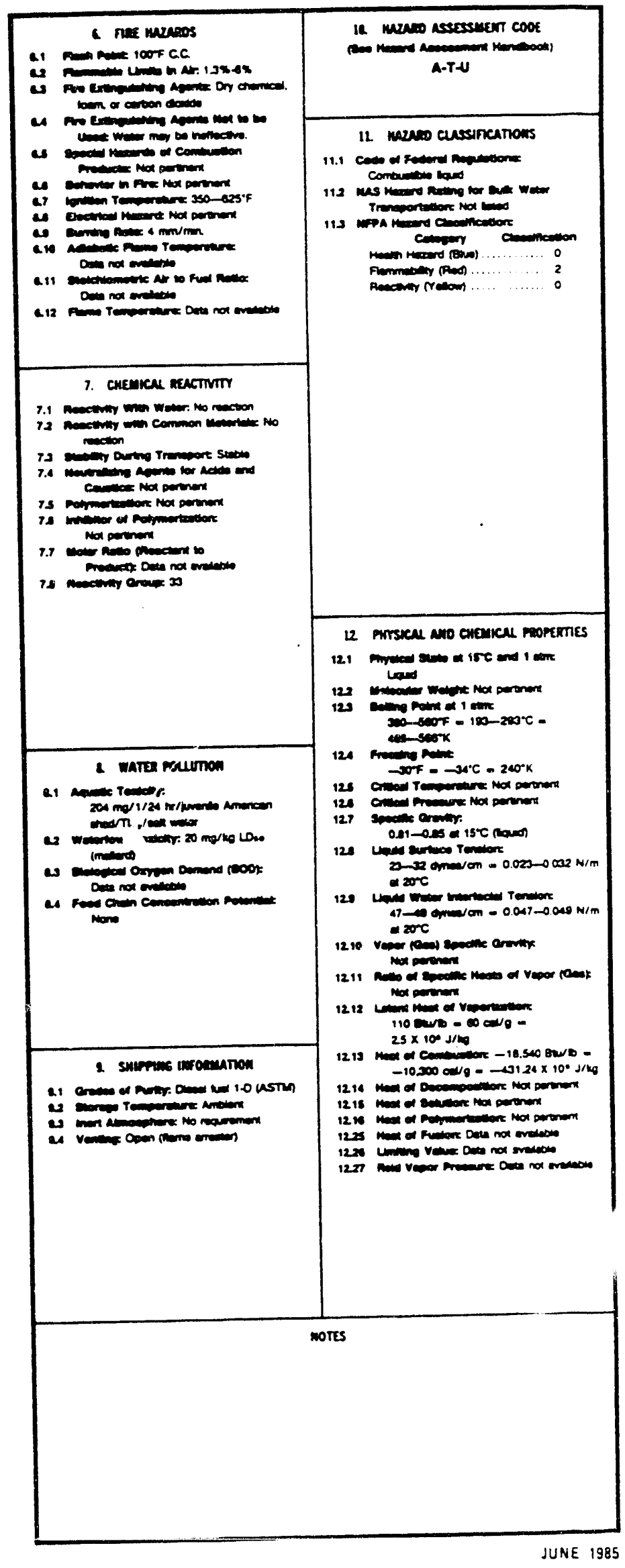




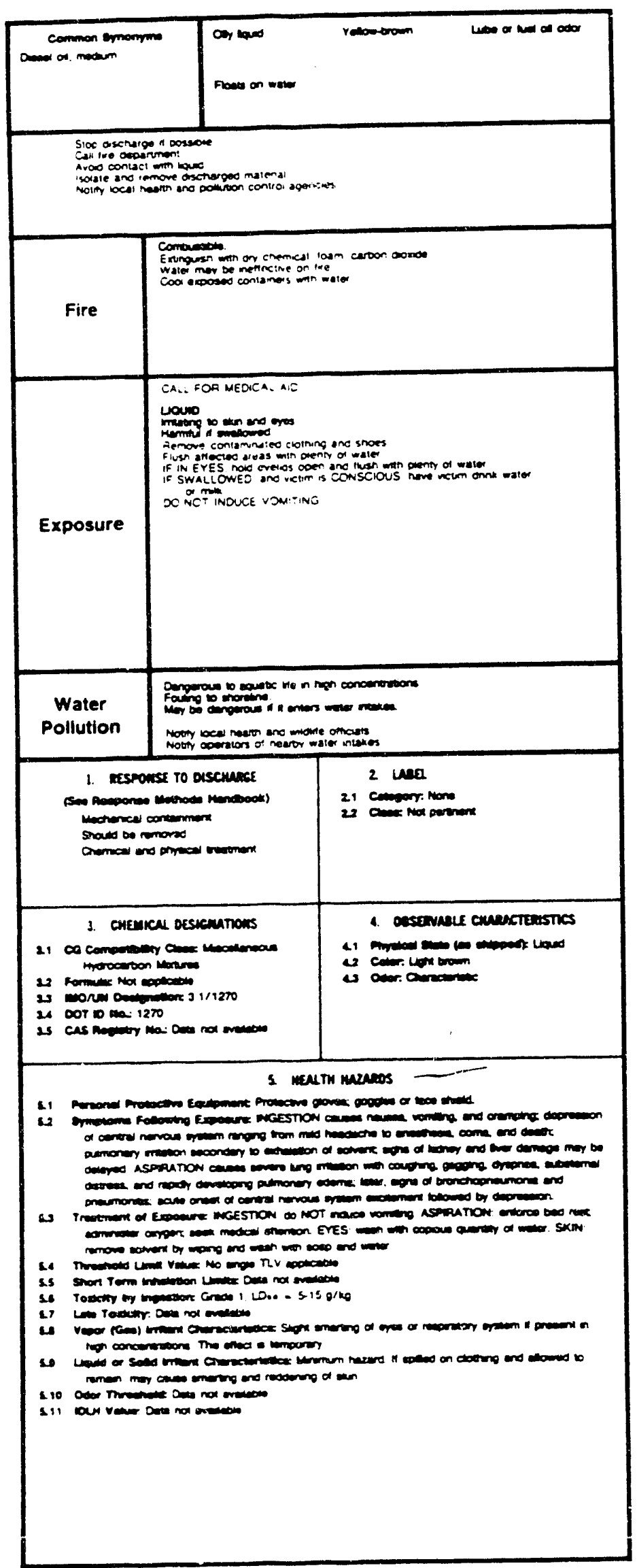

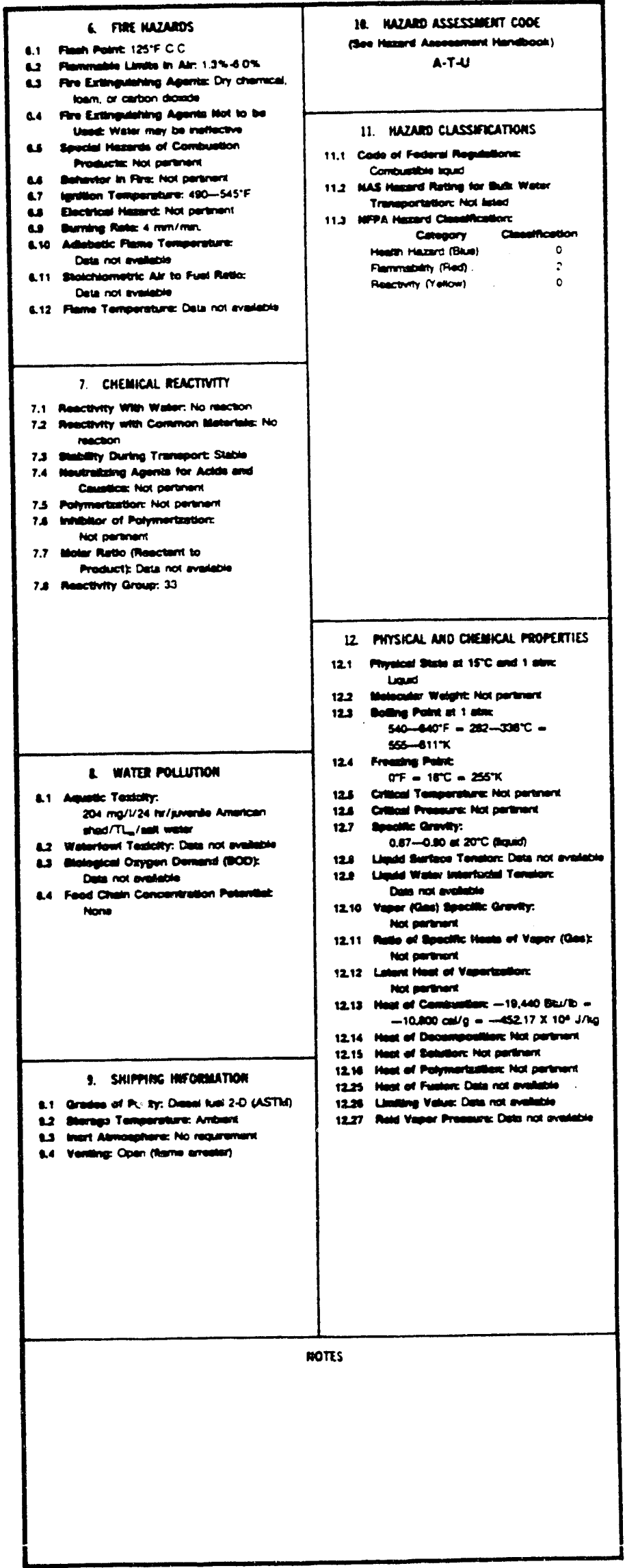


Geniue Publishing Corporation

1145 Catalyn street, Schenectady, NY 12303 (518) 377-8854

Fron Geniun's collection, to be used as reference
Product: AUTOMOTIVE GASOLINE, LEAD FREE

MSDS No: Geniun / 467

Date: October, 1981

SECTION I. MATERIAL IDENTIFICATION

Trade/Material Nane: AUTOMOTIVE GASOLINE, LEAD FREE

Description: A volatile blend of hydrocarbons for autonotive fuel.

Other Designations: Petrol, ASTM D439

CAS: 008006619

Available fro several suppliers.

SECTION II. INGREDIBNTS AND HAZARDS

Ingredient Nane:

Gasoline
Percent: Bxposure Linits:

$100 \%$ 8-hr TWA 300 ppa or

Man:

Bye: $500 \mathrm{ppa} / 1 \mathrm{H}$ Moderate irritation

Inhalation: TCLo $900 \mathrm{ppa} / 1 \mathrm{~A}$ TRX: CNS

A hydrocarbon blend that can include noraal and branched chain alkanes, cycloalkanes, alkenes, arouatics and other additives, * (Lead max $0.013 \mathrm{~g} / \mathrm{L}$ phosphorus ax 0.0013

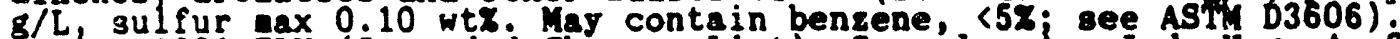

*ACGIH 19R1 TLV (Intended Changes List). See also An. Ind. Hrs. A. 39 110-117 (1978)

* The conposition of fuel is varied with altitude and geasonal requireaents for a locality. The blend nust neet antiknock requirements. (Antiknock Index $₫$ in 85, ASTM D439.)

SBCTION III PHYSICAL DATA

Appearance odors A clect, coblle liquid with a characteristis odor which can be recogisised at ahout $10 \mathrm{ppa}$ in air. (Gasoline may be colored with dre.)

Water solubilft (3): Insoluble

Vapor density (alr-1): $3.0-4.0$

\section{Bvaporation rate: N/A Specilic Eravity $\left(\mathrm{H}_{2} \mathrm{O}=1\right): 0.72-0.76$ \\ Neltins point: $-90.5-95.4$}

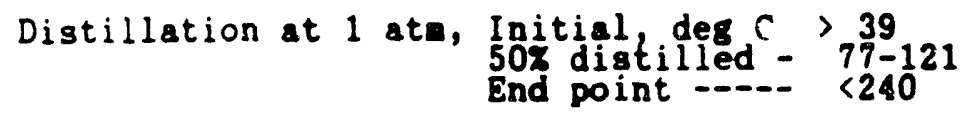

Page 1 -.-

MSDS 467 continues on pase 2 


\section{Product: AUTOMOTIVE GASOLINE, LEAD FREE}

MSDS No: Geniun / 467

Date: October, 1981
SECTION IV. FIRE AND EXPLOSION DATA

Flash Point (nethod): $-45^{\circ} \mathrm{F} \quad$ Linits: LEL $\mathbf{3}: 1.4$

Exiinguishing Medis: Dry cheaical, carbon dioxide, alconol

foan. Use of water na be ineffective to extinguish ire,

but use water spray for cooling fire-exposed druas and tanks

to prevent pressure rupture.

Unusual fire or explosion hasards: It is a dangerous fire and explosion hazard when exposed to heat and flanes. Vapors can flow alons surfaces, reach distant ignition sources and flash back. Can react violently with oxidizing agents.

Special fire-fighting procedures: Firefighters should wear self-contained breathing apparatus and full protective clothing.

Flanability Linits In Air: $x$ by voluae

Material is stable in closed containers at roon tenperature under normal storage and handling conditions. Hazardous polymerization cannot occur

Cheaical inconpatibilities: It is inconpatible with oxidising agents.

Conditione to avoid: A vixture of gasoline vapors and air can be explostre.

This is an OSHA Class IA Planable liquid.

Thernal-oxidative degradation can yield carbon monoxide and partially oxidized hydrocarbons.

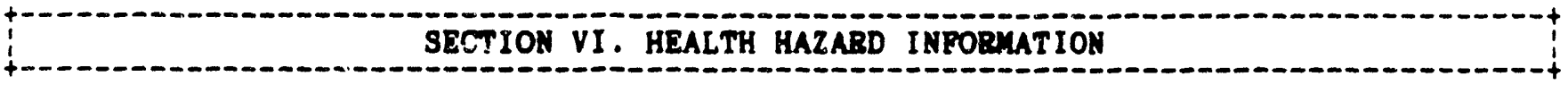

Sumary of riaks: Inhalation causes intense burning of the nucous aesbranes, throat and respiratory tract; ovarezposure to vapors can lead to bronchopneumonia; Inhalation of hich cosc. con ceuse fatal pulmonary edena. Repeated or prolonged skin exposure causes arestits. Can cause blistering of skin due to its defatting properties. Expow to ores can cause hypereeia of the conjunctiva.

Ingestion or excontre vapore can cause inebriation, drowsiness blurred vision, vertigo, confueles, voniting and cyanosis (2000 ppa produces aild anesthes is in 30 in., higher conc. are intoxlcating in less tine. Aspiration after ingestion causes bronchitis, pneumonis, or eden which can be fatal. 
Geniun Publishing Corporation

1145 Catalyn Street Schenectady, NY 12303 (518) $377-8854$

Prov Geniun's collection, to be used as reference
Product: AUTOMOTIVE GASOLINE, LEAD FREE

MSDS No: Geniun / 467

Date: October, 1981

t--

HEALTH HAZARD INFORMATION continued fron page 2

Pirst aid:

Eye contact: Flush thoroughly with running water for 15 ainutes including under eyelids.

Skin contact: Renove contaninated clothing. Wash affected area with soap and water.

Inhalation: Renove to fresh air. Restore breathing and adninister oxygen if needed.

Ingestion: Do not induce voniting. Aspiration hasard. Contact physician.

Seek pronpt nedical assistance for further treatnent, observation and support. SECTION VII. SPILL, LEAK AND DISPOSAL PROCEDURES

Spill / Leak procedures: Notify safety personnel of leaks or spills. Renove sources of heat or ignition. Provide adequate ventilation. Clean-up personnel reguire protection against i iquid contact and vapor inhalation. If leak or spill has not: ignited, use water spray to disperse vapors and to protect nen attenpting to stop the leakage. Contain spill. Do not allow to enter sewer or surface water. Add absorbent solid to sall spilis or residues and pick up por disposal.

Haste nanagement / Disposal: Burn scrap aaterisl in an spproved incinerator. Burn contaninated liquid by spraying into an incinerator. Follow Pederal, State, and Local regulations.

tSECTION VIII. SPECIAL PROTECTION INPORMATION

Personal protective equipent:

Gosgles: Aroid ere ogtapt by use of chenical safety goggles and/or full fecouleld when aplashing is possible.

Gloves: Werr protective clothing appropriate for the work situation to infine alin contact such as rubber gloves and boots.

Bespirator: Reaplrators tould be available for nonroutine or energency use above the TLV.

Other: Clothing to be changed daily and laundered. 
Geniun Publishing Corporation

1145 Catalyn Street, Schenectady, NY 12303 (518) 377-8854

Frov Geniun's collection, to be used as reference
Product: AUTOMOTIVE GASOLINE, LEAD FREE

MSDS No: Geniue / 467

Date: October, 1981

Workplace considerations:

Ventilation: Use general and local exhaust ventilation (explogion-proof) to keep vapors below the TLY requirenents in the workplace.

Sapety stations:

Eyewash fountains, showers, and washing facilities should be readily available.

Provide suitable training to those handling and working with this aterial.

(1) SECTION IX. SPEIAL PRECAUTIONS

Storage segregation: Store in closed containers in a cool, dry, well-ventilated area away ron sources of heat, ignition and strong oxidizing agents. Protect containers from physical danage. Avold direct sunlight. Storage nust meet requirenents of OSHA Class IA liquid.

Outdoor or detached storage preferred. No sooking in areas of use. Prevent static electric sparks and use explosion-proof electrical services. (Must neet code).

Other precautions: Avoid skin and eye contact. Avoid inhalation of vaporg. Wear clean work clothing daily. Indoor use of this aterial requires exhaust ventilation to reave vapors.

ICC Flanable Liquid, Red Label. LABEL: Flanable Liquid

DOT Class: PLAMAMBL LIQUID

Data source code $(8): 2,4-9,34,37$. N

UI Register: UN1203

Judgenents as to the suitability of inforaation herein for purchaser's purposes are necessarily purchaser's responsibility. Therefore, although reasonable care has been taken in the preparation of such inforation, Geniu Publishing corporation extends no warranties, akes no representations and assunes no responsibility as to the accuracy or suitability of such inforation for application to purchaser's intended purposes or for the consequences of its use. 
Geniun Publishing Corporation

1145 Catalyn Street Schenectady, N (518) 377-8854

Fron Geniun's collection, to be used as reference
Product: PERCHLOROETHYLENE

MSDS No: Geniun / 313

Revision: C

Date: Noveaber, 1978

\section{SECTION I. MATERIAL IDENTIFICATION}

Trade/Material Nane: PERCHLOROETHYLENE

Other Designations: Perchlorethylene, Tetrachloroethylene, Ethylene Tetrachloride, $\mathrm{Cl}_{2} \mathrm{C}=\mathrm{CCl}_{2}$, GE Material D5B84

CAS: $000 \quad 127 \quad 184$

TRADE NAME (MANUFACTURERS): BLACO-PER (Baron-Blakeslee); PERCHLOR (PPG); PERR (Stauffer); PERCLENE (Diamond Shamrock)

Ingredient Nane:

Perchloroethylene plus stabilizer*
Percent: Exposure Linits:

ca 100 8-hr TWA 100 ppa** with 200 ppa Ceiling

and 300 ppa 5 ainute peak in ang 3 hrs.

Rat, Inhalationi LCLO $4000 \mathrm{ppa} / 4 \mathrm{hrs}$.

* Stablized naterial usually contains a saall asount of anine and/or phenolic stabilizer. Stabilizers and levels used vary with the grade and the supplier. ** Current OSHA levels. ACGIH TLV (1978) is 100 ppa (skin). In 1976 NIOSH approved a 10-hr TWA of 50 ppa with a 100 ppa ceiling ( 15 min. sample).

NIOSH (1978) has warned of possible carcogenicity based on aniaal tests.

SECTION III. PHYSICAL DATA

Appearance Odor: Colorless 1 iguid with pleasant ethersl odor whose recognition threshold (100x of test panel, unfatigued) is $4.68 \mathrm{ppn}$ in air.
Bolling piats $2500 \mathrm{P}\left(121^{\circ} \mathrm{C}\right), 1$ ata

Vapor preapre? $15.8 .220 \mathrm{C}$, in $\mathrm{Hg}$

Water colubilite $(\mathrm{S})$ : Hojisible

Vapor denelte $(a,-1)$ i 5.83
Braporation rate: $0.27\left(\mathrm{CCl}_{4}=1\right)$

X volatile by rolume: ca 100 Specilic sravity (1月2 $O=1): 1.623$ e 
Genium Publishing Corporation

1145 Catalyn street Schenectady, NY 12303 (518) $377-8854$

Fro Geniun's collection, to be used as reference
Product: PERCHLOROETHYLENE

MSDS No: Geniun / 313

Revision: C

Date: Novenber, 1378
SECTION IV. FIRE AND EXPLOSION DATA

Plash Point (aethod): Not Conbustible Linits: LRL $\mathbf{z}$ : N/A

Extinguishing Media: Use that which is suitable for the surrounding fire.
UEL $x: N / A$

Autoignition Teap: NOEE

Unusual lire or explosion hazards: Although not conbustible, perchloroethylene can be hazardous in a fire situation because of vapor generation and from thermo-oxidative degradation at high teaperature to phosgene (highly toxic) and hydrogen chloride (corrosive).

Special lire-fighting procedures: Pirefighterg should use gelf-contgined breathing apparatus when this aterial is involved in a Pire situation.

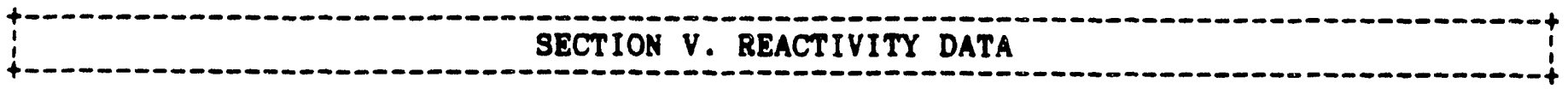

Material is stable under noraal storage and handling conditions.

Chenical inconpatibilities: Avoid aixing with caustic soda or potash. Do not allow hydrochloric acid build-up to occur in degreasing tanks (stabilizer exhausted).

Hazardous decosposition Products: Vapor exposure to high teaperature or electric arcs ay cause deconposition to hydrogen chloride and phosgene (highly toxic).

Prolonged exposure to sunlight (UV) can degrade unstabilized aterial.

SECTION VI. HEALTH HAZARD INPORMATION

Sunnary of riaks: Perchloroethylene nay cause derastitis through prolonged or repeated skin contact with liquid and irritation, lachryation, and burning sensation of the eyes by liquid or rapos contact. Loss of coordination, narcosis, treaors, abdoninal craps, irritation of the respiratory tract, and nauses naj result fron inhalation of excessive airborne concentrations. $(600 \mathrm{ppm}$ for 10 ainutes aay af fect the central nervous ajsten.) Very high exposures produce unconsciousness and even death. 
Geniun Publishing Corporation

1145 Catalyn Street Schenectady, NY 12303 (518) $377-8854$

Fron Geniun's collection, to be used as reference
Product: PERCHLOROETHYLENE

MSDS No: Geniun / 313

Revision: C

Date: Noveaber, 1978

HEALTH HAZARD INFORMATION continued fron page 2

Pirst sid:

Eje contact: Wash eyes with copious amounts of running water to relieve irritation.

Skin contact: Reaove contaninated clothes. Wash exposed skin with soap and water.

Inhalation: Resove patient to fresh air; restore breathing if necessary. Pronpty contact physician. Advise doctor not to adninister adrenalin.

Ingestion: If taken internally, induce voniting. Contact physician pronptly; advise doctor not to adninister adrenalin.

SECTION VII. SPILL, LEAR AND DISPOSAL PROCEDURES

Spill / Leak procedures: Supply maxinun ventilation. Conline spill to saall area; do not allow run of $p$ into sewer. Those involved in clean-up need protection from 1 iquid contact and vapor inhalation. Pick up spill on absorbent solid.

Waste nanagesent / Disposal: Place in covered container for disposal. Chlorinated solvents in large anounts should be burned in an approved incinerator with appropriate fune scrubbing. Also, consult licensed waste disposal conpany in your locality and consider recovery of perchloroethrlene solvent by distillation. Scrap solvent and distillation residues aust be handled as toxic waste. Follow Pederal, State and Local regulations for waste disposal.

$$
\text { t- }
$$$$
\text { SECTION VIII. SPECIAL PROTECTION INFORMATION }
$$

Fersonal protective equiprent:

Cosgles: Appropriate eye and lace protection should be used.

Glores: Neoprene, Viton, PVA or PVC coated gloves should ba used to prevent gkin expoenze.

Bespirator: Por eaergency and non-routine exposure above the TLV approved full faceplece respirators should be used - cartridge and canister types up to $300 \mathrm{ppm}$, and air-supplied or self-contained types above $500 \mathrm{ppa}$.

Other: There splashing is possible, aprons and protective clothing nay be indicated. 
Material Safety Data Sheet

Geniun Publishing Corporation 1145 Catalyn street, Schenectady, NY 12303

From Geniun's collection, to be used as reference
Product: PERCHLOROETHYLENE

MSDS No: Geniun / 313

Revision: C

Date: November, 1978

\section{SPECIAL PROTECTION INFORMATION continued fron page 3}

Workplace considerations:

Ventilation: Airborne levels should be kept below TLV levels by use of general ventilation and local exhaust ventilation. Provide floor level ventilation to renove these vapors.

Where eye contanination is possible, an eye wash fountain should be readily available.

SECIION IX. SPECIAL PRECAUTIONS

Storage segregation: Store in a cool, dry, well-ventilated place in closed containers away fros 1 ire hazards. High tenperature ( $700^{\circ} \mathrm{C}$ ) or intense UV light can deconpose perchloroethylene to toxic and corrosive aterials. Snoking, open flane, welding, etc. should not be permitted in area of use or storage.

Other precautions: It is reconended that workers with blood pregsure, heart, livf:, kidney or pulnonary probleas, with nervous systen disorders, with excessive obesity, or with alcohol consunption problens should not work in proxinity to this or other chlorinated solvents.

One study has indicated possible teratogenic effects. NIOSH has reconended that this aterial be handled as if it were a hunan carcinosen. (Current Intelligence

Bulletin No. 20, 1978$)$

Data source $\operatorname{code}(8): 1-9,12,21 . \quad N$

Judgersnts as to the suitability of infornation herein for purchaser's purposes are necessarily purchaser's responsibility. Therefore, al though reasonable care has been taken in the preparation of such information, Geniun Publishing Corporation extends no warranties, gakes no representations and assunes no responsibility as to the accuracy or suitability of auch inforation for application to purchaser s intended purposes or for the consequences of its use. 


\section{Material safetr Data shet}

Geniu Publishing Corporation

1145 Catalyn Street Schenectady, NY 12303 (518) 377-8854

Froe Geniun's collection, to be used as reference
Product: TRICHLOROETHYLENE

MSDS No: Geniuv / 312

Revision: E

Date: August, 1987
National Paint and Costings Association

Hazardous Material Identification Systen

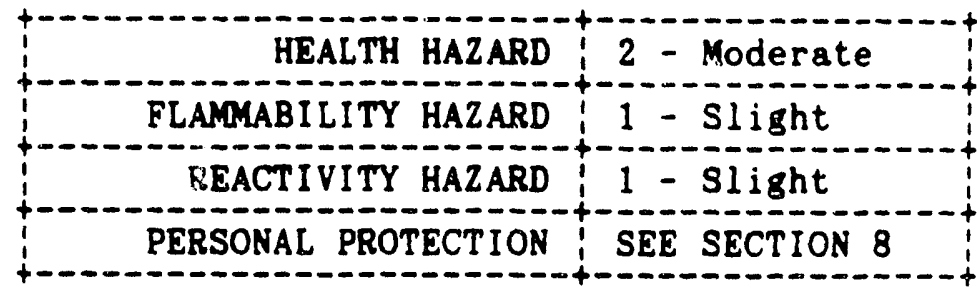

Trade/Material Nase: TRICHLOROETHYLENE

Description: Prepared fron syn-tetrachloroethane by way of elininating HCl by boiling with lime. Used to manufacture organic chemicals, pharnaceuticals; in degreasing and dry cleaning; and as a solvent for lats, waxes, rubbers, oils, paints, varnishes, ethers, and cellulose esters.

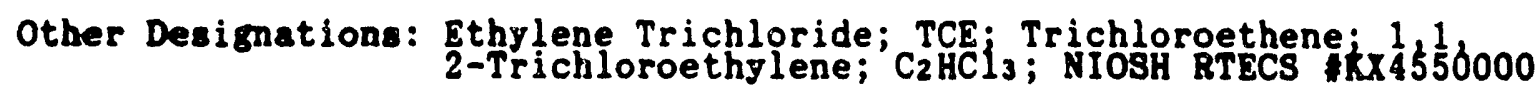

CAS: $0079-01-6$

$\begin{array}{ll}R & 1 \\ \text { I } & 3 \\ \text { S } & 1 \\ \text { K } & 0\end{array}$

COMGNTS: Trichloroethylene is a toxic solvent and a suspected occupational carcinogen.

Available fron several suppliers, including:

Manulacturer: Dow Chenical USA

2020 Dow Center

Midiand, MI 48640

Phone: $\left(\begin{array}{l}517 \\ 58-636-1000 ;(800)\end{array}\right.$

\section{SECTIOI II. INGREDIENTS AND HAZARDS}

Ingredient Nan:

Trichloroethrlono
CAS Nunber:

0079-01-6
Percent: Bxposure Linits:

100
ACGIH Values 1987-88

TLV-TWA*; 50 Ppa, 270 ax/m

TLV-STEL**: $200 \mathrm{ppa}$, $1080 \mathrm{ag} / \mathrm{a}^{3}$ 
Geniua Publishing Corporation

1145 Catalyn street Schenectady, NY (518) 377-8854

Frod Geniun's collection, to be used as reference
Product: TRICHLOROETHYLENE

MSDS No: Geniun / 312

Revision: E

Date: August, 1987 INGREDIENTS AND HAZARDS continued fron page 1

\section{NIOSH RTECS $\$ K \times 4550000$}

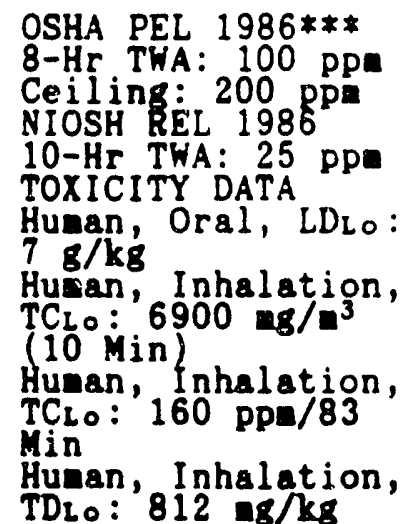

* The TLV-TWA is set to control subjective conplaints such as headache, fatigue, and irritability.

** The TLV-STEL is set to prevent incoordination and other beginning anesthetic effects fron trichloroethylene. These levels should provide a wide argin of safety in preventing liver injury.

*** The OSHA PEL is 300 ppa for 5 ainutes in any 2 hours.

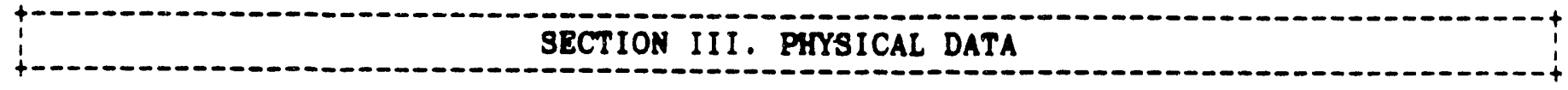

Appearance Odor: Colorless, nonflanable nobile liquid; sweetish odor like chlorofore.

Bolling point: $188.60 \mathrm{P}(870 \mathrm{C}) \quad(200 \mathrm{C})$ Specific Evaporation rate: Not Listed Nater solubility (ह): Insoluble Vapor denaitj (alre1): 4.53

Bvaporation rate: Not listed (200 C) Specific sravity $\left(\mathrm{H}_{2} \mathrm{O}=1\right): 1.4649$ at $)$

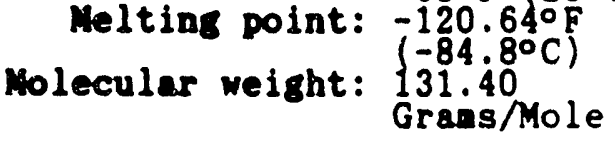

COMENTS: Trichloroethylene is highly soluble in lipids. A high vapor pressure at roon teaperature provides the potential for trichloroethylene vapors to contaninate use areas. 
Genius Publiahing Corporation

1145 Catalyn street, Schenectady, NY (518) 377-8854

Froe Genius's collection, to be used as reference
Product: IRICHLOROETHYLENE

MSDS No: Geniun / 312

Revision: $E$

Date: August, 1987

SECTION IV. FIRE AND EXPLOSION DATA

Flash Point (wethod): Not Listed

Liaits: LEL $\mathrm{x}: 8$

UBL $x: 10.5$

Extinguishing Media: Trichloroethylene has no flash point in a conventional closed tester at roon temperature, but it is aderately flanable at higher temperatures. Use dry

chenical, carbon dioxide alcohol poan, or other

extinguishing -gents suitable for the surrounding $f$ ire.

OSHA Planability Class (29 CFR 1910.106): Not Regulated

Unuaual fire or explosion hasards: During fire conditions trichloroethylene enita highly toxic and irritating funes, including hydrochloric acid and phosgene.

Special lire-lighting procedures: Wear a self-contained breathing apparatus with a full facepiece operated in a pressure-denand or another positive-pressure code. At trichloroethylene vapor levels of $300-1000 \mathrm{ppa}$, fire fighters who lack the proper respiratory equipment nay experience incoordination and impaired judgnent.

DOT Flanability Class (49 CFR 173.115): Not Regulated

SECTION V. REACTIVITY DATA

Material is stable Hazardols polynerization can occur under certain cifcunstances (see Conditions to Avoid and Coments, below).

Chenical inconpatibilities: Include nagnesiup or aluninun powder, NaOH, KOH, or other strong alkal ine naterials. Reactions with alkaline naterials may lead to the foration of dangerous explosive aixtures of chloroacetylenes.

Conditions to avoid: When trichloroethylene is beated (as in the case with vapor degreasers) or exposed to sunlight, it requires extra atabilization against oxidation, degradation, and polyerization. It is slowly deconposed by light when wist.

Hasardous decomosition Probata: Include hydrochloric acid and phosgene under certain conditions at elevated teaperatures.

COManTs: Trichloroetbjlene is stable under noraal handling and storage conditions, and hazardous poljerisation is not expected to occur. However, failure of the stabilizer at levated teaporatures or other extrene conditions ay allow

polymerization to occur. 
Geniun Publiahing Corporation

1145 Catalyn streat, Schenectady, NY (518) 377-8854

Froa Geniun's collection, to be used as reference
Product: TriICHLOROETHYLENE

MSDS No: Geniun / 312

Bevision: E

Date: August, 1987

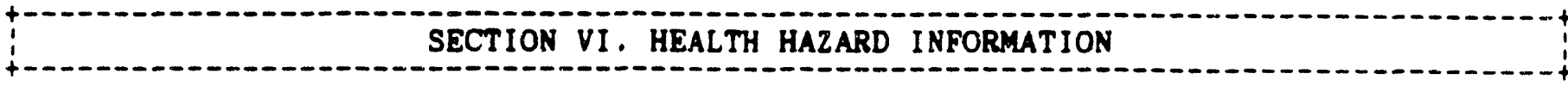

This product is considered 6 carcinogen by the NTP, IARC, and OSHA.**

Sunary of risks: Moderate exposures to trichloroethylene cause syaptons siailar to those of alcohol inebriation. Higher concentrations cause narcotic effects.

Ventricular fibrillation has been cited as the cause of death following heavy

exposures. Trichloroethylene-induced hepato cellular carcinoaas have been detected in eice during tests conducted by the National Cancer Institute (Chen Eng News 54

[April 5, (976]:4). Organ systens affected by overexposure to trichloroethylene are the central nervous systea (euphoria, analgesia, anesthesia), degeneration of the liver and kidneys, the lungs (tachypnea), heart (arrhythia) and \&kin (irritation, vesication, and paralysis of (ingers when innersed in liquid trichloroethylene). Contact with the liquid defats the skin, causing topical deratitis. Certain people appear to experience synergistic effects fron trichloroethylene exposure conconitant with exposure to caffeine, alcohol, and other drugs. *\$

Medical condition uhich ay be assravated by contact: Diseases of the liver, kidneys, lunge, and central nervous ojsten.

Target organs: Respiratory systen, central nervous systen, heart, liver, kidneys, and skin.

Priaary entry route(a): Ingestion, inhalation, skin contact.

Acute effects: Headache, vertigo, visual disturbance, tresors, nausea, voniting, derastitis, dizziness, drowsiness, and irritation to the eyes, nose, and throat.

Chronic effect(s): None Beported

Pirst aid:

Bye contact: Inediately plush eyes, including under the eyelids gently but thoroughly with plenty of running water for at least 15 inutes. Get sedical help.

Skin contact: Wanh thoroughly with soap and water. Resove and launder contaninated clothing before wearing it againj clean eterial Irom shoes and equipaent. Get nedical help.*

Inhalation Reore victin to fresh air; restore and/or support his breathing needed. Do not give adrenal in to the vietia. cot nedical help.

Ingestion: Call a polion control center. Never give anything by couth to sonenne who is unconscious or convulsing. $A$ prolessional decision regarding whether or not to induce voaiting is required. Do not give adrenalin to the victia. Get nedical help.

* GET MEDICAL ASSISTANCE = IN PLANT, PARAMEDIC, COMUNITY. Get proppt nedical assistance for further treatment, observation, and support af ter first aid. 
Geniun Publishing Corporation 1145 Catalyn street) Schenectady, NY
12303

eference
Product: TRICHLOROETHYLENE

MSDS No: Geniun / 312

Revision: E

Date: August, 1987

HEALTH HAZARD INFORMATION cont inued fron page 4

** NIOSH reconnends that trichloroethylene be treated as an occupational carcinogen. IARC carcinogenic results are anial suspect, anial positive, and huan indefinite.

*** When coabined with alcohol intake, toxic effects are increased and nay cause a red, blotchy facial and upper body rash cononly called "degreaser's flush. "Other reported symptons of trichloroethylene exposure include abnoreal fatigue headache, irritability, gastric disturbances, and intolerance to alcohol. Toxic eflects fros testing of trichloroethylene on humans include hallucination, distorted perception, soanolence (general depressed activity), and jaundice.

COMANTS: See Section 9 Coments

Spill / Leak procedures: Infora safety personnel of any trichloroethylene spill or leak and evacuate the area for large spills. Cleanup personnel nust use respiratory and 1 iquid contact protection. Adequate ventilation nust be provided. Confine the spilled trichloroethylene to as snall an area as possible. Do not allow it to run of to sewers or open waterways. Pick up spilled trichloroethylene with a vacuu cleaner or an absorbent such as veraiculite.

Haste managesent / Disposal: Consider reclamation, recycling, or destruction rather than disposel in a landfill.

Trichloroethylene is designated as a hazardous substance by the EPA (40 CRR 116.4). Trichloroethylene is reported in the 1983 BPA TSCA Inventory.

EPA Hazardous Waste Nuaber (40 CPR 261.33): U228

EPA Reportable Quantity (40 CFB 117.3): 1000 lbs (454 kgs)

Aquatic Toxicity Bating, TLa 96: Not Listed

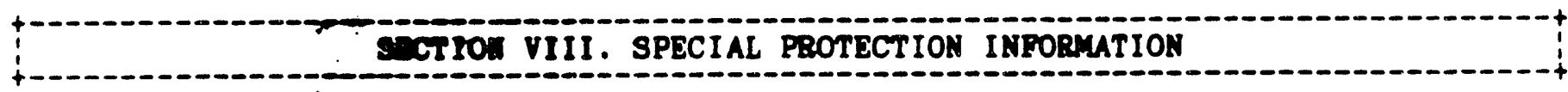

Personal protoctive egipipart:

Gosslea: Alware war protective eyeglasseg cr chenical safety gogfles. Follow the eje- and lace-protection suidelines of 29 CFR 1910.133 .

Gloves: Hear inpervious gloves. 
Geniun Publishing Corporation

1145 Catalyn Street, Schenectady, NY (518) $377-8854$

Fron Geniun's collection, to be used as eference
Product: TRICHLOROETHYLENE

MSDS Nc: Geniue / 312

Revision: $E$

Date: August, 1987

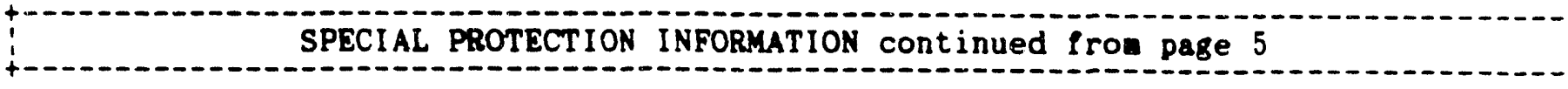

Respirator: Use a NIOSH-approved respirator per the NIOSH Guide to Chenical Hazards (Geniun ref. 88) for the naximu-use concentrations and 70 r the exposure linits cited in section 2. Follow the respirator guidelines in 29 CFR 1910.134. Ang detectable concentration of trichloroethylene requires an SCBA, full facepiece, and pressure-deficient atmospheres.

Other: Wear rubber boots, aprons, and other suitable body protection appropriate to the existing work environnent.

Workplace considerations:

Ventilation: Install and operate general and local exhaust ventilation systens of sufficient power to aintain airborne concentrations of trichlr roethylene below the OSHA PEL standards cited in section 2.

Safety stations:

Make eyewash stations, washing facilities, and safety showers available in areas of use and handling.

Contaninated equipaent:

Cotnact lenses pose a special hazard; soft lenses nay absorb irritante and all lenses concentrate thea.

Other: Because of the unresolved controversy about the carcinogenic status of trichloroethylene, all existing personal protective equipaent and engineering technology should be used to prevent any prssibility of worker contact with this naterial.

COMWENTS: Practice good personal hygiene. Keep naterial off of your clothes and equipeent. Avoid transfer of naterial from hands to mouth while eating drinking or snoking. Adhere to the sanitation requirements of $29 \mathrm{CFR} 1910.141$ and 29 CFR 1910.142.

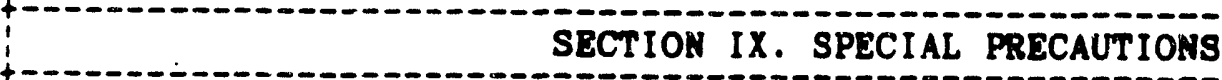

Storage segregation: Prevent trichloroethylene fron coning into contact with strong caustes such as NaOH; $\mathrm{KOH}$; chenically active netal like Ba, $\mathrm{L}_{i}$,

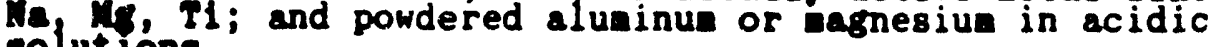
colutions.

Special handling / etorase: Store this aterial in a cool, dry, well-ventilated area. Avoid elevated teperaturea because products of toxic and corrosive deconposition from trichloroethylene na fora. Monitor the level of any stabilizer conponent that ay be added to the trichloroethylene. (Consult the technical data fron the supplier to deterpine the specifics of any added stabilizer.) If applicable follow the supplier's reconendation concerning proper rotation of stork, shelp-life requirenents, and levels of stabilizers.

Bngineering controls: Avoid collecting aluninue fines (very sall particles) or chips in a trichloroethylene vapor degresser. Monitor trichloroethylene stabilizer levels 
Geniun Publishing Corporation

1145 Catalym Street, Schenectady, NY 12303 (518) $377-8854$

From Geniun's collection, to be used as reference
Product: TRICHLOROETHYLENE

MSDS No: Genius / 312

Revision: E

Date: August, 1987

SPECIAL PRECAUTIONS continued fron page 6

regularly. Only trained personnel should operate vapor degreasers.

COMENTS: (Conents fron Section 6) Workers' responses to trichloroethylene vary significantly because of any factors, including age, heslth status, nutrition, and intake of alcohol, caffeine, and medicines. Do not use these substances before, during, or after exposure to trichloroethylene. If a worker displays any of the syaptons of exposure to trichloroethylene, thoroughly investigate all the possible contributing factors to determine, il possible, how auch the work environnent levels of trichloroethylene are responsible.

TRANSPORTATION DATA (per 49 CFR 172.101-2):

IMO Class: 6.1

IMO Label: St. Andrew's Cross $(X) *$

DOT Shipping Nane: Trichloroethylene

DOT Label: None

* Harmful - Stow away frov foodstuffs (IMO Label, Materials of Class 6.1 Packaging Group (II).

DOT Class: ORPI-A

Date source code (s): $1-9,12,14,21,73$, Un Resiater: UN1710

Prepared/revised by: Geniun Publishing Corporation

August, 1987

Judgenents as to the suitabilitg of inforwation herein for purchaser's purposes are necessarily purcheser's responsibility. Therefore, al though reasonable care has been taken in the preparation of such information Geniun Publishing corporation extends no warranties, aakes no representations and assuses no responsibility as to the accuracy or suitability of such inforaation for application to purchaser 8 intended purposes or for the consequences of its use.

Pase 7 ---

End of MSDS 312 


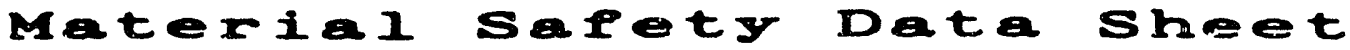

\section{Geniun Publishing Corporation 1145 Catalyn Street) Schenectady, NY 12303 \\ Fron Geniun's collection, to be used as reference \\ Product: TOLUENE \\ MSDS No: Geniun / 317 \\ Revision: D \\ Date: April, 1986}

National Paint and Coatings Association

Hazardous Material Identification System

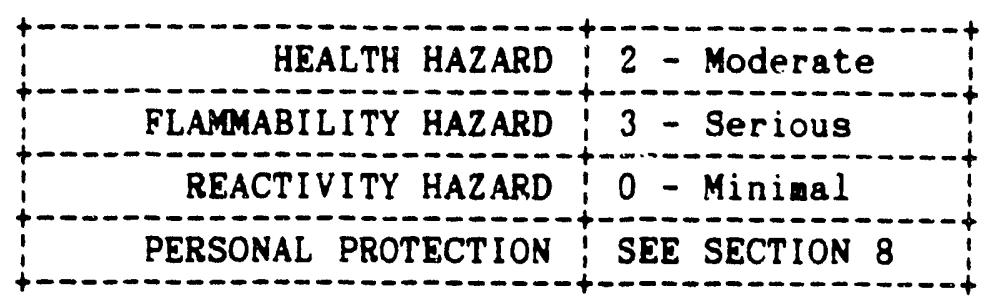

l'rade/Material Nase: TOLUENE

Other Designations: Methyl Benzene, Methyl Benzol, Phenylaethane, Toluol, $\mathrm{C}_{7} \mathrm{H}_{8}$ CAS: $0108-88-3$

Available fron any suppliers, including:

Manufacturers: Allied Corp. Morristown, NJ 07960

Phone: (201) 455-4400

Ashland Chenical Co. Industrial Cheaicals \& Solvents Div. PO Box 2219 Columbus, OH 43216

Phone: (614) 889-3844 i

Ingredient Nane:

Toluene
Percent: Exposure Linits:

ca 100

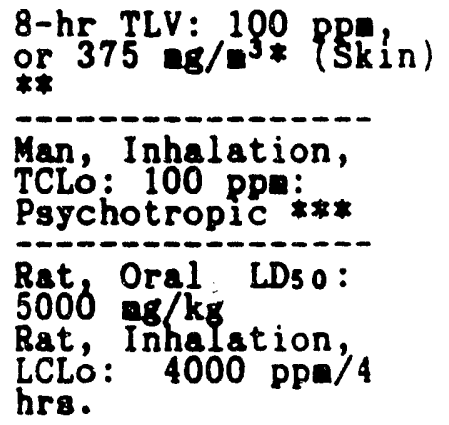


Geniun Publishing Corporation

1145 Catalyn Street Schenectsdy, NY 12303 (518) $377-8854$

From Geniun's collection, to be used as reference
Product: TOLUENB

MSDS No: Geniuv / 317

Revision: D

Date: April, 1986

INGREDIENTS AND HAZARDS continued froa פage 1

\begin{tabular}{l} 
Rabbit $\mathrm{Skin}$ \\
LD50: $14 \mathrm{gm} / \mathrm{kg}_{\mathrm{g}}$ \\
\hline Human, Eye: $300 \mathrm{ppm}$
\end{tabular}

* Current (1985-86) ACGIH TLV. The OSHA PEL is 200 ppe with an acceptable ceiling concentration of $300 \mathrm{ppm}$ and an acceptable aximua peak of $500 \mathrm{ppm} / 10$ ainutes.

** Skin designation indicates that toluene can be absorbed through intact skin and contribute to overall exposure.

*** Affects the aind.

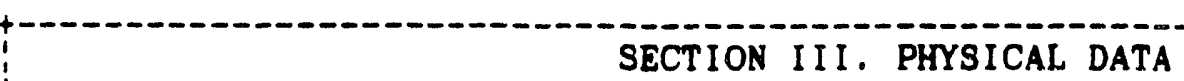

Appearence Odor: Clear, colorless liquid with a characteristic aronatic odor. The odor is detectable to nost individuals in the range of 10 to $15 \mathrm{ppn}$. Because olfactory fatigue occurs rapidly upon exposure to toluene, odor is not a good warning property.

Boiling point: $231^{\circ} \mathrm{F}\left(111^{\circ} \mathrm{C}\right)$

vapor pressure: $20^{\circ} \mathrm{C}$, an Hg: 2

Water solubility $(x):$ e 200 C, wt.x: 0.05

Vapor density $(a p=1): 3.14$

Evaporation rate: (BuAc=1): 2.24 Specilic gravity $\left(\mathrm{H}_{2} \mathrm{O}=1\right): 0.866$

Melting point: $-139 \circ \mathrm{F}\left(-95^{\circ} \mathrm{C}\right)$

$\%$ volatile by voluee: ca 100

Molecular weight: 92.15

SECTION IV. FIRE AND EXPLOSION DATA

Plash Point (nethod): $400 \mathrm{~F}\left(4^{\circ} \mathrm{C}\right) \mathrm{CC}$ Linits: LBL $\mathrm{X}: 1.27$

Extinguishing Media: Carbon dioxide, dry chenical, alcohol

foan. Do not use a solid trean of water because the strean

will scatter and aprand the IIre. Use water spray to cool

tanks/containers that are expased to fire and to disperse

vapors.

Unuaual lire or explonion hasards: This OSHA class IB flannable liquid is a dangerous fire hazard. It is a moderate fire hazard when exposed to oxidizers, heat sparks, or open flane. Vapors are heavier than air and may travel a considerable distance to an ignition source and flash back.

Special fire-fighting procedures: Fire fighters should wear gelf-contained breathing apparatus with full facepiece operated in 8 positive-pressure oode when fighting fires inyolving toluene.

Page 2 ---
UEL $8: 7.1$

Autoignition Teap: $896^{\circ} \mathrm{F}\left(480^{\circ} \mathrm{C}\right)$ 
Geniun Publishing Corporation

1145 Catalyn Street, Schenectady, NY (518) $377-8854$

Fron Geniun's collection, to be used as reference
Product: TOLUENE

MSDS No: Geniun / 317

Revision: D

Date: April, 1986

SECTION V. REACTIVITY DATA

Material is stable in closed containers at room temperature under normal storage and handling conditions. Hazardous polymerization does not occur

Cheaical incompatibilities: This aterial is inconpatiblewith strong oxidizing agents, dinitrogen tetraoxide, silver perchlorate, tetranitronethane, and uranium hexafluoride. Contact with these aterials ay cause fire or explosion. Nitric acid and toluene, especially in the presence of sulfuric acid, will produce nitrated conpounds that are dangerously explosive.

Conditions to avoid: Avoid exposure to sparks, open flane, hot surfaces, and all sources of heat and ignition. Toluene will attack sone forns of plastics, rubber, and coatings. Thermal deconposition or burning produces carbon dioxide and/or carbon monoxide.

SECTION VI. HEALTH HAZARD INFORMATION

This product is not considered a carcinogen by the NTP, IARC, or OSHA.

Sunnary of rigks: Vapors of toluene ay cause irritation of the eyes, nose, upper respiratory tract, and skin. Exposure to $200 \mathrm{pp}$ for 8 hours causes ild fatigue, weakness, confusion, lacriation (tearing), and paresthesia (a sensation of prickling, tingling, or creeping on the skin that has no objective cause). Exposure to higher concentrations ay cause headache, nausea, dizziness, dilated pupils, and euphoria, and, in severe cases, nay cause unconsciousness and death. The liquid is irritating to the eyes and skin. Contact with the eyes may cause transient correal danage, conjunctival irritation, and burns if not pronptly reaced. Repeated and/or prolonged contact with the skin aay cause drying and cracking. It nay be absorbed through the skin in toxic anounts. Ingestion causes irritation of the gastrointestinal tract and way cause effects reseabling those frou inhalation of the vapor. Chronic overexposure to toluene ay cause reversible kidney and liver injury.

Birst aid:

Eye contact: Inediately flush eyes, including under eyelids, with running water for at least 15 inutes. Get nedical attention if irritation persists.*

Skin contact: Inediately flush skin (for at least 15 ninutes) while resoving contaninated shoes and clothing. Wash exposed area $\mathrm{kith}$ soap and water. Get aedical attention if irritation persists or if a large area has been exposed.

Inhalation: Remove victiv to fresh air. Restore and/or support breathing as required. Reep victin warn and quiet. Get aedical help.* 
Material Safety Data Sheet

Geniun Publi, hing Corporation

1145 Catalyn Street Schenectady, NY 12303 (518) $377-8854$
Product: TOLUENE

MSDS No: Geniu / 317

Revision: D

Date: April, 1986

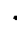 \\ 1 \\ HEALTH HAZARD INFORMATION continued fron page 3 \\ Ingestion: Give victin 1 th 2 glasses of water or ilk. Contact a poison control center. Do not induce voniting unless directed to do so. Transport victia to aedical \\ facility. Never give anything by wouth to a person who is uncollscious or convulsing. \\ * GET MEDICAL ASSISTANCE = In plant, paramedic, comunity. Get nedical help for further treatment, observation, and support after first aid, if indicated.}

SECTION VII. SPILL, LEAK ANI DISPOSAL PROCEDURES

Spill / Leak procedures: Notify safety personnel of large spills or leaks. Renove all sources of heat and ignition. Provide maximun explosion-proof ventilation. Ligit access to spill area to necessary personnel only. Renove leaking containers to safe place if feasible. Cleanup personnel need protection against contact with liquid and inhalation of vapor ( 3 ee sect. 8).

Naste aanagenent / Disposal: Absorb saall spills with paper towel or verniculite. Contain large spills and collect if feasible, or absorb with veraiculite or sand. Place waste solvent or absorbent into closed containers for disposal using nonsparking tools. Liquid can be flushed with water to an open holding area for handling. Do not flush to sewer, watershed, or waterway.

Place in suitable container for disposal by a licensed contractor or burn in an approved incinerator. Consider reclaiaing by distillation. Containated absorbent can be buried in a sanitary landfill. Follow all Federal, state, and local regulations. TLa 96: 100-10 ppa. Toluene is designated as a hazardous waste by the EPA. The EPA (RCRA) HW No. is U 220 (40 CFR 261). The reportable quantity (RQ) is $1000 \mathrm{ibs} / 454 \mathrm{~kg}$ (40 CFR 117).

SECTION VIII. SPECIAL PROTECTION INFORMATION

\section{Personal protective equireant:}

Gogfles: Safety glasses or gplash goggles should be worn in all work areas.

Glores: Neoprene gloves should be worn.

Respirator: For emergency or nonroutine exposures where the TLV aay be exceeded, use on organic chenical cartridge respirator if concentration is less than $200 \mathrm{pp}$ and an approved canister gas mask or self-contained breathing apparatus with full facepiece if concentration is greater than 200 ppa. 
Geniun Publishing Corporation

1145 Catalyn Street, Schenectady, NY (518) $377-8854$

Fron Geniun's collection, to be used as reference
Product: TOLUENE

MSDS No: Geniue / 317

Revision: D

Date: April, 1986

\section{SPECIAL PROTECTION INFORMATION continued from page 4}

Other: Apron, face shield, boots, and other appropriate protective clothing and equipaent should be available and worn as necessary to prevent skin and eye contact.

Renove contaminated clothing imediately and do not wear it until it has been properly laundered.

Horkplace considerations:

Ventilation: Provide general and local exhaust ventilation to meet TLV requireaents. Ventilation fans and other electrical service nust be nonsparking and have an explosion-proof design. Exhaust hoods should have a face velocity of at least 100 lfa (linear feet per ainute) and be designed to capture heavy vapor.

Safety atations:

Eyewash stations and safety shcwers should be readily available in use and harld ing areas.

Contact lenses pose a special hazard; soft lenses nay absorb irritants and all lenses concentrate the

Storage segregation: Store in a cool, dry, well-ventilated area away from oxidizing agents, heat, sparks, or open llane. Storage areas aust neet oshA requirenents for class IB flanable liquids. Use netal safety cans for handling snall anounts. Protect containers fró physical danage. Use only with adequate ventilation. Avoid contact with eyes, skin, or clothing. Do not inhale or ingest. Use caution when handling this coppound because it can be absorbed through intact skin in toxic anounts.

Special handling / storage: Ground and bond netal containers and equipent to prevent static sparks when aaking transfers. Do not seoke in use or storage areas. Use nonsparking tools.

Engineerins controla: Preplacesent and periodic sedical exans enphasizing the liver kidneys, nervous ajaten, lungs, heart, and blood should be provided. Workers exposed to concentratione reater than the action level ( $50 \mathrm{pp}$ ) should be exanined at least once a year. Use of alcohol can agsravate the toxic elfects of toluene.

Eaptied containere contain product residues. Handle accordingly! Toluene is designated as a hasardous substance by the EPA (40 CFR 116).

DOT Class: Planable Liguid UN Rerister: UN1294

Data source code $($ ) $): 1-9,12,16,20,21,24,26,34,81,82$. CR

Prepared/revised by: Geniun Pubishing Corp. 
Geniue Publishing Corporation

1145 Catalyn Street, Schenectady, NY 12303 (518) $377-8854$

Fron Geniun's zollection, to be used as reference
Product: TOLUENE

MSDS No: Geniun / 317

Revision: D

Date: April, 1986

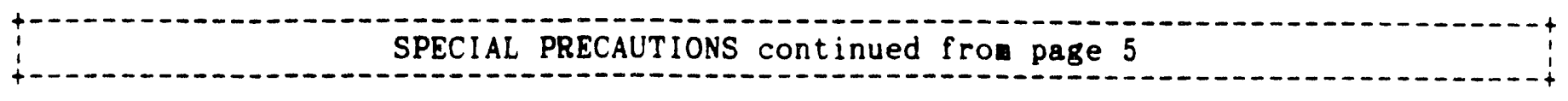

April, 1986

Judgenents as to the suitability of information herein for purchaser's purposes are necessarily purchaser's responsibility. Therefore, al though reasonable care has been taken in the preparation of such information Geniun Publishing corporation extends no warranties, aakes no representations and assuaes no responsibility as to the accuracy or suitability of such inforaation for application to purchaser's intended purposes or for the consequences of its use. 


\section{Tritium $\left({ }^{3} \mathrm{H}\right)$}

\section{Half-Life:}

Physical: 12.3 years.

Biological: $\sim 10$ days (range: $4-18$ ) total body for HTO.

Special Chemical and Biological Characcteristics: Not selectively concentrated in any organ.

Metabolized as $\mathrm{H}_{2} \mathrm{O}$. Tritium is assumed to be readily and conipletely absorbed by the body and to be distributed evenly throughout the body.

Principal Human Metabolic and Dosimetric Parameters:

$f_{1}=1.0$.

ALl $(\mu \mathrm{Ci})=8.1 \times 10^{4}(\mathrm{HTO})$.

$\operatorname{DAC}\left(\mu \mathrm{Ci} / \mathrm{cm}^{3}\right)=2.2 \times 10^{7}(\mathrm{HTO})$. 
Trade/Material Nane: XYLENE (MIXED ISOMERS)

Other Designations: Xylol, Disethylbenzene, $\mathrm{C}_{6} \mathrm{H}_{4}\left(\mathrm{CH}_{3}\right)_{2}$; ASTM D843, D845 AND D846; GE Material D5B9

CAS: 001330207

Available fron many suppliers, including: EXXON Conpany USA and Shell Cheaical Conpany.

SECTION II. INGREDIENTS AND HAZARDS

Insredient Nane:

Xylene $(0, m, p$-isoners)

$C_{7}$ to C9 Hydrocarbons*
Percent: Bxposure Linits:

$>90$

$<10$

8-hr THA $100 \mathrm{ppo}$
(skin)\$*
or $435 \mathrm{gs} / \mathrm{m}^{3}$
Xylene Typical

hylene Troical
Hupan: Inhalation TCLo 200 ppa (Irritation Effects)

Rat: Oral

LDso $4.3 \mathrm{~g} / \mathrm{kg}$

Hupan: Oral LDLo $50 \mathrm{mg} / \mathrm{kg}$

* Materisl ay contain ethylbenzene (8-hr TWA $100 \mathrm{ppa}$ ) traces of toluene, and Ca aronat ic aliphatic hydrocarbons. Sope connercial products an contain over $10 x$ non-xylene hydrocarbons, costly ethrlbenzene. * Current OSHA standard and ACGIH 1980) TLV. NIOSH has proposed a 10-hr TWA of 100 ppe with a 200 ppa ceilink level (10 ain. ganple). STATUS: NCI bioassay for Carcinosenesis study 9/78. ILV set to prevent irritant effects and CNS depreamion.

Appearance Odos: Lipht colored or colorless gobile liquid with an aronatic odor. The focolion threahold (100\% of test panel) is about $0.3 \mathrm{ppa}$ in ar (unfatisued) for $x y$ lene.

Boiline point: $135-145^{\circ} \mathrm{C}, 1$ ate vapor preasyre: ca $6 \mathrm{C}^{2} 0^{\circ} \mathrm{C}$, in $\mathrm{H}$ Vapor density $\left(\begin{array}{ll}\text { Nater } \\ \text { vapor }\end{array}\right)$ : Regligible
Traporation rate: 0.6 (BuAc=1) Spacilic ereity $\left(\mathrm{H}_{2} \mathrm{O}=1\right): 0.86-0.87$ Molecular weicht: 106.18 
Geniun Publishing Corporation

1145 Catalyn street Schenectady, NY (518) 377-8854

Frod Geniun's collection, to be used as reference
Product: XYLENE (MIXED ISOMERS)

MSDS No: Geniun / 318

Revision: C

Date: Noveaber, 1980

PHYSICAL DATA continued fron page 1

- Wider and narrower boiling range uaterials are conercially available.

SECTION IV. PIRE AND EXPLOSION DATA

Flash Point (nethod): $>77 \circ \mathrm{F}$ ( $\mathrm{TCC}$ )

Liaits: LEL 8: 1

Extinguishing Media: Use dry chenical, foan, $\mathrm{CO}_{2}$ and water fog or stean to provide a gaothering effect on lire. A used to cool pire-exposed containers.

Unusual fire or explosion hasarda: This planable liquid is a dangerous fire hasard and a eoderate explosion hassrd when exposed to heat or planes. Heavier-than-air vapors can flow along surfaces to distant ignition sources and llash back.

Special fire-fighting procedures: Firefighters should use self-contained bresthing apparatus.
Autoignition Teep:
$8670 \mathrm{p}$ SECTION V. REACTIVITY DATA

Material is stable in closed containers at roon teaperature. Hacardous polgnerization cannot occur

Conditione to aroid: It is flanable (OSHA Clase IC liquid) and can fora explosive ixturea with air. Keep away lros sources of heat, sources of ignition and strons oxidizing asents.

Theraal-oxidative degradation in air can produce toxic vapors and gases, including carbon monoxide and oxides of nitrogen.

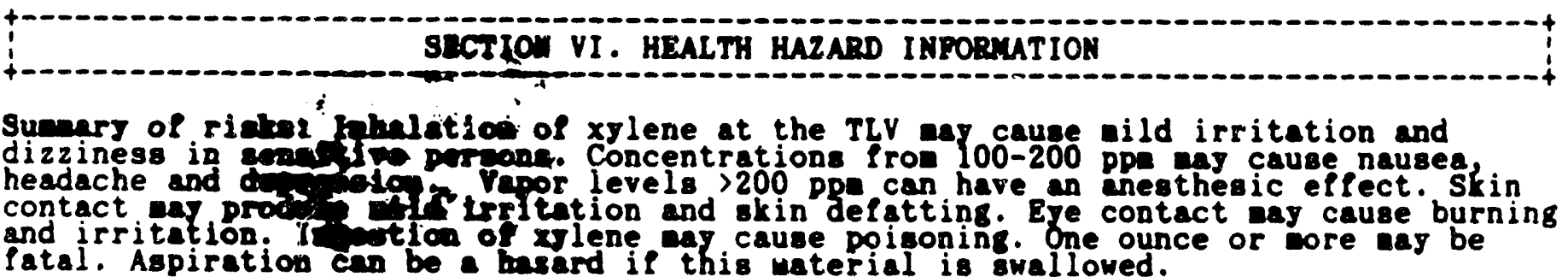

fatal. Aspiratios can be a mard if this uaterial is awallowed. 
Geniun Publishing Corporation

1145 Catalyn street, Schenectady, NY (518) $377-8854$

From Geniun's collection, to be used as reference
Product: XYLENE (MIXED ISOMERS)

MSDS No: Geniun / 318

Revision: C

Date: Novenber, 1980

HEALTH HAZARD INFORMATION continued fron page 2

Pirst aid:

Eje contact: Irrigate with water for 15 ninutes. Get nedical attention!

Skin contact: Wash with soap and water. Rewove contaninated clothing prouptly. Replace lost skin oils with approved lotions or creans.

Inhalation: Resove victin to fresh air. Restore breathing if required. Get nedical attention if syaptons persist or if nausea or collapse has occurred.

Ingeation: Get medical attention innediately! Give white mineral oil denulcent and saline cathartic, but do not induce voniting unless directed by a physician.

Maintain observation of patient for possible delayed onset of pulsonary edeas. SECTION VII. SPILL, LEAK AND DISPOSAL PROCEDURES

Spill / Leak procedures: Notify safety personnel. Renove all ignition sources. Provide adequate ventilation. Use veraiculite or sand to absorb spill; scrape up with nonsparking tools and place in a covered netal container. The absorbed waterial ay be burned in an open pit, or placed in cardboard boxes and burned in an incinerator. Spilled liquid can be flushed away from sensitive locations with a water strean;

Waste manegenent / Dispowal: Scrap liquid nay be atonired into an approved incinerator, or it may be disposed of via a licensed solvent diaposal conpany. When large asounts are involved reclaipation procedures nay prove econonical. Follow Pederal, State, and Local regulations.

AQUATIC TOXICITY rating TL 96: 100-10 ppa.

\section{SOTION VMI. SPECIAL PROTECTION INPORMATION}

Personal protectly tralpar.

Gossles: Sefta gianses or gossles should be used for eje protection.

Gloves: Buna-N rubber gloves should be worn to prevent contact of $x y$ lene with the skin. 
Material Safety Data Sheet

Geniua Publishing Corporation

1145 Catalyn Street, Schenectsdy, NY 12303 (518) 377-8854

Fron Geniun's collection, to be used as reference
Product: XYLENE (MIXED ISOMERS)

MSDS No: Geniun / 318

Revision: $C$

Date: Noveaber, 1980

\section{SPECIAL PROTECTION INFOR : ION continued froe page 3}

Bespirator: Use approved organic vapor canister respirators for short periods of nonrout ine work or energency situations at up to $1000-2000 \mathrm{ppa}$ and approved self-contained respirators for higher and unknown vapor levels. Full facepiece required.

Other: Aprons should be used.

Workplace considerations:

Ventilation: Provide general ventilation and efficient exhaust ventilation (explosion-proof equipaent) to neet TLV requirenents and to control heavier-than-air vapors. Use $>100$ if lace velocity for exhaust hoods.

Conprehensive preplacement and biennial medical exaninations to be directed toward, but not lieited to, liver, kidney, gastrointestinal disorders, skin irritation, and the central nervous system.

Eyewash stations should be readily available to use areas.

i SECTION IX. SPECIAL PRECAUTIONS

Storage segregation: Store in closed containers in a clean, cool, well-ventilated area, away fros sources of heat sources of ignition and strong oxidizing agents. Protect containers $\rho$ ron physical danage. Bond and ground aetal containers when transferring liquid. Use netal safety cans for snall asounts. Use nonsparking tools for work in solvent area. No snoking in areas of use or storage.

Otber precautions: Prevent skin contact and renove contaninated clothing pronptly. Avoid repeated or prolonged breathing of vapor. Do not ingest?

Data source code( $(a): 1-12,19-21,23,26,31,34,37-39 . \quad$ N

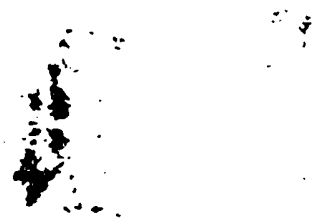

Judgenents as to the suitability of information herein for purchaser's purposes are necessarily purchaser's responsibility. Therefore, although reasonable care has been taken in the preparation of such information Geniun Publishing corporation extends no warranties, akes no representations and ssunes no responsibility as to the accuracy or suitability of such inforastion for application to purchaser's intended purposes or for the consequences of its use. 


\section{Appendix D \\ Trench and Excavation Safety}


(2) Decks and other working surfaces shall be maintained in a safe condition.

(3) Employees shall not be permitted to pass fore and aft, over, or around deckloads, unless there is a safe passage.

(4) Employees shall not be permitted to walk over deckloads from rail to coaming unless there is a safe passage. If it is necessary to stand at the outboard or inboard edge of the deckload where less than 24 inches of bulwark. rail, coaming, or other protection exists, all employees shall be provided with a suitable means of protection against falling from the deckload.

(d) First-aid and lifesaving equipment. (1) Provisions for rendering first aid and medical assistance shall be in accordance with Subpart $D$ of this part.

(2) The employer shall ensure that there is in the vicinity of each barge in use at least one U.S. Coast Guard-approved 30-inch lifering with not less than 90 feet of line attached, and at least one portable or permanent ladder which will reach the top of the apron to the surface of the water. If the above equipment is not available at the pier, the employer shall furnish it during the time that he is working the barge.

(3) Employees walking or working on the unguarded decks of barges shall be protected with U.S. Coast Guard-approved work vests or buoyant vests.

(e) Commercial diving operations. Commercial diving operations shall be subject to Subpart $T$ of Part 1910. \$ \$ 1910.401-1910.441, of this chapter.

[39 T'R 22801. June 24, 1974, as amended at 42 FT 37674, July 22. 1977]

\section{1926.606 Definitions applicable to this subpart.}

(a) "Apron"-The area along the wa. terfront edge of the pler or wharf.

(b) "Bulwark"- The side of a ship above the upper deck.

(c) "Coaming"- The raised frame, as around a hatchway in the deck, to keep out water.

(d) "Jacob's ladder"-A marine ladder of rope or chain with wooden or metal rungs.

(e) "Rall", for the purpose of \$ 1926.605. means a light structure serving as a guard at the outer edge of a ship's deck.

Subpart P-Excevations, Trenching,
and Shoring

$\$ 1926.650$ General protection requirements.

(a) Walkways, runways, and sidewalks shall be kept clear of exca. vated material or other obstructions and no sidewalks shall be undermined unless shored to carry a minimum live load of one hundred and twenty-five (125) pounds per square foot.

(b) If planks are used for raised walkways, runways, or sidewalks, they shall be laid parallel to the length of the walk and fastened together against displacement.

(c) Planks shall be uniform in thickness and all exposed ends shall be pro. vided with beveled cleats to prevent tripping.

(d) Raised walkways, runways, and sidewalks shall be provided with plank steps on strong stringers. Ramps, used in lieu of steps, shall be provided with cleats to insure a safe walking surface.

(e) All employees shall be protected with personal protective equipment for the protection of the head, eyes, respiratory organs, hands, feet, and other parts of the body as set forth in Subpart E of this part.

(f) Employees exposed to vehicular traffic shall be provided with and shall be instructed to wear warning vests marked with or made of reflectorized or high visibility material.

(g) Inployees subjected to hazardous dusts, gases, fumes, mists, or stmospheres deficient in oxygen, shall be protected with approved respira. tory protection as set forth in Subpart $D$ of this part.

(h) No person shall be permitted under loads handled by power shovels. derricks, or holsts. To avold any spill. age employees shall be required to stand away from any vehicle being loaded.

(1) Daily inspections of excavations shall be made by a competent person. If evidence of possible cave-ins or slides is apparent, all work in the excavation shall cease until the necessary 
precautions have been taken to safeguard the employees.

\subsection{Specific excavation require- ments.}

(a) Prior to opening an excavation, effort shall be made to determine whether underground installations; i.e., sewer, telephone, water, fuel, electric lines, etc., will be encountered, and if so, where such underground installations are located. When the excavation approaches the estimated location of such an installation, the exact location shall be determined and when it is uncovered, proper supports shall be provided for the existing installation. Utility companies shall be contacted and advised of proposed work prior to the start of actual excavation.

(b) Trees, boulders, and other surface encumbrances, located so as to create a hazard to employees involved in excavation work or in the vicinity thereof at any time during operations, shall be removed or made safe before excavating is begun.

(c) The walls and faces of all excavations in which employees are exposed to danger from moving ground shall be guarded by a shoring system, sloping of the ground. or some other equivalent means.

(d) Excavations shall be inspected by a competent person after every rainstorm or other hazard-increasing occurrence, and the protection agsinst slides and cave-ins shall be increased if necessary.

(e) The determination of the angle of repose and design of the supporting system shall be based on careful evalu. ation of pertinent factors such as: Depth of cut; possible variation in water content of the material while the excavation is open: anticipated changes in materials from exposure to air, sun, water, or freezing; loading imposed by structures, equipment, overlying material, or stored material; and vibration from equipment, blasting. traffic, or other sources.

(f) Supporting systems; i.e., piling, cribbing, shoring, etc., shall be designed by a qualified person and meet accepted engineering requirements. When tie rods are used to restrain the top of sheeting or other retaining systems, the rods shall be securely an- chored well back of the angle of repose. When tight sheeting or sheet piling is used, full loading due to ground water table shall be assumed. unless prevented by weep holes or drains or other means. Additional stringers, ties, and bracing shall be provided to allow for any necessary temporary removal of individual sup. ports.

(8) All slopes shall be excavated to at least the angle of repose except for areas where solid rock allows for line drilling or presplitting.

(h) The angle of repose shall be flat. tened when an excavation has water conditions, silty materials, loose boul. ders, and areas where erosion, deep frost action, and slide planes appear.

(i)(1) In excavations which employees may be required to enter, excavated or other material shall be effectively stored and retained at least 2 feet or more from the edge of the excavation.

(2) As an alternative to the clearance prescribed in paragraph (i)(1) of this section, the employer may use effective barriers or other effective retain. ing devices in lieu thereof in order to prevent excavated or other materials from falling into the excavation.

(j) Sides, slopes, and faces of all excavations shall meet accepted ens. neering requirements by scaling. benching, barricading. rock bolting. wire meshing. or other equally effective means. Special attention shall be given to slopes which may be adverse. ly affected by weather or moisture content.

(k) Support systems shall be planned and designed by a qualified person when excavation is in excess of 20 feet in depth, adjacent to structures or im. provements, or subject to vibration or ground water.

(1) Matertals used for sheeting, sheet piling, cribbing, bracing. shoring, and underpinning shall be in good service. able condition, and timbers shall be sound, free from large or loose knots, and of proper dimensions.

(m) Special precations shall be taken in sloping or shoring the sides of exca. vations adjacent to a previously back. filled excavation or a fill. particularly when the separation is less than the depth of the excavation. Particular at tention also shall be pald to joints and 
seams of material comprising a face and the slope of such seams and joints.

(n) Except in hard rock, excavations below the level of the base of footing of any foundation or retaining wall shall not be permitted, unless the wall is underpinned and all other precautions taken to insure the stability of the adjacent walls for the protection of employees involved in excavation work or in the vicinity thereof.

(o) If the stability of adjoining buildings or walls is endangered by excavations, shoring, bracing, or underpinning shall be provided as necessary to insure their safety. Such shoring, bracing, or underpinning shall be in. spected daily or more often, as conditions warrant. by a competent person and the protection effectively maintained.

(p) Diversion ditches, dikes, or other suitable means shall be used to prevent surface water from entering an excavation and to provide adequate drainage of the area adjacent to the excavation. Water shall not be allowed to accumulate in an excavation.

(q) If it is necessary to place or operate power shovels, derricks, trucks, materials, or other heavy objects on a level above and near an excavation, the side of the excavation shall be sheet-piled, shored, and braced as necessary to resist the extra pressure due to such superimposed loads.

(r) Blasting and the use of explosives shall be performea in accordance with Subpart $U$ of this part.

(s) When mobile equipment is utilized or allowed adjacent to excavations, substantial stop logs or barricades shall be installed. If possible, the grade should be away from the excava. tion.

(t) Adequate barrier physical protection shall be provided at all remotely located excavations. All wells, pits, shafts, etc., shall be barricaded or covered. Upon completion of exploration and similar operations, temporary wells, pits, shafts, etc., shall be backfilled.

(u) If possible, dust conditions shall be kept to a minimum by the use of water, salt, calcium chloride, oll, or other means. (v) In locations where oxygen deficiency or gaseous conditions are possi. ble, air in the excavation shall be tested. Controls, as set forth in Sub. parts $D$ and $E$ of this part, shall be established to assure acceptable atmos. pheric conditions. When nammable gases are present, adequate ventilation shall be provided or sources of ignition shall be eliminated. Attended emergency rescue equipment, such as breathing apparatus, a safety harness and line, basket stretcher, etc., shall be readily available where adverse atmospheric conditions may exist or develop in an excavation.

(w) Where employees or equipment are required or permitted to cross over excavations, walkways or bridges with standard guardrails shall be frovided.

(x) Where ramps are used for employees or equipment, they shall be designed and constructed by qualified persons in accordance with accepted engineering requirements.

(y) All ladders used on excavation operations shall be in accordance with the requirements of Subpart $L$ of this part.

\section{$\$ 1926.652$ Specifle trenching require- ments.}

(a) Banks more than 5 feet high shall be shored, laid back to a stable slope, or some other equivalent means of protection shall be provided where employees may be exposed to moving ground or cave-ins. Refer to Table P-1 as a guide in sloping of banks. Trenches less than 5 feet in depth shall also be effectively protected when examination of the ground indicates hazardous sround movement may be expected.

(b) Sides of trenches in unstable or soft material, 5 feet or more in depth. shall be shored, sheeted, braced, sloped, or otherwise supported by means of sufficient strength to protect the employees working within them. See Tables P-1, P-2 (following paraBraph ( 8 ) of this section).

(c) Sides of trenches in hard or compact soil, including embankments. shall be shored or otherwise supported when the trench is more than 5 feet in depth and 8 feet or more in length. In lieu of shoring, the sides of the trench 


\section{$\$ 1926.652$}

above the 5-foot level may be sloped to preclude collapse, but shall not be steeper than a 1 -foot rise to each $h$ foot horizontal. When the outside diameter of a pipe is greater than 6 feet, a bench of 4-foot minimum shall be provided at the toe of the sloped portion.

(d) Materials used for sheeting and sheet piling, bracing, shoring, and underpinning, shall be in good serviceable condition, and timbers used shall be sound and free from large or loose knots, and shall be designed and installed so as to be effective to the bottom of the excavation.

(e) Additional precautions by way of shoring and bracing shall be taken to prevent slides or cave-ins when excavations or trenches are made in locations adjacent to backfilled excavations, or where excavations are subjected to vibratlons from rallroad or highway traffic, the operation of machinery, or any other source.

(i) Employees entering bell-bottom pier holes shall be protected by the in- stallation of a removable-type casing of sufficient strength to resist shifting of the surrounding earth. Such temporary protection shall be provided for the full depth of that part of each pier hole which is above the bell. A lifeline, suitable for instant rescue and secure. ly fastened to a shoulder harness, shall be worn by each employee enter. ing the shafts. This lifeline shall be in. dividually manned and separate from any line used to remove materials ex. cavated from the bell footing.

(g)(1) Minimum requirements for trench timbering shall be in accordance with Table P-2.

(2) Braces and diagonal shores in a wood shoring system shall not be subjected to compressive stress in excess of values given by the following formula:

$$
\begin{gathered}
S=13-20 L / D \\
\text { Meximum ratio } L / D=50
\end{gathered}
$$

Where:

$L=$ Lensth, unsupported, in inches.

$D=$ Least side of the timber in inches.

$S=$ Allowable stress in pounds per square inch of cross-section. 
Chapter XVII-Occupational Safoty and Heakth Admin.

\section{Table $2-1$}

\section{APPROXIMATE ANOLE OF REPOSE}

FOR SLOPINE Of SIDES OF EXCAVATIONS

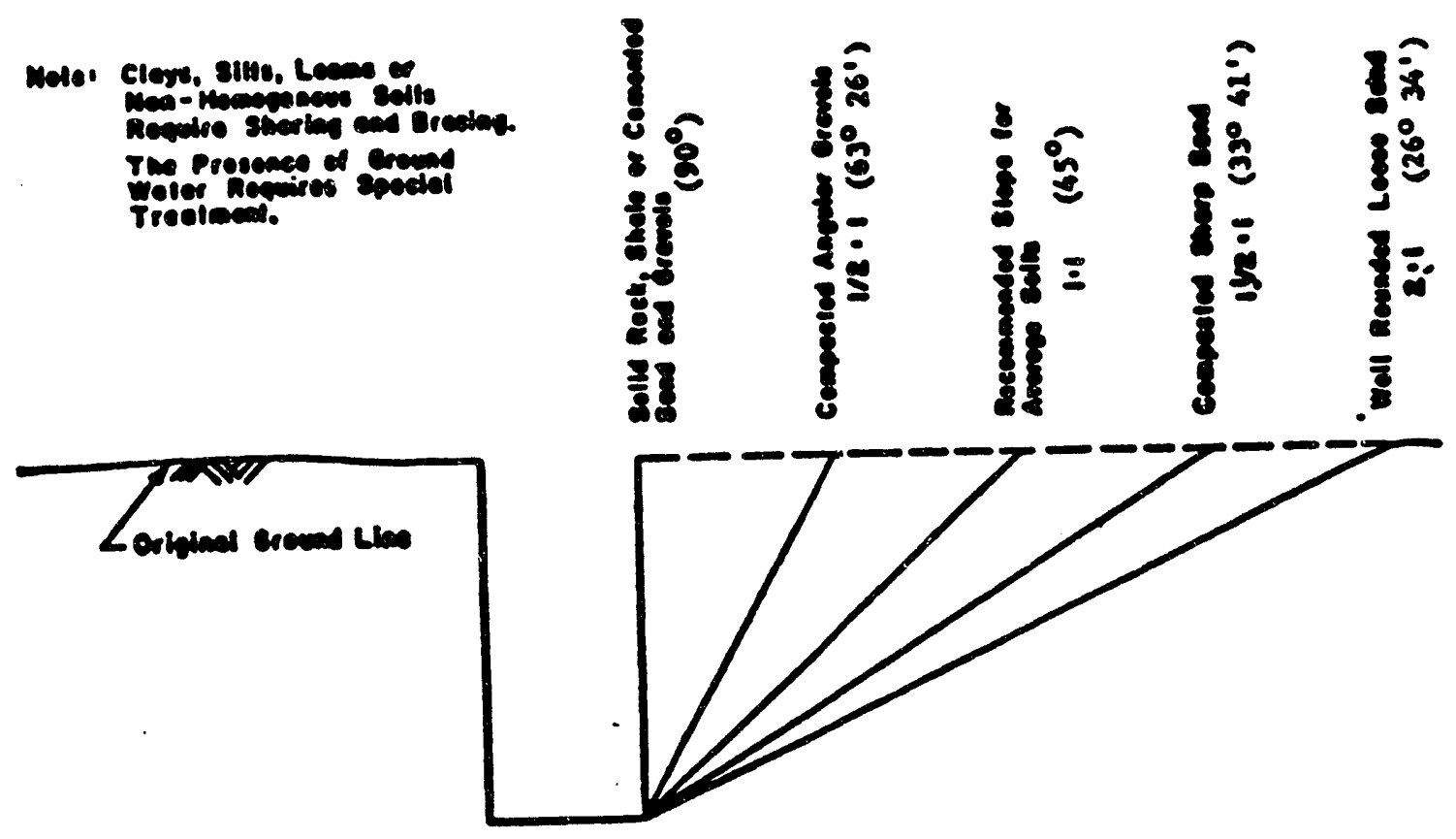




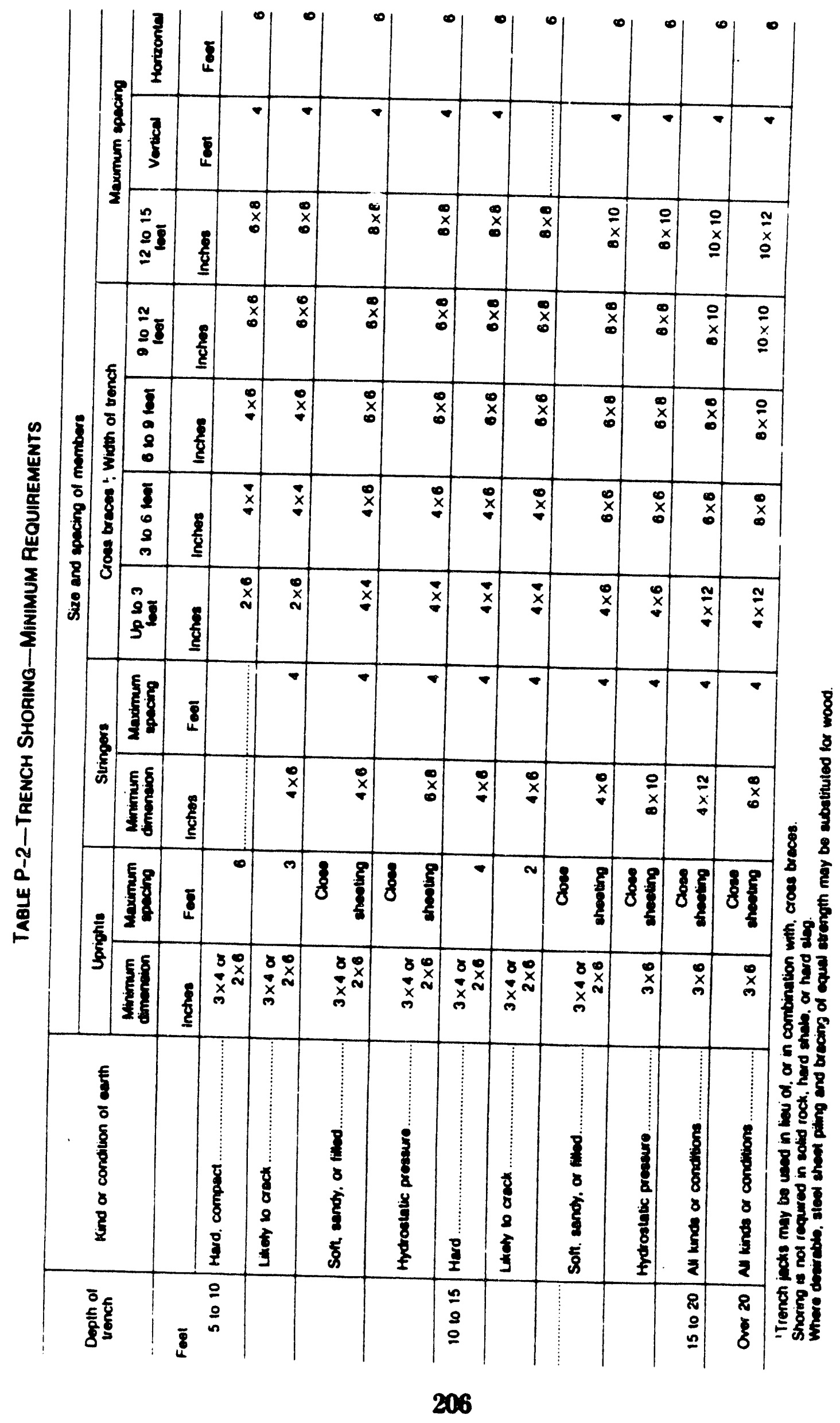


(h) When employees are required to be in trenches 4 feet deep or more, an adequate means of exit, such as a ladder or steps, shall be provided and located so as to require no more than 25 feet of lateral travel.

(i) Bracing or shoring of trenches shall be carried along with the excavation.

(j) Cross braces or trench jacks shall be placed in true horizontal position. be spaced vertically, and be secured to prevent sliding, falling, or kickouts.

(k) Portable trench boxes or sliding trench shields may be used for the protection of personnel in lieu of a shoring system or sloping. Where such trench boxes or shields are used, they shall be designed, constructed, and maintained in a manner which will provide protection equal to or greater than the sheeting or shoring required for the trench.

(1) Backfilling and removal of trench supports shall progress together from the bottom of the trench. Jacks or braces shall be released slowly and, in unstable soll, ropes shall be used to pull out the jacks or braces from above after employees have cleared the trench.

\subsection{Definitions applicable to this subpart.}

(a) "Accepted engineering requirements (or practices)"-Those requirements or practices which are compatible with standards required by a registered architect, a registered professional engineer, or other duly licensed or recognized authority.

(b) "Angle of repose"-The greatest angle above the horizontal plane at which a material will lie without slid. ing.

(c) "Bank" - A mass of soil rising above a digging level.

(d) "Belled excavation"-A part of a shaft or footing excavation, usually near the bottsin and bell-shaped; i.e., an enlargement of the cross section above.

(e) "Braces (trench)" - The horizontal members of the shoring system whose ends bear against the uprights or stringers.

(f) "Excavation"-Any manmade cavity or depression in the earth's surface, including its sides, walls, or faces. formed by earth removal and producing unsupported earth conditions by reasons of the excavation. If installed forms or similar structures reduce the depth-to-width relationship, an excavation may become a trench.

(g) "Faces"-See paragraph (k) of this section.

(h) "Hard compact soll"-All earth materials not classified as running or unstable.

(i) "Kickouts"-Accidental release or failure of a shore or brace.

(j) "Sheet pile"-A pile, or sheeting, that may form one of a continuous in. terlocking line, or a row of timber. concrete, or steel piles, driven in close contact to provide a tight wall to resist the lateral pressure of water, adjacent earth, or other materials.

(k) "Sides". "Walls", or "Faces"The vertical or inclined earth surfaces formed as a result of excavation work.

(1) "Slope"-The angle with the horizontal at which a particular earth material will stand indefinitely without movement.

(m) "Stringers" (wales)-The horizontal members of a shoring system whose sides bear against the uprights or earth.

(n) "Trench"-A narrow excavation made below the surface of the ground. In general, the depth is greater than the width, but the width of a trench is not greater than 15 feet.

(o) "Trench jack"-Screw or hydraulic type jacks used as cross bracing in a trench shoring system.

(p) "Trench shield"-A shoring system composed of steel plates and bracing. welded or bolted together. which support the walls of a trench from the ground level to the trench bottom and which can be moved along as work progresses.

(q) "Unstable soil"-Earth material. other than running; that because of its nature or the influence of related conditions, cannot be depended upon to remain in place without extra support, such as would be furnished by a system of shoring.

(r) "Uprights"-The vertical members of a shoring system.

(s) "Wales"-See paragraph (m) of this section.

$(t)$ "Walls"-See paragraph $(k)$ of this section. 


\section{Appendix E Electrical Safety}


from the area to be heated to prevent ignition.

(c) Protection against toxic preservative coatings: (1) In enclosed spaces, all surfaces covered with toxic preservatives shall be stripped of all toxic coatings for a distance of at least 4 inches from the area of heat application, or the employees shall be protected by air line respirators, meeting the requirements of Subpart $\mathbf{E}$ of this part.

(2) In the open air, employees shall be protected by a respirator, in accordance with requirements of Subpart $\mathbf{E}$ of this part.

(d) The preservative coatings shall be removed a sufficient distance from the area to be heated to ensure that the temperature of the unstripped metal will not be appreciably raised. Artificial cooling of the metal surrounding the heating area may be used to limit the size of the area required to be cleaned.

\section{Subpart K-Eloctrical}

\section{General}

\$ 1926.400 Introduction.

This subpart addresses electrical safety requirements that are necessary for the practical safeguarding of employees involved in construction work and is divided into four major divisions and applicable definitions as follows:

(a) Installation safety requirements. Installation safety requirements are contained in $\$ \$ 1926.402$ through 1926.408. Included in this category are electrical equipment and installations used to pro vide electric power and light on jobsites.

(b) Safety-related work practices. Safety-related work practices are contained in $\$ \S 1926.416$ and 1926.417. In addition to covering the hazards arising from the use of electricity at jobsites, these regulations also cover the hazards arising from the accidental contact, direct or indirect, by employees with all energized lines, above or below ground. passing through or near the jobsite.

(c) Safety-related maintenance and environmental consideraticns. Safety: related maintenance and environmental considerations are contained in $\S \S 1926.431$ and 1926.432 . (d) Safety requirements for special equipment. Safety requirements for special equipment are contained in $\S 1926.441$.

(e) Definitions. Definitions applicable to this Subpart are contained in $\$ 1926.449$.

\section{\$ 1926.401 [Reserved.]}

Installation Safety Requirements

8 1926.402 Applicability.

(a) Covered. Sections 1926.402 through 1926.408 contain installation safety requirements for electrical equipment and installations used to provide electric power and light at the jobsite. These sections apply to installations. both temporary and permanent, used on the jobsite; but these sections do not apply to existing permanent installations that were in place before the construction activity commenced.

NoTE: If the electrical installation is made in sccordance with the National Electrical Code ANSI/NFPA 70-1984, exclusive of For. mal Interpretations and Tentative Interim Amendments, it will be deemed to be in compliance with $\$ \$ 1926.403$ through 1926.408. except for $\$ \$ 1926.404(b)(1)$ and 1926.405(a)(2)(ii)(E). (F), (G), and (J).

(b) Not covered Sections 1926.402 through 1926.408 do not cover installa. tions used for the generation, transmis. sion, and distribution of electric energy. including related communicat:on, metering, control, and transforma:.un installations. (However, these regulations do cover portable and vehicle-mounted generators used to provide power for equipment used at the jobsite.) See Subpart $V$ of this Part for the construction of power distribution and transmission lines.

\subsection{General requirements.}

(a) Approval All electrical conductors and equipment shall be approved.

(b) Examination installation and use of equipment-(1) Examination The employer shall ensure that electrical equipment is free from recognized hazards that are likely to cause death or serious physical harm to employees. Safety of equipment shall be determined on the basis of the following considerations: 
(i) Suitability for installation and use in conformity with the provisions of this subpart. Suitability of equipment for an identified purpose may be evidenced by listing, labeling, or certification for that identified purpose.

(ii) Mechanical strength and durability, including, for parts designed to enclose and protect other equipment. the adequacy of the protection thus provided.

(iii) Electrical insulation.

(iv) Heating effects under conditions of use.

(v) Arcing effects.

(vi) Classification by type, size, voltage, current capacity, specific use.

(vii) Other factors which contribute to the practical safeguarding of employees using or likely to come in contact with the equipment.

(2) Installation and use Listed, labeled. or certified equipment shall be instalied and used in accordance with instructions included in the listing, labeling, or certification.

(c) Interrupting rating. Equipment intended to break current shall have an interrupting rating at systers voltage sufficient for the current that must be interrupted.

(d) Mounting and cooling of equipment-(1) Mounting. Electric equipment shall bo firmly secured to the surface on which it is mounted. Wooden plugs driven into holes in masonry, concrete, plaster, or similar materials shall not be used.

(2) Cooling. Electrical equipment which depends upon the natural circulation of air and convection principles for cooling of exposed surfaces shall be installed so that room air flow over such surfaces is not prevented by walls or by adjacent installed equipment. For equip. ment designed for floor mounting, clear. ance between top surfaces and adjacent surfaces shall be provided to dissipate rising warm air. Electrical equipment provided with ventilating openings shall be installed so that walls or other obstructions do not prevent the free circulation of air through the equipment.

(e) Splices. Conductors shall be spliced or joined with splicing devices designed for the use or by brazing. welding, or soldering with a fusible metal or alloy. Soldered splices shall first be so spliced or joined as to be mechanically and electrically secure without solder and then soldered. All splices and joints and the free ends of conductors shall be covered with an insulation equivalent to that of the con. ductors or with an insulating device designed for the purpose.

(f) Arcing parts. Parts of electric equipment which in ordinary operation produce arcs, sparks, flanes, or molten metal shall be enclosed or separated and isolated from all combustible material.

(g) Marking. Electrical equipment shall not be used unless the manufacturer's name, trademark, or other descriptive marking by which the organization responsible for the product may be identified is placed on the equipment and unless other markings are provided giving voltage, current, wattage, or other ratings as necessary. The marking shall be of sufficient durability to withstand the en:ironment involved.

(h) Identification of disconnecting means and circuits. Each disconnecting means required by this subpart for mo tors and appliances shall be legibly marked to indicate its purpose, unless located and arranged so the purpose is evident. Each service, feeder, and branch circuit, at its disconnecting means or overcurrent device, shall be legibly marked to indicate its purpose. uniless located and arranged so the pur. pose is evident. These markings shall be of sufficient durability to withstand the environment involved.

(i) 600 Volts, nominah or less. This paragraph applies to equipment operating at 600 volts, nominal, or less.

(1) Working space about electric equipment Sufficient access and working space shall be provided and maintained about all electric equipment to permit ready and safe operation and mainte nance of such equipment.

(i) Working clearances. Except as re quired or permitted elsewhere in this subpart, the dimension of the working space in the direction of access to live parts operating at 600 volts or less and likely to require examination. adjust. ment, servicing, or maintenance while alive shall not be leas than indicated in Tabla $\mathrm{K}-1$. In addition to the dimen. sior shown in Table $\mathrm{K}-1$, workspace shad not be leas than 30 inches 1762 
$\mathrm{mm}$ ) wide in front of the electric equipment. Distances shall be measured from the live parts if they are exposed. or from the enclosure front or opening if the live parts are enclosed. Walls constructed of concrete, brick, or tile are considered to be grounded. Working space is not required in back of assemblies such as dead-front switchboards or motor control centers where there are no renewable or adjustable parts such as fuses or switches on the back and where all connections are accessible from locations other than the back.

Table K-1-Working Clearances

\begin{tabular}{|c|c|c|c|}
\hline \multirow{2}{*}{ Nominal voltage to ground } & \multicolumn{3}{|c|}{$\begin{array}{c}\text { Minimum clat distance for } \\
\text { conditions' }\end{array}$} \\
\hline & (a) & (b) & (c) \\
\hline $\begin{array}{l}0-150 \\
151-600\end{array}$ & $\begin{array}{c}\text { Feot } \\
3 \\
3\end{array}$ & $\begin{array}{c}f o k^{2} \\
3 \\
31 / 2\end{array}$ & $\begin{array}{c}\text { Font } \\
3 \\
4\end{array}$ \\
\hline
\end{tabular}

'Concitions (a). (b). and (c) are as follows: (a) Exponed in pars on one side and no liwe or grounded parts on the other side of the working spece. Or expesed tive parts on both sides effoctively guarded by inaulating materid. Insuleted wirs or insulated busbers operating at not ove 300 volus an not considered liwe parts. (b) Expoesed live parts on ons sids and grounded parts on the othor side. (c) Exposed ine perts on both sides of the workspeces (not guerded as provided in Condition (a)] with the operator benween.

2For international System of Units (S1): one foot $=0.304 \mathrm{~m}$.

(ii) Clear spaces. Working space re quired by this subpart shall not be used for storage. When normally enclosed live parts are exposed for inspection or servicing, the working space, if in a passageway or general open space, shall be guarded.

(iii) Access and entrance to working space. At least one entrance shall be provided to give access to the working space about electric equipment.

(iv) Front working space. Where there are live parts normally exposed on the front of switchboards or motor control centers, the working space in front of such equipment shall not be less than 3 feet $(914 \mathrm{~mm}$ ).

(v) Headroom The minimum headroom of working spaces about service equipment. switchboards, panelboards, or motor control centers shall be 6 feet 3 inches $(1.91 \mathrm{~m})$.

(2) Guarding of live parts. - (i) Except as required or permitted elsewhere in this subpart, live parts of electrical equipment operating at 50 volts or more shall be guarded against accidental contact by cabinets or other forms of enclosures, or by any of the following means:

(A) By location in a room, vault, or similar enclosure that is accessible only to qualified persons.

(B) By partitions or screens so ar. ranged that only qualified persons will have access to the space within reach of the live parts. Any openings in such partitions or screens shall be so sized and located that persons are not likely to come into accidental contact with the live parts or to bring conducting objects into contact with them.

(C) By location on a balcony, gallery, or platform so elevated and arranged as to exclude unqualified persons.

(D) By elevation of 8 feet $(2.44 \mathrm{~m})$ or more above the floor or other working surface and so installed as to exclude unqualified persons.

(ii) In locations where electric equipment would be exposed to physical damage, enclosures or guards shall be so arranged and of such strength as to prevent such damage.

(iii) Entrances to rooms and other guarded locations containing exposed live parts shall be marked with conspicuous warning signs forbidding unqualified persons to enter.

(j) Over 600 volts, nominal-(1) General Conductors and equipment used on circuits exceeding 600 volts, nominal. shall comply with all applicable provisions of paragraphs (a) through (g) of this section and with the following pro visions which supplement or modify those requirements. The provisions of paragraphs $(j)(2),(j)(3)$, and $(j)(4)$ of this section do not apply to equipment on the supply side of the service conductors.

(2) Enclosure for electrical installafions. Electrical installations in a vault. room, closet or in an area surrounded by a wall. screen, or fence, access to which is controlled by lock and key or other equivalent means, are considered to be accessible to qualified persons only. A wall, screen, or fence less than 8 feet $(2.44 \mathrm{~m})$ in height is not consicered adequate to prevent access unless it has other features that provide a degree of isolation equivalent to an 8-(0ot $(2.44-1 n)$ fence. The entrances to all buildings, 
rooms or enciosures containing exposed live parts or exposed conductors operating at over 600 volts, nominal, shall be kept locked or shall be under the observation of a qualified person at all times.

(i) Installations accessible to qualified persons only. Electrical installations having exposed live parts shall be accessible to qualified persons only and shall comply with the applicable provisions of paragraph $(j)(3)$ of this section.

(ii) Installations accessible to unqualified persons. Electrical installations that are open to unqualified persons stall be made with rnetalenclosed equipment or shall be enclosed in a vault or in an area, access to which is controlled by a lock. Metalenclosed switchgear, unit substations, transformers, pull boxes, connection boxes, and other similar as. sociated equipment shall be marked with appropriate caution signs. If equipment is exposed to physical damage from vehicular traffic, guards shall be provided to prevent such damage. Ventilating or similar openings in metalenclosed equipment shall be designed so thrst foreign objects inserted through these openings will be deflected from energized parts.

(3) Workspace about equipment. Sufficient space shall be provided and maintained about electric equipment to permit ready and safe operation and maintenance of such equipment. Where energized parts are exposed, the minimum clear workspace shall not be less than 6 feet 6 inches $(1.98 \mathrm{~m})$ high (measured vertically from the floor or platform), or less than 3 feet $(914 \mathrm{~mm}$ ) wide (measured parallel to the equipment). The depth shall be as required in Table K-2. The workspace shall be adequate to permit at least a 90-degree opening of doors or hinged panels.

(i) Working space. The minimum clear working space in front of electric equipment such as switchboards, control panels, switches, circuit breakers, motor controllers, relays, and similar equipment shall not be less than specified in Table K-2 unless otherwise specified in this subpart. Distances shall be measured from the live parts if they are exposed, or from the enclosure front or opening if the live parts are enclosed. However, working space is not required in back of equipment such as deadfront switchboards or control assemblies where there are no renewable or adjustable parts (such as fuses or switches) on the back and where all connections are accessible from locations other than the back. Where rear access is required to work on deenergized parts on the back of enclosed equipment, a minimum working space of 30 inches $(762 \mathrm{~mm})$ horizontally shall be provided.

\section{TABLE K-2-MINIMUM DEPTH OF CLEAR WORKING SPACE IN FRONT OF ELECTRIC EQUIPMENT}

\begin{tabular}{|c|c|c|c|}
\hline \multirow[t]{2}{*}{ Nomind vortegs to ground } & \multicolumn{3}{|c|}{ Conditions' } \\
\hline & (a) & (b) & (c) \\
\hline $\begin{array}{l}\mathbf{6 0 1} \text { to } \mathbf{2 . 5 0 0} \ldots \ldots \ldots \ldots \ldots \\
\mathbf{2 . 5 0 1} \text { to } \mathbf{9 . 0 0 0} \ldots \ldots \ldots \ldots \ldots \\
\mathbf{9 . 0 0 1} \text { to } \mathbf{2 5 . 0 0 0} \ldots \ldots \ldots \ldots \ldots \\
\mathbf{2 5 . 0 0 1} \text { to } \mathbf{7 5} \mathrm{kV} \ldots \ldots \ldots \ldots \ldots \\
\text { Abow } \mathbf{7 5 k V} \ldots \ldots \ldots \ldots \ldots \ldots\end{array}$ & $\begin{array}{c}\text { Fon } \\
3 \\
4 \\
5 \\
6 \\
8\end{array}$ & $\begin{array}{c}\text { Feer } \\
4 \\
5 \\
6 \\
8 \\
10 \\
\end{array}$ & $\begin{array}{c}\text { Feer } \\
5 \\
6 \\
9 \\
10 \\
12\end{array}$ \\
\hline
\end{tabular}

'Conowions (a). (b), and (c) are as follows: (a) Exposed ine perts on ons sude and no live or groundes parts on the other side of the working soece. of exposed live parts on both sides eflectively guerded by inaveting materials. Insulated wre or insuleved busbers operating at not over 300 volts are not convidered tive pars. (b) Exponed live parts on one side and grounded parts on the other side. Wals constructed $c$ concrim. onct, of tib ere considered to be grounded surteces (c) Exposed tive peris on both suces of the workspece Inot guarded provided in Condition (a)l with the operator benmean.

2for SI units: on toot $=0.3040 \mathrm{~m}$.

(ii) Lighting outlets and points of control The lighting outlets shall be so arranged that persons changing lamps or making repairs on the lighting sys. tem will not be endangered by live parts or other equipment. The points of control shall be so located that persons are not likely to come in contact with any live part or moving part of the equipment while turning on the lights.

(iii) Elevation of unguarded live parts. Unguarded live parts above working space shall be maintained at elevations not less than specified in Table $K-3$.

TABLE K-3 ELEVATION OF UNGUARDED Energiagd Parts above Working Space

\begin{tabular}{|c|c|}
\hline 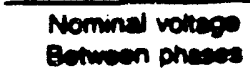 & Minmmum elevation \\
\hline $\begin{array}{l}601-7.500 \\
7.501-35.000 \\
\text { Over } 35 x V\end{array}$ & $\begin{array}{l}8 \text { text } 8 \text { menus' } \\
9 \text { toet } \\
9 \text { leck + } 0.37 \text { inches } \\
\text { per KV ebow 35kV }\end{array}$ \\
\hline
\end{tabular}

'For ST unw ons inch - $25.4 \mathrm{~mm}$; one toot $=03048 \mathrm{~m}$ 
(4) Entrance and access to workspace. At least one entrance not less than 24 inches $(610 \mathrm{~mm})$ wide and 6 feet 6 inches $(1.98 \mathrm{~m})$ high shall be provided to give access to the working space about electric equipment. On switchboard and control panels exceeding 48 inches $(1.22$ $\mathrm{m}$ ) in width, there shall be one entrance at each end of such board where practicable. Where bare energized parts at any voltage or insulated energized parts above 600 volts are located adjacent to such entrance, they shall be guarded. (Information collection requirements contained in paragraphs (g) and (h) were approved by the Office of Management and Budget under control num. ber: 1218-0130.)

$\$ 1926.404$ Wiring deaign and protection.

(a) Use and identification of grounded and grounding conductors. -

(1) Identification of conductors. A conductor used as a grounded conductor shall be identifiable and distinguishable from all other conductors. A conductor used as an equipment grounding conductor shall be identifiable and distinguishable from all other conductors.

(2) Polarity of connections. No grounded conductor shall be attached to any terminal or lead so as to reverse designated polarity.

(3) Use of grounding terminals and devices. A grounding terminal or grounding-type device on a receptacle, cord connector, or attachment plug shall not be used for purposes other than grounding.

(b) Branch circuits. - (1) Ground-fault protection - (i) General The employer shall use either ground-fault circuit interrupters as specified in paragraph (b)(I)(iu) of this section or an assured equipment grounding conductor program as specified in paragraph (b)(I)(iii) of this section to protect employees on construction sites. These requirements are in addition to any other requiro ments for equipment grounding conductors.

(ii) Ground-fault circuit interrupters. Ail 120-volt, singlephase, 15- and 20ampere receptacle outlets on construction sites, which are not a part of the permanent wiring of the building or structure and which are in use by emoloyees, shall have approved ground- fault circuit interrupters for personnel protection. Receptacles on a two-wire, single-phase portable or vehicle-mounted generator rated not more than $5 \mathrm{~kW}$. where the circuit conductors of the generator are insulated from the generator frame and all other grounded surfaces, need not be protected with ground-fault circuit interrupters.

(iii) Assured equipment grounding conductor program. The employer shall establish and implement an assured equipment grounding conductor program on construction sites covering all cord sets, receptacles which are not a part of the building or structure, and equipment connected by cord and plug which are available for use or used by employees. This program shall comply with the following minimum require ments:

(A) A written description of the pro gram, including the specific procedures adopted by the employer, shall be available at the jobsite for inspection and copying by the Assistant Secretary and any affected employee.

(B) The employer shall designate one or more competent persons (as defined in $\$ 1926.32(\$))$ to implement the pro gram.

(C) Each cord set, attachment cap. plug and receptacle of cord sets, and any equipment connected by cord and plug, except cord sets and receptacles which are fixed and not exposed to damage. shall be visually inspected be fore each day's use for external defects, such as deformed or missing pins or insulation damage, and for indications of possible internal damage. Equipment found damaged or defective shall not be used until repaired.

(D) The following tests shall be performed on all cord sets, receptacles which are not a part of the permanent wiring of the building or structure, and cord- and plug-connected equipment re quired to be grounded:

(1) All equipment grounding conductors shall be tested for continuity and shall be electrically continuous.

(2) Each receptacle and attachment cap or plug shall be tested for correct attachment of the equipment grounding conductor. The equipment grounding conductor shall be connected to its proper terminal. 
(E) All required tests shall be performed:

(1) Before first use;

(2) Before equipment is returned to service following any repairs;

(3) Before equipment is used after any incident which can be reasonably suspected to have caused damage (for example, when a cord set is run over); and

(4) At intervals not to exceed 3 months, except that cord sets and receptacles which are fixed and not exposed to damage shall be tested at intervals not exceeding 6 months.

(F) The employer shall not make available or permit the use by employees of any equipment which has not met the requirements of this paragraph (b)(1)(iii) of this section.

(G) Tests performed as required in this paragraph shall be recorded. This test record shall identify each receptacle, cord set, and cord- and plugconnected equipment that passed the test and shall indicate the last date it was tested or the interval for which it was tested. This record shall be kept by means of logs, color coding, or other effective means and shall be maintained until replaced by a more current record. The record shall be made available on the jobsite for inspection by the Assistant Secretary and any affected employee.

(2) Outlet devices. Outlet devices shall have an ampere rating not less than the load to be served and shall comply with the following.

(i) Single receptacles. A single receptacle installed on an individual branch circuit shall have an ampere rating of not less than that of the branch circuit.

(ii) Two or more receptacles. Where connected to a branch circuit supply two or more receptacles or outlets, re ceptacle ratings shall conform to the values listed in Table $K-4$.

(iii) Receptacles used for the connection of motors. The rating of an attachment plug or receptacle used for cordand plug-connection of a motor to a branch circuit shall not exceed 15 amperes at 125 volts or 10 amperes at 250 volts if individual overload protection is omitted.

(c) Outside conductors and lamps(1) 600 volts, nominal, or less. Paragraphs (c)(I)(i) through (c)(l)(iv) of this
TABle K-4-Receptacle RATINGS for VAaIOUS SIzE CIRCUITS

\begin{tabular}{cc}
\hline $\begin{array}{c}\text { Circuit rating } \\
\text { amperes }\end{array}$ & $\begin{array}{c}\text { Receptacie rating } \\
\text { amperes }\end{array}$ \\
\hline 15 & Not over 15 \\
20 & 15 or 20 \\
30 & 30 \\
40 & 40 or 50 \\
50 & 50 \\
\hline
\end{tabular}

section apply to branch circuit, feeder, and service conductors rated 600 volts, nominal, or less and run outdoors as open conductors.

(i) Conductors on poles. Conductors supported on poles shall provide a horizontal climbing space not less than the following:

(A) Power conductors below communication conductors -30 inches 1762 mm).

(B) Power conductors alone or above communication conductors: 300 volts or less-24 inches $(610 \mathrm{~mm})$; more than 300 volts -30 inches $(762 \mathrm{~mm})$.

(C) Communication conductors below power conductors: with power conductors 300 volts or less-24 inches 1610 $\mathrm{mm}$ ); more than 300 volts -30 inches (762 mm).

(ii) Clearance from ground Open conductors shall conform to the following minimum clearances:

(A) 10 feet $(3.05 \mathrm{~m})$-above finished grade, sidewalks, or from any platform or projection from which they might be reached.

(B) 12 feet $(3.66 \mathrm{~m})$-over areas subject to vehicular traffic other than truck traffic.

(C) 15 feet $(4.57 \mathrm{~m})$-over areas other than those specified in paragraph (c)(I)(ii)(D) of this section that are subject to truck traffic.

(D) 18 feet $(5.49 \mathrm{~m})$-over public streets, alleys, roads, and driveways.

(iii) Clearance from building openings. Conductors shall have a clearance of at least 3 feet $(914 \mathrm{~mm})$ from windows, doors, fire escapes, or similar locations. Conductors run above the top level of a window are considered to be out of reach from that window and, therefore, do not have to be 3 feet $(914 \mathrm{~mm})$ away.

(iv) Clearance over roofs. Conductors above roof space accessible to employees on foot shall have a clearance from the highest point of the roof surface of 
not less than 8 feet $(2.44 \mathrm{~m})$ vertical clearance for insulated conductors, not less than 10 feet $(3.05 \mathrm{~m})$ vertical or diagonal clearance for covered conductors, and not less than 15 feet $(4.57 \mathrm{~m})$ for bare conductors, except that:

(A) Where the roof space is also accessible to vehicular traffic, the vertical clearance shall not be less than 18 feet $(5.49 \mathrm{~m})$. or

(B) Where the roof space is not normally accessible to employees on foot, fully insulated conductors shall have a vertical or diagonal clearance of not less than 3 feet $(914 \mathrm{~mm})$, or

(C) Where the voltage between conductors is 300 volts or less and the roof has a slope of not less than 4 inches $(102 \mathrm{~mm})$ in 12 inches $(305 \mathrm{~mm})$, the clearance from roofs shall be at least 3 feet $(914 \mathrm{~mm})$, or

(D) Where the voltage between conductors is 300 volts or less and the conductors do not pass over more than 4 feet $(1.22 \mathrm{~m})$ of the overhang portion of the roof and they are terminated.at a through-the-roof raceway or support, the clearance from roofs shall be at least 18 inches $(457 \mathrm{~mm})$.

2 Location of outdoor lamps. Lamps for outdoor lighting shall be located below all live conductors, transformers. or other electric equipment, unless such equipment is controlled by a disconnecting means that can be locked in the open position or unless adequate clearances or other safeguards are provided for relamping operations.

(d) Services-(1) Disconnecting means-(i) General Means shall be provided to disconnect all conductors in a building or other structure from the service-entrance conductors. The disconnecting means shall plainly indicate whether it is in the open or closed position and shall be installed at a readily accessible location nearest the point of entrance of the serviceentrance conductors.

(ii) Simultaneous opening of poles. Each service disconnecting means shall simultaneously disconnect all ungrounded conductors.

(2) Services over 600 volts, nominal The following additional requirements apply to services over 600 volts, nominal. (i) Guarding. Serviceentrance conductors installed as open wires shall be guarded to make them accessible only to qualified persons.

(ii) Warning signs. Signs warning of high voltage shall be posted where unauthorized employees might come in contact with live parts.

(e) Overcurrent protection-(1) 600 volts, nominal or less. The following requirements apply to overcurrent pro tection of circuits rated 600 volts, nominal, or less.

(i) Protection of conductors and equipment Conductors and equipment shall be protected from overcurrent in accordance with their ability to safely conduct current. Conductors shall have sufficient ampacity to carry the load.

(ii) Grounded conductors. Except for motor-running overload protection. overcurrent devices shall not interrupt the continuity of the grounded conductor unless all conductors of the circuit are opened simultaneously.

(iii) Disconnection of fuses and ther mal cutouts. Except for devices provided for current-limiting on the supply side of the service disconnecting means, all cartridge fuses which are accessible to other than qualified persons and all fuses and thermal cutouts on circuits over 150 volts to ground shall be provided with disconnecting means. The disconnecting means shall be installed so that the fuse or thermal cutout can be disconnected from its supply without disrupting service to equipment and circuits unrelated to those protected by the overcurrent device.

(iv) Location in or on premises. Overcurrent devices shall be readily accessible. Overcurrent devices shall not be located where they could create an employee safety hazard by being ex posed to physical damage or located in the vicinity of easily ignitible material.

(v) Arcing or suddenly moving parts. Fuses and circuit breakers shall be so located or shielded that employees will not be burned or otherwise injured by their operation.

(vi) Circuit breakers. (A) Circuit breakers shall clearly indicate whether they are in the open (off) or closed (on) position.

(B) Where circuit breaker handles on 
switchboards are operated vertically rather than horizontally or rotationally, the up position of the handle shall be the closed (on) position.

(C) If used as switches in 120-volt. fluorescent lighting circuits, circuit breakers shall be marked "SWD."

(2) Over 600 volts, nominal Feeders and branch circuits over 600 volts, nominal, shall have short-circuit protection.

(f) Grounding. Paragraphs (f)(1) through (f)(11) of this section contain grounding requirements for systems, cir. cuits, and equipment.

(1) Systems to be grounded The following systems which supply premises wiring shall be grounded:

(i) Three-wire DC systems. All 3-wire DC systems shall have their neutral conductor grounded.

(ii) Two-wire DC systems. Two-pire DC systems operating at over 50 volts through 300 volts between conductors shall be grounded unless they are rectifier-derived from an AC system complying with paragraphs (f)(1)(iii), (f)(1)(iv), and (f)(1)(v) of this section.

(iii) $A C$ circuits, less than 50 volts. AC circuits of less than 50 volts shall be grounded if they are installed as overhead conductors outside of build. ings or if they are supplied by trans. formers and the transformer primary supply system is ungrounded or exceeds 150 volts to ground.

(iv) $A C$ systems, 50 volts to 1000 volts. AC systems of 50 volts to 1000 volts shall be grounded under any of the following conditions, unless exempted by paragraph (fH(1Kv) of this section:

(A) If the system can be so grounded that the maximum voltage to ground on the ungrounded conductors does not exceed 150 volts;

(B) If the system is nominally rated 480 Y $/ 277$ volt, 3-phase, 4-wire in which the neutral is used as a circuit conductor:

(C) If the system is nominally rated 240/120-volt, 3-phase, 4-wire in which the midpoint of one phase is used as a circuit conductor; or

(D) If a service conductor is uninsulated.

(v) Exceptions. AC systems of 50 volts to 1000 volts are not required to be grounded if the system is separately derived and is supplied by a transformer that has a primary voltage rating less than 1000 volts, provided all of the following conditions are met:

(A) The system is used exclusively for control circuits,

(B) The conditions of maintenance and supervision assure that only qualified persons will service the installation.

(C) Continuity of control power is re quired, and

(D) Ground detectors are installed on the control system.

(2) Separately derived systems. Where paragraph (f)(1) of this section requires grounding of wiring systems whose power is derived from generator, transformer, or converter windings and has no direct electrical connection, including a solidly connected grounded circuit conductor, to supply conductors originating in another system, paragraphs (f)(5) of this section shall also apply.

(3) Portable and vehicle-mounted generators-(i) Portable generators. Under the following conditions, the frame of a portable generator need not be grounded and may serve as the ground. ing electrode for a system supplied by the generator:

(A) The generator supplies only equipment mounted on the generator and/or cord- and plug-connected equipment through receptecles mounted on the generator, and

(B) The noncurrent-carrying metal parts of equipment and the equipment grounding conductor terminals of the receptacles are bonded to the generator frame.

(ii) Vehicle-mounted generators. Under the following conditions the frame of a vehicle may serve as the grounding electrode for a system supplied by a generator located on the vehicle:

(A) The frame of the generator is bonded to the vehicle frame, and

(B) The generator supplies only equipment located on the vehicle and/or cord. and plug-connected equipment through receptacles mounted on the vehicle or on the generator, and

(C) The noncurrent-carrying metal parts of equipment and the equipment grounding conductor terminals of the receptacles are bonded to the generator frame, and

(D) The system complies with all other provisions of this section. 
(iii) Neutral conductor bonding. A neutral conductor shall be bonded to the generator frame if the generator is a component of a separately derived system. No other conductor need be bonded to the generator frame.

(4) Conductors to be grounded. For AC premises wiring systems the identified conductor shall be grounded.

(5) Grounding connections(i) Grounded system. For a grounded system, a grounding electrode conductor shall be used to connect both the equipment grounding connector and the grounded circuit conductor to the grounding electrode. Both the equipment grounding conductor and the grounding electrode conductor shall be connected to the grounded circuit conductor on the supply side of the service disconnecting means, or on the supply side of the system disconnecting means or overcurrent devices if the system is separately derived.

(ii) Ungrounded systems. For an ungrounded service-supplied system, the equipment grounding conductor shall be connected to the grounding electrode conductor at the service equipment. For an ungrounded separately derived system. the equipment grounding condurtor shall be connected to the grounding electrode conductor at, or ahead of, the system disconnecting means or overcur. rent devices.

(6) Grounding path. The path to ground from circuits, equipment, and enclosures shall be permanent and continuous.

(7) Supports, enclosures, and equipment to be grounded-(i) Supports and enclosures for conductors. Metal cable trays, metal raceways, and metal enclosures for conductors shall be grounded, except that:

(A) Metal enclosures such as sleeves that are used to protect cable assem. blies from physical damage need not be grounded; and

(B) Metal enclosures for conductors added to existing installations of open wire, knob-and-tube wiring, and nonmetallic-sheathed cable need not be grounded if all of the following conditions are met: m);

(1) Runs are less than 25 feet 17.62

(2) Enclosures are free from probable contact with ground, grounded metal. metal laths, or other conductive materials; and

(3) Enclosures are guarded against employee contact.

(ii) Service equipment enclosures. Metal enclosures for service equipment shall be grounded.

(iii) Fixed equipment. Exposed noncurrent-carrying metal parts of fixed equipment which may become energized shall be grounded under any of the following conditions:

(A) If within 8 feet $(2.44 \mathrm{~m})$ vertically or 5 feet $(1.52 \mathrm{~m})$ horizontally of ground or grounded metal objects and subject to employee contact.

(B) If located in a wet or damp location and subject to employee contact.

(C) If in electrical contact with metal.

(D) If in a hazardous (classified) loca. tion.

(E) If supplied by a metal-clad, metalsheathed, or grounded metal raceway wiring method.

(F) If equipment operates with any terminal at over 150 volts to ground; however, the following need not be grounded:

(1) Enclosures for switches or circuit breakers used for other than service equipment and accessible to qualified persons only:

(2) Metal frames of electrically heated appliances which are permanently and effectively insulated from ground; and

(3) The cases of distribution apparatus such as transformers and capacitors mounted on wooden poles at a height excesding 8 feet $(2.44 \mathrm{~m})$ above ground or grade level.

(iv) Equipment connected by cord and plug. Under any of the conditions described in paragraphs $(\mathrm{f})(7)(\mathrm{iv})(\mathrm{A})$ through (f)(7)(iv)(C) of this section, exposed noncurrent-carrying metal parts of cord- and plug-connected equipment which may become energized shall be grounded:

(A) If in a hazardous (classified) location (see $\$ 1926.407$ ).

(B) If operated at over 150 volts to ground, except for guarded motors and metal frames of electrically heated appliances if the appliance frames are permanently and effectively insulated from ground.

(C) If the equipment is one of the 
types listed in paragraphs (f)(7)(iv)(C)(1) through $(\mathrm{f})(7)($ iv) (C) (5) of this section. However, even though the equipment may be one of these types, it need not be grounded if it is exempted by paragraph (f)(7)(iv)(C)(6).

(I) Hand held motor-operated tools;

(2) Cord- and plug-connected equipment used in damp or wet locations or by employees standing on the ground or on metal floors or working inside of metal tanks or boilers;

(3) Portable and mobile X-ray and associated equipment;

(4) Tools likely to be used in wet and/or conductive locations; and

(5) Portable hand lamps.

(6) Tools likely to be used in wet and/or conductive locations need not be grounded if supplied through an isolating transformer with an ungrounded secondary of not over 50 volts. Listed or labeied portable tools and appliances protected by a system of double insulation, or its equivalent, need not be grounded. If such a system is employed, the equipment shall be distinctively marked to indicate that the tool or appliance utilizes a system of double insulation.

(v) Nonelectrical equipment. The metal parts of the following nonelectrical equipment shall be grounded: frames and tracks of electrically operated cranes: frames of nonelectrically driven elevator cars to which electric conductors are attached; hand-operated metal shifting ropes or cables of electric elevators, and metal partitions, grill work, and similar metal enclosures around equipment of over $1 \mathrm{kV}$ between conductors.

(8) Methods of grounding equipment-(i) With circuit conductors. Noncurrent-carrying metal parts of fixed equipment, if required to be grounded by this subpart, shall be grounded by an equipment grounding conductor which is contained within the same raceway, cable, or cord, or runs with or encloses the circuit conductors. For DC circuits only, the equipment grounding conductor may be run separately from the circuit conductors.

(ii) Grounding conductor. A conductor used for grounding fixed or movable equipment shall have capacity to conduct safely any fault current which may be imposed on it. (iii) Equipment considered effectively grounded Electric equipment is consid. ered to be effectively grounded if it is secured to, and in electrical contact with. a metal rack or structure that is provided for its support and the metal rack or structure is grounded by the method specified for the noncurrentcarrying metal parts of fixed equipment in paragraph $(f)(8)(i)$ of this section. Metal car frames supported by metal hoisting cables attached to or running over metal sheaves or drums of grounded elevator machines are also considered to be effectively grounded.

(9) Bonding. If bonding conductors are used to assure electrical continuity, they shall have the capacity to conduct any fault current which may be im. posed.

(10) Made electrodes. If made electrodes are used, they shall be free from nonconductive coatings, such as paint or enamel; and, if practicable, they shall be embedded below permanent moisture level. A single electrode consisting of a rod, pipe or plate which has a resistance to ground greater than $25 \mathrm{ohms}$ shall be augmented by one additional electrode installed no closer than 6 feet $(1.83 \mathrm{~m})$ to the first electrode.

(11) Grounding of systems and cir cuits of 1000 volts and over high voltage)-(i) General If high voltage systems are grounded, they shall comply with all applicable provisions of paragraphs (f)(1) through (f)(10) of this section as supplemented and modified by this paragraph (f)(11).

(ii) Grounding of systems supplying portable or mobile equipment. Systems supplying portable or mobile high voltage equipment, other than substations installed on a temporary basis, shall comply with the following.

(A) Portable and mobile high voltage equipment shall be supplied from a system having its neutral grounded through an impedance. If a deltaconnected high voltage system is used to supply the equipment, a system neutral shall be derived.

(B) Exposed noncurrent-carrying metal parts of portable and mobile equipment shall be connecked by an equipment grounding conductor to the point at which the system neutral impedance is grounded. 
(C) Ground-fault detection and relay. ing shall be provided to automatically de-energize any high voltage system component which has developed a ground fault. The continuity of the equipment grounding conductor shall be continuously monitored so as to deenergize automatically the high voltage feeder to the portable equipment upon loss of continuity of the equipment grounding conductor.

(D) The grounding electrode to which the portable or mobile equipment system neutral impedance is connected shall be isolated from and separated in the ground by at least 20 feet $(6.1 \mathrm{~m})$ from any other system or equipment grounding electrode, and there shall be no direct connection between the grounding electrodes, such as buried pipe, fence or like objects.

(iii) Grounding of equipment. All noncurrent-carrying metal parts of portable equipment and fixed equipment including those associated fences, housings, enclosures, and supporting structures shall be grounded. However, equipment which is guarded by location and isolated from ground need not be grounded. Additionally, pole-mounted distribution apparatus at a height exceeding 8 feet $(2.44 \mathrm{~m})$ above ground or grade level need not be grounded.

(Information collection requirements con. tained in paragraphs $(b)(1)($ iii) $(A)$ and (b)(1)(iii)(G) were approved by the Office of Management and Budget under control number: 1218-0062; information collection requirements contained in paragraph (f)(7)(iv) MC)(6) were approved by the Office of Management and Budget under control number. 1218-0130)

81926.405 Wiring methods, components, and equipment for general use.

(a) Wiring methods. The provisions of this paragraph do not apply to conductors which form an integral part of equipment such as motors, controllers, motor control centers and like equipment.

(1) Generad requirements. -(i) Electrical continuity of metal raceways and enclosures. Metal raceways, cable armor, and other metal enclosures for conduc. tors shall be metallically joined together into a continuous electric conductor and shall be so connected to all boxes. fittings, and cabinets as to provide effective electrical continuity.

(ii) Wiring in ducts. No wiring systems of any type shall be installed in ducts used to transport dust. loose stock or flammable vapors. No wiring system of any type shall be installed in any duct used for vapor removal or in any shaft containing only such ducts.

(2) Temporary wiring-(i) Scope. The provisions of paragraph (a)(2) of this section apply to temporary electrical power and lighting wiring methods which may be of a class less than would be required for a permanent installation. Except as specifically modified in paragraph (a)(2) of this section, all other requirements of this subpart for permanent wiring shall apply to temporary wiring installations. Temporary wiring shall be removed immediately upon completion of construction or the pur. pose for which the wiring was installed.

(ii) General requirements for temporary wiring. (A) Feeder shall originate in a distribution center. The conductors shall be run as multiconductor cord or cable assemblies or within raceways; or. where not subject to physical damage. they may be run as open conductors on insulators not more than 10 feet 13.05 m) apart.

(B) Branch circuits shall originate in a power outlet or panelboard. Conductors shall be run as multiconductor cord or cable assemblies or open conductors, or shall be run in raceways. All conductors shall be protected by overcurrent devices at their ampacity. Runs of open conductors shall be located where the conductors will not be subject to physical damage, and the conductors shall be fastened at intervals not exceeding 10 feet $(3.05 \mathrm{~m})$. No branch-circuit conductors shall be laid on the floor. Each branch circuit that supplies receptacles or fixed equipment shalf contain a separate equipment grounding conductor if the branch circuit is run as open conductors.

(C) Receptacles shall be of the grounding type. Unless installed in a complete metallic raceway, each branch circuit shall contain a separate equipment grounding conductor, and all receptacles shall be electrically connected to the grounding conductor. Receptacles for uses other than temporary lighting 
shall not be installed on branch circuits which supply temporary lighting. Receptacles shall not be connected to the same ungrounded conductor of multiwire circuits which supply temporary lighting.

(D) Disconnecting switches or plug connectors shall be installed to permit the disconnection of all ungrounded conductors of each temporary circuit.

(E) All lamps for general illumination shall be protected from accidental con. tact or breakage. Metal-case sockets shall be grounded.

(F) Temporary lights shall not be sus. pended by their electric cords unless cords and lights are designed for this means of suspension.

(G) Portable electric lighting used in wet and/or other conductive locations, as for example, drums, tanks, and vessels, shall be operated at 12 volts or less. However, 120-volt lights may be used if protected by a ground-fault circuit interrupter.

(H) A box shall be used wherever a change is made to a raceway system or a cable system which is metal clad or metal sheathed.

(I) Flexible cords and cables shall be protected from damage. Sharp cormers and projections shall be avoided. Flexi. ble cords and cables may pass through doorways or other pinch points, if protection is provided to avoid damage.

(J) Extension cord sets used with pos: table electric tools and appliances shall be of three-wire type and shall be de signed for hard or extra-hard usage. Flexible cords used with temporary and portable lights shall be designed for hard or extra-hard usage.

Note: The National Electrical Code. ANSI/NFPA 70 , in Article 400. Table 400-4, lists various types of flexible cords, some of which are noted as being designed for hard or extra-hard usage. Examples of these types of flexible conds include hard service cord (types S. ST, SO, STO) and junior hand service cord (types SJ, SJO, SJT, SJTO).

(iii) Guarding. For temporary wiring over 600 volts, nominal. fencing, barmers, or other effective means shall be provided to prevent access of other than authorized and qualified personnel.

(b) Cabinets, boxes, and fittings(1) Conductors entering boxes, cabinets, or fittings. Conductors entering boxes, cabinets, or fittings shall be protected from abrasion, and openings through which conductors enter shall be effec. tively closed. Unused openings in cabinets, boxes, and fittings shall also be effectively closed.

(2) Covers and canopies. All pull boxes, junction boxes, and fittings shall be provided with covers. If metal covers are used, they shall be grounded. In energized installations each outlet box shall have a cover, faceplate, or fixture canopy. Covers of outlet boxes having holes through which flexible cord pendants pass shall be provided with bush. ings designed for the purpose or shall have smooth, well-rounded surfaces on which the cords may bear.

(3) Pull and junction boxes for systems over 600 volts, nominal In addtion to other requirements in this section for pull and junction boxes, the following shall apply to these boxes for systems over 600 volts, nominal:

(i) Complete enclosure. Boxes shall provide a complete enclosure for the contained conductors or cables.

(ii) Covers. Boxes shall be closed by covers securely fastened in place. Underground box covers that weigh over 100 pounds $(43.6 \mathrm{~kg})$ meet this requirement. Covers for boxes shall be permanently marked "HIGH VOLTAGE." The marking shall be on the outside of the box cover and shall be readily visible and legible.

(c) Knife switches. Single-throw knife switches shall be so connected that the blades are dead when the switch is in the open position. Single-throw knife switches shall be so placed that gravity will not tend to close them. Single-throw knife switches approved for use in the inverted position shall be provided with a locking device that will ensure that the blades remain in the open position when so set. Double-throw knife switches may be mounted so that the throw will be either vertical or horizontal. However, if the throw is vertical, a locking device shall be provided to ensure that the blades remain in the open position when so set.

(d) Switchboards and panelboards. Switchboards that have any exposed live parts shall be located in permanently dry locations and accessible only to qualified persons. Panelboards shall 
be mounted in cabinets, cutout boxes, or enclosures designed for the purpose and shall be dead front. However, panelboards other than the dead front externally-operable type are permitted where accessible only to qualified persons. Exposed blades of knife switches shall be dead when open.

(e) Enclosures for damp or wet locations-(1) Cabinets, fittings, and boxes. Cabinets, cutout boxes, fittings, boxes, and panelboard enclosures in damp or wet locations shall be installed so as to prevent moisture or water from entering and accumulating within the enclosures. In wet locations the enclosures shall be weatherproof.

(2) Switches and circuit breakers. Switches, circuit breakers, and switchboards installed in wet locations shall be enclosed in weatherproof enclosures.

(f) Conductors for general wiring. All conductors used for general wiring shall be insulated unless otherwise permitted in this Subpart. The conductor insulation shall be of a type that is suitable for the voltage, operating temperature, and location of use. Insulated conductors shall be distinguishable by appropriate color or other means as being grounded conductors, ungrounded conductors, or equipment grounding conductors.

(g) Flexible cords and cables-(1) Use of flexible cords and cables-(i) Permitted uses. Flexible cords and cables shall be suitable for conditions of use and location. Flexible cords and cables shall be used only for:

(A) Pendants;

(B) Wiring of fixtures;

(C) Connection of portable lamps or appliances;

(D) Elevator cables;

(E) Wiring of cranes and hoists;

(F) Connection of stationary equipment to facilitate their frequent interchange;

(G) Prevention of the transmission of noise or vibration; or

(H) Appliances where the fastening means and mechanical connections are designed to permit removal for maintenance and repair.

(ii) Attachment plugs for cords. If used as permitted in paragraphs (g)(1)(i)(C), (G)(1)(i)(F), or (g)(1)(i)(H) of this section, the flexible cord shall be equipped with an attachment plug and shall be energized from a receptacle outlet.

(iii) Prohibited uses. Unless necessary for a use permitted in paragraph $(g)(1)(i)$ of this section, flexible cords and cables shall not be used:

(A) As a substitute for the fixed wiring of a structure;

(B) Where run through holes in walls, ceilings, or floors;

(C) Where run through doorways, windows, or similar openings, except as permitted in paragraph (a)(2)(ii)(I) of this section;

(D) Where attached to building surfaces; or

(E) Where concealed behind building walls, ceilings, or floors.

(2) Identification, splices, and terminations-(i) Identification A conductor of a flexible cord or cable that is used as a grounded conductor or an equipment grounding conductor shall be distinguishable from other conductors.

(ii) Marking. Type SJ, SJO, SJT. SJTO, S, SO, ST, and STO cords shall not be used unless durably marked on the surface with the type designation. size, and number of conductors.

(iii) Splices. Flexible cords shall be used only in continuous lengths without splice or tap. Hard service flexible cords No. 12 or larger may be repaired if spliced so that the splice retains the insulation, outer sheath properties, and usage characteristics of the cord being spliced.

(iv) Strain relief. Flexible cords shall be connected to devices and fittings so that strain relief is provided which will prevent pull from being directly transmitted to joints or terminal screws.

(v) Cords passing through holes. Flexible cords and cables shall be protected by bushings or fittings where passing through holes in covers, outlet boxes, or similar enclosures.

(h) Portable cables over 600 volts, nominal Multiconductor portable cable for use in supplying power to portable or mobile equipment at over 600 volts. nominal, shall consist of No. 8 or larger conductors employing flexible stranding. Cables operated at over 2000 volts shall be shielded for the purpose of confining the voltage stresses to the insulation. Grounding conductors shall be provided. 
Connectors for these cables shall be of a locking type with provisions to prevent their opening or closing while energized. Strain relief shall be provided at connections and terminations. Portable cables shall not be operated with splices unless the splices are of the permanent molded. vulcanized, or other equivalent type. Termination enclosures shall be marked with a high voltage hazard warning, and terminations shall be accessible only to authorized and qualified personnel.

(i) Fixture wires-(1) General Fixture wires shall be suitable for the voltage, temperature, and location of use. $A$ fixture wire which is used as a grounded conductor shall be identified.

(2) Uses permitted. Fixture wires may be used:

(i) For installation in lighting fixtures and in similar equipment where enclosed or protected and not subject to bending or twisting in use; or

(ii) For counecting lighting fixtures to the branch-circuit conductors supplying the fixtures.

(3) Uses not permitted Fixture wires shall not be used as branch-circuit conductors except as permitted for Class 1 power-limited circuits.

(j) Equipment for general use(1) Lighting fixtures, lampholders, lamps, and receptacles-(i) Live parts. Fixtures, lampholders, lamps, rosettes, and receptacles shall have no live parts normally exposed to employee contact. However, rosettes and cleat-type lampholders and receptacles located at least 8 feet $(2.44 \mathrm{~m})$ above the floor may have exposed parts.

(ii) Support Fixtures, lampholders, rosettes, and receptacles shall be securely supported. A fixture that weighs more than 6 pounds $(2.72 \mathrm{~kg})$ or exceeds 16 inches $(406 \mathrm{~mm})$ in any dimension shall not be supported by the screw shell of a lampholder.

(iii) Portable lamps. Portable lamps shall be wired with flexible cord and an attachment plug of the polarized or grounding type. If the portable lamp uses an Edison-based lampholder, the grounded conductor shall be identified and attached to the screw shell and the identified blade of the attachment plug. In addition. portable handlamps shall comply with the following.
(A) Metal shell, paperlined lampholders shall not be used.

(B) Handlamps shall be equipped with a handle of molded composition or other insulating material;

(C) Handlamps shall be equipped with a substantial guard attached to the lampholder or handle;

(D) Metallic guards shall be grounded by the means of an equipment grounding conductor run within the power supply cord.

(iv) Lampholders. Lampholders of the screw-shell type shall be installed for use as lampholders only. Lampholders installed in wet or damp locations shall be of the weatherproof type.

(v) Fixtures. Fixtures installed in wet or damp locations shall be identified for the purpose and shall be installed so that water cannot enter or accumulate in wireways, lampholders, or other electrical parts.

(2) Receptacles, cord connectors, and attachment plugs (caps)(i) Configuration Receptacles, cord connectors, and attachment plugs shall be constructed so that no receptacle or cord connector will accept an attachment plug with a different voltage or current rating than that for which the device is intended. However, a 20. ampere T-slot receptacle or cord connector may accept a 15-ampere attachment plug of the same voltage rating. Receptacles connected to circuits having different voltages, frequencies, or types of current (ac or dc) on the same premises shall be of such design that the attachment plugs used on these circuits are not interchangeable.

(ii) Damp and wet locations. A receptacle installed in a wet or damp location shall be designed for the location.

(3) Appliances-(i) Live parts. Appliances, other than those in which the current-carrying parts at high temperatures are necessarily exposed, shall have no live parts normally exposed to employee contact.

(ii) Disconnecting means. A means shall be provided to disconnect each appliance.

(iii) Rating. Each appliance shall be marked with its rating in volts and amperes or volts and watts.

(4) Motors. This paragraph applies to 
motors, motor circuits, and controllers.

(i) In sight from If specified that one piece of equipment shall be "in sight from" another piece of equipment, one shall be visible and not more than 50 feet $(15.2 \mathrm{~m})$ from the other.

(ii) Disconnecting means-(A) A disconnecting means shall be located in sight from the controller location. The controller disconnecting means for motor branch circuits over 600 volts, nominal, may be out of sight of the controller, if the controller is marked with a warning label giving the location and identification of the disconnecting means which is to be locked in the open position.

(B) The disconnecting means shall disconnect the motor and the controller from all ungrounded supply conductors and shall be so designed that no pole can be operated independently.

(C) If a motor and the driven machinery are not in sight from the controller location, the installation shall comply with one of the following conditions:

(1) The controller disconnecting means shall be capable of being locked in the open position.

(2) A manually operable switch that will disconnect the motor from its source of supply shall be placed in sight from the motor location.

(D) The disconnecting means shall plainly indicate whether it is in the open (off) or closed (on) position.

(E) The disconnecting means shall be readily accessible. If more than one disconnect is provided for the same equipment, only one need be readily accessible.

(F) An individual disconnecting means may be used for a group of motors under any one of the following conditions:

(1) If a number of motors drive special parts of a single machine or piece of apparatus, such as a metal or wood. working machine, crane, or hoist;

(2) If a group of motors is under the protection of one set of branch-circuit protective devices; or

(3) If a group of motors is in a single room in sight from the location of the disconnecting means.

(iii) Motor overload, short-circuit, and ground-fault protection. Motors, motorcontrol apparatus, and motor branch- circuit conductors shall be protected against overheating due to motor overloads or failure to start, and against short-circuits or ground faults. These provisions do not require overload protection that will stop a motor where a shutdown is likely to introduce addi. tional or increased hazards, as in the case of tire pumps, or where continued operation of a motor is necessary for a safe shutdown of equipment or process and motor overload sensing devices are connected to a supervised alarm.

(iv) Protection of live parts-all volt. ages. (A) Stationary motors having commutators, collectors, and brush rig. ging located inside of motor end brackets and not conductively connected to supply circuits operating at more than 150 volts to ground need not have such parts guarded. Exposed live parts of motors and controllers operating at 50 volts or more between terminals shall be guarded against accidental contact by any of the following:

(1) By installation in a room or enclosure that is accessible only to qualified persons;

(2) By installation on a balcony, gallery, or platform, so elevated and arranged as to exclude unqualified persons; or

(3) By elevation 8 feet $(2.44 \mathrm{~m})$ or more above the floor.

(B) Where live parts of motors or controllers operating at over 150 volts to ground are guarded against accidental contact only by location, and where adjustment or other attendance may be necessary during the operation of the apparatus, insulating mats or platforms shall be provided so that the attendant cannot readily touch live parts unless standing on the mats or platforms.

(5) Transformers-(i) Application. The following paragraphs cover the installa. tion of all transformers, except:

(A) Current transformers;

(B) Dry-type transformers installed as a component part of other apparatus;

(C) Transformers used with Class 2 and Class 3 circuits, sign and outline lighting, electric discharge lighting, and power-limited fire-protective signaling circuits.

(ii) Operating voltage. The operating voltage of exposed live parts of trans: former installations shall be indicated 
by warning signs or visible markings on the equipment or structure.

(iii) Transformers over $35 k V$. Dry. type, high fire point liquid-insulated, and askarel-insulated transformers installed indoors and rated over $35 \mathrm{kV}$ shall be in a vault.

(iv) Oil-insulated transformers. If they present a fire tazard to employees, oilinsulated transformers installed indoors shall be in a vault.

(v) Fire protection Combustible mate rial, combustible buildings and parts of buildings, fire escapes, and door and window openings shall be safeguarded from fires which may originate in oilinsulated transformers attached to or adjacent to a building or combustible material.

(vi) Transformer voults. Transformer vaiults shall be constructed so as to contain fire and combustible liquids within the vault an to prevent unauihorized access. Locks and latches shall be so arranged that a vault door can be readily opened from the inside.

(vii) Pipes and ducts. Any pipe or duct system, foreign to the vault installation shail not enter or pass through a transformer vault.

(viii) Material storage. Materials 3hall not be stored in transformer vaults.

(6) Capacitors-(i) Drainage of stored charge. All capacitors, except surge capacitors or capacitors included as a component part of other apparatus, shall be provided with an automatic means of draining the stored charge and maintaining the discharged state after the capacitor is disconnected from its source of supply.

(ii) Over 600 volts. Capecitors rated over 600 volts, nominal, shall comply with the following additional require ments:

(A) Isolating or disconnecting switches (with no interrupting rating) shall be interiocked with the load inter. rupting device or shall be provided with prominently displayed caution signs to prevent switching load current.

(B) For series capacitors the proper switching shall be assured by use of at least one of the following.

(1) Mechanically sequenced isolating and bypass switches,

(2) Interlocks, or

(3) Swritching procedure prominently displayed at the switching location.
(Information collection requirements contained in paragraphs (g)(2)(ii), (j)/(3)(iii). (j)4K(ii)(A). (j)(5)(ii), and (j)(6)(ii)(B)(3) were ap proved by the Office of Management and Budget under control number. 1218-0130)

81926.406 Specific purpose equipment and installations.

(a) Cranes and hoists. This paragraph applies to the installation of electric equipment and wiring used in connection with cranes, monorail hoists, hoists, and all runways.

(1) Diszonnecting means-(i) Runway conductor disconnecting means. A readily accessible disconnecting means shall be provided between the runway contact conductors and the power supply.

(ii) Disconnecting means for cranes and monorail hoists. A disconnecting means, capable of being locked in the open position, shall be provided in the leads from the runway contact conductors or other power supply or any crane or monorail hoist.

(A) If this additional disconnecting means is not readily accessible from the crane or monorail hoist operating station, means shall be proviejed at the operating station to open the power circuit to all motors of the crane or monorail hoist.

(B) The additional disconnect may be omitted if a monorail hoist or handpropelled crane bridge installation meets all of the following:

(1) The unit is iloor controlled;

(2) The unit is within view of the power supply disconnecting means; and

(3) No fired work platform has been provided for servicing the unit.

(2) Control A limit switch or other device shall be provided to prevent the load block from passing the safe upper limit of travel of any hoisting mechanism.

(3) Clearance. The dimension of the worloing space in the direction of access to live parts which may require examination, adjustment, servicing, or maintenance while alive shall be a minimum of 2 feet 6 inches $17.62 \mathrm{~mm}$. Where controls are enclosed in cabinets, the door(s) shall open at least 90 degrees or be removable, or the installation shall provide equivalent access.

(4) Grounding. All exposed metal parts of cranes, monorail hoists, hoists 
and accessories including pendant controls shall be metallically joined to gether into a continuous electrical conductor so that the entire crane or hoist will be grounded in accordance with $\$ 1926.404(f)$. Moving parts, other than removable accessories or attachments, having metal-to-metal bearing surfaces shall be considered to be electrically connected to each other through the bearing surfaces for grounding purposes. The trolley frame and bridge frame shall be considered as electrically grounded through the bridge and trolley wheels and its respective tracks unless conditions such as paint or other insulating materials prevent reliable metalto-metal contact. In this case a separate bonding conductor shall be provided.

(b) Elevators, escalators, and moving walks-(1) Disconnecting means. Elevators, escalators, and moving walks shall have a single means for disconnecting all ungrounded main power supply conductors for each unit.

(2) Control panels. If control panels are not located in the same space as the drive machine, they shall be located in cabinets with doors or panels capable of being locked closed.

(c) Electric welders-disconnecting means-(1) Motorgenerator, AC transformer, and DC rectifier arc welders. A disconnecting means shall be provided in the supply circuit for each motorgenerator arc welder, and for each AC transformer and DC rectifier arc welder which is not equipiss with a disconnect mounted as an interral part of the welder.

(2) Resistance welders. A switch or circuit breaker shall be provided by which each resistance welder and its control equipment can be isolated from the supply circuit. The ampere rating of this disconnecting means shall not be less than the supply conductor ampacity.

(d) X-ray equipment-(1) Disconnecting means-(i) General A disconnecting means shall be provided in the supply circuit. The disconnecting means shall be operable from a location readily accessible from the X-ray control. For equipment connected to a 120-volt branch circuit of 30 amperes or less, a grounding-type attachment plug cap and receptacle of proper rating may serve as a disconnecting means. (ii) More than one piece of equipment. If more than one piece of equipment is operated from the same high-voltage circuit, each piece or each group of equipment as a unit shall be provided with a high-voltage switch or equivalent disconnecting means. This disconnecting means shall be constructed. enclosed. or located so as to avoid contact by employees with its live parts.

(2) Control Radiographic and fluoroscopic types. Radiographic- and fluoroscopic-type equipment shall be effectively enclosed or shall have interlocks that deenergize the equipment automatically to prevent ready access to live current-carrying parts.

\subsection{Hezardous (classified) locations.}

(a) Scope. This section sets forth requirements for electric equipment and wiring in locations which are classified depending on the properties of the flammable vapors, liquids or gases, or combustible dusts or fibers which may be present therein and the likelihood that a fiammable or combustible concentration or quantity is present. Each room, section or area shall be considered individually in determining its classification. These hazardous (classified) locations are assigned six designations as follows:

Class I, Division 1

Class I, Division 2

Class II. Division 1

Class II, Division 2

Class III, Division 1

Class III, Division 2

For definitions of these locations see 8 1926.449. All applicable requirements in this subpart apply to all hazardous (classified) locations, unless modified by provisions of this section.

(b) Electrical installations. Equipment, wiring methods, and installations of equipment in hazardous (classified) locations shall be approved as intrinsically safe or approved for the hazardous (classified) location or safe for the hazardous (classified) location. Requirements for each of these options are as follows:

(1) Intrinsically safe. Equipment and associated wiring approved as intrinsically safe is permitted in any hazardous (classified) location included in its listing or labeling. 
(2) Approved for the hazardous /classified) location-(i) General Equipment shall be approved not only for the class of location but also for the ignitible or combustible properties of the specific gas, vapor, dust, or fiber that will be present.

NOTE: NFPA 70, the National Electrical Code, lists or defines hazardous gases, vapors, and dusts by "Groups" characterized by their ignitible or combustible properties.

(ii) Marking. Equipment shall not be used unless it is marked to show the class, group, and operating temperature or temperature range, based on opera. tion in a 40-degree $C$ ambient, for which it is approved. The temperature mark. ing shall not exceed the ignition temperature of the specific gas, vapor, or dust to be encountered. However, the follow. ing provisions modify this marking requirement for specific equipment:

(A) Equipment of the non-heatproducing type (such as junction boxes, conduit, and fittings) and equipment of the heat-producing type having a maximum temperature of not more than 100 degrees C (212 degrees F) need not have a marked operating temperature or temperature range.

(B) Fixed lighting fixtures marked for use only in Class I, Division 2 locations need not be marked to indicate the group.

(C) Fixed general-purpose equipment in Class I locations, other than lighting fixtures, which is acceptable for use in Class I, Division 2 locations need not be marked with the class, group, division, or operating temperature.

(D) Fixed dust-tight equipment, other than lighting fixtures, which is scceptable for use in Class II. Division 2 and Class III locations need not be marked with the class, group, division, or operating temperature.

(3) Safe for the hazardous (classified) location Equipment which is safe for the location shall be of a type and design which the employer demonstrates will provide protection from the hazards arising from the combustibility and flammability of vapors, liquids, gases, dusts, or fibers.

Note: The National Electrical Code. NFPA 70. contains guidelines for determin. ing the type and deaign of equipment and installations which will meet this require ment. The guidelines of this document ad. dress electric wiring, equipment, and systems installed in hazardous (classified) locations and contain specific provisions for the following: wiring methods, wiring connections, conductor insulation, flexible cords. sealing and drainage, transformers, capacitors, switches, circuit breakers. fuses, motor controllers, receptacles, attachment plugs. meters, relays, instruments, resistors, generators, motors, lighting fixtures, storage battery charging equipment, electric cranes, electric hoists and similar equipment, utilization equipment, signaling systems, alarm sys. tems, remote control systems, local loud speaker and communication systems, ventila. tion piping. live parts, lightning surge protection, and grounding. Compliance with these guidelines will constitute one means, but not the only means, of compliance with this paragraph.

(c) Conduits. All conduits shall be threaded and shall be made wrenchtight. Where it is impractical to make a threaded joint tight, a bonding jumper shall be utilized.

(Information collection requirements contained in paragraph (b)(2)(ii) were approved by the Oftice of Management and Budget under control number: 1218-0130)

\subsection{Special ayatema.}

(a) Systems over 600 volts, nominal Paragraphs (ak1) through (a)(4) of this section contain general requirements for all circuits and equipment operated at over 600 volts.

(1) Wiring methods for fixed installa. tions-(i) Above-ground Above-ground conductors shall be installed in rigid metal conduit, in intermediate metal conduit, in cable trays, in cablebus, in other suitable raceways, or as open runs of metal-clad cable designed for the use and purpose. However, open runs of non-metallic-sheathed cable or of bare conductors or busbars may be installed in locations which are accessible only to qualified persons. Metallic shielding components, such as tapes, wires, or braids for conductors, shall be srounded. Open runs of insulated wires and cables having a bare lead sheath or a braided outer covering shall be supported in a manner designed to prevent physical damage to the braid or sheath.

(ii) Installations emerging from the ground Conductors emerging from the ground shall be enclosed in raceways. 
Raceways installed on poles shall be of rigid metal conduit, intermediate metal conduit. PVC schedule 80 or equivalent extending from the ground line up to a point 8 feet $(2.44 \mathrm{~m})$ above finished grade. Conductors entering a building shall be protected by an enclosure from the ground line to the point of entrance. Metallic enclosures shall be grounded.

(2) Interrupting and isolating devices-(i) Circuit breakers. Circuit break. ers located indoors shall consist of metal-enclosed or fire-resistant, cellmounted units. In locations accessible only to qualified personnel, open mounting of circuit breakers is permitted. A means of indicating the open and closed position of circuit breakers shall be provided.

(ii) Fused cutouts. Fused cutouts installed in buildings or transformer vaults shall be of a type identified for the purpose. They shall be readily acces. sible for fuse replacement.

(iii) Equipment isolating means. A means shall be provided to completely isolate equipment for inspection and repairs. Isolating means which are not designed to interrupt the load current of the circuit shall be either interlocked with a circuit interrupter or provided with a sign warning against opening them under load.

(3) Mobile and portable equipment(i) Power cable connections to mobile machines. A metallic enclosure shall be provided on the mobile machine for enclosing the terminals of the power cable. The enclosure shall include provisions for a solid connection for the ground wire(s) terminal to ground effectively the machine frame. The method of cable termination used shall prevent any strain or pull on the cable from stressing the electrical connections. The enclosure shall have provision for locking so only authorized qualified persons may open it and shall be marked with a sign warning of the presence of energized parts.

(ii) Guarding live parts. All energized switching and control parts shall be enclosed in effectively grounded metal cabinets or enclosures. Circuit breakers and protective equipment shall have the operating means projecting through the metal cabinet or enclosures so these units can be reset without locked doors being opened. Enclosures and metal cabinets shall be locked so that only author. ized qualified persons have access and shall be marked with a sign waming of the presence of energized parts. Collector ring assemblies on revolving-type machines (shovels, draglines, etc.) shall be guarded.

(4) Tunnel installations-(i) Application. The provisions of this paragraph apply to installation and use of highvoltage power distribution and utilization equipment which is associated with tunnels and which is portable and/or mobile, such as substations, trailers. cars, mobile shovels, draglines, hoists. drills, dredges, compressors, pumps. conveyors, and underground excavators.

(ii) Conductors. Conductors in tunnels shall be installed in one or more of the following:

(A) Metal conduit or other metal raceway,

(B) Type MC cable, or

(C) Other suitable multiconductor cable.

Conductors shall also be so located or guarded as to protect them from physical damage. Multiconductor portable cable may supply mobile equipment. An equipment grounding conductor shall be run with circuit conductors inside the metal raceway or inside the multiconductor cable jacket. The equipment grounding conductor may be insulated or bare.

(iii) Guarding live parts. Bare terminals of transformers, switches, motor controllers, and other equipment shall be enclosed to prevent accidental contact with energized parts. Enclosures for use in tunnels shall be drip-proof, weatherproof, or submersible as required by the environmental conditions.

(iv) Disconnecting means. A disconnecting means that simultaneously opens all ungrounded conductors shall be installed at each transformer or motor location.

(v) Grounding and bonding. All nonenergized metal parts of electric equipment and metal raceways and cable sheaths shall be grounded and bonded to all metal pipes and rails at the portal and at intervals not exceeding 1000 feet $(305 \mathrm{~m})$ throughout the tunnel. 
(b) Class 1, Class 2 and Class 3 remote control signaling, and power limited circuits-(1) Classification Class 1. Class 2, or Class 3 remote control, signaling, or power-limited circuits are characterized by their usage and electrical power limitation which differentiates them from light and power circuits. These circuits are classified in accord. ance with their respective voltage and power limitations as summarized in paragraphs (b)(1)(i) through (b)(1)(iii) of this section.

(i) Class 1 circuits. -(A) A class 1 power-limited circuit is supplied from a source having a rated output of not more than 30 volts and 1000 volt. amperes.

(B) A Class 1 remote control circuit or a Class 1 signaling circuit has a voltage which does not exceed 600 volts; however, the power output of the source need not be limited.

(ii) Class 2 and Class 3 circuits. (A) Power for Class 2 and Class 3 circuits is limited either inherently (in which no overcurrent protection is re quired) or by a combination of a power source and overcurrent. protection.

(B) The maximum circuit voltage is 150 volts $A C$ or $D C$ for a Class 2 inherently limited power source, and 100 volts $A C$ or $D C$ for a Class 3 inherently limited power source.

(C) The maximum circuit voltage is 30 volts $A C$ and 60 volts $D C$ for a Class 2 power source limited by overcurrent protection, and 150 volts AC or DC for a Class 3 power source limited by overcurrent protection.

(iii) Application The maximum circuit voltages in paragraphs (b)(1)(i) and (b)(1)(ii) of this section apply to sinusoidal AC or continuous DC power sources, and where wet contact occurrence is not likely.

(2) Marking. A Class 2 or Class 3 power supply unit shall not be used unless it is durably marked where plainly visible to indicate the class of supply and its electrical rating.

(c) Communications systems(1) Scope These provisions for communication systems apply to such systems as central-station-connected and noncentral-station-connected telephone circuits, radio receiving and transmitting equipment, and outside wiring for fire and burglar alarm, and similar central station systems. These installations need not comply with the provisions of $\$ \$ 1926.403$ through 1926.408(b), except $\$ 1926.404(\mathrm{c})(1)$ (ii) and \$ 1926.407 .

(2) Protective devices-(i) Circuits exposed to power conductors. Communication circuits so located as to be exposed to accidental contact with light or power conductors operating at over 300 volts shall have each circuit so exposed provided with an approved protector.

(ii) Antenna lead-ins. Each conductor of a lead-in from an outdoor antenna shall be provided with an antenna discharge unit or other means that will drain static charges from the antenna system.

(3) Conductor location-(i) Outside of buildings. - (A) Receiving distribution lead-in or aerial-drop cables attached to buildings and lead-in conductors to radio transmitters shall be so installed as to avoid the possibility of accidental contact with electric light or power conductors.

(B) The clearance between lead-in conductors and any lightning protection conductors shall not be less than 6 feet $(1.83 \mathrm{~m})$.

(ii) On poles. Where practicable, communication sonductors on poles shall be located below the light or power conduc. tors. Communications conductors shall not be attached to a crossarm that carries light or power conductors.

(iii) Inside of buildings. Indoor antennas, lead-ins, and other communication conductors attached as open conductors to the ingide of buildings shall be located at least 2 inches $(50.8 \mathrm{~mm})$ from conductors of any light or power or Class 1 circuits unless a spocial and equally protective method of conductor separation is employed.

(4) Equipment location. Outdoor metal structures supporting antennas, as well as self-supporting antennas such as vertical rods or dipole structures, shall be located as far away from over. head conductors of electric light and power circuits of over 150 volts to ground as necessary to avoid the possibility of the antenna or structure falling into or making accidental contact with such circuits.

(5) Grounding-(i) Lead-in conductors. 
If exposed to contact with electric light or power conductors, the metal sheath of aerial cables entering buildings shall be grounded or shall be interrupted close to the entrance to the building by an insulating joint or equivalent device. Where protective devices are used, they shall be grounded.

(ii) Antenna structures. Masts and metal structures supporting antennas shall be permanently and effectively grounded without splice or connection in the grounding conductor.

(iii) Equipment enclosures. Transmitters shall be enclosed in a metal frame or grill or separated from the operating space by a barrier, all metallic parts of which are effectively connected to ground. All external metal handles and controls accessible to the operating personnel shall be effectively grounded. Unpowered equipment and enclosures shall be considered grounded where connected to an attached coaxial cable with an effectively grounded metallic shield.

(Information collection requirements contained in paragraph (bK2) were approved by the Office of Management and Budget under control number. 1218-0130)

8 1926.409-8 1926.415. [Reserved]

\section{Safory-Related Work Practicos}

81926.416 General requirements.

(a) Protection of employees. (1) No employer shall permit an employee to work in such proximity to any part of an electric power circuit that the employee could contact the electric power circuit in the course of work, unless the employee is protected against electric shock by deenergizing the circuit and grounding it or by guarding it effectively by insulation or other means.

(2) In work areas where the exact location of underground electric powerlines is unknown, employees using jack-hammers, bars, or other hand tools which may contact a line shall be provided with insulated protective gloves.

(3) Before work is begun the employer shall ascertain by inquiry or direct observation, or by instruments, whether any part of an energized electric power circuit, exposed or concealed, is so located that the performance of the work may bring any person, tool, or machine into physical or electrical contact with the electric power circuit. The employer shall post and maintain proper waming signs where such a circuit exists. The employer shall advise employees of the location of such lines, the hazards involved, and the protective measures to be taken.

(b) Passageways and open spaces. (1) Barriers or other means of guarding shall be provided to ensure that workspace for electrical equipment will not be used as a passageway during periods when energized parts of electrical equipment are exposed.

(2) Working spaces, walkways, and similar locations shall be kept clear of cords so as not to create a hazard to employees.

(c) Load ratings. In existing installations, no changes in circuit protection shall be made to increase the load in excess of the load rating of the circuit wiring.

(d) Fuses. When fuses are installed or removed with one or both terminals energized, special tools insulated for the voltage shall be used.

(e) Cords and cables. (1) Worn or frayed electric cords or cables shall not be used.

(2) Extension cords shall not be fastened with staples, hung from nails, or suspended by wire.

81928.417 Lockout and tagging of circuits.

(a) Controls. Controls that are to be deactivated during the course of work on energized or deenergized equipment or circuits shall be tagged.

(b) Equipment and circuits. Equipment or circuits that are deenergized shall be rendered inoperative and shall have tags attached at all points where such equipment or circuits can be energized.

(c) Tags. Tags shall be placed to identify plainly the equipment or circuits being worked on.

\section{1928.418-8 1926.430 [Reverved]}

\section{Sofory-Rolated Maintenance and Envirenmontal Considerations}

81928.431 Maintenance of equipment.

The employer shall ensure that all wiring components and utilization equip- 
ment in hazardous locations are maintained in a dust-tight, dust-ignitionproof, or explosion-proof condition, as appropriate. There shall be no loose or missing screws, gaskets, threaded connections, seals, or other impairments to a tight condition.

81926.432 Environmental deteriaration of equipment.

(a) Deteriorating agents. (1) Unless identified for use in the operating environment, no conductors or equipment shall be located:

(i) In damp or wet locations;

(ii) Where exposed to gases, fumes, vapors, liquids, or other agents having a deteriorating effect on the conductors or equipment; or

(iii) Where exposed to excessive temperatures.

(2) Control equipment, utilization equipment, and busways approved for use in dry locations only shall be protected against damage from the weather during building construction.

(b) Protection against corrosion. Metal raceways, cable armor, boxes, cable sheathing, cabinets, elbows, couplings, fittings, supports, and support hardware shall be of materials appropriate for the environment in which they are to be installed.

\section{1926.433-8 1926.440 [Recerved]}

\section{Sofory Requiroments for Special Equipmont}

81926.441 Batteries and battery charging.

(a) General requirements. (1) Batteries of the unsealed type shall be located in enclosures with outside vents or in well ventilated rooms and shall be arranged so as to prevent the escape of fumes, gases, or electrolyte spray into other areas.

(2) Ventilation shall be provided to ensure diffusion of the gases from the battery and to prevent the accumulation of an explosive mirture.

(3) Racks and trays shall be substantial and shall be treated to make them resistant to the electrolyte.

(4) Floors shall be of acid resistant construction unless protected from acid accumulations.
(5) Face shields, aprons, and rubber gloves shall be provided for workers handling acids or batteries.

(6) Facilities for quick drenching of the eyes and body shall be provided within 25 feet $(7.62 \mathrm{~m})$ of battery handling areas.

(7) Facilities shall be provided for flushing and neutralizing spilled electrolyte and for fire protection.

(b) Charging. (1) Battery charging installations shall be located in areas des. ignated for that purpose.

(2) Charging apparatus shall be protected from damage by trucks.

(3) When batteries are being charged, the vent caps shall be kept in place to avoid electrolyte spray. Vent caps shall be maintained in functioning condition.

\section{1926.412-8 1926.448 [Reserved]}

\section{Dofinitions}

81926.449 Definitions applicable to this subpart.

The definitions given in this section apply to the terms used in Subpart $K$. The definitions given here for "approved" and "qualified person" apply, instead of the definitions given in $\$ 1926.32$, to the use of these terms in Subpart K.

Acceptable. An installation or equipment is acceptable to the Assistant Secretary of Labor, and approved within the meaning of this Subpart $K$ :

(a) If it is accepted, or certified, or listed, or labeled. or otherwise deter. mined to be safe by a qualified testing laboratory capable of determining the suitability of materials and equipment for installation and use in accordance with this standard; or

(b) With respect to an installation or equipment of a kind which no qualified testing laboratory accepts, certifies, lists, labels, or determines to be safe, if it is inspected or tested by another Federal agency, or by a State, municipal, or other local authority responsible for enforcing occupational safety provisions of the National Electrical Code, and found in compliance with those provisions; or

(c) With respect to custom-made equipment or related installations which are designed, fabricated for, and in- 
tended for use by its manufacturer on the basis of test data which the employer keeps and makes available for inspection to the Assistant Secretary and his authorized representatives.

Accepted. An installation is "accepted" if it has been inspected and found to be safe by a qualified testing laboratory.

Accessible. (As applied to wiring methods.) Capable of being removed or exposed without damaging the building structure or finish, or not permanently closed in by the structure or finish of the building. (See "concealed" and "exposed')

Accessible. (As applied to equipment.) Admitting close approach; not guarded by locked doors, elevation, or other effective means. (See "Readily accessible. ')

Ampacity. The current in amperes a conductor can carry continuously under the conditions of use without exceeding its temperature rating.

Appliances. Utilization equipment, generally other than industrial, normally built in standardized sizes or types, which is installed or connected as a unit to perform one or more functions.

Approved Acceptable to the authority enforcing this Subpart. The authority enforcing this Subpart is the Assistant Secretary of Labor for Occupational Safety and Health. The definition of "acceptable" indicates what is acceptable to the Assistant Secretary of Labor, and therefore approved within the meaning of this Subpart.

Askarel A generic term for a group of nonflammable synthetic chlorinated hydrocarbons used as electrical insulating media Askarels of various compositional types are used. Under arcing conditions the gases produced, while consisting predominantly of noncombustible hydrogen chloride, can include varying amounts of combustible gases depending upon the askarel type.

Attachment plug (Plug cap)(Cap). A device which, by insertion in a receptacle, establishes connection between the conductors of the attached flexible co:d and the conductors connected permanently to the receptacle.

Automatic. Self-acting, operating by its own mechanism when actuated by some impersonal influence, as for exam. ple, a change in current strength, pressure, temperature, or mechanical config. uration.

\section{Bare conductor. See "Conductor."}

Bonding. The permanent joining of metallic parts to form an electrically conductive path which will assure electrical continuity and the capacity to conduct safely any current likely to be imposed.

Bonding jumper. A reliable conductor to assure the required electrical conductivity between metal parts required to be electrically connected.

Branch circuit. The circuit conductors between the final overcurrent device protecting the circuit and the outlet(s).

Building. A structure which stands alone or which is cut off from adjoining structures by fire walls with all openings therein protected by approved fire doors.

Cabinet An enclosure designed either for surface or flush mounting, and provided with a frame, mat, or trim in which a swinging door or doors are or may be hung. it:

Certified Equipment is "certified" if

(a) Has been tested and found by a qualified testing laboratory to meet applicable test standards or to be safe for use in a specified manner, and

(b) Is of a kind whose production is periodically inspected by a qualified testing laboraotory. Certified equipment must bear a label, tag, or otber record of certification.

Circuit breaker. (a) 1600 volts nominal, or leas.) A device designed to open and close a circuit by nonautomatic means and to open the circuit automatically on a predetermined overcurrent without injury to itself when properly applied within its rating.

(b) (Over 600 volts, nominal.) A switching device capable of making, carrying, and breaking currents under normal circuit conditions, and also making. carrying for a specified time, and breaking currents under specified abnormal circuit cunditions, such as those of short circuit.

Class I locations. Class I locations are those in which flammable gases or vapors are or may be present in the air in quantities sufficient to produce explo- 
sive or ignitible mixtures. Class I locations include the following:

(a) Class I, Division 1. A Class I, Division 1 location is a location:

(1) In which ignitible concentrations of flammable gases or vapors may exist under normal operating conditions; or

(2) In which ignitible concentrations of such gases or vapors may exist frequently because of repair or mainte nance operations or because of leakage; or

(3) In which breakdown or faulty op eration of equipment or processes might release ignitible concentrations of flam. mable gases or vapors, and might also cause simultaneous failure of electric equipment.

NoTE: This classification usually includes locations wivere volatile flammable liquids or liquefied flammable gases are transferred from one container to another, interiors of spray booths and areas in the vicinity of spraying and painting operations whore volatile flammable solvents are used: locations containing open tanks or vats of volatile flammable liquids; drying rooms. or compart. ments for the evaporation of flammable solvents; inadequately ventilated pump rooms for flammable gas or for volatile flammable liquids; and all other locations where ignitible concentrations of flammable vapars or gases are likely to occur in the course of normal operations.

(b) Class I, Division 2 A Class I, Division 2 location is a location:

(1) In which volatile flammable liquids or flammable gases are handled, processed, or used, but in which the hazardous liquids, vapors, or gases will normally be confined within closed containers or closed systems from which they can escape only in case of accidental rupture or breakdown of such containers or systems, or in case of abnormal operation of equipment; or

(2) In which ignitible concentrations of gases or vapors are normally pre vented by positive mechanical ventilation, and which might become hazardous through failure or abnormal operations of the ventilating equipment; or

(3) That is adjacent to a Class I, Division 1 location, and to which ignitible concentrations of gases or vapors might occasionally be communicated unless such communication is prevented by adequate positive-pressure ventila- tion from a source of clean air, and effective safeguards against ventilation failure are provided.

NoTE: This classification usually includes locations where volatile flammable liquids or flammable gases or vapors are used, but which would become hazardous only in case of an accident or of some unusual operating condition. The quantity of flammable mate rial that might escape in case of accident. the adequacy of ventilating equipment, the total area involved, and the record of the industry or business with respect to explosions or fires are all factors that merit consideration in determining the classification and extent of each location.

Piping without valves, checks, meters, and similar devices would not ordinarily introduce a hazardous condition even though used for flammable liquids or gases. Locations used for the storage of flammable liquids or of liquefied or compressed gases in sealed containers would not normally be considered hazardous unless also subject to other hazardous conditions.

Electrical conduits and their associated enclosures separated from process fluids by a single seal or barrier are classed as a Divi. sion 2 location if the outside of the conduit and enclosures is a nonhazardous location.

Class II locations. Class II locations are those that are hazardous because of the presence of combustible dust. Class II locations include the following:

(a) Class II, Division 1. A Class II, Division 1 location is a location:

(1) In which combustible dust is or may be in suspension in the air under normal operating conditions, in quantities sufficient to produce explosive or ignitible mirtures; or

(2) Where mechanical failure or abnormal operation of machinery or equipment might cause such explosive or ignitible mixtures to be produced, and might afso provide a source of ignition through simultaneous failure of electric equipment, operation of protective devices, or from other causes, or

(3) In which combustible dusts of an electrically conductive nature may be present.

Nore: Combustible dusts which are electri. cally nonconducive include dusts produced in the handling and processing of grain and grain products, pulverized sugar and cocos, dried egg and milk powders. pulverized spices, starch and pastes. potato and woodflour, oil meal from beans and seed. dried hay, and other organic materials which 
may produce combustible dusts when processed or handled. Dusts containing magnesium or aluminum are particularly hazardous and the use of extreme caution is necessary to avoid ignition and explosion.

(b) Class II, Division 2. A Class II, Divison 2 location is a location in which:

(1) Combustible dust will not normally be in suspension in the air in quantities sufficient to produce explosive or ignitible mixtures, and dust accumulations are normally insufficient to interfere with the normal operation of electrical equipment or other apparatus; or

(2) Dust may be in suspension in the air as a result of infrequent malfunction. ing of handling or processing equipment, and dust accumulations resulting therefrom may be ignitible by abnormal operation or failure of electrical equipment or other apparatus.

Note: This classification includes locations where dangerous concentrations of suspended dust would not be likely but where dust accumulations might form on or in the vicinity of electric equipment. These areas may contain equipment from which appreciable quantities of dust would escape under abnor$\mathrm{mal}$ operating conditions or be adjacent to a Class II Division 1 location, as described above, into which an explosive or ignitible concentration of dust may be put into suspension under abnormal operating conditions.

(a) Class III locations. Class III locations are those that are hazardous be cause of the presence of easily ignitible fibers or flyings but in which such fibers or flyings are not likely to be in suspension in the air in quantities sufficient to produce ignitible mixtures. Class III locations include the following:

(a) Class III, Division 1. A Class III, Division 1 location is a location in which easily ignitible fibers or materials pro ducing combustible flyings are handled. manufactured, or used.

NoTE: Easily ignitible fibers and flyings include rayon, cotton (including cotton linters and cotton wastel, sisal or henequen, istle. jute, hemp, tow, cocos fiber, oakum, baled waste kapok. Spanish moss, excelsior, sawdust, woodchips, and other materials of similar nature.

(b) Class III, Division 2 A Class III, Division 2 location is a location in which easily ignitible fibers are stored or handled, except in process of manufacture.

Collector ring. A collector ring is an assembly of slip rings for transferring electrical energy from a stationary to a rotating member.

Concealed Rendered inaccessible by the structure or finish of the building. Wires in concealed raceways are consid. ered concealed, even though they may become accessible by withdrawing them. [See "Accessible. (As applied to wiring methods.)"]

Conductor-(a) Bare. A conductor having no covering or electrical insula. tion whatsoever.

(b) Covered. A conductor encased within material of composition or thickness that is not recognized as electrical insulation.

(c) Insulated A conductor encased with material of composition and thick. ness that is recognized as electrical insulation.

Controller. A device or group of devices that serves to govern, in some predetermined manner, the electric power delivered to the apparatus to which it is connected.

Covered conductor. Soe "Conductor."

Cutout. (Over 600 volts, nominal.) An assembly of a fuse support with either a fuseholder, fuse carrier, or disconnecting blade. The fuseholder or fuse carrier may include a conducting element (fuse link), or may act as the disconnecting blade by the inclusion of a nonfusible member.

Cutout box. An enclosure designed for surface mounting and having swinging doors or covers secured directly to and telescoping with the walls of the box proper. (See "Cabinet")

Damp location See "Location"

Dead front Without live parts exposed to a person on the operating side of the equipment.

Device. A unit of an electrical system which is intended to carry but not utilize electric energy.

Disconnecting means. A device, or group of devices, or other means by which the conductors of a circuit can be disconnected from their source of supply. 
Disconnecting (or Isolating) switch (Over 600 volts, nominal) A mechanical switching device used for isolating a circuit or equipment from a source of power.

Dry location See "Location."

Enclosed. Surrounded by a case, housing, fence or walls which will prevent persons from accidentally contacting energized parts.

Enclosure. The case or housing of apparatus, or the fence or walls surrounding an installation to prevent personnel from accidentally contacting energized parts, or to protect the equipment from physical damage.

Equipment. A general term including material, fittings, devices, appliances, fixtures, apparatus, and the like, used as a part of, or in connection with, an electrical installation.

Equipment grounding conductor. See "Grounding conductor, equipment."

Explosion-proof apparatus. Apparatus enclosed in a case that is capable of withstanding an explosion of a specified gas or vapor which may occur within it and of preventing the ignition of a specified gas or vapor surrounding the enclosure by sparks, flashes, or explosion of the gas or vapor within, and which operates at such an external temperature that it will not ignite a surrounding flammable atmosphere.

Exposed (As applied to live parts.) Capable of being inadvertently touched or approached nearer than a safe distance by a person. It is applied to parts not suitably guarded, isolated, or insulated. (See "Accessible." and "Concealed ')

Exposed (As applied to wiring methods.) On or attached to the surface or behind panels designed to allow access. [See "Accessible. (As applied to wiring methods.)"]

Exposed. (For the purposes of $\$ 1926.408$ (d). Communication systems.) Where the circuit is in such a position that in case of failure of supports or insulation, contact with another circuit may result.

Externally operable. Capable of being operated without exposing the operator to contact with live parts.
Feeder. All circuit conductors between the service equipment, or the generator switchboard of an isolated plant, and the final branch-circuit overcurrent device.

Festoon lighting. A string of outdoor lights suspended between two points more than 15 feet $(4.57 \mathrm{~m})$ apart.

Fitting. An accessory such as a locknut, bushing, or other part of a wiring system that is intended primarily to perform a mechanical rather than an electrical function.

Fuse. (Over 600 volts, nominal.) An overcurrent protective device with a circuit opening fusible part that is heated and severed by the passage of overcur. rent through it. A fuse comprises all the parts that form a unit capable of performing the prescribed functions. It may or may not be the complete device necessary to connect it into an electrical circuit.

Ground A conducting connection, whether intentional or accidental, be tween an electrical circuit or equipment and the earth, or to some conducting body that serves in place of the earth.

Grounded Connected to earth or to some conducting body that serves in place of the earth.

Grounded effectively. (Over 600 volts, nominal.) Permanently connected to earth through a ground connection of sufficiently low impedance and having sufficient ampacity that ground fault current which may occur cannot build up to voltages dangerous to personnel.

Grounded conductor. A system or circuit conductor that is intentionally grounded.

Grounding conductor. A conductor used to connect equipment or the grounded circuit of a wiring system to a grounding electrode or electrodes.

Grounding conductor, equipment. The conductor used to connect the noncurrent-carrying metal parts of equipment, raceways, and other enclosures to the system grounded conductor and/or the grounding electrode conduc. tor at the service equipment or at the source of a separately derived system.

Grounding electrode conductor. The conductor used to connect the grounding electrode to the equipment ground- 
ing conductor and/or to the grounded conductor of the circuit at the service equipment or at the source of a separately derived system.

Ground-fault circuit interrupter. A device for the protection of personnel that functions to deenergize a circuit or portion thereof within an established period of time when a current to ground exceeds some predetermined value that is less than that required to operate the overcurrent protective device of the supply circuit.

Guarded. Covered, shielded, fenced, enclosed, or otherwise protected by means of suitable covers, casings, barriers, rails, screens, mats, or plattorms to remove the likelihood of approach to a point of danger or contact by persons or objects.

Hoistway. Any shaftway, hatchway, well hole, or other vertical opening or space in which an elevator or dumbwaiter is designed to operate.

Identified (conductors or terminals). Identified, as used in reference to a conductor or its terminal, means that such conductor or terminal can be recog. nized as grounded.

Identified (for the use). Recognized as suitable for the specific purpose. function, use, environment, application, etc. where described as a requirement in this standard. Suitability of equipment for a specific purpose, environment, or application is determined by a qualified testing laboratory where such identification includes labeling or listing.

Insulated conductor. See "Conductor."

Interrupter switch lOver 600 volts, nominal.) A switch capable of making. carrying, and interrupting specified currents.

Intrinsically safe equipment and associated wiring. Equipment and associated wiring in which any spark or thermal effect, produced either normally or in specified fault conditions, is incapable. under certain prescribed test conditions, of causing igmition of a mixture of flammable or combustible material in air in its most easily ignitible concentration.

Isolated Not readily accessible to persons unless special means for access are used.
Isolated power system A system comprising an isolating transformer or its equivalent, a line isolation monitor. and its ungrounded circuit conductors.

Labeled Equipment or materials to which has been attached a label, symbol or other identifying mark or a qualified testing laboratory which indicates com. pliance with appropriate standards or performance in a specified manner.

Lighting outlet An outlet intended for the direct connection of a lampholder, a lighting fixture, or a pendant cord terminating in a lampholder. Listed Equipment or materials included in a list published by a qualified testing laboratory whose listing states either that the equipment or material meets appropriate standards or has been tested and found suitable for use in a specified manner.

Location-(a) Damp location. Par. tially protected locations under canopies, marquees, roofed open porches, and like locations, and interior locations subject to moderate degrees of moisture, such as some basements.

(b) Dry location A location not nor. mally subject to dampness or wetness. A location classified as dry may be temporarily subject to dampness or wetness, as in the case of a building under construction.

(c) Wet location Installations underground or in concrete slabs or masonry in direct contact with the earth, and locations subject to saturation with wa. ter or other liquids, such as locations exposed to weather and unprotecied. Mobile $X$-ray. X-ray equipment mounted on a permanent base with wheels and/or casters for moving while completely assembled.

Motor control center. An assembly of one or more enclosed sections having a common power bus and principally containing motor control units.

Outlet A point on the wiring system at which current is taken to supply utilization equipment.

Overcurrent Any current in excess of the rated current of equipment or the ampacity of a conductor. It may result from overload (see definition), short circuit, or ground fault. A current in excess of rating may be accommodated 
by certain equipment and conductors for a given set of conditions. Hence the rules for overcurrent protection are specific for particular situations.

Overload Operation of equipment in excess of normal, full load rating, or of a conductor in excess of rated ampacity which, when it persists for a sufficient length of time, would cause damage or dangerous overheating. A fault, such as a short circuit or ground fauit, is not an overload. (See "Overcurrent.)

Panelboard A single panel or group of panel units designed for assembly in the form of a single panel; including buses, automatic overcurrent devices, and with or without switches for the control of light, heat, or power circuits; designed to be placed in a cabinet or cutout box placed in or against a wall or partition and accessible only from the front. (See "Switchboard")

Portable X-ray. X-ray equipment designed to be hand-carried.

Power fuse (Over 600 volts, nominal.) See "Fuse."

Power outlet. An enclosed assembly which may include receptacles, circuit breakers, fuseholders, fused switches, buses and watt-hour meter mounting means; intended to serve as a means for distributing power required to operate mobile or temporarily installed equipment.

Premises wiring system. That interior and exterior wiring, including power, lighting, control and signal circuit wiring together with all of its associated hardware, fittings, and wiring devices, both permanently and temporarily installed, which extends from the loed end of the service drop, or load end of the service lateral conductors to the outlet(s). Such wiring does not include wiring internal to appliances, fixtures, motors, controllers, motor control centers, and similar equipment.

Qualified person One familiar with the construction and operation of the equipment and the hazards involved.

Qualified testing laboratory. A properly equipped and staffed testing laboratory which has capabilities for and which provides the following services:

(a) Experimental testing for safety of specified items of equipment and materi- ais referred to in this standard to determine compliance with appropriate test standards or performance in a specified manner;

(b) Inspecting the run of such items of equipment and materials at factories for product evaluation to assure compliance with the test standards:

(c) Service-value determinations through field inspections to monitor the proper use of labels on products and with authority for recall of the label in the event a hazardous product is installed:

(d) Employing a controlled procedure for identifying the listed and/or labeled equipment or materials tested; and

(e) Rendering creditable reports or findings that are objective and without bias of the tests and test methods employed.

Raceway. A channel designed expressly for holding wires, cables, or busbars, with additional functions as permitted in this subpart. Raceways may be of metal or insulating material, and the term includes rigid metal conduit, rigid nonmetallic conduit, intermediate metal conduit, liquid tight flexible metal conduit, flexible metallic tubing. flexible metal conduit, electrical metallic tubing, underfloor raceways, cellular concrete floor raceways, cellular metal floor raceways, surface raceways. wireways, and busways.

Readily accessible. Capable of being reached quickly for operation, renewal, or inspections, without requiring those to whom ready access is requisite to climb over or remove obstacles or to resort to portable ladders, chairs, etc. (See "Accessible.')

Receptacle. A receptacle is a contact device installed at the outlet for the connection of a single attachment plug. A single receptacle is a single contact device with no other contact device on the same yolke. A multiple receptacle is a single device containing two or more receptacles.

Receptacle outlet An outlet where one or more receptacles are installed.

Remote-control circuit. Any electric circuit that controls any other circuit through a relay or an equivalent device.

Sealable equipment. Equipment en- 
closed in a case or cabinet that is orovided with a means of sealing or locking so that live parts cannot be made accessible without opening the enclosure. The equipment may or may not be operable without opening the enclosure.

Separately derived system A pre mises wiring system whose power is derived from generator, transformer, or converter windings and has no direct electrical connection, including a solidly connected grounded circuit conductor. to supply conductors originating in another system.

Service. The conductors and equipment for delivering energy from the electricity supply system to the wiring system of the premises served.

Service conductors. The supply conductors that extend from the street main or from transformers to the ser. vice equipment of the premises supplied.

Service drop. The overhead service conductors from the last pole or other aerial support to and including the splices, if any, connecting to the serviceentrance conductors at the building or other structure.

Service-entrance conductors, overhead system. The service conductors between the terminals of the service equipment and a point usually outside the building, clear of building walls, where joined by tap or splice to the service drop.

Service-entrance conductors, under ground system. The service conductors between the terminals of the service equipment and the point of connection to the service lateral. Where service equipment is located outside the build. ing walls, there may be no serviceentrance conductors, or they may be entirely outside the building.

Service equipment. The necessary equipment, usually consisting of a circuit breaker or switch and fuses, and their accessories, located near the point of entrance of supply conductors to a building or other structure, or an otherwise defined area, and intended to constitute the main control and means of cutoff of the supply.

Service raceway. The raceway that encloses the serviceentrance conductors.

Signaling circuit Any electric circuit that energizes signaling equipment.

Switchboard A large single panel, frame, or assembly of panels which have switches, buses, instruments, overcurrent and other protective devices mounted on the face or back or both. Switchboards are generally accessible from the rear as well as from the front and are not intended to be installed in cabinets. (See "Panelboard")

Switches-(a) General-use switch A switch intended for use in general distribution and branch circuits. It is rated in amperes, and it is capable of interrupting its rated current at its rated voltage.

(b) General-use snap switch A form of general-use switch so constructed that it can be installed in flush device boxes or on outlet box covers, or otherwise used in conjunction with wiring systems recognized by this subpart.

(c) Isolating switch A switch intended for isolating an electric circuit from the source of power. It has no interrupting rating, and it is intended to be operated only after the circuit has been opened by some other means.

(d) Motor-ircuit switch A switch, rated in horsepower, capable of interrupting the maximum operating overload current of a motor of the same horsepower rating as the switch at the rated voltage.

Switching devices. (Over 600 volts, nominal.) Devices designed to close and/or open one or more electric circuits. Included in this category are circuit breakers, cutouts, disconnecting (or isolating) switches, disconnecting means, and interrupter switches.

Transportable $X$-ray. X-ray equipment installed in a vehicle or that may readily be disassembled for transport in a vehicle.

Utilization equipment. Utilization equipment means equipment which utilizes electric energy for mechanical. chemical, heating, lighting, or similar useful purpose.

Utilization system A utilization system is a system which provides electric power and light for employee workplaces, and includes the premises wiring system and utilization equipment. 
Ventilated Provided with a means to permit circulation of air sufficient to remove an excess of heat, fumes, or vapcrs.

Volatile flammable liquid A flummable liquid having a flash point below 38 degrees C (100 degrees F) or whose temperature is above its flash point, or a Class II combustible liquid having a vapor pressure not exceeding 40 psia $(276 \mathrm{kPa})$ at $38^{\circ} \mathrm{C}\left(100^{\circ} \mathrm{F}\right)$ whose temperature is above its flash point.

Voltage. (Of a circuit.) The greatest root-mean-square (effective) difference of potential between any two conductors of the circuit concerned

Voltage, nominal A nominal value assigmed to a circuit or system for the purpose of conveniently desigmating its voltage class (as 120/240, 480 Y/277,600, etc.). The actual voltage at which a circuit operates can vary from the nominal within a range tiat permits satisfactory operation of equ ipment.

Voltage to ground For grounded circuits, the voltage between the given conductor and that point or conductor of the circuit that is grounded; for ungrounded circuits, the greatest voltage between the given conductor and any other conductor of the circuit.

Watertight So constructed that moisture will not enter the enclosure.

Weatherproof. So constructed or protected that exposure to the weather will not interfere with successful operation. Rainproof, raintight, or watertight equipment can fulfill the requirements for weatherproof where varying weather conditions other than wetness, such as snow, ice, dust, or temperature extremes, are not a factor.

Wet location See "Location"

\section{Subpart L-Loddors and Secffolding}

\subsection{Ladder.}

(2) General requirements. (1) Except where either permanent or temporary stairways or sultable ramps or runways are provided, ladders described in this subpart shall be used to give safe access to all elevations.

(2) The use of iadders with broken or missing rungs or steps, broken or split side rails, or other faulty or defective construction is prohibited. When ladders with such defects are discovered, they shall be immediately withdrawn from service. Inspection of metal ladders shall include checking for corrosion of interiors of open end hollow rungs.

(3) Manufactured portable wood ladders provided by the employer shall be in accordance with the provisions of the American National Standards In. stitute, A 14.1-1968, Safety Code for Portable Wood Ladders.

(4) Portable metal ladders shall te of strength equivalent to that of wood ladders. Manufactured portable metal ladders provided by the employer shall be in accordance with the provisions of the American National Standards Institute. A 14.2-1956, Safety Code for Portable Metal Ladders.

(5) Fixed ladders shall be in accord. ance with the provisions of the Ameri. can National Standards Institute, A 14.3-1956, Safety Code for Fixed Ladders.

(6) Portable ladder feet shall be placed on a substantial base, and the area around the top and bottom of the ladder shall be kept clear.

(7) Portable ladders shall be used at such a pitch that the horizontal distance from the top support to the foot of the ladder is about one-quarter of the working length of the ladder (the lensth along the ladder between the foot and the top support). Ladders shall not be used in a horizontal posi. tion as platforms, runways, or scaf. folds.

(8) Ladders shall not be placed in passageways, doorways, driveways, or any location where they may be dis. placed by sctivities being conducted on any other work. unless protected by barricades or guards.

(9) The side rails shall extend not less than 36 inches above the landing. When this is not practical, grab rails, which provide a secure grip for an employee moving to or from the point of access, shall be installed.

(10) Portable ladders in use shall be tied, blocked, or otherwise secured to prevent their being displaced.

(11) Portable metal ladders shall not be used for electrical work or where they may contact electrical conductors.

(b) Job-made ladders. (1) Job-made ladders shall be constructed for intended use. If a ladder is to provide 
Appendix F

OSP Example 


\title{
LAWRENCE LIVERMORE NATIONAL LABORATORY
}

\author{
Operational Safety Procedure \\ Revised: \\ 3-14-93 \\ No. $\underline{0.121}$ \\ Expires: \\ 3-14-94 \\ Review Level: A
}

\section{TITLE: LIVERMORE GROUND WATER INVESTIGATION}

REASON FOR ISSUE: An Operational Safety Procedure is required for all off-site operations where the Laboratory has primary management responsibility.

RESPONSIBILITIES: R.C.Ragaini, Environmental Protection Department Head, and his Associate $\mathrm{E}$. Hoffman (Alternate) are responsible for implementing the controls contained in this safety procedure and in other applicable Laboratory safety standards and for the safety of this operation.

LOCATION: Drilling and sampling operations may be conducted in the Livermore Valley and areas surrounding Site 300.

\section{WORK TO BE DONE:}

1. Aquifer mapping and sampling.

2. Well drilling and emplacement of drilling and pumping equipment.

3. Sample collection.

\section{HAZARDS ANALYSIS:}

The sources of possible personnel injury or property damage associated with the operations are:

1. Drilling Operations

Personnel working in and near drilling rigs and platforms where hazards include moving machinery, high pressure, flammable and/or combustible fluids, scaffolding, cranes, falling objects, drilling through underground utilities, flying machinery parts, overhead power lines, and unsafe footing.

\section{Electrical Hazards}

Electric power is supplied by gasoline or diesel engine generators. Working conditions may be wet and electrical shock possible.

3. Material Handling

Lifting of heavy and bulky equipment and boxes on and off truck at emplacement locations is required.

OPERATING AND PERSONNEL CONTROLS: To effectively control the above hazards and to minimize the possibility of personnel injury or property damage, these requirements shall be followed: 
1. The Underground Services Alert (U.S.A.), City of Livermore, land owners, and Zone 7 Water Board will be notified seven (7) days prior to commencement of drilling. After clearance by these notified agencies as to location of buried utilities, the LLNL Field Supervisor will mark location of new monitoring well.

2. The LLNL Health \& Safety Manual will be made available to all personnel involved in the field operations. They will be required to be familiar with portions of the manual applicable to the particular operation.

3. The contractor is responsible for providing first aid and medical assistance to his employees if they are injured or become ill. Emergency telephone numbers for Medical Assistance and Fire Department shall be posted at each work site and shall be site specific; i.e., 911 for Livermore City areas, ext. 3-5333 for Site 300, and ext. 2-7333 for LLNL main site proper and other LLNL/DOE property. All injuries and accidents will be reported promptly to the Field Supervisor. Hazards Control will also be notified as soon as possible.

4. Before any operations on a facility controlled by another organization, the Field Supervisor shall contact the host Facility Safety Officer to determine site safety regulations, and to resolve any discrepancy between those regulations and this OSP.

5. In any field operation, the Field Supervisor will be responsible for safe working conditions, will halt work if site conditions are not deemed safe, and will not resume work until the unsafe conditions have been corrected. An LLNL employee who is the only LLNL employee working among the personnel shall act as Field Supervisor for LLNL participation in the work.

6. Clothing and equipment suitable for unusual work conditions will be made available and utilized as needed. Wearing of hard hats, safety glasses, and safety shoes will be required on all drilling operations.

7. Safety belts and lanyards will be worn whenever it is necessary to climb up on the aerial platform.

8. Each operation will be conducted in accordance with the Laboratory's "Working Alone" policy as defined in the LLNL Health \& Safety Manual, Section 26.15. In the event that it is necessary for individuals to work alone under any circumstance, the Field Supervisor will ensure that, at a minimum, adequate communications are maintained and that other persons are aware of the itinerary, intended work locations, and estimated return time of the persons working alone.

9. All electrical systems shall be checked for grounding continuity and for compliance with the National Electrical Code during initial installation and periodically during operation.

10. Any equipment or materials left in the field unattended must be turned off, secured, and barricaded. 
11. Open trenches or excavations must have barricades to provide protection for pedestrians, bicyclists, and motor vehicles. Each barricade that will be in place during darkness must be equipped with a yellow flasher.

12. All hoses operating under pressure will be securely tethered.

13. If any operation requires entry onto private property, the Field Supervisor will ensure that appropriate permission has been received in advance for entry onto the property and receive assurance from the property owner or manager that all persons associated with the property are aware of the LLNL operation.

14. The Hazards Control Safety Team Leader shall be notified prior to drilling in any new location.

This Operational Safety Procedure was reviewed by:
R. C. Ragaini
Environmental Protection Department Head
F. Hoffman
T. R. Crites
Environmental Restoration Division Leader
I. M. Meisel
Hazards Control Department Head
E. C. Draney
Hazards Control Acting Safety Team Leader
E. M. Fawcett
Site 300 Resident Manager
Hazards Control Safety Team 5 Leader 


\section{LIVERMORE SITE 200 AND SITE 300 OFF-SITE GROUND WATER} INVESTIGATION ACTIVITIES

\subsection{Reason For Issue}

1.1 An Operational Safety Procedure is required for all off-site operations where the Laboratory has primary management responsibility. Carcinogens and other hazardous substances (e.g. benzene, chlorinated hydrocarbons, radionuclides, metals) may be encountered during drilling operations. This OSP also serves as an administrative tool to summarize many of the requirements of the Health and Safety Manual which are pertinent to this operation. This OSP supplements the existing Site 200 and Site 300 Site Safety Plans which address this work (UCRL- 21174 and UCRL-21172).

\subsection{Work To Be Done And Location Of The Activity}

2.1 Aquifer mapping and sampling.

2.2 Drilling and construction of monitor wells, extraction wells, piezometers and the installation of associated pumping equipment.

2.3 Soil, rock, and ground water sample collection.

2.4 Geophysical measurements at surface.

2.5 Location: Off-site in the Livermore Valley and areas surrounding Site 300.

\subsection{Responsibilities}

3.1 R. Bainer, Site 200 (Ext. 2-4635) and M. Taffet Site 300 (Ext. 2-6114) are responsible for the safety of this operation and for assuring that all work is performed in conformance with this OSP, the FSP at Site 300, and applicable sections in the Health \& Safety Manual and Environmental Protection Handbook. In their absence, I. Duarte, Site 200 (Ext. 3-2638) and I. Greci, Site 300 (Ext. 3-5043) shall assume these responsibilities. 
3.2 Others involved in this operation include $W$. McConachie, Environmental Protection Department, (Ext. 3-3501); Environmental Restoration Division Leader; I. Ziagos, Site 200 Restoration Section Leader, (Ext. 2-5479); A. Lamarre Site 300 Restoration Section Leader, Ext. (2-0757).

3.3 Any changes in operations that improve or do not significantly affect safety and environmental controls may be approved by the Authorizing Individual for this OSP and the ES\&H Team Leader. The Responsible Individual will ensure that this action is documented in a memorandum. Any changes in operations that increase the hazard level, introduce additional hazards, or decrease safety shall not be made until a revision of or supplement to this OSP has been reviewed and approved consistent with the review and approval process for the original OSP.

3.4 Before starting operation, the responsible individual shall verify and document that the operating personnel have read and understand the OSP and applicable sections of the FSP at Site 300.

\subsection{Hazards Analysis}

\subsection{Drilling Operations}

Personnel working in and near drilling rigs are exposed to a variety of mechanical hazards including moving machinery, high pressure (e.g. hydraulic lines), flammable and/or combustible fluids (gasoline in ground water), unsafe use of cranes, falling objects, drilling through underground utilities, flying machinery parts, and unsafe walking and working surfaces. The consequences of accidents involving these physical hazards can range from minor injury to fatal injury.

\subsection{Electrical Hazards}

Electric power is often supplied by gasoline or diesel engine generators. Working conditions may be wet and electrical shock with possible fatal consequences may occur. (In addition, it is possible that drilling operations may encounter buried electrical utilities, potentially resulting in exposure to very high voltages which could be fatal and/or initiate fires.) 


\subsection{Underground Utilities}

Drilling operations may encounter buried utilities including gas and electrical lines. Drilling into electrical lines may potentially result in exposure to very high voltages that could be fatal and/or initiate fires. Drilling into gas lines may potentially result in an explosion.

\subsection{Material Handling}

Lifting of heavy and bulky equipment and boxes on and off trucks at emplacement locations is required. Physical injury, particularly back strain or crushing injuries, may occur.

\subsection{Contaminated Materials}

Drillers, geologists, samplers and support personnel may come in contact with sediments, rock, soil, ground water and drilling fluids which have been contaminated with varying concentrations of hazardous materials. The benzene component of gasoline, some halogenated solvents, some metals, and the radionuclides which may be encountered may be carcinogenic or hazardous; repeated exposure to these materials by inhalation, ingestion, or skin absorption may increase the risk of developing cancer or other ailments. In addition, overexposure to halogenated solvents may result in central nervous system damage, liver damage, as well as adverse reproductive genetic effects. Skin contact with halogenated solvents can also di-fat the skin, resulting in localized irritation, skin cracking, and infections, a condition referred to as primary dermatitis. It is anticipated that the concentration of most of these contaminants in ground water, rock, soil, drilling fluids or sediments will be so low as not to pose an occupational exposure concern. However, there may be exceptions encountered (e.g. pockets of pure gasoline floating on the water table) where exposure of the drilling crew could be significant. Where high concentrations of gasoline or other flammable material is present, the possibility of fire or explosion of vapors trapped in the borehole may exist.

\subsection{Geophysical Measurements}

A variety of surface geophysical measurements may be conducted using seismic and electrical tehniques. Seismic sources including vibrators, weight drops, airguns and shotgun shells, present the possibility of injury. Some seismic sources emit loud noises and can 
cause hearing damage. Most electrical methods have no associated hazards, although the possibility of electrical shock may be present in some applications.

\subsection{Noise}

Drilling equipment is capable of producing sound levels in excess of 85 $\mathrm{dB}(\mathrm{A})$, the 8-hour Threshold Limit Value recommended by the American Conference of Governmental Industrial Hygienists (ACGIH) and adopted by LLNL.

\subsection{Controls}

The hazards listed in Section 4.0 are addressed in the LLNL Health and Safety Manual, the Environmental Restoration Program Standard Operating Procedures, the Environmental Restoration Series Site Safety Plan and the Safety and Operations Manual for Site 300. These documents are provided to and discussed with all personnel including those involved in drilling and sampling operations before work begins so that each worker is familiar with portions of the documents pertaining to the particular operation.

The Site Safety Officer or desigrnated person is responsible for safe working conditions and shall halt work if site conditions are deemed unsafe. Operations shall not be resurned until the conditions have been corrected. In addition, a daily safety metting shall be conducted with the Field Geologist prior to the commencemen't of drilling operations to highlight specific safety concerns particular to the day's operations.

The following section lists additional safeguards to address the specific hazards described in Section 4.0.

\subsection{Drilling Operations}

5.1.1 All subcontractors working on and around drill rigs shall be properly trained to work on these rigs by their companies in accordance with LLNL recognized standards.

5.1.2 At a minimum, workers are required to wear level $D$ protective clothing-which includes hard hats, gloves, safety glasses, and steel-toed shoes. The Field Geologist shall be responsible for the enforcement of personal protective clothing requirements. 
Hearing protection may be required if noise is above acceptable levels as determined by Hazards Control.

5.1.3 Only trained operators shall be used for drilling operations. In addition, the safe use of drilling machinery shall be highlighted during the daily safety meeting. All hoses operating under pressure shall be securely tethered.

5.1.4 Workers required to climb drilling masts to perform maintenance and repairs are required to wear safety belts and/or lanyards. All workers required to work on the mast of the drill rig shall be properly trained in the use of safety belts and lanyards by their companies to conform with LLNL standards.

5.1.5 An exclusion zone shall be clearly marked with barricades, signs and/or taping where only trained personnel associated with the drilling operations are permitted.

5.1.6 Open boreholes and wells shall be covered and/or secured when unattended.

\subsection{Electrical Hazards}

All electrical systems used during drilling and sampling operations shall be checked for proper grounding during the initial installation.

\subsection{Underground Utilities}

The Underground Services Alert (U.S.A.), City of Livermore, land owners, and Zone 7 Water Board shall be notified seven ( 7 ) days prior to commencement of drilling off-site near Livermore. San Joaquin County Health Services, U.S.A. and landowners shall be notified prior to commencement of drilling off-site near Site 300 . After clearance by these agencies as to location of buried utilities, the LLNL designated Drilling Supervisor shall approve the location of new wells to avoid any possibility of disrupting these utilities.

\subsection{Material Handling}

Workers are instructed in safe handling and lifting practices. If any specialized lifting equipment is to be used, only trained operators shall be authorized to use such equipment. 


\subsection{Contaminated Materials}

The appropriate Health and Safety Technician and Environmental Analyst shall be notified prior to the commencement of any new drilling or downhole geophysical operations. Clothing and equipment, including appropriate monitoring equipment suitable for the work conditions as specified by Hazards Control, shall be used as needed. The Field Geologist shall monitor the breathing zone, drill cuttings and /or drilling mud and fluids with an Organic Vapor Meter (OVM) and/or an Organic Vapor Analyzer (OVA), and a radiation meter. If organic vapor or radiation levels exceed twice background levels, or in the absence of background concentrations, $5 \mathrm{ppm}$, when measured, using either an OVM or OVA or there is evidence of contamination that could impact worker health and safety, then the Field Geologist shall cease operations and contact the designated Drilling Supervisor who shall contact the appropriate technical support personnel from Hazards Control. If necessary, personal protective clothing shall be upgraded to prevent worker exposure.

\subsection{Geophysical Measurements}

If explosives are reed as a seismic source, the Shot Loader and Detonator shall be fuiy licensed and trained as to the proper handling and initiating of the charges. Hearing protection shall be required for personnel operating seismic sources or other geophysical instruments that generate noise above acceptable levels as determined by Hazards Control.

\section{$5.7 \quad$ Noise}

Whenever new or previously unevaluated drilling equipment is used, the drilling geologist shall contact Hazards Control ES\&H Team 4 to obtain a noise survey. If noise exposures approach or exceed $85 \mathrm{~dB}(\mathrm{~A})$ hearing protection, as recommended by Hazards Control shall be worn by all employees working within the designated hazard radius.

\subsection{Other Safety Documents}

The LLNL Health \& Safety Manual, the Environmental Restoration Program Standard Operating Procedures, and the Environmental Restoration Series Site Safety Plan shall be made available to all personnel involved in the field operations. They shall be required to be familiar with portions of the manual applicable to the particular 
operation. A daily safety meeting with the field personnel shall be conducted by the Field Geologist prior to the commencement of drilling operations.

5.9 Before conducting any operations on a facility controlled by another organization, the Site Safety Officer or designated Drilling Supervisor shall contact the host Facility Safety Officer to determine site safety regulations, and to resolve any discrepancy between those regulations and this OSP.

5.10 In any field operation, the designated Site Safety Officer or Drilling Supervisor shall be responsible for safe working conditions, shall halt work if site conditions are not deemed safe, and shall not resume work until the unsafe conditions have been corrected. Hazards Control shall also be notified as soon as possible. The Field Geologist shall oversee and enforce all field activities.

5.11 Each operation shall be conducted in accordance with the Laboratory's "Working Alone" policy as defined in the LLNL Health \& Safety Manual, Section 26.15. In the event that it is necessary for individuals to work alone under any circumstance, the Site Safety Officer or designated Drilling Supervisor shall ensure that, at a minimum, adequate communications are maintained and that other persons are aware of the itinerary, intended work locations and estimated return time of the persons working alone.

5.12 Any equipment or materials left in the field unattended shall be turned off, secured and barricaded prior to leaving the site.

5.13 If any operation requires entry onto private property, the Site Safety Officer or designated Drilling Supervisor shall ensure that appropriate permission has been received in advance for entry onto the property, and receive assurance from the property owner or manager that all persons associated with the property are aware of the LLNL operation.

\subsection{Environmental Concerns and Controls}

6.1 The primary environmental concerns are cross-contamination of water bearing zones and surface contamination from drill cuttings and/or drilling fluids. 
6.1.1 During drilling operations, the drill cuttings or drilling fluids shall be monitored by the Field Geologist as outlined in Section 5.5 to ensure that no cross-contamination or surface contamination occurs.

6.2 At Site 300 disruption of habitat of two endangered species, the San Joaquin kit fox (Vulpes macrotis mutica) and the large-flowered fiddleneck (Amsinka grandiflora) could occur.

6.2.1 Sixty days prior to the commencement of drilling, a survey will be conducted to determine the presence or absence of Kit fox dens and the type. No offsite drilling or other activities shall be performed within 25 feet of a kit fox den at any time.

6.2.2 No drilling activities will be conducted which may endanger a population of large-flowered fiddleneck.

6.3 Drilling debris, decontamination materials and discarded safety equipment shall be placed in separate containers labeled "Potentially Hazardous Waste-Pending Analysis" and stored in the Environmental Restoration Division's designated Waste Accumulation Area at Building 597 or, for work at Site 300, Building 843 Waste Accumulation Area until analytical results are received. Any materials found to be contaminated shall be disposed of through Hazardous Waste Management.

6.4 Drilling mud shall be disposed of according to Environmental Protection Department's Environmental Restoration Series Standard Operating Procedures for Site 200, dated July 1990, (M-24S Rev. 1.3) and Site 300 dated August, 1992, (UCRL-MA-10911S).

6.5 No drilling operations will be conducted in identified historic or prehistoric sites at Site 300, and access through these sites will be restricted by means of stakes, flagging, barricades, etc.

\subsection{Training}

7.1 All authorized operators shall have completed the following safety courses if they are utilizing intrusive methods into potentially contaminated areas: 
HS-0001 - New Employee Orientation.

HS-4050 - Health Hazards Communication.

EP-0006 - Hazardous Waste Handling Practices - Untrained personnel may work under the supervision of trained personnel. Employees must be trained within 6 months of hire date and annually thereafter.

HS-0095 - Health and Safety for Employees and Visitors at Site 300.

7.2 Personnel involved shall have received at a minimum the 40 hours of CERCLA/SARA Health and Safety classroom training and 24 hours of field training pursuant to the requirements of 29 CFR Section 1910.120. Supervisory personnel shall have taken an additional 8 hours of specialized supervisory training. All personnel shall have taken the annual 8 hour refresher Health and Safety training as necessary.

7.3 If noise levels are found to exceed $85 \mathrm{~dB}(\mathrm{~A})$ all LLNL and supplemental labor employees working on the site shall attend HS-4360 "Noise".

7.4 The responsible individual shall ensure that all required training, including on-the-job training if applicable, is complete and documented.

\subsection{Maintenance}

8.1 All field monitoring equipment shall be calibrated as specified in the respective Site 200 and Site 300 Site Safety Plans, LLNL Document Numbers UCRL-21174 dated July, 1989, and UCRL-21172 dated October, 1989.

8.2 Drilling equipment shall be maintained by the drilling subcontractor.

\subsection{Quality Assurance}

9.1 Quality Assurance requirements are detailed both in the Quality Assurance Project Plan - LLNL Ground Water Project, UCAR \# 10219 dated June, 1989, (Site 200) and in the Quality Assurance Project Plan, LLNL Site 300 Environmental Restoration Project, UCRL-AR-103160, Rev. 1 (Site 300). 
Lawrence Livermore National Laboratory

Operational Safety Procedure No: 0-121

Review Level: A
Effective: $\quad 1 / 93$

Expires: $1 / \%$ 4

Page 10

\subsection{Emergency Response Procedures}

10.1 Contractors are responsible for providing first aid and medical assistance to their employees if they are injured or become ill. Emergency telephone numbers for Medical Assistance and Fire Department shall be posted at each work site and shall be site specific, i.e., 911 for Livermore City areas, 911 for Site 300, and 911. for LLNL main site property and other LLNL/DOE property. All injuries and accidents shall be reported promptly to the Site Safety Officer or designated Drilling Supervisor. Hazards Control will also be notified as soon as possible.

\subsection{References}

11.1 Site Safety Plan for Lawrence Livermore National Laboratory CERCLA Investigations UCRL-21174, July, 1989.

11.2 Site Safety Plan for Site 300 Environmental Restoration UCRL \#21172, October, 1989.

11.3 Environmenta' Restoration Program Standard Operating Procedures, July 1990, \#M-245 Rev. 1.3.

11.4 LLNL Site 300 Environmental Restoration Project Standard Operating Procedures (SOPs) UCRL-MA-109115, April, 1992

11.5 Quality Assurance Project Plan - LLNL Ground Water Project UCAR \# 10219, June, 1989.

11.6 Quality Assurance Project Plan Lawrence Livermore National Laboratory Site 300 Environmental Restoration Project, UCRL-AR103160, Rev. 1, October, 1992 
Lawrence Livermore National Laboratory Operational Safety Procedure No: 0-121 Review Level: A
Effective: $\quad 1 / 93$

Expires: 1/94

Page 11

\subsection{Review and Approval}

This OSP was reviewed by: $\frac{\text { Roleet W-Bawe } 11-9-92}{\text { RESPONSIBLE INDIVIDUAL }}$

Robert Bainer, Site 200

Environmental Restoration Division

Environmental Protection Depariment

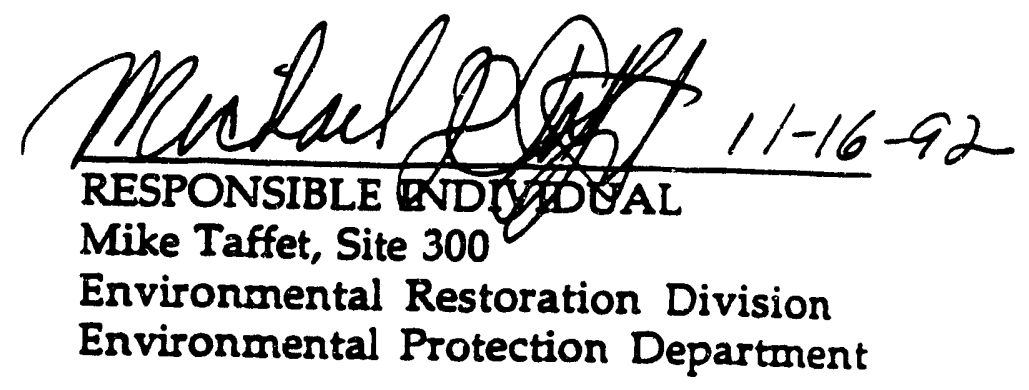

Albut 2 amane SITE 300 SECTION LEADER Albert Lamarre

Environmental Restoration Division Environmental Protection Department

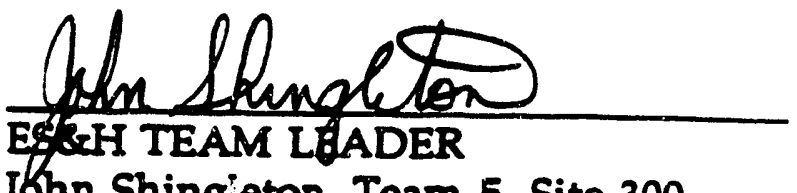
John Shingieton, Team 5, Site 300 Operational Safety Division

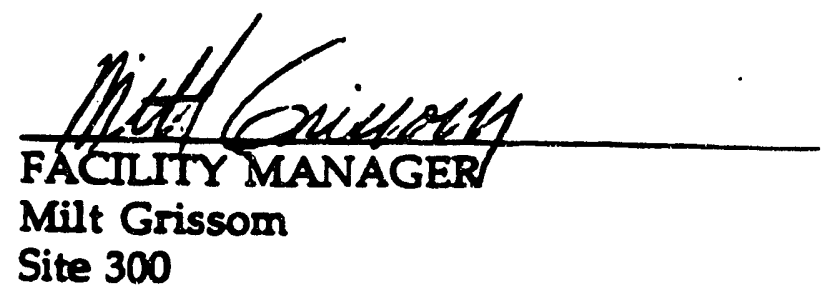

$T \cdot:$ OSP is approved by:

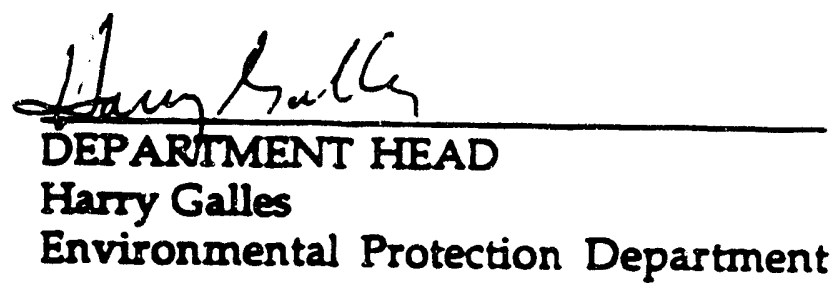

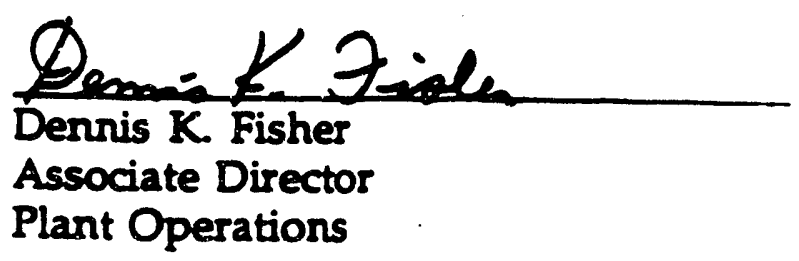


Lawrence Livermore National Laboratory

Operational Safety Procedure No: 0-121

Review Level: A
Effective: $\quad 1 / 93$

Expires: 1/94

Page 12

\begin{tabular}{lc}
\multicolumn{2}{l}{ CONTROLLED DISTRIBUTION: } \\
\hline R. Bainer & L-619 \\
Milt Grissom & L-871 \\
W. MCConachie & L-627 \\
M. Taffet & L-528
\end{tabular}

UNCONTROLLED DISTRIBUTION

J. Duarte

D. Fisher

J. Greci

K. Young

A. Lamarre

J. Ziagos
L-619

L-030

L-843

L-692

L-619

L-619 


\section{Appendix G \\ Levels Of Personal Protection**}




\section{APPENDIX G \\ LEVELS OF PERSONAL PROTECTION**}

LEVEL A - To be selected when the greatest level of skin, respiratory, and eye protection is required.

\section{Level A equipment; used as appropriate.}

1. Pressure-demand, full face-piece self-contained breathing apparatus (SCBA), or pressuredemand supplied air respirator with escape SCBA, approved by the National Institute for Occupational Safety and Health (NIOSH).

2. Totally encapsulating chemical-protective suit.

3. Coveralls.*

4. Long underwear.*

5. Gloves, outer, chemical-resistant.

6. Gloves, inner, chemical-resistant.

7. Boots, chemical-resistant, steel toe and shank.

8. Hard hat (under suit).*

9. Disposable protective suit, gloves and boots (Depending on suit construction, may be worn over totally encapsulating suit).

10. Two-way radios (worn inside encapsulating suit).

*Optional, as applicable.

LEVEL B - The highest level of respiratory protection is necessary, but a lesser level of skin protection is needed.

Level $B$ equipment; used as appropriate.

1. Pressure-demand, full-face piece self-contained breathing apparatus (SCBA), or pressuredemand supplied air res,irator with escape SCBA (NIOSH approved).

2. Hooded chemical-resistant clothing (overalls and long-sleeved jacket; coveralls; one or twopiece chemical-splash suit; disposable chemical-resistant overalls).

3. Coveralls.*

4. Gloves, outer, chemical-resistant.

5. Gloves, inner, chemical resistant.

6. Boots, outer, chemical-resistant steel toe and shank.

7. Boot-covers, outer, chemical resistant (disposable)*.

8. Hard hat. 
9. Two-way radios (worn inside encapsulating suit).

10. Face shield.*

*Optional, as applicable.

LEVEL C. The concentrations(s) and type(s) of airborne substance(s) is known and the criteria for using air purifying respirators are met.

Level $C$ equipment; used as appropriate.

1. Full-face or half-mask, air purifying, canister equipped respirators (NIOSH approved).

2. Hooded chemical-resistant clothing (overalls; two-piece chemical-splash suit; disposable chemical-resistant overalls).

3. Coveralls.*

4. Gloves, outer, chemical-resistant.

5. Gloves, inner, chemical resistant.

6. Boots, outer, chemical-resistant steel toe and shank.*

7. Boot-covers, outer, chemical resistant (disposable).*

8. Hard hat.

9. Escape mask.*

10. Two-way radios (worn under outside protective clothing).

11. Face shield.*

*Optional, as applicable.

LEVEL D - A work uniform affording minimal protection: used for nuisance contamination only.

1. Coveralls.

2. Gloves.*

3. Boots/shoes, chemical-resistant steel toe and shank.

4. Boots, outer, chemical-resistant (disposable).*

5. Safety glasses or chemical splash goggles.*

6. Hard hat.

7. Escape mask*

8. Face shield.*

*Optional as applicable. 
The types of hazards for which levels A, B, C, and D protection are appropriate are described below:

\section{Level A protection should be used when:}

1. The hazardous substance has been identified and requires the highest level of protection for skin, eyes, and the respiratory system based on either the measured (or potential for) high concentration of atmospheric vapors, gases, or particulates; or the site operations and work functions involve a high potential for splash, immersion, or exposure to unexpected vapors, gases, or particulates of materials that are harmful to skin or capable of being absorbed through the intact skin,

2. Substances with a high degree of hazard to the skin are known or suspected to be present, and skin contact is possible, or

3. Operations must be conducted in confined, poorly ventilated areas and the absence of conditions requiring Level $\mathrm{A}$ have not yet been determined.

Level $B$ protection should be used when:

1. The type and atmospheric concentration of substances have been identified and require a high level of respiratory protection, but less skin protection.

NOTE: This involves atmospheres with IDLH concentrations of specific substances that do not represent a severe skin hazard; or that do not meet the criteria for use of air-purifying respirators.

2. The atmosphere contains less than 19.5 percent oxygen, or

3. The presence of incompletely identified vapors or gases is indicated by a direct-reading organic vapor detection instrument, but vapors and gases are not suspected of containing high levels of chemicals harmful to skin or capable of being absorbed through the intact skin.

\section{Level $C$ protection should be used when:}

1. The atmospheric contaminants, liquid splashes, or other direct contact will not adversely affect or be absorbed through any exposed skin,

2. The types of air contaminants have been identified, concentrations measured, and a canister respirator is available that can remove the contaminants, and

3. All criteria for the use of air-purifying respirators are met.

\section{Level. D protection should be used when:}

1. The atmosphere contains no hazard, and

2. Work functions preclude splashes, immersion, or the potential for unexpected inhalation of or contact with hazardous levels of any chemicals.

NOTE: As stated before combinations of personal protective equipment other than those described for Levels A, B, C, and D protection may be more appropriate and may be used to provide the proper level of protection.

**This information is from 29 CFR 1910.120 Appendix B. 

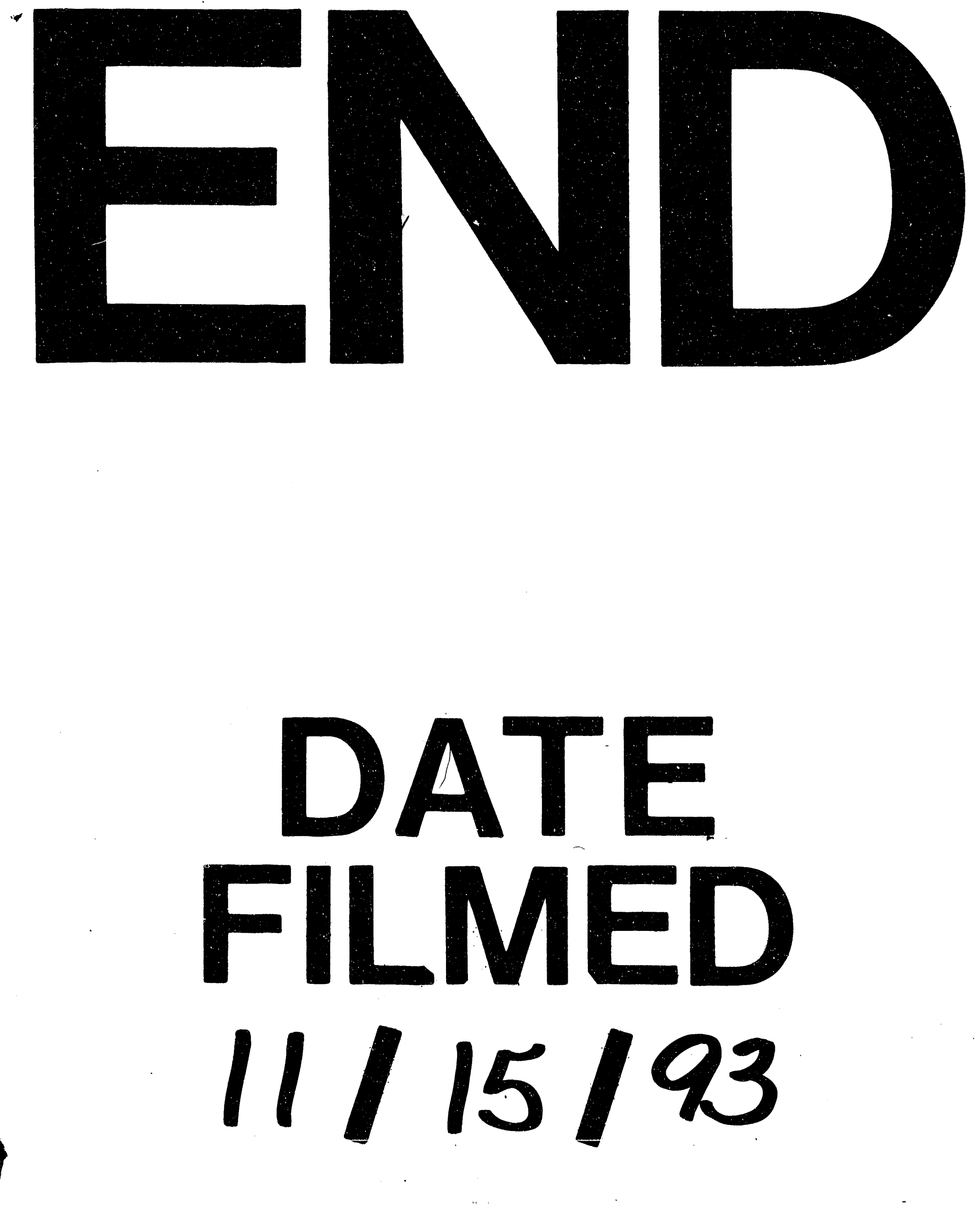

| 
$\because$ 